\title{
PROGRAMA DE ENTRENAMIENTO INDIVIDUALIZADO EN MUJER CON OSTEOPOROSIS DIAGNOSTICADA Y RIESGOS ASOCIADOS AL SÍNDROME METABÓLICO
}

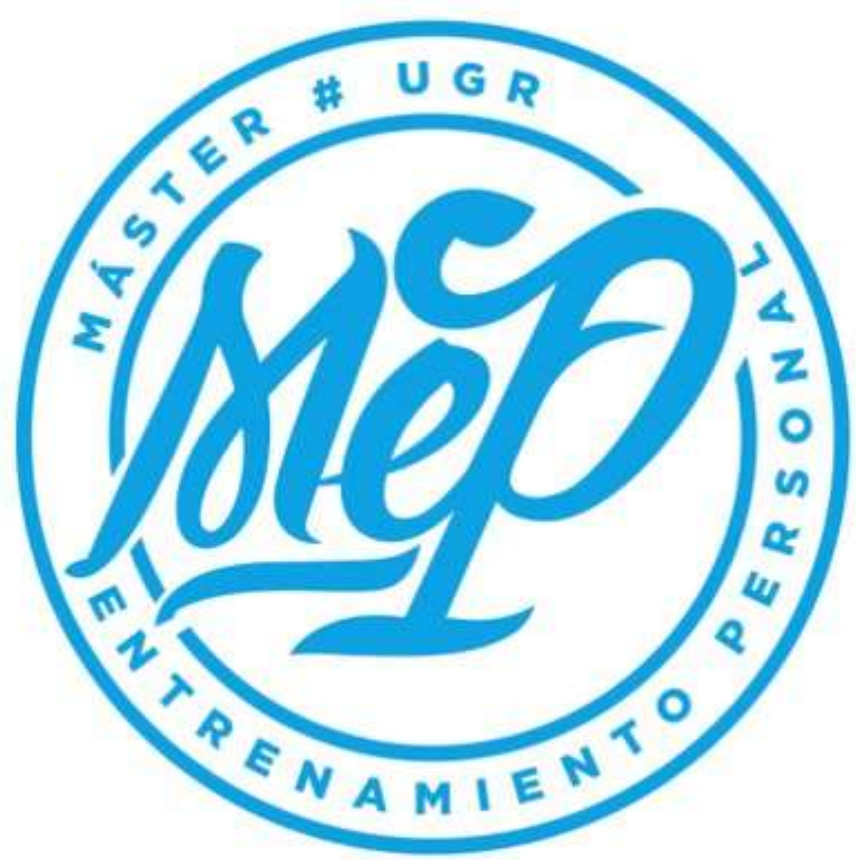

AUTORA: IRENE MANZANO SOLER TUTOR: MIGUEL MARTÍN HERRERA

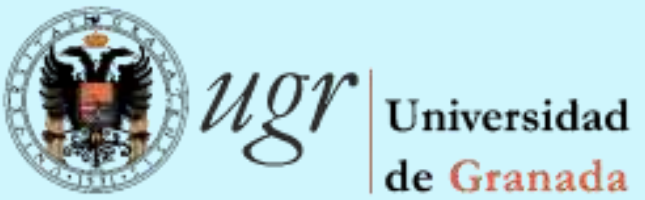

MASTER PROPIO ENTRENAMIENTO PERSONAL

IX EDICIÓN 2019-2020

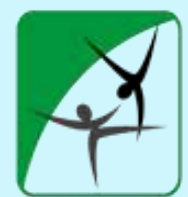

FACULTADDE CIENCIAS DEL DEPORTE

Universidad de Granada 


\section{PROGRAMA DE ENTRENAMIENTO INDIVIDUALIZADO EN MUJER CON OSTEOPOROSIS DIAGNOSTICADA Y RIESGOS ASOCIADOS AL SÍNDROME METABÓLICO}

\section{ÍNDICE}

1. Contextualización.

1.1. Descripción, situación y propósito del cliente: Resultados de la entrevista inicial y cuestionarios autoadministrados.

1.2. Recursos necesarios para el programa de intervención.

1.3.1 Temporales.

1.3.2. Espaciales.

1.3.3. Materiales.

1.3.4. Humanos.

1.3. Aspectos éticos, legales y jurídicos.

2. Evaluación inicial.

2.1. ¿Qué evalúo? Justificación de los contenidos a evaluar.

2.1.1. Aspectos de la calidad de vida relacionada con la salud.

2.1.2. Calidad de sueño.

2.1.3. Hábitos de AF.

2.1.4. Hábitos saludables.

2.1.5. Actitud.

2.1.6. Parámetros biomédicos.

2.1.7. Valoración anatómico-funcional y rangos de movimiento.

2.1.8. Necesidades de movimiento.

2.1.9. Condición física relacionada con la salud.

2.2. ¿Cómo evalúo? Herramientas de evaluación.

2.2.1. Disposición inicial al programa: PAR-Q +, Estratificación NSCA.

2.2.2. Calidad de vida relacionada con la salud: SF-36 y PSS-14.

2.2.3. Análisis del sueño: ISI, PSQUI y Xiaomi Band 4.

2.2.4. Hábitos de AF: IPAQ y Xiaomi Band 4.

2.2.5. Tabaco y alcohol: ENS.

2.2.6. Parámetros actitudinales: NSCA.

2.2.7. Parámetros fisiológicos y antropometría.

2.2.8. Evaluación anatómico-funcional.

2.2.9. Necesidades de movimiento.

2.2.10. Condición física relacionada con la salud: tests específicos de equilibrio, fuerza muscular y capacidad cardiorrespiratoria.

2.3. ¿Qué datos he obtenido? Resultados de la evaluación.

2.3.1. Parámetros biomédicos.

2.3.2. Resultados de la evaluación anatómico-funcional.

2.3.3. Resultados de los tests de condición física.

2.3.4. Informe final de los hallazgos.

3. Análisis de la casuística.

3.1. Mujer y postmenopausia.

3.2. Osteoporosis.

3.3. Riesgo cardiovascular: síndrome metabólico.

3.4. Calidad de vida relacionada con la salud.

3.5. Interpretación e interrelación de los resultados obtenidos en la evaluación inicial. 
4. Objetivos del programa de intervención.

5. Justificación del programa de intervención.

5.1. Carga mecánica y movimiento para la mejora de la salud ósea.

5.2. Contrarrestando los efectos de la sarcopenia y la dinapenia.

5.3. Variabilidad de respuestas del sistema para la disminución del riesgo de fractura y caída.

5.4. Mejora de los parámetros cardiovasculares.

5.5. Capacidad funcional, control motor y necesidades de movimiento.

5.6. Papel de la educación en la calidad de vida.

6. Programa de intervención.

6.1. Secuenciación de las fases de entrenamiento del programa de intervención.

6.2. Fase 1: adaptación.

6.2.1. Objetivos específicos y contenidos de entrenamiento.

6.2.2. Metodología.

6.2.3. Secuenciación de contenidos.

6.2.4. Sesiones.

6.2.5. Control y monitorización del entrenamiento.

6.2.6. Evaluación del progreso.

6.3. Fase 2: desarrollo.

6.3.1. Objetivos específicos y contenidos de entrenamiento.

6.3.2. Metodología.

6.3.3. Secuenciación de contenidos.

6.3.4. Sesiones.

6.3.5. Control y monitorización del entrenamiento.

6.3.6. Evaluación del progreso.

6.4. Fase 3: potenciación y autonomía.

6.4.1. Objetivos específicos y contenidos de entrenamiento.

6.4.2. Metodología.

6.4.3. Secuenciación de contenidos.

6.4.4. Sesiones.

6.4.5. Control y monitorización del entrenamiento.

6.4.6. Evaluación del progreso: evaluación final.

7. Resultados y discusión.

7.1. Resultados de la evaluación final. Discusión del grado de consecución de los objetivos planteados y posibles causas.

7.2. Puntos fuertes y débiles del programa de intervención, posibles alternativas.

7.3. Limitaciones, dificultades y soluciones.

8. Conclusiones.

9. Líneas futuras de intervención.

10. Bibliografía. 
11. Anexos.

11.1. Anexo 1: Informes médicos.

11.2. Anexo 2: Cuestionarios autoadministrados en la entrevista inicial.

11.3. Anexo 3: Documentos legales y jurídicos.

11.4. Anexo 4: Protocolo de evaluación de perímetros.

11.5. Anexo 5: Protocolo de evaluación de tensión arterial en reposo (NSCA)y valores de referencia.

11.6. Anexo 6: Ficha de evaluación inicial completa.

11.7. Anexo 7: Sesiones educativas y retos semanales.

11.8. Anexo 8: Plantilla de registro y control del entrenamiento.

\section{Listado de figuras.}

Figura 1. Objetivos de la entrevista inicial y su relación con las cuestiones planteadas en la misma.

Figura 2. Resultados de la versión automatizada SF-36

Figura 3. Comparativa de los valores medios de referencia en SF-36 a los 60 años y el resultado de nuestra alumna.

Figura 4. Recursos espaciales: Paseo Marítimo desde el Ático del domicilio.

Figura 5. Recursos materiales utilizados durante el programa de intervención

Figura 6. Monitorización del sueño pre-intervención a través de Xiaomi Band 4.

Figura 7. Extracto de monitorización de la AF diaria pre-intervención a través de Xiaomi Band 4.

Figura 8. Evaluación de la postura a través de la plomada.

Figura 9. Resultados de equilibrio extraídos de Lockhart Monitor.

Figura 10. Evaluación de Y Balance Test.

Figura 11. Resultados extraídos de Xiaomi Band 4 en el test de 2km UKK.

Figura 12. Adaptación propia de Engel (1977) sobre el modelo biopsicosocial en el que se basa la reflexión de abordaje integral.

Figura 13. Comparación de la estructura ósea sana y afectada por osteoporosis.

Figura 14. Representación gráfica de los diferentes diagnósticos: evolución de la discontinuidad y disfuncionalidad trabecular.

Figura 15. Prevalencia de los tipos de fractura según la edad: muñeca, vertebral y cadera.

Figura 16. Aumento del riesgo de mortalidad tras una fractura.

Figura 17. Clasificación de los niveles de colesterol según ATP III.

Figura 18. Concepción personal de nuestra alumna de la esfera de calidad de vida y estrategias a seguir para alcanzar el objetivo.

Figura 19. Hallux valgus.

Figura 20. Análisis de la marcha.

Figura 21. Plomada de Kendall.

Figura 22. Interrelacionado de las características propias que constituyen la casuística.

Figura 23. Mecanostato óseo de Frost.

Figura 24. Carga necesaria para inducir una respuesta osteogénica.

Figura 25. Relación de los componentes que generan un riesgo de fractura.

Figura 26. Papel de la educación en el entrenamiento como modulador de los efectos. Situación personal. 
Figura 27. Secuenciación de las fases durante los meses de junio, julio y agosto.

Figura 28. Respuesta ante la orden de coger algo del suelo con mayor y menor flexión de rodilla.

Figura 29. Cambios en la presión arterial diastólica y sistólica en la Fase 1 con respecto a la evaluación inicial.

Figura 30. Promedio de la calidad del sueño pre y post Fase 1, monitorizado a través de Xiaomi Band 4.

Figura 31. Ligeros progresos en los niveles de fuerza en la fase 1.

Figura 32. Mejora de la rigidez en los 3 tests de movilidad.

Figura 33. Comparación del promedio de la PRS inicial de la sesión entre Fase 1 y 2.

Figura 34. Comparación de resultados pre test y post fase 2 en la capacidad neuromuscular de cada extremidad.

Figura 35. Comparación de los niveles de presión arterial entre fases 1 y 2 del programa de intervención.

Figura 36. Comparación del rango de movimiento medido en ${ }^{\circ}$ entre fases 1 y 2.

Figura 37. Comparación de los valores de dinamometría en ambas extremidades entre fase 1 y fase 2.

Figura 38. Modelo de aprendizaje basado en Optimal Theory.

Figura 39. Disminución de los valores relacionados con el riesgo cardiovascular. Aumento de la masa muscular como papel protector.

Figura 40. Disminución de la FC y los valores de presión arterial.

Figura 41. Mejora en los distintos test de condición física.

Figura 42. Estabilograma One Leg Test pre-test y post test.

Figura 43. Diferencias pre y post de la distancia recorrida en centímetros en Y Balance Test

Figura 44. Mejora de los niveles de fuerza en todos los tests.

Figura 45. Mejora postural post test en vista lateral y posterior.

Figura 46. Aumento del ROM en todos los tests realizados durante la evaluación inicial.

Figura 47. Reducción del consumo semanal de tabaco y alcohol.

Figura 48. Mantenimiento y mejora de la calidad de vida en las dimensiones incluidas dentro de los objetivos secundarios del programa de intervención (vitalidad, disminución de cansancio).

Figura 49. Mejora de los valores relacionados el objetivo de vitalidad.

\section{Listado de tablas}

Tabla 1. Resumen de resultados derivados de las cuestiones en la entrevista inicial.

Tabla 2. Resultados de los niveles de AF en las diferentes dimensiones de la alumna.

Tabla 3. Cuestionarios autoadministrados en la entrevista inicial relacionados con los contenidos y la evidencia científica.

Tabla 4. Herramientas de evaluación inicial relacionadas con los contenidos y la evidencia científica.

Tabla 5. Tests realizados en la evaluación inicial para determinar diversos rangos de movimiento.

Tabla 6. Tests realizados en la evaluación inicial en relación a las necesidades de movimiento.

Tabla 7. Resultados de los parámetros biomédicos obtenidos a través de las herramientas detalladas en la evaluación inicial.

Tabla 8. Percentiles de referencia y categorización según los valores de presión arterial.

Tabla 9. Valores de referencia de porcentaje graso y perímetro de cintura y cadera. 
Tabla 10. Resumen de los hallazgos obtenidos a través de la valoración postural, rangos de movimiento y evaluación dinámica funcional.

Tabla 11. Resultados de la evaluación inicial de condición física.

Tabla 12. Resultados de Y Balance Test.

Tabla 13. Resultados de la dinamometría previa al programa de intervención.

Tabla 14. Valores de referencia de los diferentes tests de condición física realizados en la evaluación inicial.

Tabla 15. Clasificación de los resultados más relevantes derivados de la entrevista y evaluación inicial.

Tabla 16. Factores de riesgo cardiovasculares.

Tabla 17. Estratificación y clasificación basada en factores de riesgo cardiovascular.

Tabla 18. Objetivos principales y secundarios del programa de intervención.

Tabla 19. Multiplicación del pico de fuerza de reacción vertical del suelo relativa al peso corporal en diversos ejercicios.

Tabla 20. Objetivos generales y específicos y su relación con los contenidos de entrenamiento de la Fase 1 de adaptación.

Tabla 21. Principios de entrenamiento para el contenido de entrenamiento de fuerza en Fase 1.

Tabla 22. Principios de entrenamiento para el contenido continuo e interválico en la Fase 1.

Tabla 23. Secuenciación de sesiones del mes de junio.

Tabla 24. Estímulos pertenecientes a cada sesión para la consecución de objetivos de la Fase 1.

Tabla 25. Escala visual subjetiva de percepción del esfuerzo utilizada durante el programa de intervención.

Tabla 26. Objetivos generales y específicos y su relación con los contenidos de entrenamiento de la Fase 2 de desarrollo.

Tabla 27. Principios de entrenamiento para el contenido de entrenamiento de fuerza en Fase 2.

Tabla 28. Principios de entrenamiento continuo e interválico en la Fase 2.

Tabla 29. Secuenciación de sesiones del mes de julio.

Tabla 30. Estímulos pertenecientes a cada sesión para la consecución de objetivos de la Fase 2.

Tabla 31. Objetivos generales y específicos y su relación con los contenidos de entrenamiento de la fase 3 de potenciación y autonomía.

Tabla 32. Principios de entrenamiento para el contenido de entrenamiento de fuerza en Fase 3.

Tabla 33. Principios de entrenamiento para el contenido de trabajo continuo en Fase 3.

Tabla 34. Principios de entrenamiento interválico en Fase 3.

Tabla 35. Secuenciación de sesiones del mes de agosto.

Tabla 36. Estímulos pertenecientes a cada sesión para la consecución de objetivos de la Fase 3.

Siglas y acrónimos

ACSM. American College of Sports Medicine.

ADA. Asociación Americana de Diabetes.

AF. Actividad física.

ALPHA-FIT. Assessing Levels of PHysical Activity and fitness at population level.

ATP III. Adult Treatment Panel III. 
CVM. Contracción voluntaria máxima.

DMO. Densidad mineral ósea.

DOMS. Delayed Onset Muscle Soreness.

DXA. Densitometría ósea.

ENS. Encuesta Nacional de Salud.

FC. Frecuencia cardiaca.

FMS. Functional Movement Screen.

FNP. Facilitación Neuromuscular Propioceptiva.

GH. Hormona del crecimiento.

HDL. Colesterol high density lipoprotein.

HIIT. Entrenamiento de alta intensidad.

IDF. Federación Internacional de Diabetes.

IL-6. Interleuquina 6.

IPAQ. Cuestionario Internacional de Actividad Física.

IGF-1. Factor de crecimiento insulínico tipo 1.

ISI. Índice de Gravedad del Insomnio.

JAMA. Journal of the American Medical Association.

JCR. Journal Citation Reports.

LDL. Colesterol low density lipoprotein.

LP. Lumbopélvico.

L4. Vértebra lumbar 4.

MIIT. Entrenamiento interválico de moderada intensidad.

NIH. National Institutes of Health.

NSCA. National Strength and Conditioning Association.

PAR-Q. Cuestionario de Aptitud para la Actividad Física.

PRS. Perceived Recovery Status.

PSQUI. Índice de Calidad de Sueño de Pittsburgh.

PSS-14. Escala de Estrés Percibido.

Q-H. Cuádriceps-Isquiosurales.

RCTs. Randomized controlled trial.

RM. Repetición máxima.

ROM. Rango de movimiento.

RPE. Escala Subjetiva de Esfuerzo Percibido.

TAC o TC. Tomografía axial computarizada.

TAS. Tensión arterial sistólica.

TAD. Tensión arterial diastólica.

TNF- $\alpha$. Factor de necrosis tumoral.

UA. Unidades arbitrarias.

VO2MÁX. Volumen máximo de oxígeno.

YBT. Y Balance Test. 


\section{CONTEXTUALIZACIÓN}

\subsection{Descripción, situación y propósito del cliente: Resultados de la entrevista inicial.}

El programa de intervención expuesto a continuación se adapta a una mujer de 60 años de edad, en postmenopausia, limpiadora de profesión y activa por tanto durante su periodo laboral (de aquí en adelante denominada "alumna"). Sin embargo, suele acumular niveles bajos de actividad física (AF) durante su tiempo de ocio y tiempo libre, aunque a veces sale a andar acompañada de amigos o familiares.

Resulta esencial recapitular información relevante que nos permita conocer a la perfección la situación real de nuestra alumna, para así construir un programa que se adapte a los objetivos, necesidades y capacidades de la misma. A partir de la información mencionada en la entrevista inicial, construiremos una evaluación integral con datos objetivos a través de herramientas validadas, que serán tratados en el siguiente punto. Teniendo en cuenta esto, la entrevista inicial tendrá los siguientes objetivos principales, que serán abordados a través de diversas cuestiones detalladas a continuación:

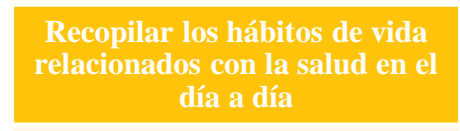

- Valora tu calidad de sueño del 0-10, siendo 0 pésima y 10 excelente.

- ¿Refieres niveles de ansiedad o estrés en tu día a día? Valora del 010 , siendo 0 nunca y 10 siempre.

- ¿Tienes molestias o dolores en tu día a día? Valora del 0-10, siendo 0 nunca y 10 siempre.

- ¿Cómo consideras que es tu alimentación?

- ¿Mantienes hábitos no saludables tales como consumo de alcohol o tabaco?

Establecer por orden de prioridad los objetivos personales de nuestra alumna a corto, medio y largo plazo.

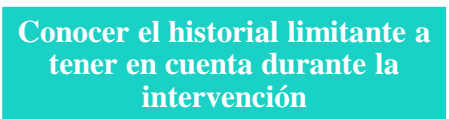

- ¿Has padecido alguna lesión o patología diagnosticada?

- ¿Existe algún antecedente familiar cercano de enfermedad prevalente a tener en cuenta?

- ¿Consumes algún fármaco de forma asidua?

- Verificación de los datos administración PAR-Q, Riesgo Cardiovascular, ENS, SF-36, PSS14, ISI, PSIQUI.

Identificar posibles factores de riesgo extrapolados a cualquier aspecto, para evaluarlos específicamente.

Detectar las necesidades de derivación sanitaria
Conocer los hábitos de AF,

ejercicio y deporte, así como gustos y preferencias.

- A grandes rasgos, ¿cuánto tiempo permaneces en movimiento y sentada en tu trabajo? ¿Y en tu tiempo libre?

- ¿Has practicado algún deporte o ejercicio físico con regularidad?

• ¿Cuáles son tus gustos y preferencias?

- Verificación de los datos: administración de IPAQ, Actitud NSCA.

Detectar las necesidades personales que puedan ser abordadas en el programa para así establecer los objetivos de entrenamiento.

Figura 1. Objetivos de la entrevista inicial y su relación con las cuestiones planteadas en la misma. 


\begin{tabular}{|c|c|c|c|}
\hline Datos personales & \multicolumn{3}{|c|}{ Emilia, 60 años. Ocupación: limpiadora } \\
\hline \multirow{5}{*}{$\begin{array}{l}\text { Hábitos de vida } \\
\text { relacionados con la } \\
\text { salud }\end{array}$} & $\begin{array}{l}\text { Calidad de } \\
\text { sueño }\end{array}$ & \multicolumn{2}{|c|}{$\begin{array}{c}\text { Considera que duerme mal e interrumpidamente todos los } \\
\text { días, su tiempo total en cama suelen ser 5-6h. Realiza una } \\
\text { siesta de 20-30 minutos todos los días. Puntuación subjetiva: } \\
4 / 10\end{array}$} \\
\hline & Estrés & \multicolumn{2}{|c|}{$\begin{array}{c}\text { No refiere de forma asidua. En algunas ocasiones siente que } \\
\text { está algo más estresada (5/10), traduciéndose en mayor } \\
\text { cansancio. }\end{array}$} \\
\hline & Dolor & \multicolumn{2}{|c|}{$\begin{array}{l}\text { Molestia } 2 / 10 \text { en zona lumbar que no inhabilita en su día a } \\
\text { día, si bien tiene } 1 \text { o } 2 \text { episodios críticos al año. }\end{array}$} \\
\hline & $\begin{array}{l}\text { Nutrición y } \\
\text { hábitos } \\
\text { saludables }\end{array}$ & \multicolumn{2}{|c|}{$\begin{array}{l}\text { Considera que su alimentación es equilibrada, basada en } \\
\text { verdura y proteína especialmente, aunque no consume } \\
\text { frutas, ya que no se ajusta a sus preferencias. Ingiere alcohol } \\
\text { a diario en el almuerzo y cena, en concreto un quinto de } \\
\text { cerveza en cada una. Es fumadora. }\end{array}$} \\
\hline & Ansiedad & \multicolumn{2}{|c|}{$\begin{array}{c}\text { No refiere altos niveles de ansiedad en su día a día } \\
\text { Puntuación subjetiva: } 0 / 10\end{array}$} \\
\hline Historial clínico & \multicolumn{3}{|c|}{$\begin{array}{ll}\text { - } & \text { Osteoporosis en columna lumbar } \\
\text { - } & \text { Osteopenia en cuello femoral } \\
\text { - } & \text { Fractura de cúbito y radio en muñeca izquierda } \\
\end{array}$} \\
\hline Medicación & \multicolumn{3}{|c|}{ CARDYL $80 \mathrm{mg}$} \\
\hline \multirow{3}{*}{ Hábitos de AF } & \multicolumn{2}{|c|}{ Durante el trabajo } & $\begin{array}{c}\text { Se desplaza en vehículo, pero está de pie y en } \\
\text { continuo movimiento durante las 5-9h de } \\
\text { trabajo, dependiendo del día. }\end{array}$ \\
\hline & \multicolumn{2}{|c|}{$\begin{array}{l}\text { Durante su tiempo } \\
\text { libre }\end{array}$} & $\begin{array}{c}\text { Sale a andar 2-3 días en semana. Ve la TV al } \\
\text { mediodía y por la noche todos los días, estima } \\
\text { una media de 5-6 h diarias sentada. }\end{array}$ \\
\hline & \multicolumn{2}{|c|}{ Preferencias } & $\begin{array}{l}\text { Únicamente le gusta andar, nunca ha } \\
\text { entrenado, escasa predisposición. }\end{array}$ \\
\hline $\begin{array}{l}\text { Antecedentes } \\
\text { familiares }\end{array}$ & \multicolumn{3}{|c|}{$\begin{array}{l}\text { - Tumor en vejiga (75 años) y prediabetes controlada por parte de } \\
\text { madre. } \\
\text { Marcapasos por parte de padre (82 años). Predisposición genética a } \\
\text { diabetes. }\end{array}$} \\
\hline Suelo Pélvico & \multicolumn{3}{|c|}{$\begin{array}{l}\text { No refiere incontinencia urinaria ante el esfuerzo, pero sí ligera incontinencia } \\
\text { de urgencia }\end{array}$} \\
\hline $\begin{array}{c}\text { Objetivos } \\
\text { personales }\end{array}$ & \multicolumn{3}{|c|}{$\begin{array}{ll}\text { - } & \text { Sentirse mejor, menos cansada, calidad de vida } \\
\text { - } & \text { Evitar dolores asociados a su patología/condición }\end{array}$} \\
\hline
\end{tabular}

Tabla 1. Resumen de los resultados derivados de las cuestiones en la entrevista inicial.

Según los últimos informes médicos [Anexo 1], se define un cuadro de osteoporosis en columna y osteopenia en cadera (cuello femoral), refiriendo dolor 2/10 en zona lumbar, así como escasos episodios de ciática hasta la rodilla. Una de las principales causas de su patología se debe a que nuestra alumna pasó a una etapa menopaúsica precoz, concretamente a los 41 años.

Debemos destacar que sufrió una fractura de cúbito y radio en la muñeca izquierda hace unos 15 años, de la cual quedan secuelas derivadas en términos de déficit bilateral de pronación con respecto a la derecha.

Actualmente toma como medicación CARDYL 80 mg (en concreto media pastilla de $40 \mathrm{mg}$ diaria) para la hipercolesterolemia derivada de un antiguo hipertiroidismo que a día de hoy está controlado. Anteriormente, añadía una pastilla de calcio recetada por su médico debido a su patología, sin embargo, dejó de tomarla hace 6 meses porque le producían ardores. 
Los antecedentes familiares a tener en cuenta son:

- Por parte de su madre, a los 75 años un tumor en la vejiga extirpado y controlado actualmente a través de revisiones periódicas. Además, suele tener azúcar alta (prediabetes), controlada a través de medicación diaria.

- Por parte de su padre, a los 82 años tuvieron que administrarle un marcapasos, debido a una insuficiencia cardiaca (bajo bombeo de sangre), aunque no llego a padecer un infarto.

Los objetivos personales detallados en la entrevista inicial son principalmente mejorar la calidad de vida y reducir la sintomatología asociada a los cambios postmenopáusicos a largo plazo. Además, quiere evitar padecer los dolores derivados de su patología, sin necesidad de tener que medicarse en las ocasiones donde le inhabilita (aproximadamente 1 o 2 episodios al año). Su sensación día a día es de cierto cansancio durante y después del trabajo, por lo que se convierte en uno de los objetivos principales a corto plazo.

\section{Resultados de los cuestionarios autoadministrados en la entrevista inicial.}

Teniendo en cuenta la información obtenida en las diversas cuestiones planteadas en la entrevista inicial, debemos valorar concretamente y de manera objetiva diversos aspectos, desde los que plantear un punto de partida y obtener una disposición inicial al programa.

A continuación, se presentan únicamente los resultados obtenidos de los diferentes cuestionarios autoadministrados en la entrevista inicial, si bien la justificación de su elección como contenido a evaluar y explicación de las diversas herramientas se tratará en el siguiente apartado "Evaluación Inicial". Además, todos ellos pueden consultarse cumplimentados en su totalidad en el [Anexo 2].

\section{PAR-Q y extensión +.}

En primer lugar, evaluaremos los posibles riesgos previos a la realización del programa de intervención, de cara a detectar la necesidad de derivar a un profesional sanitario.

En este caso, la única cuestión a tener en cuenta es la relacionada con problemas osteo-articulares, que se derivan de la propia osteoporosis. Sin embargo, al incorporar la extensión PAR-Q+, concluimos que todos los ítems son respondidos negativamente.

Riesgo cardiovascular (Estratificación NSCA: Coburn, J., \& Malek, M., 2014).

Teniendo en cuenta los umbrales determinados por estos autores como factores de riesgo, concluímos que nuestra alumna presenta los siguientes criterios:

- Edad de riesgo (60 años).

- Fumadora actualmente.

- Dislipidemia, toma medicación para reducir lípidos.

Por tanto, consideramos su riesgo cardiovascular como moderado, en el que se establece que no es necesaria una prueba de esfuerzo previa ni una supervisión médica durante esfuerzos máximos o submáximos (American College of Sport Medicine, 2015). 


\section{Encuesta Nacional de Salud (ENS): Tabaco y alcohol.}

Con el objetivo de tener datos concretos sobre los hábitos perjudiciales mencionados en la entrevista inicial, usamos las dimensiones de tabaco y alcohol de ENS, en la que se establece el consumo de:

- 10 cigarrillos diarios. Nuestra alumna comenzó a fumar a los 21 años, y nunca ha tenido intención de abandonarlo. No está expuesta nunca o casi nunca al humo de otras personas en el día a día.

- Dos quintos de cerveza al día, en almuerzo y cena. No ingiere otro tipo de bebidas alcohólicas desde hace años.

\section{SF-36.}

Obtenemos un buen resultado general de 80'88/100 puntos (Figura 2), entre lo que debemos destacar dimensiones susceptibles de mejora: vitalidad y salud mental. En el caso de la vitalidad observamos una clara relación entre los datos subjetivos mencionados en la entrevista inicial, correspondiéndose con uno de los objetivos personales detallados de nuestra alumna. Con respecto a la salud mental, se obtiene un valor ligeramente más bajo que el resto de dimensiones. Sin embargo, se mantiene dentro de los valores normativos para el rango de edad.
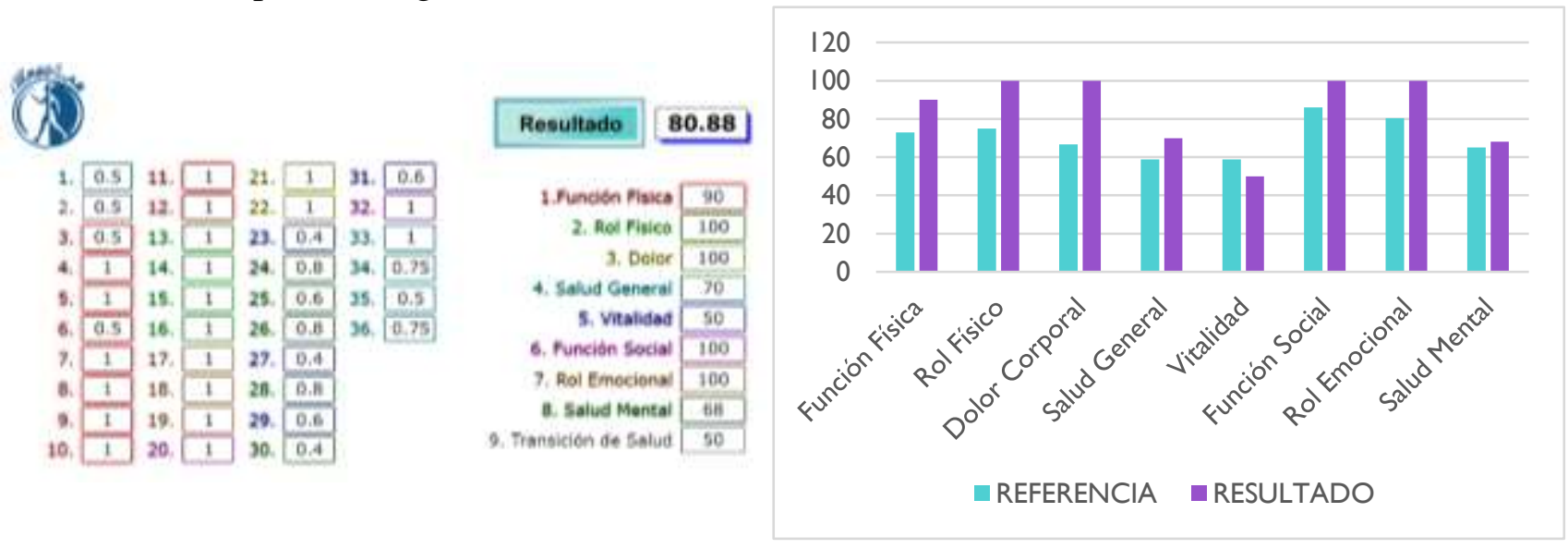

Figura 2 (izquierda). Resultados de versión automatizada SF-36.

Figura 3 (derecha). Comparativa de los valores medios de referencia a los 60 años y el resultado de nuestra alumna.

\section{PSS-14.}

Obtenemos un resultado de 15/56 de estrés percibido, por lo que determinamos que esta dimensión no afecta gravemente a la calidad de vida y gestión de las situaciones diarias. Sin embargo, deberemos tenerla en cuenta a la hora de programar nuestro entrenamiento y evitar que ciertos episodios de estrés afecten al cansancio percibido, tal y como se informa en la entrevista inicial.

\section{ISI}

El índice de gravedad del insomnio es de $12 / 28$, por lo que nos encontramos ante un insomnio moderado, por debajo del umbral clínico grave. 


\section{PSQUI}

La puntuación obtenida es de 5/21, a tener en cuenta únicamente la escasez de horas en cama (acostándose a altas horas de la madrugada) y dificultad expresa en las dimensiones de latencia del sueño (periodo desde el comienzo del sueño y la fase REM), así como perturbación del mismo.

\section{IPAQ}

Debido a su profesión, la actividad diaria suele ser elevada. Según IPAQ, se acumulan:

\begin{tabular}{c|c|c|}
\hline TRABAJO (5 DÍAS) & OCIO Y TIEMPO LIBRE & HOGAR \\
\hline $\begin{array}{c}300 \mathrm{~min} / \mathrm{sem}(900 \mathrm{METS}) \text { con cargas } \\
\text { livianas (AF moderada) }\end{array}$ & $\begin{array}{c}100 \mathrm{~min} / \mathrm{sem}(330 \mathrm{METS}) \mathrm{de} \\
\text { caminata (1 o } 2 \text { días únicamente) }\end{array}$ & $\begin{array}{c}\text { 60 min/sem (180 METS) caminando y } \\
\text { con ligeras cargas moderadas }\end{array}$ \\
$\begin{array}{c}600 \mathrm{~min} / \mathrm{sem}(1980 \mathrm{METS}) \text { andando } \\
\text { en actividad laboral }\end{array}$ &
\end{tabular}

Tabla 2. Resultados de los niveles de AF en las diferentes dimensiones.

Debemos de manejar con cautela estos datos, ya que, aunque las actividades laborales se realicen durante más de 10 minutos seguidos, el ritmo o intensidad son muy variables, lo que dificulta la estimación de una media por parte de la alumna.

Sin embargo, debemos destacar que su comportamiento sedentario, concretamente de televisión, es de 2100 minutos a la semana ( 5 horas al día) y no realiza ninguna actividad vigorosa. En la dimensión de trasporte no activo (coche) acumula 75 minutos a la semana.

De esta manera, la categoría correspondiente según IPAQ sería la de actividad física moderada, al acumular al menos 30 minutos al día de AF moderada/caminar 5 días a la semana (a pesar de que suele ser en su dimensión laboral y no en su tiempo libre), pero no realizar ninguna actividad vigorosa ni mantener estos niveles los 7 días de la semana; a lo que sumamos la acumulación de minutos de comportamiento sedentario.

\section{Actitud NSCA}

Los resultados en la evaluación de actitud corroboran la escasa motivación hacia el programa de entrenamiento (3 ítems calificados con una puntuación de 1), lo que tendremos que tener en cuenta para desarrollar correctamente los objetivos, así como la metodología de trabajo para potenciar la motivación y adherencia. Debemos destacar que la autoeficacia y comodidad con su imagen corporal es alta en este caso.

\subsection{Recursos necesarios para el programa de intervención.}

\subsubsection{Temporales.}

El programa de entrenamiento abarcará 3 meses desde junio a agosto de 2020, en un total de 14 semanas, a través 2 sesiones de carácter concurrente a la semana. Además, incorporaremos hasta $\mathbf{2}$ días semanales de AF y/o ejercicio de componente aeróbico (se detallará más adelante la progresión). De cara a adaptarnos a la disponibilidad y preferencia de nuestra alumna, intentaremos establecer una serie de herramientas para potenciar la autonomía, con el objetivo de evitar el sedentarismo en el caso de no poder acudir presencialmente. 


\subsubsection{Espaciales.}

Situaremos la mayoría de sesiones presenciales en el domicilio ubicado en Almería. Aprovechando la cercanía del mismo al Paseo Marítimo y la playa, utilizaremos estos recursos en caso de necesidad de mayor espacio para la realización de ejercicios o posibilidad de usar los puntos de calistenia al aire libre, así como para favorecer la adherencia y motivación.

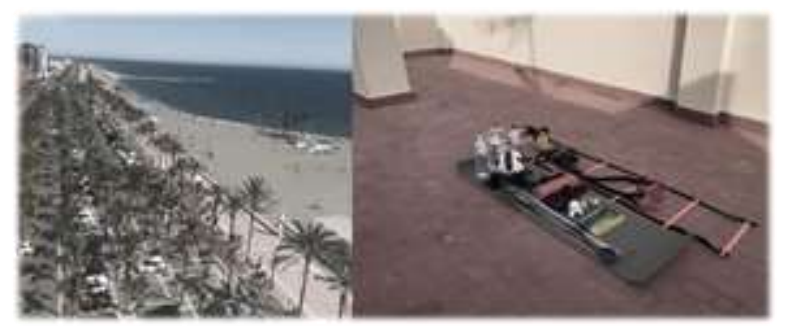

Figura 4. Paseo Marítimo (izquierda) desde el Ático del domicilio (derecha)

\subsubsection{Materiales.}

A los materiales que se observan en la imagen debemos incluir los empleados para la evaluación y monitorización: tensiómetro digital Vital Control, cinta métrica, dinamómetro Rise Pro WH-C300, Xiaomi Band 4, apps iOS.

Figura 5. Recursos materiales utilizados durante el programa de intervención.

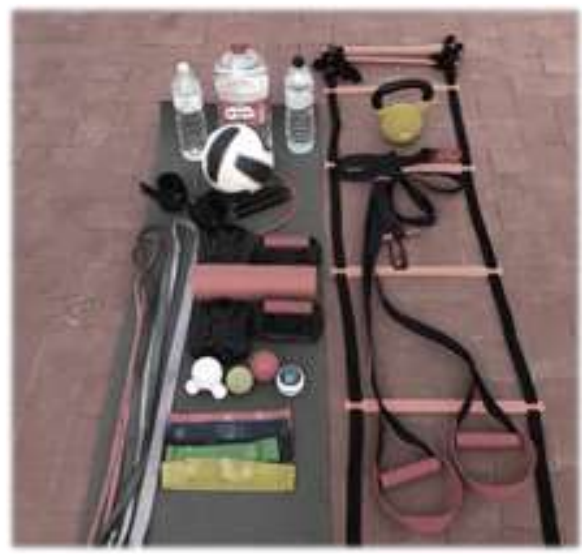

\subsubsection{Humanos}

Teniendo en cuenta la casuística de nuestra alumna, el proceso estará supervisado por un médico. En primer lugar, se mantiene un contacto directo y presencial en consulta el 17 de Julio de 2020 para la comunicación de los resultados de la analítica y el seguimiento de las pruebas de prevención correspondientes a los 60 años (densitometría y citología). Posteriormente, establecemos la casuística de nuestra alumna y planteamos un breve resumen de los objetivos a alcanzar y procedimientos a seguir en el programa de entrenamiento basado en la evidencia. De esta manera, concretamos por ambas partes la mejor ruta a seguir, evitando así interferencias con los tratamientos farmacológicos y potenciando la complementación de estos, consiguiendo por tanto el visto bueno para el inicio del ejercicio.

En cuanto al método de comunicación posterior a la consulta (y debido a la situación sanitaria provocada por la COVID-19), si fuese necesario, procederemos a mantener un contacto a través de correo electrónico ante posibles cambios o imprevistos en la situación o planteamiento del programa. 


\subsection{Aspectos éticos, legales y jurídicos.}

La reciente salida del Código Deontológico de la profesión en el $90^{\circ}$ Pleno del Consejo General de la Educación Física del Colegio Oficial de Licenciados en Educación Física y en Ciencias de la Actividad Física y del Deporte de Andalucía (COLEF), diseñado exclusivamente para los educadores físicos, nos permitirá establecer una serie de comportamientos éticos a nivel profesional de obligatorio cumplimiento (COLEF, 2019):

- Tener en cuenta las consecuencias en la salud y la ciudanía de los clientes.

- Trabajar bajo la responsabilidad y respeto hacia la persona, basándonos en la confianza, honestidad y trasparencia, así como favoreciendo la dignidad y principio de no discriminación.

- Actuar siendo prudentes en la aplicación de los diferentes métodos y herramientas, asumiendo, si fuere el caso, los errores cometidos y ofreciendo ante estos una explicación clara y constructiva.

- Mantener una actitud activa en el enriquecimiento profesional, a través de la constante formación y actualización de conocimientos basados en la evidencia científica, que nos permitirá intervenir de la mejor manera posible.

- Ser conscientes de las limitaciones en competencias profesionales, debiendo derivar y ceder funciones a un equipo multidisciplinar.

En este último aspecto, y teniendo en cuenta el reconocimiento por parte del Ministerio de Sanidad, Consumo y Bienestar Social de las competencias de los profesionales titulados universitarios del ejercicio físico, estos: "pueden dirigir, supervisar y evaluar la práctica de ejercicio físico, adaptado a las características, necesidades y preferencias de estas personas [de cualquier edad, que tengan algún problema de salud, aquellas con diversidad funcional o con capacidades diferentes], contribuyendo a la adherencia, a las prescripciones de los profesionales sanitarios y al mantenimiento de la práctica de la actividad física regular". Si bien "en todos aquellos casos que lo precisen, por ejemplo, por existencia de comorbilidad o pluripatología, resulta especialmente importante la realización de valoración previa, que descarte contraindicaciones, y la indicación, por parte del profesional o distintos profesionales sanitarios responsables del plan integral de intervención terapéutica de cada persona". (Ministerio de Sanidad, Consumo y Bienestar Social, 2019).

Teniendo en cuenta esto, la Ley 5/2016 del 19 de julio del Deporte de Andalucía nos acota dentro de nuestro sector en "Entrenadores Deportivos" como Graduados en Ciencias de la Actividad Física y el Deporte, cuyas competencias se extrapolan a "actividades deportivas con personas que requieran especial atención en razón a la edad, capacidad física y psíquica, circunstancias sociales o vinculadas a la salud”.

En compromiso con la regulación profesional, y con el objetivo de cumplir con los aspectos legales descritos en los anteriores documentos, dispondremos de un seguro de responsabilidad civil incluido en la Colegiación Oficial (Colegiada N63937) [Anexo $3]$. 
Además, siguiendo la propuesta de Herbert (2014), cumpliremos con los siguientes aspectos legales y jurídicos del entrenamiento personal en esta intervención [Anexo 3]:

- Consentimiento informado de los beneficios del entrenamiento y asunción de riesgos, cuya firma por ambas partes exime de responsabilidad civil.

- Protección de datos, asegurando el derecho a la intimidad y la confidencialidad.

\section{EVALUACIÓN INICIAL.}

El primer paso para estructurar el programa de intervención consiste en recopilar información objetiva acerca de nuestro sujeto, a través una evaluación inicial que nos permitirá establecer unos objetivos concretos e individuales para diseñar los diversos estímulos de entrenamiento acorde a la casuística, las necesidades y el contexto de la alumna.

\section{1.¿Qué evalúo? Justificación de los contenidos a evaluar.}

Teniendo en cuenta los datos obtenidos en la entrevista inicial, debemos de traducir esta información subjetiva, en cuantificable y medible, esencial para un conocimiento preciso y capaz de ser reevaluado durante el proceso de entrenamiento. Por tanto, evaluaremos los aspectos más destacados derivados de esta entrevista. Además, incorporaremos aquellos contenidos necesarios según la justificación de la evidencia científica.

\subsubsection{Aspectos de la calidad de vida relacionada con la salud.}

Uno de sus objetivos personales detallado en la entrevista es mejorar la calidad de vida y bienestar en general. De esta manera, podremos conocer con exactitud los valores de las determinadas dimensiones que componen la calidad de vida relacionada con la salud, es decir, todos aquellos aspectos considerados básicos para desempeñar actividades de la vida cotidiana con normalidad, incluyendo los psicosociales.

\subsubsection{Calidad de sueño.}

Constituye una de las principales alarmas de la entrevista inicial, ya que considera que duerme mal todos los días, refiriendo ciertos niveles de cansancio a diario.

El análisis de la calidad de sueño nos permite conocer algunos factores de riesgo a través de sus alteraciones, siendo un predictor de muerte por todas las causas (Shen, $\mathrm{Wu}$, \& Zhang, 2016), especialmente a nivel cardiovascular (Nagai, Hoshide, \& Kario, 2010). Esto último resulta esencial, teniendo en cuenta la edad de nuestra alumna y sus hábitos en relación al tabaco y el alcohol.

Además, durante las diferentes fases del sueño se producen cambios hormonales a nivel anabólico (aumento de la síntesis proteica para la ganancia y mantenimiento de la masa muscular, absorción de aminoácidos por parte de los tejidos, aumento de la síntesis de RNA y eritropoyesis, disminución de la hormona estimulante de la tiroides, aumento de la hormona del crecimiento...) a tener en cuenta para conseguir las diferentes adaptaciones al entrenamiento. 


\subsubsection{Hábitos de AF.}

Disponemos de cierta información derivada de la entrevista, sin embargo, debemos de obtener datos concretos y cuantificables desde donde tener un punto de partida en el programa. Además de conocer los niveles exactos de esta dimensión, nos permitirá detectar posibles factores de riesgo como el sedentarismo, comportamiento que constituye una de las principales asociaciones con morbilidad y mortalidad por todas las causas, especialmente a nivel cardiovascular (Young et al., 2016) (que tal y como hemos mencionado anteriormente, resulta esencial tener en cuenta en este caso), pero que puede atenuarse con el incremento de los niveles de AF y ejercicio (Ekelund et al., 2016)

\subsubsection{Hábitos saludables.}

Como educadores físicos, es esencial promover hábitos de vida saludables. De nada sirve conseguir el mejor estímulo, si no somos capaces de mantenerlo en el tiempo y acompañarlo con aquellas acciones que no disparen factores de riesgo en la salud, tales como alcohol o tabaco en este caso. Junto al programa de entrenamiento deberemos intentar limitar aquellos hábitos perjudiciales, lo que nos permitirá construir mejoras a largo plazo, es decir, educar desde un punto de vista integral. Es necesario, por tanto, conocer el inicio desde donde partimos para compararlo al finalizar el programa.

\subsubsection{Actitud}

Teniendo en cuenta la información obtenida de la entrevista inicial, observamos poca predisposición al ejercicio. Una evaluación inicial a nivel actitudinal permitirá comprobar si las estrategias utilizadas durante el programa de entrenamiento resultan motivantes, con el objetivo de ser capaces de potenciar la adherencia a la AF y el ejercicio a largo plazo.

\subsubsection{Parámetros biomédicos.}

El conocimiento de los parámetros biomédicos (composición corporal, perímetro de cintura, tensión arterial, frecuencia cardiaca en reposo, bioquímica...) de nuestra alumna permitirá establecer una información cuantitativa a nivel fisiológico. Gracias a esto, tendremos la posibilidad de hallar factores de riesgo a tener en cuenta para el diseño del estímulo de entrenamiento. Además, facilitará la monitorización durante el programa, pudiendo establecer así posibles respuestas positivas o adversas al ejercicio, ya que parámetros como la FC y la tensión arterial son indicadores indirectos de la intensidad.

\subsubsection{Valoración anatómico-funcional y rangos de movimiento.}

Siguiendo parte de la metodología de Kendall's (2007), obtendremos multitud de información acerca de las diferentes características, limitaciones y desequilibrios estructurales o musculares. El objetivo de esta evaluación consiste en recopilar aquellos datos relevantes para el correcto diseño de los estímulos de entrenamiento, teniendo en cuenta las características de nuestra alumna, y favoreciendo por tanto el principio de individualidad. 


\subsubsection{Necesidades de movimiento.}

Tras obtener estas características, procederemos a conocer que patrones básicos de movimiento se corresponden con las necesidades de la vida cotidiana, así como el comportamiento motor en los mismos, identificando posibles limitaciones funcionales a trabajar durante la intervención y acorde a los objetivos.

\subsubsection{Condición física relacionada con la salud.}

Según Suni, Husu, \& Rinne (2009), las diferentes dimensiones de condición física son un excelente predictor del estado de salud presente y futuro.

A través de la evaluación de los diferentes componentes de la condición física no solo podremos establecer un punto de partida en nuestro programa, sino obtener parámetros comparables durante el proceso de intervención (monitorización), así como la elección adecuada de la orientación de los diferentes estímulos de entrenamiento.

\section{2. ¿Cómo evalúo? Herramientas de evaluación.}

Escogeremos las herramientas y cuestionarios desde el punto de vista de la validez, fiabilidad y viabilidad de las mismas, soportadas por la evidencia científica, y detalladas a continuación.

Teniendo en cuenta los contenidos expuestos anteriormente, llevaremos a cabo una evaluación útil y de calidad, ajustándonos a los medios económicos, materiales y temporales, teniendo en cuenta que no siempre podremos acceder al gold standard y bajo la filosofía de "más no siempre es mejor, poco es mejor que nada".

Deberemos de atender, por tanto, a las necesidades personales y de movimiento en la vida diaria de nuestra alumna. El proceso de evaluación debe ajustarse, al igual que el entrenamiento, al criterio de individualización del sujeto.

\begin{tabular}{|c|c|c|}
\hline CONTENIDO & HERRAMIENTA & SOPORTE CIENTÍFICO \\
\hline $\begin{array}{c}\text { Disposición inicial al } \\
\text { programa }\end{array}$ & $\begin{array}{c}\text { PAR-Q y extensión } \\
\text { Estratificación NSCA }\end{array}$ & $\begin{array}{c}\text { ACSM (2015) } \\
\text { Bredin et al. (2013) } \\
\text { Coburn \& Malek (2014) }\end{array}$ \\
\hline $\begin{array}{c}\text { Calidad de vida } \\
\text { relacionada con la salud }\end{array}$ & $\begin{array}{c}\text { SF-36 automatizado } \\
\text { PSS-14 }\end{array}$ & $\begin{array}{c}\text { Vilagut et al. (2005) } \\
\text { Remor et al. (2001) }\end{array}$ \\
\hline Calidad de sueño & ISI & Bastien, Vallières, \& Morin, \\
PSQUI & (2001)
\end{tabular}

Tabla 3. Cuestionarios autoadministrados en la entrevista inicial, relacionadas con los contenidos y la evidencia científica. Pueden consultarse cumplimentados en su totalidad en [Anexo 2]. 


\subsubsection{Disposición inicial al programa}

\section{PAR-Q y extensión +}

El cuestionario autoadministrado PAR-Q (15-69 años) es considerado un método de evaluación eficaz y simple verificado por la evidencia (American College of Sports Medicine, 2015), de manera que al contestar 1 o más de las 7 preguntas afirmativamente, pondremos en conocimiento del personal sanitario la situación para determinar la inclusión del sujeto en un programa de AF y ejercicio. Como complemento en caso de responder alguna cuestión afirmativa y para evitar falsos positivos, usaremos la extensión PAR-Q+ nacida de una revisión de Bredin, Gledhill, Jamnik \& Warburton (2013).

Tal y como plantean estos autores, siguiendo una progresión lógica en intensidad y carga, $\mathbf{e}$ individualizando y supervisando el programa a la casuística que se plantea, no existe riesgo asociado a la práctica que pueda agravar la situación, siendo aún peores las consecuencias derivadas de la inactividad y el sedentarismo.

Debemos tener en cuenta, que en este caso trabajamos con una persona con una patología diagnosticada, por lo que resulta esencial que un médico supervise el proceso. De esta manera, podremos asegurarnos de que la patología no es severa y está controlada, justificando por tanto la inclusión en el programa de entrenamiento.

\section{Estratificación NSCA: Riesgo cardiovascular.}

Teniendo en cuenta el Manual de Evaluación de la NSCA, Coburn \& Malek (2014) nos proponen una estratificación basada en factores de riesgo cardiovascular, que modularán los contenidos y objetivos de nuestro entrenamiento: edad, antecedentes familiares de origen cardiovascular, consumo de tabaco, sedentarismo, obesidad, hipertensión, dislipidemia, hipertensión, prediabetes y colesterol de alta densidad (como factor de riesgo negativo).

\subsubsection{Calidad de vida relacionada con la salud}

\section{SF-36.}

El cuestionario autoadministrado más apoyado por la evidencia científica en multitud de países es el SF-36. En concreto, en España, Vilagut et al. (2005) afirman en su revisión la utilidad, validez y fiabilidad de la información aportada por el mismo a través de la función física, rol físico, dolor corporal, salud general, vitalidad, función social, rol emocional y salud mental. En concreto, escogeremos la versión automatizada por mayor comodidad.

Según la entrevista inicial, y a grandes rasgos, no hay indicios de algunas dimensiones como depresión y ansiedad, pero sí de cierto estrés. Sin embargo, a través de una evaluación a nivel general (teniendo en cuenta la amplitud y subjetividad del concepto de calidad de vida) con SF-36 podremos conocer que aspectos son más susceptibles o problemáticos. 


\section{PSS-14}

Con el objetivo de abordar la dimensión específica de estrés percibido (Remor et al., 2001), acorde a la información subjetiva de 5/10 detallada en la entrevista inicial. Por tanto, determinamos de qué manera puede afectar este aspecto en nuestra planificación del programa, y nos permite conocer un punto de partida a partir del cual progresar.

Los resultados de este cuestionario se obtienen con la suma de los 14 ítems, teniendo una puntuación inversa las preguntas 4, 5, 6, 7, 9, 10 y $13(0=4,1=3,2=2$, $3=1, \mathrm{y} 4=0)$.

\subsubsection{Análisis del sueño.}

Evaluaremos la gravedad del insomnio a través del cuestionario ISI (Bastien, Vallières, \& Morin, 2001), así como la calidad del mismo con el Índice de Calidad de Sueño de Pittsburgh (PSQUI) (Buysse et al., 1989) debido a su impacto científico y utilidad en este caso. De esta manera, obtendremos datos cuantificables que determinen el estado de partida y guíen el proceso de seguimiento y consecución de objetivos del programa de intervención.

Con el objetivo de obtener una recopilación de datos diaria sobre la calidad del sueño utilizaremos la monitorización de Xiaomi Band 4, siendo conscientes de que no se trata del método ideal para su análisis, debido a la multitud de variables fisiológicas a tener en cuenta en el proceso. Sin embargo, desde el punto de vista de la validez, la evidencia sugiere que este tipo de sensores son útiles para el análisis tradicional y general, es decir, fuera de objetivos clínicos o investigación avanzada (Kubala et al., 2019). Por tanto, su mayor potencial reside en la comparación de los datos intrasujeto a diario, siendo una herramienta indirecta útil que permite visualizar el progreso de manera rápida, práctica y sencilla; e incluso, como método de motivación personal para mejorar día a día esta calidad a través de los hábitos programados.

Figura 6. Monitorización del sueño preintervención a través de Xiaomi Band 4.

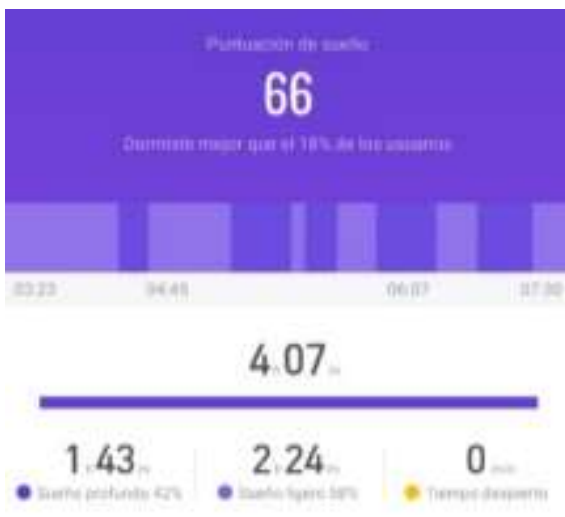

\subsubsection{Hábitos de AF}

El Cuestionario Internacional de Actividad Física (IPAQ) nos permitirá conocer los hábitos de AF moderada y vigorosa en las dimensiones de ocio, transporte, trabajo y hogar, además de los parámetros de sedentarismo. Así, marcaremos un punto de partida para diseñar los diferentes estímulos en el programa de entrenamiento e identificar posibles marcadores de riesgo relacionados con estos hábitos.

Esta herramienta indirecta ha sido respaldada por la evidencia científica a lo largo de los años en más de 12 países (Craig et al., 2003). 
Con el objetivo de complementar esta información, compararemos los datos de IPAQ con los del podómetro (Bortolozo et al. 2017) de Xiaomi Band 4 desde el punto de vista de la viabilidad del dispositivo, así como la validez y fiabilidad de la toma de datos según Xie et al. (2018).

Además, con el uso de esta toma de datos diaria, podemos potenciar la adherencia y motivación hacia al entrenamiento, de cara a mejorar el aspecto actitudinal de nuestra alumna.

Figura 7. Extracto de monitorización de la AF diaria preintervención a través de Xiaomi Band 4.

\subsubsection{Hábitos no saludables: tabaco y alcohol}

Teniendo en cuenta la información exportada de la entrevista inicial en relación a la nutrición y hábitos

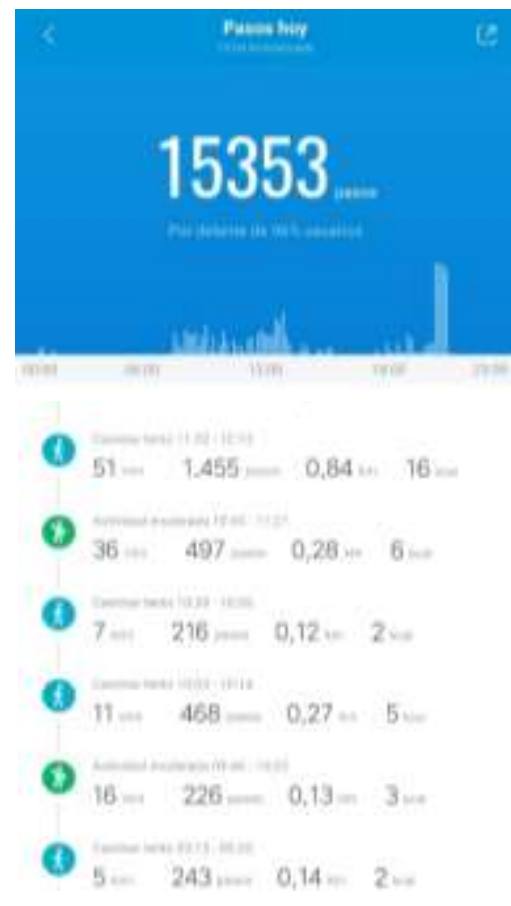
saludables, extraemos únicamente los apartados de "consumo de alcohol" y "consumo y exposición al tabaco" de la Encuesta Nacional de Salud de España (ENS) (Ministerio de Sanidad, Consumo y Bienestar Social, 2017).

No incluimos dimensiones relacionadas con la alimentación puesto que observamos unos buenos hábitos en este aspecto, y no constituye un factor limitante ni en los objetivos personales de nuestra alumna, ni en los del programa de intervención, como posteriormente veremos.

\subsubsection{Parámetros actitudinales.}

Utilizaremos la Evaluación de la Actitud propuesta por la NSCA (Coburn \& Malek, 2014), para conocer la predisposición al ejercicio y las expectativas de nuestra alumna con respecto al programa de entrenamiento.

\subsubsection{Parámetros antropométricos y fisiológicos.}

\section{Composición corporal}

Para hallar el peso, así como para estimar el porcentaje muscular y graso. Utilizaremos el método indirecto de bioimpedancia Keito K8, que si bien no es el gold standard (DXA) si es una herramienta muy viable, y proporcionará una evaluación inicial que permitirá controlar el progreso hacia la consecución de objetivos, siempre y cuando las mediciones se realicen en las mismas condiciones para favorecer el principio de fiabilidad (Thompson, Gordon, \& Pescatello, 2014).

Dentro de estos datos, cobrará especial importancia el porcentaje de masa muscular, ya que como observamos en la revisión de Prado et al. (2018), la sarcopenia se asocia con multitud de patologías cardiovasculares y complicaciones en el continuum médico. 


\begin{tabular}{|c|c|c|c|}
\hline \multicolumn{2}{|c|}{ CONTENIDO } & HERRAMIENTA & SOPORTE CIENTÍFICO \\
\hline \multirow{5}{*}{$\begin{array}{c}\text { Parámetros } \\
\text { biomédicos: } \\
\text { antropometría y } \\
\text { fisiología }\end{array}$} & $\begin{array}{l}\text { Composición } \\
\text { corporal }\end{array}$ & $\begin{array}{l}\text { Bioimpedancia Keito } \\
K 8\end{array}$ & $\begin{array}{l}\text { Thompson et al. (2014). } \\
\text { Prado et al. (2018). }\end{array}$ \\
\hline & $\begin{array}{l}\text { Perímetro de cintura } \\
\text { y cadera }\end{array}$ & Cinta métrica & $\begin{array}{c}\text { Donato (1998). } \\
\text { Ashwell, Gunn, \& } \\
\text { Gibson (2012). } \\
\text { Coburn \& Malek (2014). }\end{array}$ \\
\hline & Tensión arterial & $\begin{array}{l}\text { Tensiómetro digital } \\
\text { VitalControl }\end{array}$ & Ramos et al. (2008) \\
\hline & FC en reposo & Apple Watch Series 5 & Shcherbina et al. (2017) \\
\hline & $\begin{array}{l}\text { Densidad mineral } \\
\text { ósea }\end{array}$ & DXA & Chun (2011) \\
\hline \multirow{2}{*}{$\begin{array}{l}\text { Evaluación } \\
\text { anatómico- } \\
\text { funcional y rangos } \\
\text { de movimiento }\end{array}$} & Valoración postural & $\begin{array}{l}\text { Plomada digital (App } \\
\text { Posture Checker) }\end{array}$ & Kendall et al (2007) \\
\hline & $\begin{array}{c}\text { Rangos de } \\
\text { movimiento y rigidez } \\
\text { relativa }\end{array}$ & $\begin{array}{l}\text { Goniómetro digital } \\
(\text { App Medidas } i O S)\end{array}$ & $\begin{array}{l}\text { Kendall et al. (2007) } \\
\text { Cook et al. (2006). }\end{array}$ \\
\hline $\begin{array}{l}\text { Necesidades de } \\
\text { movimiento }\end{array}$ & $\begin{array}{l}\text { Valoración dinámica } \\
\text { funcional }\end{array}$ & $\begin{array}{l}\text { Análisis visual } \\
\text { apoyado por fotografía } \\
\text { y video (iOS) }\end{array}$ & Sahrmann (2002) \\
\hline \multirow{7}{*}{$\begin{array}{c}\text { Condición física } \\
\text { relacionada con la } \\
\text { salud }\end{array}$} & Equilibrio estático & $\begin{array}{c}\text { One leg test (ALPHA- } \\
\text { fit) y Lockhart Monitor } \\
\text { App }\end{array}$ & Laukkanen et al. (2000) \\
\hline & $\begin{array}{l}\text { Resistencia muscular } \\
\text { tren superior }\end{array}$ & $\begin{array}{c}\text { Push-up } 90^{\circ} \\
\text { modificada } 1 \\
\text { (FITNESSGRAM) }\end{array}$ & $\begin{array}{l}\text { Plowman \& Meredith } \\
\text { (2013). }\end{array}$ \\
\hline & $\begin{array}{l}\text { Resistencia muscular } \\
\text { tren inferior }\end{array}$ & $\begin{array}{l}\text { Chair stand 30" } \\
\text { (Rikli \& Jones) }\end{array}$ & Rikli \& Jones (1999). \\
\hline & $\begin{array}{l}\text { Fuerza isométrica } \\
\text { extensión de rodilla }\end{array}$ & \multirow{3}{*}{$\begin{array}{l}\text { Dinamometría (Rise } \\
\text { Pro } W H-C 300)\end{array}$} & \multirow{3}{*}{$\begin{array}{c}\text { Hasegawa et al. (2008) } \\
\text { Stearns et al. (2013) }\end{array}$} \\
\hline & $\begin{array}{l}\text { Fuerza isométrica en } \\
\text { extensión de cadera }\end{array}$ & & \\
\hline & $\begin{array}{c}\text { Fuerza isométrica en } \\
\text { tracción }\end{array}$ & & \\
\hline & $\begin{array}{c}\text { Capacidad } \\
\text { cardiorrespiratoria }\end{array}$ & $\begin{array}{l}\text { Test de } 2 \mathrm{~km} \text { UKK } \\
\quad \text { (ALPHA-fit) }\end{array}$ & Laukkanen et al. (2000) \\
\hline
\end{tabular}

Tabla 4. Herramientas de evaluación inicial relacionadas con los contenidos y la evidencia científica.

\section{Perímetro de cintura y cadera}

A través de una cinta métrica, un método muy válido, viable y fiable siguiendo un correcto protocolo (Coburn \& Malek, 2014) detallado en [Anexo 4], con el objetivo de relacionar dichos perímetros con posibles factores de riesgo, tales como patologías cardiovasculares o síndrome metabólico (Donato, 1998); siendo esta medida un mejor predictor que el IMC, al no diferenciar este último entre masa muscular y magra (Ashwell, Gunn, \& Gibson, 2012). Gracias a estos perímetros, podremos calcular el índice cinturacadera, una estimación indirecta de la grasa visceral abdominal. 


\section{Tensión arterial en reposo}

Como método directo para identificar posibles factores de riesgo cardiovasculares y/o derivación sanitaria, así como el posterior conocimiento de respuestas adversas al ejercicio (Sieira, Ricart \& Estrany, 2010). Utilizaremos un tensíometro digital VitalControl, por su facilidad de uso con respecto al método manual (más utilizado por el personal sanitario), así como por su validez según la evidencia (Ramos et al, 2008), siempre que sigamos el mismo protocolo detallado en [Anexo 5].

\section{Frecuencia cardiaca en reposo}

Disponemos del dispositivo Apple Watch Series 5, que cuenta con multitud de sensores entre los que destaca la fotopletismografía por haz de luz (PPG), lo que lo convierte en una herramienta interesante para el conocimiento de la frecuencia cardiaca en reposo al ser un dispositivo válido y fiable según la evidencia. (Shcherbina et al., 2017). A partir de este dato, podremos estimar el cálculo de la FC Máxima [208' 75 (0’73*edad)] y la FC de reserva (FC Máx- FC Reposo) como métodos de cuantificación de la carga durante el entrenamiento al tratarse de un dispositivo no invasivo fácil y cómodo de portar. Así, conseguiremos establecer la intensidad de entrenamiento gracias a la fórmula de Karvonen \& Vuorimaa (1988) a través del cálculo FC objetivo= (FC reserva * \%intensidad) + FC reposo.

\section{Densidad mineral ósea}

La densitometría radiológica dual (DXA) es el gold standard de referencia (Chun, 2011) para la evaluación de la densidad mineral ósea (DMO), en este caso en los puntos del cuello del fémur y L2-L4. Disponemos de 2 informes correspondientes a las revisiones periódicas del año 2019 y 2020 [Anexo 1]. Esta evaluación resulta esencial para conocer el estado de partida de la patología de nuestra alumna, así como posibles estimaciones futuras para comprobar el efecto de la dosis de entrenamiento.

\section{Bioquímica}

Dispondremos de una analítica de sangre previa al programa de intervención [Anexo 1], de manera que podamos observar aquellos parámetros asociados a enfermedades cardiovasculares, para posteriormente, determinar aquellos criterios de entrenamiento y mejorar este aspecto.

\subsubsection{Evaluación anatómico funcional y rangos de movimiento.}

\section{Plomada de Kendall}

El ser humano está diseñado para moverse. Sin embargo, un rápido vistazo al control postural en estático en una visión frontal, lateral y posterior, nos permite marcar un punto de partida rápido desde el cual progresar hacia una valoración dinámica y funcional, escogiendo aquellas pruebas acordes a las evidencias visualizadas en diversas articulaciones y cadenas tensionales (Myers, 2010)

Figura 8. Evaluación de la postura a través de la plomada. Extraído de Kendall et al (2007).

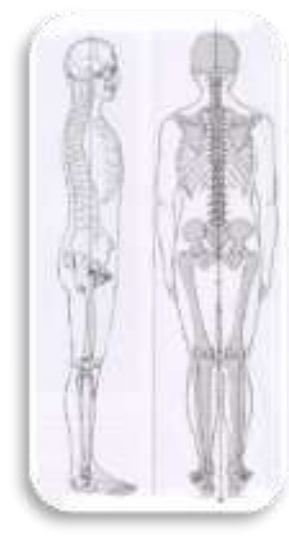




\section{Rangos de movimiento}

Resulta esencial determinar los rangos de movimiento de aquellas articulaciones implicadas en las distintas necesidades de movimiento, y que puedan relacionarse con las características personales y longitudes/tensiones musculares óptimas para evitar susceptibilidades de movimiento en articulaciones sub o supra adyacentes (Cook et al. 2006).

\begin{tabular}{|c|c|c|}
\hline TEST & JUSTIFICACIÓN & EVIDENCIA \\
\hline $\begin{array}{l}\text { Dorsiflexión de } \\
\text { tobillo }\end{array}$ & $\begin{array}{c}\text { Una dorsiflexión de tobillo adecuada }\left(45^{\circ} \text { o } 10 \mathrm{~cm}\right) \text { es esencial } \\
\text { para las fases de la marcha, así como para diversos patrones de la } \\
\text { vida diaria como bajar escaleras. La dorsiflexión deteriorada y } \\
\text { limitada con la edad, especialmente en mujeres, aumenta } \\
\text { exponencialmente el riesgo de caída. }\end{array}$ & $\begin{array}{l}\text { Bennell et al. } \\
\text { (1998) }\end{array}$ \\
\hline $\begin{array}{l}\text { Rotación interna } \\
\text { y externa de } \\
\text { cadera: en } 90^{\circ} \\
\text { flexión y neutra } \\
\text { prono }\end{array}$ & $\begin{array}{l}\text { Con el objetivo de detectar posibles déficits de movilidad que } \\
\text { nos hagan intuir debilidad o rigidez muscular, así como para } \\
\text { descartar factores de riesgo modificables o no modificables } \\
\text { (estructura ósea). Estas limitaciones deberán tenerse en cuenta a } \\
\text { la hora de programar nuestra intervención, y mejorarlos en el } \\
\text { caso de que fuese posible y necesario. Los rangos óptimos son } \\
55^{\circ} \mathrm{RE} \mathrm{y} 45^{\circ} \mathrm{RI} \text {. }\end{array}$ & $\begin{array}{l}\text { Sahrmann } \\
\text { (2002) }\end{array}$ \\
\hline $\begin{array}{l}\text { Movilidad } \\
\text { escapular }\end{array}$ & $\begin{array}{l}\text { El correcto ritmo escapular y el rango de movimiento en flexión, } \\
\text { abducción, aducción y tracción, es de vital importancia en } \\
\text { aquellos patrones overhead que nuestra alumna repite durante su } \\
\text { jornada laboral. }\end{array}$ & García (2019) \\
\hline Thomas Test & $\begin{array}{l}\text { Para determinar la rigidez o flexibilidad relativa de los flexores } \\
\text { de cadera, que pueda afectar tanto a los movimientos cotidianos } \\
\text { como a nuestra propuesta de entrenamiento. }\end{array}$ & $\begin{array}{l}\text { Kendall et al } \\
\text { (2007) }\end{array}$ \\
\hline $\begin{array}{c}\text { Knee Extended } \\
\text { Test }\end{array}$ & $\begin{array}{c}\text { Por su relación con la región coxolumbopélvica, cuyo resultado } \\
\text { en rigidez determinará posible susceptibilidad al movimiento en } \\
\text { otras regiones, por lo que deberemos tenerlo en cuenta para } \\
\text { corregirlo al inicio de programa y asegurarnos un entorno seguro } \\
\text { y eficiente acorde a las necesidades de movimiento en nuestro } \\
\text { entrenamiento. Su rango óptimo está en torno a } 150^{\circ} \text { en extensión } \\
\text { de rodilla (Youdas et al, 2015). }\end{array}$ & $\begin{array}{l}\text { Sahrmann } \\
\text { (2002) }\end{array}$ \\
\hline Koala Test & $\begin{array}{c}\text { De igual manera, la rigidez de los tejidos o escasa fuerza } \\
\text { muscular de los flexores de cadera puede condicionar diversos } \\
\text { patrones motores, produciendo compensaciones en otras } \\
\text { articulaciones y estructuras que intentarán suplir la función de los } \\
\text { mismos. }\end{array}$ & $\begin{array}{l}\text { Modificado de } \\
\text { Bennasar } \\
\text { Kendall et al } \\
\quad(2007)\end{array}$ \\
\hline
\end{tabular}

Tabla 5. Tests realizados en la evaluación inicial para determinar diversos rangos de movimiento.

\subsubsection{Necesidades de movimiento}

Teniendo en cuenta las necesidades de movimiento en la vida diaria personal y laboral de nuestra alumna, escogeremos aquellos test cuya evidencia científica se ajuste a dichos patrones, basándonos por tanto en una evaluación eficiente, eficaz $\mathbf{y}$ personalizada. A partir de la observación de los mismos, la evaluación progresará manteniendo estos principios. 


\begin{tabular}{|c|c|c|}
\hline Side Bending & $\begin{array}{l}\text { A través de la inclinación lateral del tronco podemos observar } \\
\text { posibles diferencias bilaterales que denoten rigidez o desviación } \\
\text { (escoliosis) en las estructuras del raquis, y que debamos por tanto } \\
\text { tener en cuenta a la hora de escoger los estímulos de } \\
\text { entrenamiento óptimos a las necesidades de movimiento. }\end{array}$ & $\begin{array}{l}\text { Sahrmann } \\
\text { (2002) }\end{array}$ \\
\hline Tredelemburg & $\begin{array}{c}\text { Con el objetivo de observar el comportamiento de la región } \\
\text { coxofemoral, así como la posible inhibición de músculos vitales } \\
\text { como el glúteo medio, esencial en las fases monopodales de la } \\
\text { marcha. }\end{array}$ & $\begin{array}{l}\text { Sahrmann } \\
\text { (2002) }\end{array}$ \\
\hline $\begin{array}{l}\text { Flexión de la } \\
\text { columna en el } \\
\text { plano sagital } \\
\begin{array}{c}\text { Squat } \\
\text { modificado }\end{array}\end{array}$ & $\begin{array}{c}\text { Similar a uno de los patrones más comunes durante el trabajo } \\
\text { (agacharse a coger pesos), en la que podemos observar } \\
\text { susceptibilidad en aquellas estructuras implicadas en el } \\
\text { movimiento. }\end{array}$ & $\begin{array}{l}\text { Sahrmann } \\
\text { (2002) }\end{array}$ \\
\hline Overhead Squat & $\begin{array}{l}\text { Los patrones overhead son de vital importancia durante su } \\
\text { jornada laboral. A pesar de que la valoración Functional } \\
\text { Movement Screen (FMS) resulta muy general al acotar la causa- } \\
\text { efecto según el resultado, ejercicios como este pueden ser útiles } \\
\text { para observar la interdependencia segmentaria en el sujeto. De } \\
\text { esta manera, observando su comportamiento, podremos guiar el } \\
\text { resto de la evaluación hacia aquellos datos que resulten } \\
\text { significativos. }\end{array}$ & $\begin{array}{l}\text { Cook et al. } \\
\text { (2006). }\end{array}$ \\
\hline $\begin{array}{l}\text { Squat } \\
\text { monopodal } \\
\text { modificado }\end{array}$ & $\begin{array}{l}\text { De nuevo, obtener una visión rápida y global de la acción } \\
\text { conjunta y coordinada de pie-rodilla-cadera en fase monopodal } \\
\text { nos permitirá identificar posibles déficits que puedan guiar el } \\
\text { resto de la evaluación, así como el manejo de dicha información } \\
\text { para las necesidades de movimiento. }\end{array}$ & $\begin{array}{c}\text { Khamis et al. } \\
\text { (2015) }\end{array}$ \\
\hline $\begin{array}{l}\text { Flexión plantar } \\
\text { monopodal }\end{array}$ & $\begin{array}{l}\text { Gemelo y soleo resultan esenciales para la locomoción, } \\
\text { interviniendo de forma activa en la flexión plantar y como factor } \\
\text { limitante (rigidez) en flexión dorsal. Recordemos que una } \\
\text { restricción en la dorsiflexión aumenta exponencialmente el riesgo } \\
\text { caída. Por tanto, la comprobación de los niveles de fuerza } \\
\text { resistencia (repeticiones) de esta musculatura a través del test de } \\
\text { flexión plantar monopodal de 30", nos permitirá observar posibles } \\
\text { consecuencias en el pie y el resto de articulaciones (referencia de } \\
25 \text { repeticiones) }\end{array}$ & $\begin{array}{c}\text { Hebert-Losier } \\
\text { et al. (2017) }\end{array}$ \\
\hline $\begin{array}{c}\text { Análisis de la } \\
\text { marcha }\end{array}$ & $\begin{array}{c}\text { A los } 60 \text { años, un } 15 \% \text { de los individuos presentan alteraciones en } \\
\text { la marcha, aumentando exponencialmente este porcentaje con la } \\
\text { edad }\end{array}$ & Cerda (2014) \\
\hline
\end{tabular}

Tabla 6. Tests realizados en la evaluación inicial en relación a las necesidades de movimiento.

\subsubsection{Condición física relacionada con la salud}

\section{Equilibrio.}

El equilibrio es una de las capacidades motoras que más se deterioran con la edad (Nelson, 2007). Además, esta capacidad es esencial durante la propia funcionalidad de la marcha. A pesar de que nuestra alumna no presenta problemas de vértigo o mareo que determinen factores de riesgo, resulta esencial evaluar su capacidad para controlar el equilibrio de cara a posibles caídas inesperadas, evitando así agraves de su patología.

Escogeremos el test a una pierna de 60 segundos (One Leg Test), correspondiente a la batería ALPHA fitness europea para adultos (Laukkanen et al., 2000). 
La evaluación consiste en contabilizar los segundos en los que el sujeto es capaz de mantenerse en un único apoyo a elegir (el pie que no está en contacto con el suelo debe colocarse en la parte medial de la extremidad de apoyo, justo debajo de la rodilla). Los brazos pueden usarse para reequilibrarse cuando se considere necesario, y se permiten hasta 2 intentos. Se considera fallo: despegar la pierna contraria del punto establecido de la rodilla o bien la pérdida de apoyo/movimientos laterales contra el suelo del pie correspondiente a la pierna evaluada. El resultado de la prueba se determinan únicamente con los valores referencia de la pierna escogida para el test. Sin embargo, con el objetivo de determinar posibles déficits bilaterales, realizaremos la prueba en ambas extremidades para comparar resultados.

Además, incorporaremos a la medición el estabilograma de la aplicación Lockhart Monitor, con el objetivo de obtener una gráfica de referencia.

Teniendo en cuenta la casuística de nuestra alumna, evaluaremos en profundidad el riesgo de caída y posibles asimetrías con uno de los test de valoración neuromuscular más apoyados por la evidencia (Lee et al., 2015; Powden et al., 2019) el Y Balance Test. Procederemos a colocar tres gomas elásticas como railes (anterior, posteromedial y posterolateral) con una cinta métrica, para calcular la distancia en $\mathrm{cm}$ que puede desplazar un gliding por el suelo de manera controlada y sin perder el contacto directo con el utensilio. Escogeremos la mejor marca de un máximo de 3 intentos.

\section{Fuerza muscular}

Los bajos niveles de fuerza muscular se asocian con riesgo de mortalidad por todas las causas, más allá del porcentaje de masa muscular, por lo que su evaluación es esencial para predecir la salud durante el envejecimiento (Li et al., 2018). Escogeremos aquellos test que involucren grandes grupos musculares bajo la orientación de resistencia muscular, ya que es la capacidad que más se ajusta a las necesidades diarias de nuestra alumna, todos ellos basados en la evidencia científica. En concreto, valoraremos:

- Fuerza resistencia de tren superior en patrón de empuje, a través del test de flexión de brazos modificado (Plowman \& Meredith, 2013). La evaluación consiste en conseguir el mayor número de repeticiones de push-up (hasta flexión de $90^{\circ}$ de codo/un palmo del suelo y sin separación de los brazos del tronco) desde rodillas en 60 segundos. En el caso de no aguantar el minuto se anotarán el número de repeticiones y tiempo.

- Fuerza resistencia de tren inferior, a través de chair stand test (Rikli \& Jones, 2002). Debemos de contabilizar las repeticiones en un tiempo de 30" de sentarselevantarse de la silla (pegada a la pared, por seguridad), con brazos cruzados en el pecho.

Además de las pruebas de condición física relacionada con la salud, incluiremos los siguientes tests con dinamómetro (Rise Pro WH-C300), para determinar unos datos objetivos como punto inicial de partida en términos de fuerza, realizando dos intentos y extrayendo la media de los mismos: 
- Fuerza isométrica máxima voluntaria en extensión de rodilla (desde $\left.90^{\circ}\right)$. Los niveles de fuerza en cuádriceps resultan esenciales en acciones como levantarse de la silla, subir escaleras, velocidad de la marcha y estabilidad dinámica, (Hasegawa et al., 2008), cuyos valores disminuyen considerablemente con la edad debido a la pérdida de masa muscular. Teniendo en cuenta esto, a través de dinamometría, evaluaremos la fuerza isométrica máxima voluntaria del cuádriceps para conocer el punto de partida y monitorizar los efectos del entrenamiento.

- Fuerza isométrica máxima voluntaria en extensión de cadera. El glúteo es el músculo más potente del cuerpo humano, vital durante la marcha, especialmente en la propulsión (glúteo mayor) y estabilización de la cadera en la fase monopodal (glúteo medio). Por ello, favoreceremos la intervención del glúteo en el test a través una ligera abducción y rotación externa (Stearns et al., 2013).

- Fuerza isométrica máxima voluntaria en tracción unilateral en bipedestación. En este caso, evaluaremos un patrón más complejo en el que se ven implicados una mayor cantidad de músculos (cadena cruzada posterior y CORE) del tren superior, para monitorizar el progreso tras la intervención a través de la dinamometría (ya que no disponemos de un dinamómetro manual para el Handgrip Test, cuya evidencia es mayor).

\section{Capacidad cardiorrespiratoria}

El fitness cardiorrespiratorio es una capacidad esencial en el campo de la salud, ya que se relaciona directamente a la inversa con mortalidad tanto en hombres como mujeres (Imboden et al., 2018). La medida cuantitativa para establecer la capacidad cardiorrespiratoria se conoce como volumen máximo de oxígeno (Vo2Máx). En este sentido, a mayor nivel de Vo2Máx, entendido como la cantidad de oxígeno que el organismo es capaz de procesar y usar, menor es el riesgo de padecer multitud de enfermedades metabólicas. El Vo2Máx se relaciona directamente con la FC de reserva, siendo esta el $100 \%$ de intensidad en un ejercicio concreto.

La estimación directa del Vo2 máximo a través de una prueba de esfuerzo de laboratorio monitorizada con analizador de gases, es la herramienta de referencia según la evidencia para la evaluación de la capacidad cardiorrespiratoria (ACSM, 2015). Sin embargo, al no disponer de estos medios, es importante optar por métodos indirectos (test de campo).

Uno de los test indirectos con más evidencia, e incluido en la batería ALPHA fitness europea para adultos, es el test UKK de $2 \mathbf{~ k m}$ (Laukkanen et al., 2000). Dicha prueba submáxima consiste en caminar durante $2 \mathrm{~km}$ a un ritmo ligero pero sin llegar a trotar, mientras se monitoriza la frecuencia cardiaca final y el tiempo empleado en realizar dicha distancia. Es importante mantener el ritmo regular y constante durante todo el test. 


\section{3. ¿Qué datos he obtenido? Resultados de la evaluación.}

\subsubsection{Parámetros biomédicos.}

\begin{tabular}{cc}
\hline \multicolumn{2}{c}{ PARÁMETROS FISIOLÓGICOS } \\
\hline $\begin{array}{c}\text { Tensión arterial } \\
\text { en reposo }\end{array}$ & $134 / 63 \mathrm{mmHg}$ \\
\hline FC Reposo & $86 \mathrm{lpm}$ \\
\hline FC Máxima & $165 \mathrm{lpm}$ \\
\hline FC Reserva & C. Lumbar -3.7. Mayor hacia L4 \\
\hline & Cuello femoral -1.4 \\
\cline { 2 - 2 } DMO (T Score) & Glucosa $125 \mathrm{mg} / \mathrm{dL}$ \\
\hline & Colesterol total $236 \mathrm{mg} / \mathrm{dL}$ \\
Bioquímica & HDL $138 \mathrm{mg} / \mathrm{dL}$ \\
& Plaquetas $381.000 \mathrm{mcL} / \mathrm{dL}$ \\
\hline
\end{tabular}

\begin{tabular}{cc}
\hline \multicolumn{2}{c}{ ANTROPOMETRÍA } \\
\hline Peso & $58^{\prime} 1 \mathrm{~kg}$ \\
\hline$\%$ graso & $35^{\prime} 6 \%(20.6 \mathrm{~kg})$ \\
\hline Masa magra & $37.5 \mathrm{~kg}$ \\
\hline Talla & $1{ }^{\prime} 54 \mathrm{~m}$ \\
\hline IMC & $24^{\prime} 41$ \\
\hline $\begin{array}{c}\text { Perímetro } \\
\text { cintura/cadera }\end{array}$ & $85 / 95 \mathrm{~cm}$ \\
\hline Índice cintura/cadera & 0 ' 89
\end{tabular}

Tabla 7. Resultados de los parámetros biomédicos obtenidos a través de las herramientas detalladas en la evaluación inicial.

\begin{tabular}{|c|cc|}
\hline PERCENTIL MUJERES & $\begin{array}{c}\text { Sistólica }(\mathbf{m m} \mathbf{H g}) \text { a los } \mathbf{6 0} \\
\text { años }\end{array}$ & $\begin{array}{c}\text { Diastólica }(\mathbf{m m} \mathbf{H g}) \mathbf{a} \text { los } \mathbf{6 0} \\
\text { años }\end{array}$ \\
90 & 120 & 70 \\
80 & 120 & 75 \\
70 & 125 & 76 \\
60 & 128 & 80 \\
50 & 130 & 80 \\
40 & 136 & 80 \\
30 & 140 & 84 \\
20 & 142 & 88 \\
10 & 160 & 98 \\
CATEGORÍA & Sistólica (mm Hg) & Diastólica (mm Hg) \\
Normal & $<120$ & $80-89$ \\
Prehipertensión & $120-139$ & $90-99$ \\
Hipertensión en estadio 1 & $140-159$ & 100 o + \\
Hipertensión en estadio 2 & 160 o + &
\end{tabular}

Tabla 8. Percentiles de referencia y categorización según los valores de presión arterial. Destacado en amarillo los resultados de la evaluación. Modificado de Coburn \& Malek (2014).

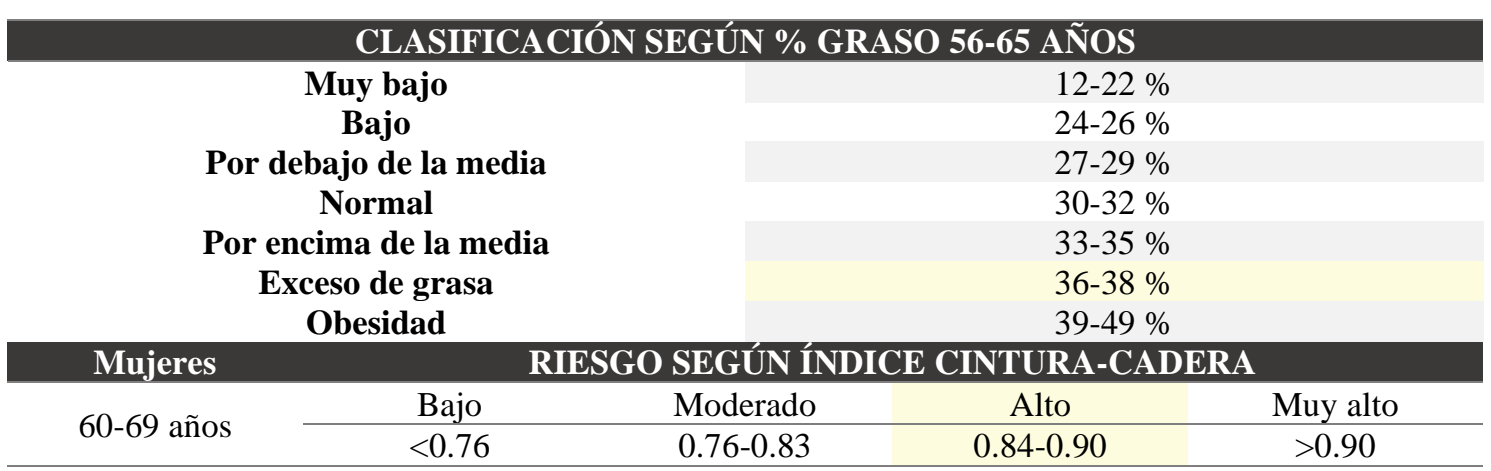

Tabla 9. Valores de referencia de porcentaje graso y perímetro de cintura y cadera: destacada en amarillo la clasificación correspondiente a nuestra alumna. Modificado de Coburn \& Malek (2014). 


\subsubsection{Resultados de la evaluación anatómico-funcional.}

El procedimiento de la evaluación a través de los diferentes test (Tabla 5 y 6 ) y los resultados completos de todos ellos pueden consultarse en su totalidad en [Anexo 6]. A continuación, se presenta un resumen de los resultados más significativos, divididos por articulaciones:

TEST

Pie-tobillo

Complejo

coxolumbopélvico

Rodilla

Cintura escapular

Análisis de la marcha
RESULTADOS

Pie cavo, hallux valgus en ambos, especialmente deformado el izquierdo, produciéndose sobrepronación de antepié. Dorsiflexión de $23^{\circ}$ en ambas, limitación de la cadena posterior acorde a su patología plantar. Flexión plantar 22 y 24 repeticiones derecho e izquierdo respectivamente (pérdida de rango en la repetición 19 aproximadamente)

Ligero síndrome de flexión. RE y RI de cadera limitada en ambas piernas, $35^{\circ}$ y $22^{\circ}$ respectivamente, coincidiendo en neutro y $90^{\circ}$ de flexión. No hay movilidad lumbopélvica (compensación torácica), rigidez en isquiosurales, perdiendo anteversión pélvica en $120^{\circ}$, debilidad en psoas iliaco y glúteo que produce colapso plantar en pronación ante patrones básicos de movimiento (especialmente overhead squat)

Valgo dinámico de rodilla como consecuencia del colapso plantar, alimentado por debilidad de glúteo medio.

Flexión de hombro $167^{\circ}$ con compensación en extensión torácica y cabeza adelantada. Escápula derecha deprimida e izquierda elevada, acorde a su ligera escoliosis en los últimos niveles dorsales, afectando al ritmo escapular y a la tensión en la cadena cruzada posterior izquierda.

Pérdida de contacto temprana del primer dedo en la fase de propulsión y escasa anteriorización tibial, compensando con caída de antepié (especialmente izquierdo). Longitud de zancada corta. Ligera RI para buscar el desplazamiento de la carga hacia el borde lateral del pie (lo que puede provocar un aumento de las fuerzas rotacionales en la rodilla, con el riesgo de mayor desgaste articular). Caída de la pelvis en el plano frontal durante la fase monopodal.

Tabla 10. Resumen de los hallazgos obtenidos a través de la valoración postural, rangos de movimiento y evaluación dinámica funcional.

\subsubsection{Resultados de los test de condición física.}

One Leg Test

Flexión de brazos modificada

Chair Stand Test

24 repeticiones

15 repeticiones
1' con cada pierna, aunque mayor

inestabilidad con

modificada

izquierda (Figura 9)

\section{COMPARACIÓN CON LOS VALORES DE REFERENCIA A LOS 60 AÑOS (Tabla 14)}

Nivel alto

Excelente

Bueno, dentro del

rango $12-17$ para

dicha edad

Tabla 11. Resultados de la evaluación inicial de condición física. 

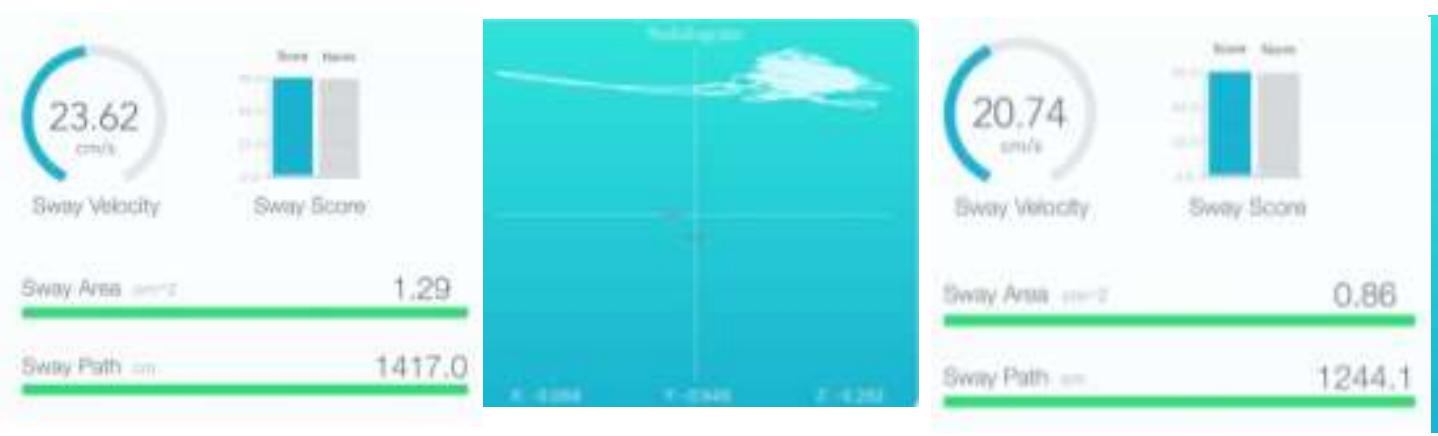

Figura 9. Resultados de equilibrio extraídos de Lockhart Monitor: En primer lugar, velocidad y estabilograma de pierna izquierda. En segundo lugar, parámetros de la pierna derecha.

\begin{tabular}{|c|ccc|}
\hline Y BALANCE TEST & Rendimiento izg en apoyo & Rendimiento der en apoyo & Referencia 60 años \\
Desplazamiento anterior & $63 \mathrm{~cm}$ & $61 \mathrm{~cm}$ & $54 \mathrm{~cm}$ \\
Postero-medial & $93 \mathrm{~cm}$ & $89 \mathrm{~cm}$ & $84 \mathrm{~cm}$ \\
Postero-lateral & $79 \mathrm{~cm}$ & $77 \mathrm{~cm}$ & $80 \mathrm{~cm}$ \\
Tabla 12 Resultados en Y Balance Test $(Y B T)$. Basado en Freund et al., (2018)
\end{tabular}

Tabla 12. Resultados en Y Balance Test (YBT). Basado en Freund et al., (2018)

A pesar de que el YBT suele usarse para localizar asimetrías entre miembros en deportistas y en el ámbito de la prevención y readaptación, existen diversos valores de referencia (Freund et al., 2018) para adultos (aunque la muestra de los estudios con este tipo de población es escasa) que nos indican que, en este caso, hay un buen rendimiento para la edad determinada (Tabla 12), relacionandose además con la fuerza de la cadera y parámetros funcionales como la velocidad de marcha. Teniendo en cuenta este buen rendimiento, es más importante observar las diferencias entre miembros en el desplazamiento postero-medial, con el objetivo de disminuir por debajo $\mathbf{d e} \mathbf{4 c m}$ este valor, relacionándose con un menor riesgo de lesión en deportistas (Smith et al., 2015), que en este caso extrapolareremos al riesgo de caída (su situación de riesgo diaria).
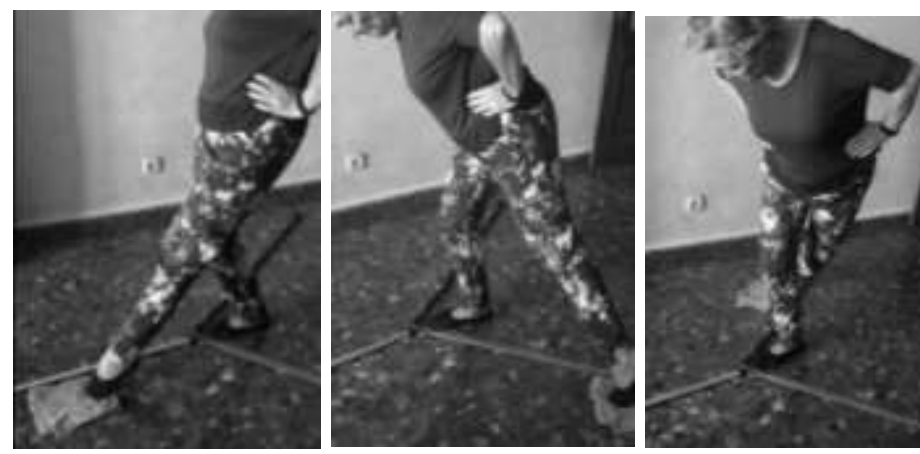

Figura 10. Evaluación de Y Balance Test

\begin{tabular}{ccc} 
Extensión de rodilla & Extensión de cadera & Tracción unilateral \\
\hline $\begin{array}{c}\text { Dcha.180.4 Newtons } \\
\text { Izq. 172.6 Newtons }\end{array}$ & Dcha.151 Newtons & $\begin{array}{c}\text { Dcha.136.3 Newtons } \\
\text { Izq. 141.2 Newtons }\end{array}$ \\
\hline & &
\end{tabular}

Tabla 13. Resultados de la dinamometría que determina los valores iniciales previos al programa de intervención. 


\section{Capacidad cardiorrespiratoria.}

La estimación de VO2Máx es de 20'61 ml/kg/min, lo que se corresponde con el límite inferior del nivel alto de capacidad aeróbica de acuerdo a los valores de referencia medios (Laukkanen et al., 2000) de la población para los 60 años.

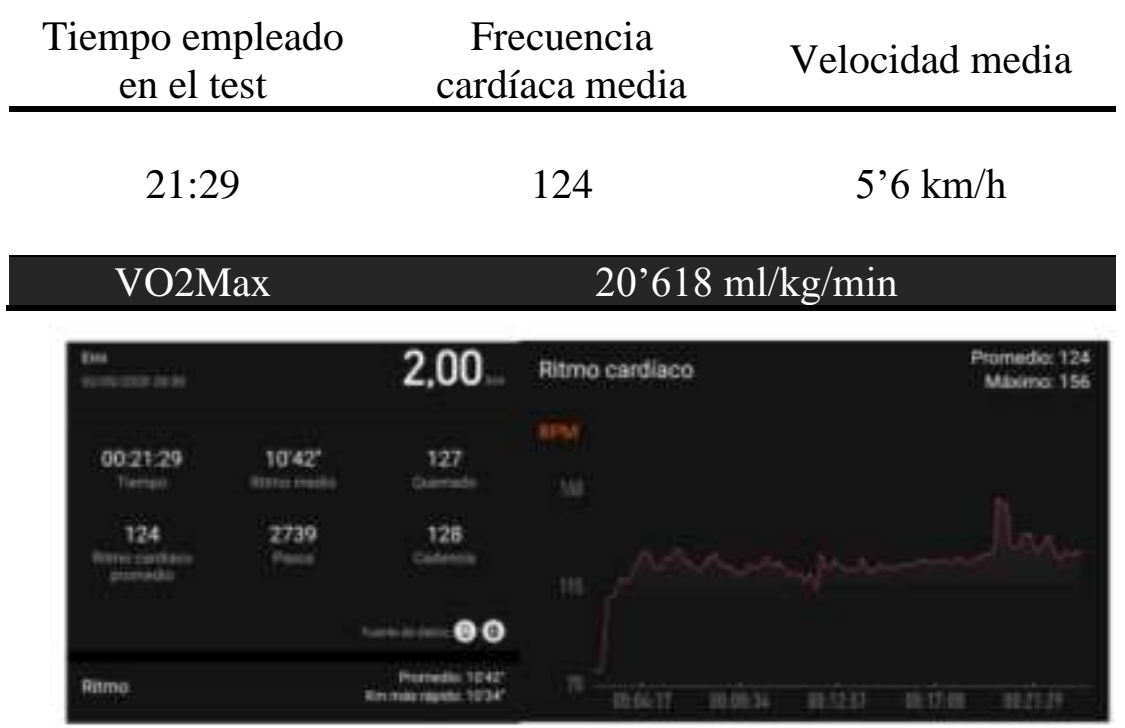

Figura 11. Resultados extraídos de Xiaomi Band 4 en el test de $2 \mathrm{~km}$ UKK

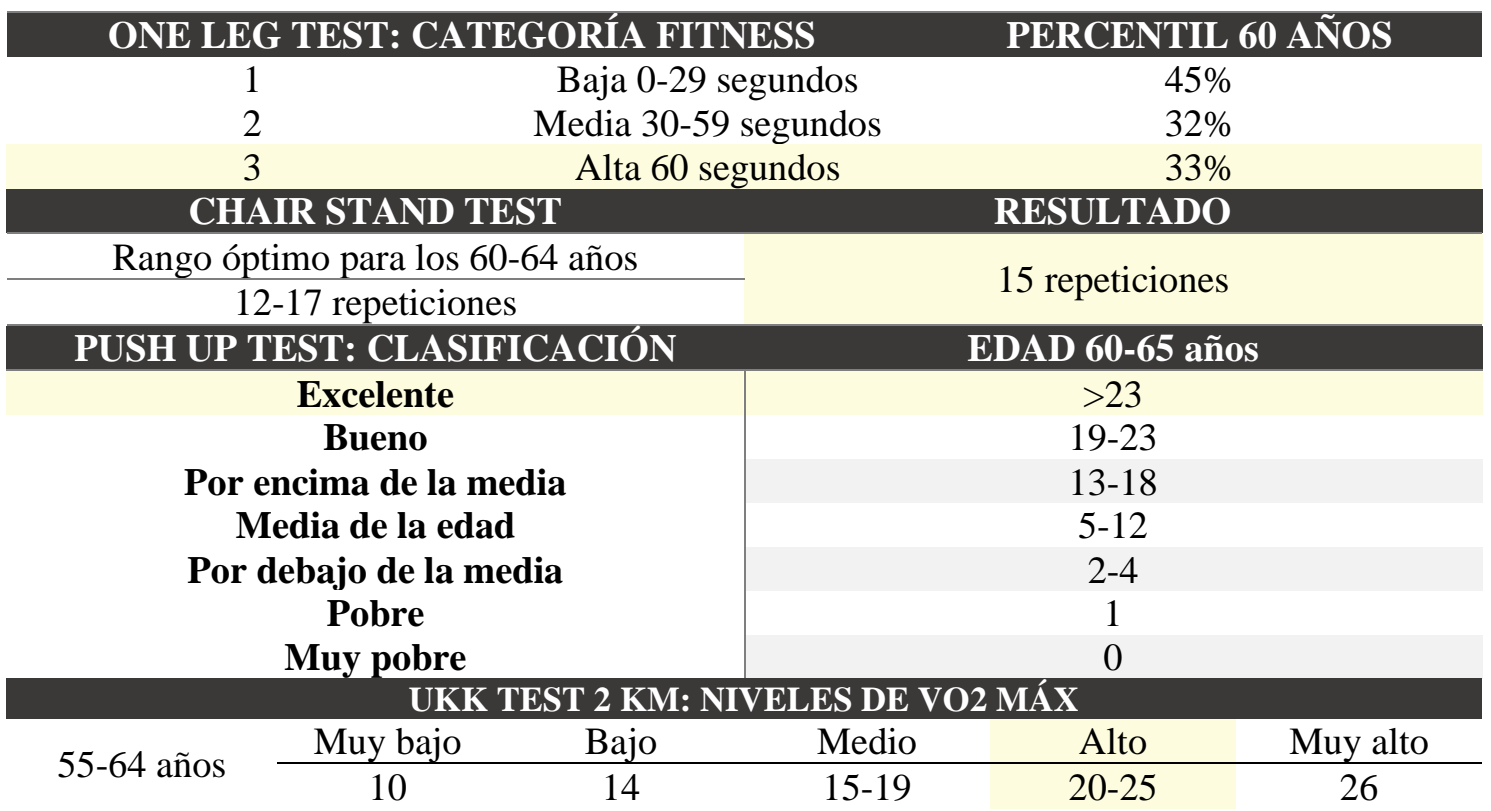

Tabla 14. Valores de referencia de los diferentes test de condición física realizados en la evaluación inicial. Modificado de los diferentes manuales de las baterías: Laukkanen et al. 2000, Rikli \& Jones 1999, Plowman \& Meredith 2013. 


\subsubsection{Informa final de los hallazgos.}

A continuación, se presenta un informe final con los resultados clasificados de mayor a menor riesgo (rojo alto, amarillo moderado, verde bajo o nulo), cuya justificación nos permitirá establecer una serie de prioridades en nuestro programa de intervención.

Debemos destacar que pueden detectarse factores limitantes, déficits u otros aspectos a tener en cuenta, especialmente durante las primeras sesiones. En este caso, y siempre que sea necesario, incluiremos evaluaciones integradas en las mismas, llegando incluso a realizar diversos tests como parte principal de la sesión.

\begin{tabular}{|c|c|c|}
\hline CONTENIDO & RESULTADO & JUSTIFICACIÓN \\
\hline Historial previo & $\begin{array}{c}\text { Fractura de cúbito y radio } \\
\text { izquierda. Medicación } \\
\text { CARDYL }\end{array}$ & $\begin{array}{c}\text { No hay riesgo asociado a antecedentes personales o } \\
\text { familiares, PAR-Q apto. }\end{array}$ \\
\hline Calidad de vida & $\begin{array}{l}80^{\prime} 88 \text { ptos, valores por } \\
\text { encima de la media (Figura } \\
2 \text { y } 3 \text { ) }\end{array}$ & $\begin{array}{l}\text { No presenta niveles de ansiedad, estrés, dolor y } \\
\text { otras dimensiones de la calidad de vida. Debemos } \\
\text { tener en cuenta únicamente los niveles de vitalidad, } \\
\text { propios de sus objetivos personales. }\end{array}$ \\
\hline Calidad de sueño & $\begin{array}{l}\text { Gravedad del insomnio } \\
\text { moderada, escasas horas en } \\
\text { cama, dificultad inicial para } \\
\text { conciliar el sueño, } \\
\text { perturbaciones. }\end{array}$ & $\begin{array}{l}\text { No considera que su cansancio se deba a su calidad } \\
\text { del sueño, ya que suele aparecer sobre las 14:00, } \\
\text { posterior al trabajo. Con una pequeña siesta se } \\
\text { recupera. Sin embargo, esta dimensión es } \\
\text { mejorable, teniendo en cuenta además su necesidad } \\
\text { para que se lleven a cabo los cambios inducidos por } \\
\text { el entrenamiento. }\end{array}$ \\
\hline $\begin{array}{l}\text { Niveles de } \\
\text { Actividad }\end{array}$ & $\begin{array}{l}\text { Actividad Moderada, } 15000 \\
\text { pasos diarios }\end{array}$ & $\begin{array}{l}\text { Cumple con las recomendaciones de AF moderada, } \\
\text { pero debe de acumular mayores niveles de vigorosa, } \\
\text { así como reducir los minutos en sedentarismo. Son } \\
\text { necesarias alternativas que le resulten interesantes. }\end{array}$ \\
\hline $\begin{array}{l}\text { Hábitos no } \\
\text { saludables }\end{array}$ & $\begin{array}{l}\text { Consumo de tabaco y } \\
\text { alcohol a diario }\end{array}$ & $\begin{array}{c}\text { Constituyen uno de los factores de riesgo } \\
\text { cardiovascular. Un abordaje integral debe intentar } \\
\text { reducir estos hábitos, o al menos concienciar sobre } \\
\text { su peligro para la salud e interferencia en los } \\
\text { resultados. }\end{array}$ \\
\hline Actitud & $\begin{array}{l}\text { Escasa predisposición a la } \\
\text { AF y el ejercicio }\end{array}$ & $\begin{array}{c}\text { A tenerlo en cuenta para diseñar estrategias y } \\
\text { conseguir una adecuada adherencia al } \\
\text { entrenamiento. }\end{array}$ \\
\hline Perímetros & $\begin{array}{c}\text { Cintura } 85 / \text { Cadera } 95 \mathrm{~cm} . \\
\text { Índice cintura-cadera }=00^{\prime} 89\end{array}$ & $\begin{array}{l}\text { Debemos destacar que, tras la menopausia, la } \\
\text { distribución de grasa se altera, asemejándose al } \\
\text { patrón masculino, por lo que el índice de cintura- } \\
\text { cadera normativo de riesgo se establece en torno a } \\
0,9 \text { (Ferland et al., 1989). Los datos obtenidos } \\
\text { reflejan un riesgo cardiovascular y grasa visceral } \\
\text { abdominal (método indirecto) moderado-alto en } \\
\text { comparación con los valores normativos, a pesar de } \\
\text { no clasificarse como obesidad abdominal }(88 \mathrm{~cm})\end{array}$ \\
\hline
\end{tabular}




\begin{tabular}{|c|c|c|}
\hline CONTENIDO & RESULTADO & JUSTIFICACIÓN \\
\hline Masa grasa & $35^{\prime} 6 \%(20.6 \mathrm{~kg})$ & \multirow{2}{*}{$\begin{array}{l}\text { La mejora de la composición corporal aumentando } \\
\text { los niveles de masa muscular favorecerá una mejor } \\
\text { salud metabólica y funcional, teniendo en cuenta el } \\
\text { papel protector y endocrino del músculo } \\
\text { esquelético. Los niveles de porcentaje graso son } \\
\text { algo elevados por encima de la media, lo que } \\
\text { constituye un riesgo cardiovascular, especialmente } \\
\text { observando el resultado de los perímetros. }\end{array}$} \\
\hline Masa magra & $37.5 \mathrm{~kg}$ & \\
\hline Tensión arterial & $134 / 63$ & $\begin{array}{c}\text { Tensión sistólica ligeramente elevada, } \\
\text { categorizándose como una ligera prehipertensión. } \\
\text { El consumo de tabaco afecta a este parámetro. }\end{array}$ \\
\hline $\begin{array}{l}\text { Densidad mineral } \\
\text { ósea }\end{array}$ & $\begin{array}{l}\text { Osteoporosis en columna } \\
\text { lumbar: }-3.7 T \text { score } \\
\text { Osteopenia en cuello } \\
\text { femoral: }-1.4 T \text { score }\end{array}$ & $\begin{array}{l}\text { Resulta esencial tener en cuenta la DMO para } \\
\text { adecuar los estímulos de entrenamiento y evitar un } \\
\text { posible riesgo de fractura, especialmente acusado } \\
\text { en los últimos niveles de la columna lumbar (L-4) }\end{array}$ \\
\hline Analítica & $\begin{array}{c}\text { Glucosa } 125 \mathrm{mg} / \mathrm{dL} \\
\text { Colesterol total } 236 \mathrm{mg} / \mathrm{dL} \\
\text { LDL } 138 \mathrm{mg} / \mathrm{dL} \\
\text { HDL } 85 \mathrm{mg} / \mathrm{dL} \\
\text { Plaquetas } 381.000 \mathrm{mcL}\end{array}$ & $\begin{array}{l}\text { Glucosa alterada en ayunas (prediabetes), } \\
\text { dislipidemia diagnosticada y tratada actualmente } \\
\text { con medicación, aumentando el riesgo por los altos } \\
\text { niveles de plaquetas. Por tanto, constituyen factores } \\
\text { de riesgo cardiovascular que deberemos afrontar en } \\
\text { los criterios de entrenamiento. }\end{array}$ \\
\hline Pie-tobillo & $\begin{array}{l}\text { Hallux valgus, dorsiflexión } \\
\text { limitada } 23^{\circ} \\
22 \text { y } 24 \text { repeticiones flexión } \\
\text { plantar, por debajo del valor } \\
\text { óptimo (pérdida de rango a } \\
\text { partir de la repetición 19) }\end{array}$ & $\begin{array}{l}\text { Constituye un factor fundamental a tener en cuenta } \\
\text { en la progresión de entrenamiento, ya que su } \\
\text { limitación afecta a todas las estructuras } \\
\text { suprayacentes, por lo que deberemos de diseñar } \\
\text { estrategias y estímulos adecuados para intentar } \\
\text { corregir o disminuir sus consecuencias. }\end{array}$ \\
\hline Rodilla & $\begin{array}{l}\text { Valgo dinámico de rodilla } \\
\text { en diversos patrones }\end{array}$ & $\begin{array}{l}\text { Sin embargo, no encontramos hallazgos } \\
\text { relacionados directamente con la articulación de la } \\
\text { rodilla, sino como consecuencia de su patología } \\
\text { plantar y una debilidad de glúteo medio. }\end{array}$ \\
\hline $\begin{array}{c}\text { Complejo } \\
\text { coxolumbopélvico }\end{array}$ & $\begin{array}{l}\text { Movilidad lumbopélvica } \\
\text { escasa. RE y RI de cadera } \\
\text { limitada en ambas, déficit } \\
\text { ligeramente mayor en } \\
\text { derecha. Rigidez en } \\
\text { isquiosurales, perdiendo } \\
\text { anteversión en } 120^{\circ} \text {, que } \\
\text { limita el movimiento de } \\
\text { extensión de rodilla. } \\
\end{array}$ & $\begin{array}{l}\text { De igual manera, deberemos de tener en cuenta } \\
\text { estas limitaciones para su corrección y un correcto } \\
\text { diseño de los estímulos de entrenamiento. Así, } \\
\text { evitaremos compensaciones a través de otras } \\
\text { estructuras, que podrán producir sobrecarga o } \\
\text { mayor desgaste en ellas. }\end{array}$ \\
\hline Raquis dorsal & $\begin{array}{l}\text { Cifosis dorsal, movilidad } \\
\text { escapular mejorable. } \\
\text { Flexión de hombro } 167^{\circ} \\
\text { (limitación pectoral y dorsal } \\
\text { ancho). }\end{array}$ & $\begin{array}{l}\text { Como consecuencia principalmente de su ligera } \\
\text { escoliosis, que afecta a la elevación de su escápula } \\
\text { izquierda y a la línea tensional cruzada posterior. } \\
\text { No constituye un riesgo exponencial, pero sí deberá } \\
\text { tenerse en cuenta de nuevo para el correcto diseño y } \\
\text { progresión del entrenamiento. Si deberá ser } \\
\text { mejorable su flexión de hombro, esencial en su vida } \\
\text { laboral, y limitada especialmente por su rigidez } \\
\text { anterior y consecuente cifosis dorsal. }\end{array}$ \\
\hline
\end{tabular}




\begin{tabular}{|c|c|c|}
\hline CONTENIDO & RESULTADO & JUSTIFICACIÓN \\
\hline Raquis cervical & $\begin{array}{l}\text { Ligera protracción de } \\
\text { cabeza }\end{array}$ & No es significativo ni tiene ninguna sintomatología \\
\hline $\begin{array}{l}\text { Análisis de la } \\
\text { marcha }\end{array}$ & $\begin{array}{l}\text { Ligera sobrepronación de } \\
\text { antepié como consecuencia } \\
\text { del despegue temprano del } \\
\text { primer dedo, la falta de } \\
\text { dorsiflexión y su hallux } \\
\text { valgus. Caída frontal de la } \\
\text { pelvis. }\end{array}$ & $\begin{array}{c}\text { Su resultado es dependiente de sus consecuencias a } \\
\text { nivel de pie-tobillo. Por tanto, interviniendo en ello } \\
\text { y junto a glúteo medio (evitando caída de la pelvis), } \\
\text { podremos mejorar este patrón de marcha. }\end{array}$ \\
\hline Equilibrio & Nivel alto & \multirow{3}{*}{$\begin{array}{l}\text { Los resultados se encuentran dentro de los rangos } \\
\text { óptimos para los } 60 \text { años, siendo ligeramente menor } \\
\text { en el tren inferior, acorde a la pérdida de masa } \\
\text { muscular en esta zona conforme pasan los años. } \\
\text { Así, deberemos tener en cuenta la importancia de la } \\
\text { aplicación de fuerza en patrones cotidianos. }\end{array}$} \\
\hline $\begin{array}{l}\text { Fuerza en tren } \\
\text { superior }\end{array}$ & Excelente & \\
\hline $\begin{array}{l}\text { Fuerza en tren } \\
\text { inferior }\end{array}$ & $\begin{array}{l}\text { Valor bueno según el rango } \\
\text { para dicha edad }\end{array}$ & \\
\hline $\begin{array}{c}\text { Fitness } \\
\text { cardiorrespiratorio }\end{array}$ & $\begin{array}{l}\text { Nivel alto de capacidad } \\
\text { aeróbica (límite inferior con } \\
\text { capacidad media) 20’61 } \\
\mathrm{ml} / \mathrm{kg} / \mathrm{min}\end{array}$ & $\begin{array}{l}\text { A pesar de encontrarse con una estimación de } \\
\text { capacidad aeróbica alta, debemos recordar que el } \\
\text { consumo de tabaco afecta exponencialmente a esta } \\
\text { capacidad, que además constituye un factor de } \\
\text { riesgo cardiovascular. Partimos de unos niveles } \\
\text { buenos (siendo conscientes de la limitación del } \\
\text { método indirecto), pero el estímulo aeróbico } \\
\text { resultará esencial en nuestro programa. }\end{array}$ \\
\hline
\end{tabular}

Tabla 15. Clasificación de los resultados más relevantes derivados de la entrevista y evaluación inicial.

\section{ANÁLISIS DE LA CASUÍSTICA.}

\section{Paradigma biopsicosocial de Engel y "Exercise is Medicine".}

El abordaje integral del sujeto es una idea que viene repitiéndose a lo largo de todo el trabajo, y que solo puede ser posible concibiendo al individuo como una persona y todo lo que lo define, rodea e influencia: emociones, motivación, bienestar personal, autoeficacia, entorno, ambiente... Todo ello interactúa y afecta directamente a la capacidad de la persona para expresarse o predisponerse a una acción. De esta manera, debemos tener claro que no es suficiente con conocer a nivel biomédico, anatómico, fisiológico, biomecánico o neurológico los factores que afectan al individuo, sino entender como estos rigen el comportamiento a nivel global como un todo, en este caso a través del movimiento acotado a través de una tarea.

Figura 12. Adaptación propia de Engel (1977) sobre el modelo biopsicosocial en el que se basa la reflexión de abordaje integral.
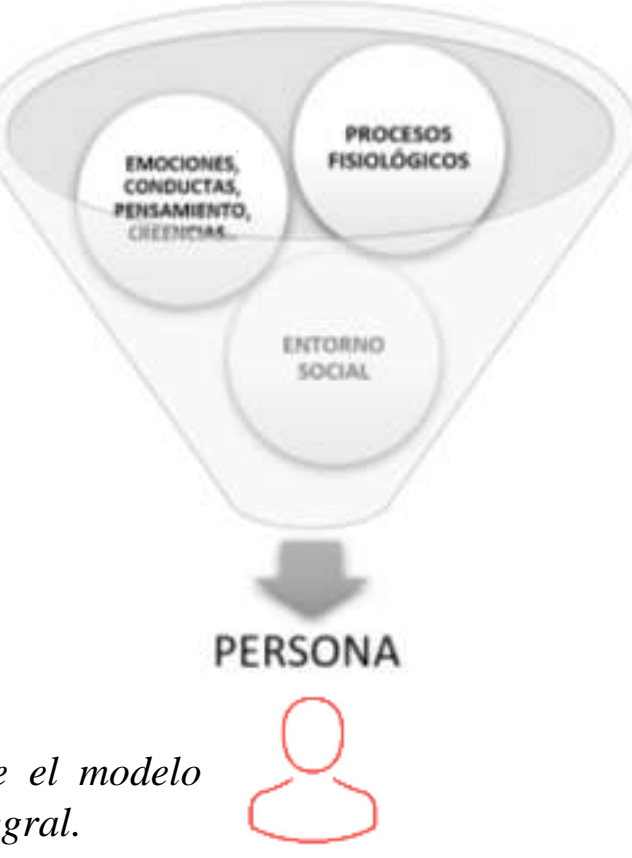
Imaginemos que el enfoque médico tradicional que establece una causa-efecto aislada nos proporciona los apellidos del individuo, todo aquello que nos resulta útil para conocer en profundidad los detalles de la persona. Sin embargo, conocer en primer lugar su nombre, es decir, quién es y todo lo que lo define y afecta a cómo se desenvuelve en el día a día, es el primer paso para entablar una relación de calidad.

Este símil nos hace entender que, cómo profesionales, un enfoque holístico es el más adecuado para conseguir una intervención a nivel integral. Es decir, por una parte, resulta esencial conocer el funcionamiento de aquellos mecanismos biológicos que afectan a las diferentes características de la persona, a través de un modelo biomédico que permita mantener un lenguaje común con el personal sanitario (en este caso sería el conocimiento de la osteoporosis como patología). Sin embargo, y siguiendo con este ejemplo, de nada sirve poner la lupa en conocer a la perfección la patología si no sabemos qué significa para la persona, como le afecta en su día a día, si es la consecuencia secundaria de otra patología, de malos hábitos... En definitiva, solo con una vista panorámica podremos comprender que todo es más complejo. Nuestro objetivo debe ser obtener la mejor visión posible, siendo conscientes de las limitaciones debido a la complejidad del sistema.

Mirar más allá y tener en cuenta todas estas relaciones, favorecerá un correcto diseño del programa de intervención y sus objetivos, cuya meta no es solo potenciar el bienestar, sino también un pensamiento crítico y autonomía a través de la educación. No habrá mayor motivación personal de nuestra alumna como lo es el empoderamiento y el conocimiento de lo que suponen las acciones, en este caso el movimiento, en la salud del individuo. Esto favorecerá la adherencia a largo plazo, que al fin y al cabo es la base de la pirámide para comenzar y mantener un programa de $\mathrm{AF}$ y ejercicio.

Sin dejar atrás esta idea principal, cabe destacar que el paradigma del ejercicio ha evolucionado notablemente en los últimos años, como podemos observar en las tendencias fitness de American College of Sports Medicine del 2020 (Thompson, 2019). En esta encuesta anual destaca el auge de Exercise is Medicine, entendiendo el ejercicio como prevención primaria, así como la derivación a profesionales cualificados en AF y ejercicio tras el diagnóstico de la enfermedad, lo que coincide con la clara evidencia del efecto de los programas de entrenamiento en más de 26 enfermedades crónicas según Pedersen \& Saltin (2015).

\section{Marco teórico basado en la evidencia científica.}

Para establecer un correcto marco teórico que nos ayude a entender todos los datos obtenidos de la evaluación inicial, es esencial una lectura crítica de la evidencia científica de mayor calidad. Por tanto, la información obtenida se basa en las revisiones sistemáticas más actuales acordes a las características de nuestra alumna, así como en publicaciones de revistas de alto impacto (JCR), tanto en el marco de las Ciencias de la Actividad Física, Ejercicio y Deporte (en el JCR 1er cuartil entre 1'2-4'1), como en Medicina por la propia naturaleza de las patologías, a través de grandes revistas como Journal of the American Medical Association (JAMA) y manuales de editoriales referentes como Springer. En cuanto a este último aspecto, debemos tener en cuenta que el diagnóstico clínico es competencia exclusiva del personal sanitario especializado. Sin embargo, es importante que, como profesionales del ejercicio y agentes de salud en este sentido, hablemos y comprendamos un lenguaje común para asegurar la calidad del abordaje de la persona. 


\subsection{Mujer y postmenopausia.}

La menopausia es una etapa natural en la vida de la mujer que se diagnostica clínicamente en torno a los 51 años (Langdren et al., 2004). Teniendo en cuenta la esperanza de vida de la población adulta más allá de los 80 años, la etapa de postmenopausia ocupa casi un tercio de la vida de la mujer (Takahashi et al., 2015). Dicha etapa se caracteriza especialmente por los cambios hormonales, en el que el signo vital del ciclo menstrual desaparece por completo ante la diminución de producción endógena desde el eje hipotálamo-hipófisis-ovario de progesterona en primer lugar, y posteriormente de estrógenos.

El papel de los estrógenos es fundamental, pues de su descenso de aproximadamente 200 picogramos por $\mathrm{ml}$ de plasma $(\mathrm{pg} / \mathrm{ml}$ ) a $10 \mathrm{pg} / \mathrm{ml}$ se derivan una serie de consecuencias (Cervellati \& Bergamini, 2016). Esta hormona esteroidea proveniente del colesterol y convertida desde los andrógenos a través de la aromatasa, constituye un auténtico protector del sistema cardiovascular de la mujer. A continuación, justificaremos esta afirmación a través de los principales cambios a tener en cuenta en la postmenopausia:

\section{Perfil lipídico: grasa visceral y riesgo cardiovascular.}

Los estrógenos se sintetizan a través de la lipoproteína de baja densidad (LDL), lo que comúnmente llamamos "colesterol malo", de manera que este se convierte en el principal sustrato para los estrógenos. Por tanto, ante la disminución de la producción de estrógenos, los niveles de LDL aumentan en la mujer (Thaung Zaw et al., 2018). A esto, se une una hipótesis (al ser un estudio de privatización con ratas; Kamei et al., 2005), en la que el metabolismo de las grasas se ve mermado debido a la baja expresión de enzimas y genes protagonistas en la oxidación de ácidos grasos como fuente de energía, como consecuencia de la disminución de los niveles de estrógenos.

Teniendo en cuenta esto, el papel protector de los estrógenos ante los lípidos desaparece, aumentando los niveles totales de colesterol, y predominando un modelo de acumulación de grasa visceral abdominal debido a la mayor expresión de andrógenos (en concreto la testosterona), pues son responsables de sintetizar el estradiol, uno de los estrógenos más importantes (Stefanska et al., 2015).

Un ejemplo claro es que, durante su etapa fértil, la mujer mantiene una distribución de grasa en cadera, glúteo y piernas (genoide) gracias a los estrógenos producidos por el ovario. Sin embargo, en el hombre predominan en la zona central (androide). Es por ello, que cuando esta producción cesa en el ovario tras la menopausia, el reparto de grasa se asemeja más a los varones (recordemos que la hormona predominante en hombres es la testosterona), aumentando así el perímetro de cintura, directamente asociado con la grasa visceral (Kapuš, Gába, \& Lehnert, 2020).

Atendiendo a estos cambios en el perfil lipídico, así como por la desaparición del papel protector y vasodilatador de los estrógenos en la pared de los vasos, el riesgo cardiovascular de la mujer se dispara en esta fase de su vida. Esto constituye la principal causa de mortalidad en esta población (Abdulnour et al., 2012), cuyas consecuencias se agravan con un estilo de vida no saludable, la falta de descanso y el descenso de la AF (en la que tenemos un papel fundamental). 
Todos estos procesos aumentan las posibilidades de padecer síndrome metabólico, ya que contribuyen a la resistencia a la insulina, hipertensión, y otros factores ya mencionados en la misma dinámica. (Ko \& Kim, 2020).

\section{Masa muscular y fuerza}

Otro de los principales rasgos que caracterizan esta fase de la mujer es la pérdida de masa muscular esquelética (0.6-1\% anual a partir de los 50 años), conocida como sarcopenia, que a su vez provoca una disminución de los niveles de fuerza (dinapenia). Al disminuir la sección trasversal del músculo, se acumula mayor porcentaje de colágeno de mala calidad, lo que restringe además el movimiento.

A la pérdida gradual de estrógenos se une el desequilibrio entre síntesis proteica, degradación y estrés oxidativo. Este último da lugar a un ambiente catabólico en multitud de niveles (neuronal, mitocondrial, muscular...) debido a la acumulación de radicales libres que no se eliminan y al daño celular de la mitocondria que impide producir energía finalizando en apoptosis (Zacarías-Flores et al, 2018).

Debemos destacar en este aspecto, que el mecanismo por el cual los estrógenos contribuyen directamente a la pérdida de masa muscular no está claro aún, y existe controversia en la evidencia en la que se apoyan ambas posiciones, es decir, hasta qué punto influencia o no esta hormona sexual en la sarcopenia.

La hipótesis más apoyada (Messier et al., 2011), apunta a los receptores beta de estrógeno del propio músculo esquelético en la membrana celular, citoplasma y membrana nuclear (afectando así a la síntesis de proteínas y células satélite tras la disminución de los niveles de estrógeno), así como al aumento de las citoquinas proinflamatorias (factor alfa de necrosis tumoral TNF- $\alpha$, IL-6...), y diminución de la testosterona biodisponible, que favorecen este ambiente catabólico anteriormente mencionado. Las fibras tipo II y las propiedades contráctiles, en general, son las más afectadas por la sarcopenia, debido a la importancia de las hormonas sexuales femeninas en el sistema nervioso y la función neuromuscular, pues estructuras como nervios o tendones poseen gran cantidad de receptores de estrógenos, al igual que el músculo esquelético.

La principal consecuencia que puede derivar de la sarcopenia es la pérdida de funcionalidad, que conlleva riesgo de caídas, fracturas y/o fragilidad diaria, cuyos efectos se relacionan a su vez directamente con el riesgo de enfermedades crónicas y mortalidad. (Peterson \& Braunschweig, 2016)

Cabe destacar, que la sarcopenia tiene una estrecha relación con la osteoporosis (cuya casuística trataremos en profundidad en el siguiente apartado), llegándose incluso a acuñar el término de osteosarcopenia, tal y como observamos en el libro de Duque (2019).

\section{Consecuencias de una menopausia precoz y los hábitos no saludables}

La exposición a unos niveles normativos de hormonas sexuales como los estrógenos durante menos años, es decir, a través de una menopausia precoz antes de los 45 años, disminuyen aún más el papel protector de las mismas. 
De esta manera, las consecuencias asociadas a la condición de postmenopausia mencionadas anteriormente se acentúan mucho más, entre las que destaca especialmente la cardiopatía coronaria, mortalidad cardiovascular y mortalidad general, según la revisión de Muka et al. (2016).

$\mathrm{Al}$ igual ocurre con los hábitos no saludables como alcohol y tabaco, que aceleran exponencialmente procesos como la sarcopenia (Kwon et al., 2017), por lo que las consecuencias no siempre llegan a ser no modificables al asociarse con la edad, sino que en muchas ocasiones, como la de nuestra alumna, pueden mitigarse al abordar los factores modificables de estilo de vida.

\subsection{Osteoporosis}

Según el consenso de expertos de NIH publicado en JAMA (2001), la osteoporosis es una patología relacionada con la salud ósea, caracterizada por una baja resistencia del hueso, lo que se atribuye a la disminución de la densidad mineral ósea (cantidad) y el deterioro de la microarquitectura del mismo (calidad). De esta manera, aumenta el riesgo de fractura en zonas diana como la cadera, columna lumbar y antebrazo distal.

El proceso por el cual se desarrolla el deterioro de la densidad mineral ósea (DMO) es el desequilibrio entre la regeneración de hueso a través de la actividad de los osteoblastos y la destrucción del mismo a través de los osteoclastos (Bartl \& Bartl, 2019). Es lo que se conoce como remodelado óseo, modificándose el hueso "viejo" (resorción ósea o modelado) por una nueva formación (remodelado o reconstrucción)

El tipo de osteoporosis más común es la involutiva (primaria, desuso...), es decir, la que se origina al cabo de los años como consecuencia del envejecimiento (más comúnmente en mujeres tras la menopausia, como posteriormente veremos). Esto supone que, debido al aumento de la esperanza de vida, esta patología provoque un gran gasto sanitario en Europa, considerándose incluso una "epidemia silenciosa" que afecta ya a más de 3.5 millones de mujeres (1 de cada 3) en nuestro país (Herlund et al., 2013).

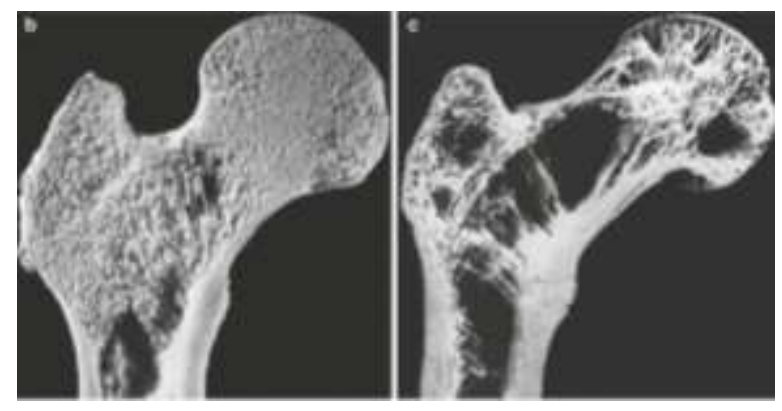

Figura 13. Comparación de la estructura ósea sana (derecha) y afectada por la patología (izquierda). Extraída de "The Osteoporosis Manual”" (Bartl \& Bartl, 2019). 


\section{Fisiopatología: la importancia de las hormonas sexuales.}

En la misma dinámica de lo descrito anteriormente, las hormonas sexuales femeninas juegan un papel fundamental en el mantenimiento de la masa ósea, por lo que, tras la menopausia, la mujer experimenta una caída brusca de la densidad mineral ósea, primero en el hueso trabecular y posteriormente a nivel cortical (Karlamangla, Burnett-Bowie, \& Crandall, 2018). La Sociedad Española de Medicina Interna estima que casi el 50\% de la pérdida de densidad mineral ósea en la vida de la mujer se atribuye a la menopausia.

Los estrógenos ayudan a mantener los factores que limitan la actividad de los osteoclastos, y los andrógenos potencian los que hacen predominar la actividad osteoblástica. De esta manera, en la postmenopausia, los osteoclastos crean cavidades en el hueso (resorción ósea) a un ritmo desmesurado que no puede sobrellevar la posterior actuación de los osteoblastos para generar el hueso nuevo. (Lupsa \& Insogna, 2015).

Debido a este papel de las hormonas femeninas, esta patología prevalece en mayor proporción que en el hombre, cuya casuística suele ser una osteoporosis secundaria provocada por otros factores, especialmente los malos hábitos (alcohol) y/o el uso de glucocorticoides que disminuyen la absorción de calcio y vitamina D (Watts et al., 2012).

\section{Factores de riesgo modificables y no modificables.}

Según Black \& Rosen (2016), la edad y el sexo son factores de riesgo no modificables, que afecta a su vez al alcance del pico de masa ósea durante la adolescencia (que recordemos, se desarrolla antes en mujeres que en hombres, y por tanto, con un menor pico). También lo son la herencia genética y su relación con la raza, que llega a determinar entre el 60-80\% de la DMO, así como los procesos hormonales naturales de la mujer. La menopausia precoz, como hemos comentado anteriormente, aumenta exponencialmente las posibilidades de padecer dicha patología con mayor gravedad, siendo por tanto otro factor de riesgo no modificable a tener en cuenta.

Por otro lado, aquellos factores de riesgo modificables (20-40\%) en los jugamos un papel fundamental son el consumo de alcohol, tabaco, la inactividad física y la nutrición (Rubin et al., 2013), que desarrollaremos en profundidad posteriormente desde el punto de vista del tratamiento.

\section{Diagnóstico clínico.}

La herramienta por excelencia debido a su validez, fiabilidad y seguridad (baja radiación en comparación con otros medios) para clasificar al individuo en el continuum de esta patología es la densitometría de rayos $\mathbf{X}$ dual en cuello femoral $\mathbf{y}$ a nivel lumbar, conocida como DXA (Brown \& Josse, 2002). Gracias a ella, se obtiene una puntuación denominada " $T$ Score" que compara el número de desviaciones estándar del pico de masa ósea en la población de referencia. Cabe destacar que diversas organizaciones como National Bone Health Alliance, han desarrollado clasificaciones más allá de $T$ y $Z$ score, en relación a la fragilidad y las fracturas padecidas. Sin embargo, no entraremos en detalle en ellas ya que no se corresponden con el caso de nuestra alumna.

Los valores standard de "T Score" para el diagnóstico cuantitativo indirecto por DXA que determinan el riesgo de fractura en postmenopausia (Orueta \& Gómez-Caro, 2010), son: 
- Normalidad. Con una puntuación " $T$ ” mayor a -1

- Osteopenia. Denominada como pre-osteoporosis, con rangos iguales o menores a -1 y mayor a -2.5 .

- Osteoporosis. Por debajo de -2.5 "T Score".

- Osteoporosis grave. Por debajo de -2.5 y acompañado además de una fractura osteoporótica por fragilidad.
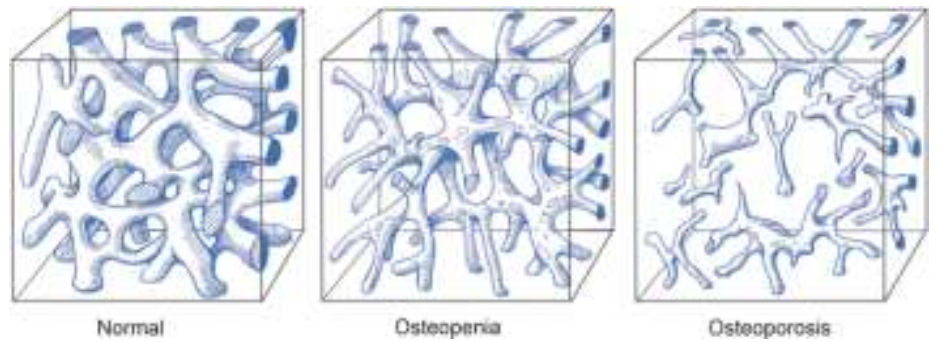

Figura 14. Representación gráfica de los diferentes diagnósticos: evolución de la discontinuidad y disfuncionalidad trabecular. Extraída de "The Osteoporosis Manual" (Bartl \& Bartl, 2019).

Por otro lado, a nivel cualitativo, la masa ósea resulta complicada de evaluar, ya que la herramienta más común es la tomografía computarizada o TAC/TC (con alta radiación) y la radiografía tradicional. Sin embargo, la fiabilidad de esta última disminuye tanto por la baja calidad de revelado, así como por la necesidad de una disminución de hasta un $35 \%$ de masa ósea para que sea percibida a través de esta herramienta. Según Sosa (2004), las alarmas que pueden detectarse en ella son la pérdida de la cantidad de trabéculas o sus conexiones trasversales (predominando las verticales), remarque y porosidad cortical, tamaño y altura de la vértebra, aumento de longitud del cuello del fémur... Esta última, se produce como consecuencia de la formación de hueso cortical superficial del periostio, aumentado el diámetro externo de los huesos largos al compensar las grandes cavidades producidas por la actividad de los osteoclastos y aumentando el riesgo de fractura (Alhborg et al., 2003).

El objetivo de este diagnóstico consiste en detectar de manera precoz aquellos factores adicionales al curso natural de la mujer que desarrollen un riesgo de fractura en cualquier parte del cuerpo (Kanis et al. 2005). En este sentido, la DMO es el mejor predictor $(60 \%)$, solo por detrás de una propia fractura anterior y sin tener en cuenta la calidad del tejido y su resistencia (40\%), según Ammann \& Rizzoli (2003) y coincidiendo con las guías publicadas por la ACSM (2004).

Se considera que una vez se diagnostica la osteoporosis, cada punto de disminución en "T Score" supone en torno a una pérdida del $10 \%$ de DMO, aumentando hasta el doble el riesgo de fractura (Harris et al. 2006). Sin embargo, multitud de fracturas se producen con un diagnóstico de osteopenia, por lo que se corrobora que otros factores como la calidad de la estructura y la capacidad de aplicar fuerza, el control neuromuscular, equilibrio o ROM afectan al riesgo de caída y fractura (Beck et al., 2017).

Recordemos que el diagnóstico constituye una competencia exclusiva del médico especialista, si bien es importante que, como profesionales del ejercicio y su relación con la salud, mantengamos un lenguaje clínico común y un conocimiento básico de la patología. 
Objetivos en el tratamiento de osteoporosis como educadores físicos: recomendaciones según la evidencia.

Teniendo en cuenta todo lo descrito anteriormente, el ejercicio se postula desde hace años, tal y como observamos en el panel de expertos NIH (2001), como el tratamiento no farmacológico más estudiado, cuyos efectos secundarios son evidentemente más bajos. El ejercicio físico es el único tratamiento capaz de mejorar fuerza, masa muscular, densidad mineral ósea y equilibrio a la misma vez (ACSM, 2004); por lo que es una interesante solución para disminuir la alta incidencia de esta patología a largo plazo.

La evidencia nos sugiere que, como entrenadores, nuestro primer objetivo debe de ser la disminución del riesgo de fractura, y no solo buscar el aumento de la densidad mineral ósea. Esto se debe a que a pesar de que los efectos del entrenamiento serán positivos en el aumento de la DMO, estos se observan más a largo plazo, puesto que la mineralización se completa alrededor de varios meses (a diferencia de la resorción que dura unas 2 semanas) y su margen de mejora es más pequeño. Además, la DMO no nos permite diferenciar a nivel cualitativo la estructura ósea.

Para llegar a conseguir nuestro objetivo a través del ejercicio, deberemos tener en cuenta 3 ideas fundamentales:

\section{$1^{\circ}$. Potenciar los niveles de masa muscular para el mantenimiento de la DMO y aumento de los niveles de fuerza.}

El aumento de la masa muscular y sus componentes mecánicos de tracción durante el movimiento, favorecen la estimulación del periostio en el hueso gracias a su conexión con las fibras de colágeno. De la misma manera, a mayor volumen muscular mayor es el flujo sanguíneo de llegada a la extremidad, lo que continúa favoreciendo un ambiente de osteogénesis en la masa ósea (Kaji, 2013). Desde el punto de vista molecular, numerosos factores apuntan a la relación entre el tejido muscular y óseo, entre los que destacan especialmente el papel endocrino de las mioquinas: hormona del crecimiento (GH), factor de crecimiento similar a la insulina (IGF-1), IL-6, irisina...(Gomarasca el al. 2020). Estas mioquinas no solo actúan en el músculo, sino también en la estructura ósea con un papel anabólico, promoviendo la formación ósea. El propio DXA utiliza ecuaciones que relacionan la mineralización y la masa magra.

Esta relación entre masa muscular y ósea debe plasmarse según la evidencia a través del entrenamiento de fuerza, pues el principal factor anabólico es la carga de impacto gracias a las propiedades de mecanotransducción, siendo en la mayoría de los casos insuficiente como tensión mínima efectiva el bajo impacto en actividades como caminar (Fonseca et al. 2014).

Además, el aumento de la sección trasversal del músculo tendrá una relación directa con el aumento de los niveles de fuerza, lo que a su vez disminuirá el riesgo de fractura, como veremos a continuación. 


\section{$2^{\circ}$. Limitar el riesgo de caída y favorecer la actividad osteogénica.}

Con la disminución de la DMO y la aparición de la sarcopenia, se estima que la mayoría de fracturas en esta etapa de la mujer se provocan a raíz de microtraumatismos por caída (Campodónico et al. 2018). Por tanto, el entrenamiento debe de intervenir en aquellas situaciones que favorezcan la limitación del riesgo de caída.

Figura 15. Prevalencia de los tipos de fractura según la edad: muñeca, vertebral y cadera. Extraída de "The Osteoporosis Manual" (Bartl \& Bartl, 2019).

Uniendo esta idea con el punto anterior, el aumento de los niveles de fuerza mejorará la funcionalidad en el día a día, disminuyendo este riesgo de fractura que contribuye a una alta tasa de mortalidad. (Zhao, Feng, \& Wang, 2017).

Figura 16. Aumento del riesgo de mortalidad tras una fractura. Extraída de "The Osteoporosis Manual” (Bartl \& Bartl, 2019).
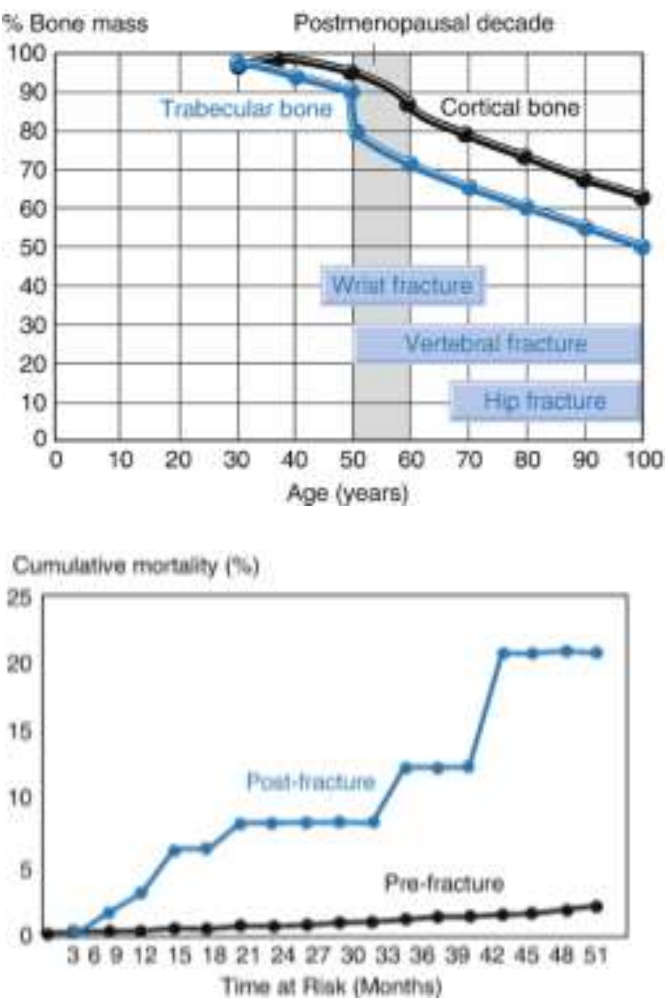

\section{$3^{\circ}$. Favorecer la educación para disminuir los hábitos no saludables.}

Como venimos mencionando, la respuesta del programa de intervención debe ir acompañada de unos buenos hábitos para potenciar los efectos positivos y completar un abordaje integral del sujeto.

En este sentido, según la revisión de Naranjo et al. (2018), los hábitos no saludables como el tabaco y el alcohol exacerban la pérdida de densidad mineral ósea y la absorción de calcio, constituyendo un obstáculo para la prevención de fracturas.

En concreto, se estima que el consumo de tabaco disminuye hasta un $\mathbf{1 0 \%}$ más la DMO en comparación con las mujeres no fumadoras, y que un $\mathbf{2 0 \%}$ de las fracturas se atribuyen a este hábito no saludable. Los mecanismos aún se desconocen, pero parece ser que las sustancias tóxicas y la nicotina inhiben la segregación de estrógenos y aceleran la menopausia, disminuye la absorción de nutrientes esenciales en el proceso de remodelación, inhibe la acción de los osteoblastos y la circulación sanguínea en hueso, aumenta los radicales libres... (Bartl \& Bartl, 2019).

\subsection{Riesgo cardiovascular: síndrome metabólico.}

El síndrome metabólico es el conjunto de alteraciones metabólicas que constituyen un riesgo para la salud cardiovascular (Gami et al., 2007): grasa visceral, resistencia a la insulina, hipertensión arterial, altos niveles de triglicéridos y bajos niveles de colesterol HDL. Según las guías del III Panel de Expertos para el tratamiento de dislipidemia en el adulto (ATP III) publicadas en JAMA en 2001, para su diagnóstico, el sujeto debe de presentar al menos 3 de las siguientes condiciones: 
- Perímetro de cintura superior a $120 \mathrm{~cm}$ en hombres, $88 \mathrm{~cm}$ en mujeres.

- Niveles de triglicéridos $\geq 150 \mathrm{mg} / \mathrm{dL}$

- $\quad$ Tensión arterial sistólica (TAS) $\geq 130 \mathrm{mmHg}$ o distólica (TAD) $\geq 85 \mathrm{mmHg}$

- Colesterol HDL $<40 \mathrm{mg} / \mathrm{dL}$ en hombres y $<50 \mathrm{mg} / \mathrm{dL}$ en mujeres

- Glucosa en ayunas $>110 \mathrm{mg} / \mathrm{dL}$

Las posibilidades de mortalidad por causa cardiovascular se multiplican hasta el doble al padecer síndrome metabólico (Shin et al., 2013), cuyos principales factores de riesgo se pueden evitar, pues corresponden con los estilos de vida no saludables y el sedentarismo. Cabe destacar que en la actualidad existe cierta controversia en otras guías clínicas (ADA, IDF...), en cuanto a los criterios de diagnóstico del síndrome metabólico. Sin embargo, todas confluyen en la conclusión principal de la relación entre mortalidad por todas las causas y la acumulación de los factores de riesgo anteriormente mencionados.

\section{Hipertensión arterial.}

Como observamos en los resultados de la evaluación inicial (Tabla 8), la situación de nuestra alumna se categoriza como prehipertensión sistólica, pues se encuentra por debajo del rango 140/90 (correspondiente al diagnóstico de hipertensión) pero por encima de la TAS y TAD óptima de 120/80. Sin embargo, cabe destacar que organizaciones como el Colegio Americano de Cardiología han modificado recientemente la clasificación de hipertensión a 130/80 en su continente (Whelton et al., 2018), lo que advierte ya del riesgo cardiovascular que supone estar por encima de los valores normativos, como lo es el caso de nuestra alumna: prehipertensión catalogada en España, cuya clasificación coincide con la establecida por las guías de manejo de hipertensión (James et al., 2014) del Joint National Committe publicadas a lo largo de estos años.

Según un estudio de Menéndez et al. (2016), a través de una encuesta nacional en nuestro país, se estimó que la prevalencia de hipertensión arterial en España era mayor al $42 \%$ de la población (aproximadamente 16.5 millones de personas), esta aumenta con la edad y en alrededor del $30 \%$ de las mujeres constituye una enfermedad asintomática y no diagnosticada. Además, la hipertensión arterial está directamente relacionada con las alteraciones de la glucosa, especialmente en mujeres, como veremos a continuación.

La naturaleza de esta patología es multifactorial, si bien en un gran porcentaje de casos está asociada a estilos de vida no saludables (Catalá-López et al., 2012), entre los que destaca el consumo de tabaco, como es el caso de nuestra alumna.

Este, estimula la actividad del sistema nervioso simpático como consecuencia del vertido de catecolaminas al torrente sanguíneo (noradrenalina y adrenalina), lo que produce vasoconstricción y cuyas consecuencias principales son el aumento de la frecuencia cardiaca y la tensión arterial de forma aguda (Perumareddi, 2019). Estos efectos empeoran con la acumulación de grasa en las paredes arteriales, dañando su estructura y función.

El principal objetivo en el que coinciden las principales guías, es intentar reducir la tensión arterial a la horquilla de valores óptimos, pues obviarla y no tratarla (aunque en este caso no sea necesario medicación) aumenta los riesgos de que esta se eleve progresivamente hasta convertirse en patología a nivel vascular y renal. 
Teniendo en cuenta las características de nuestra alumna, la presión sistólica (134 mm $\mathrm{Hg}$ ) elevada de forma aislada puede darnos información del aumento de rigidez de las arterias con el envejecimiento (empeorando aún más con el consumo de alcohol y tacaco), que deberemos analizar para generar estímulos de entrenamiento que mejoren la función endotelial, evitando así el agravamiento de los niveles de presión arterial.

\section{Alteración de la glucosa en ayunas: resistencia a la insulina.}

Una de las principales consecuencias de acumular factores de riesgo que determinan el síndrome metabólico, es la resistencia a la insulina. Esta, se produce por una alteración del metabolismo de la glucosa, lo que da lugar en este caso a un estadio de prediabetes, la antesala de la diabetes. Un metaanálisis del año 2016 con una muestra de más de 600.000 sujetos, indica que encontrarse fuera de los valores de normoglucemia dispara exponencialmente el riesgo mortalidad cardiovascular, enfermedad coronaria $\mathbf{y}$ accidente cerebrovascular (Huang et al., 2016).

La insulina segregada por el páncreas es la hormona encargada de mantener el equilibrio de la glucosa circulante y aporte a los tejidos (ya que esta, en sangre, resulta muy tóxica para el organismo). Cuando esta homeostasis se ve alterada, el cuerpo genera una sobreproducción de insulina (hiperinsulinemia, generando resistencia), a lo que la glucosa responde pasando una mayor cantidad de esta al torrente sanguíneo (Levinson, 2014).

En el caso de las mujeres, tras la menopausia y la consecuente distribución de grasa abdominal, se establece un marco el que el tejido adiposo visceral genera un entorno inflamatorio donde no se permite que la insulina actúe de forma adecuada. Por tanto, existen diversos factores de riesgo independientes que provocan esta alteración de la glucosa, como son la genética y el sexo, si bien de nuevo casi todos están relacionados con los hábitos no saludables y el sedentarismo, por lo que la modificación de los estilos de vida constituye un tratamiento eficaz, eficiente, rentable y seguro (Glechner et al., 2018).

Si este desequilibrio no se revierte, la sobresolicitación del páncreas genera un deterioro del mismo, desencadenándose la diabetes. Por ello, intentar disminuir esta resistencia a la insulina a través del entrenamiento y los buenos hábitos permitirá que la prediabetes no evolucione. Además, en relación a lo anterior y según varios metaanálisis (Wang et al, 2017), el metabolismo de la glucosa alterado aumenta las posibilidades de desarrollar hipertensión, por lo que alimenta el bucle de síndrome metabólico.

\section{Dislipidemia.}

La analítica [Anexo 1] refleja que, a pesar de obtener unos niveles de HDL altos, (considerándose factor protector por su función trasportadora de colesterol desde los tejidos y las paredes arteriales para su posterior eliminación) el conjunto de colesterol total y LDL se encuentran dentro del límite alto (hipercolesterolemia) según la clasificación ATP III (Figura 17). 


\begin{tabular}{|ll|}
\hline Colesterol total $(\mathrm{mg} / \mathrm{dl})$ & \\
$<200$ & Deseable \\
$200-239$ & Límite alto \\
$\geq 240$ & Alto \\
Colesterol LDL (mg/dl) & \\
$<100$ & Óptimo \\
$100-129$ & Casi óptimo \\
$130-159$ & Límite alto \\
$160-189$ & Alto \\
$\geq 190$ & Muy alto \\
Colesterol HDL (mg/dl) & Bajo \\
$<40$ & Alto \\
$\geq 60$ & \\
\hline
\end{tabular}

Figura 17. Clasificación de los niveles de colesterol según ATP III. Extraído de Rubio et al. (2004)

En este sentido, el diagnóstico de dislipidemia contribuye a la aterosclerosis, favoreciendo la acumulación de lípidos (placa de ateroma) en las paredes arteriales, generando mayor tensión por engrosamiento y aumentando exponencialmente el riesgo de accidente cardiovascular al limitarse el flujo sanguíneo (Cuspidi et al., 2018).

Todo esto, favorece un entorno inflamatorio y un alto estrés oxidativo en el que la placa aterosclerótica se vuelve inestable, lo que causa en realidad el accidente, pues la capa fibrosa que la recubre es muy fina y se fragmenta por la actividad de los macrófagos, vertiendo al torrente sanguíneo los lípidos que forman su núcleo, con propiedades altamente trombóticas (Narula et al., 2013). Además, los niveles elevados de plaquetas observados en la analítica [Anexo 1], estiman un mayor riesgo de episodio cardiovascular al contribuir a la trombosis coronaria y obstrucción arterial por sus capacidades coagulantes. Por último, teniendo en cuenta los factores determinantes del síndrome metabólico, el aumento de la presión arterial contribuye al riesgo de ruptura de la placa.

Este entorno inflamatorio y oxidativo afecta a su vez a la disfunción endotelial, encargada de regular el tono y diámetro vascular para regular el flujo y perfusión sanguínea. El endotelio que recubre los vasos sanguíneos tiene altas capacidades vasodilatadoras y antitrombóticas (especialmente por la secreción de óxido nítrico), por lo que mejorar su función nos permite disminuir el riesgo de evento cardiovacular (Fichtlscherer et al., 2004).

\section{Grasa visceral}

A pesar de no obtener un perímetro de cintura de $88 \mathrm{~cm}$, considerado obesidad abdominal, el porcentaje graso total y el perímetro cintura-cadera obtenidos durante la evaluación inicial reflejan un riesgo moderado-alto, con mayores posibilidades de desarrollo de síndrome metabólico.

El acúmulo de grasa en la zona abdominal predominante tras la menopausia por el cese de acción de las hormonas sexuales, se relaciona con la tendencia a la resistencia a la insulina (De Mutsert et al., 2018; Huang et al., 2016). Los mecanismos fisiológicos que dan respuesta a esto son la disfuncionalidad del tejido adiposo (lipotoxicidad), que genera una inflamación constante en el organismo como consecuencia del vertido de citoquinas proinflamatorias al no poder la célula adiposa expandirse más. Este hecho produce un almacenamiento de grasa de forma ectópica (fuera de su lugar) en órganos vitales empeorando su funcionalidad, así como el estado de prediabetes y riesgo cardiovascular, contribuyendo al bucle de síndrome metabólico. 


\subsection{Calidad de vida relacionada con la salud}

Atendiendo al modelo biopsicosocial plasmado al inicio de la casuística, cabe destacar que los parámetros biomédicos mencionados en estos puntos no rigen de forma exclusiva la situación o condición de nuestra alumna.

Más allá de la concepción de salud como ausencia de enfermedad, nuestro programa de intervención se basa en un abordaje integral a través del entrenamiento individualizado, que permita potenciar la calidad de vida. Para ello, el primer paso consiste en averiguar en qué consiste este concepto para nuestra alumna durante la entrevista inicial, extrayendo por tanto las dimensiones clave a mejorar.

La dimensión principal que nuestra alumna destaca para conseguir un estado de bienestar consiste no solamente en no enfermar, sino en mitigar la sensación de fatiga durante y después del trabajo, permitiendo así el desempeño en cualquier actividad social deseada. Teniendo en cuenta esto, y con el objetivo de disminuir este cansancio, deberemos abordar la calidad de sueño y la aparición de episodios de dolor puntuales que comunica que presenta, generalmente tras jornadas laborales intensas.

De esta manera, entendiendo de forma multifactorial y personal el concepto de salud y calidad de vida, y coincidiendo con definiciones oficiales como las de la Organización Mundial de la Salud, conseguiremos alcanzar un bienestar físico, social y emocional, utilizando como herramienta la actividad física, el ejercicio y los hábitos de vida saludables. Para que este efecto se mantenga a lo largo de toda la esperanza de vida, deberemos de conseguir que acciones puntuales o aisladas se conviertan en un estilo de vida, potenciando por tanto la motivación, adherencia y autonomía.

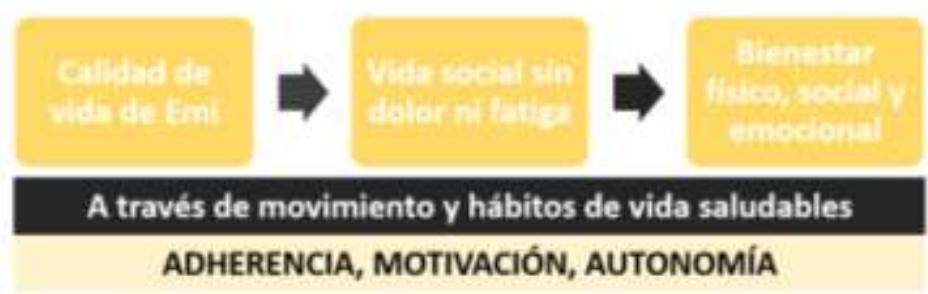

Figura 18. Concepción personal de nuestra alumna de la esfera de calidad de vida y estrategias a seguir para alcanzar el objetivo

\subsection{Interpretación e interrelación de los resultados obtenidos en la evaluación inicial.}

A continuación, procederemos a interrelacionar todos los resultados obtenidos en la evaluación inicial, para interpretar como afecta cada uno de ellos a la situación única y personal de nuestra alumna, más allá de los valores normativos. Estos últimos pueden ser consultados en las Tablas 7, 8, 9, 10 y 11 que se encuentran en el punto de "Evaluación Inicial" y de manera clasificada en el "Informe final de hallazgos" (Tabla 15)

\section{Parámetros fisiológicos.}

La tensión arterial en reposo es de 134/63, lo que nos indica una ligera prehipertensión sistólica (TAS) aislada, que supone un riesgo moderado a nivel cardiovascular (Tabla 8). Podemos relacionar este resultado especialmente con los hábitos no saludables, en concreto, con el tabaco. Deberemos tener en cuenta el consumo del mismo, ya que aumenta la presión arterial en reposo y durante el ejercicio. 
A nivel bioquímico, la analítica recogida en el [Anexo 1] nos informa de:

- Glucosa alterada en ayunas, con un nivel de $125 \mathrm{mg} / \mathrm{dL}$, lo que indica un estadío de prediabetes.

- Colesterol total indicando dislipidemia $236 \mathrm{mg} / \mathrm{dL}$, con LDL de $138 \mathrm{mg} / \mathrm{dL}$.

- Niveles de plaquetas ligeramente elevados a $381.000 \mathrm{mc} / \mathrm{L}$

- Niveles de HDL altos $85 \mathrm{mg} / \mathrm{dL}$, como factor positivo.

Según los valores de referencia del panel ATP III, nuestra alumna se encuentra a las puertas del diagnóstico de este síndrome, pues obtiene como positivos 2 de los ítems: hipertensión arterial y alteración de la glucosa en ayunas. Además, los niveles de grasa visceral se consideran altos, ya que el perímetro de cintura se encuentra en $85 \mathrm{~cm}$, a pesar de no entrar dentro de la categoría de obesidad abdominal de $88 \mathrm{~cm}$ para mujeres.

Sin embargo, debemos destacar que, en este caso, la epigenética probablemente haya jugado un papel importante, ya que toda la familia paterna padeció diabetes tipo II.

Además, mantiene una dislipidemia diagnosticada, como consecuencia secundaria de un hipertiroidismo que a día de hoy está controlado, tal y como observamos en la analítica y gracias a medicación.

Si bien las posibilidades incrementan de esta manera, los desencadenantes de la enfermedad siguen siendo los factores de riesgo modificables del entorno (falta de actividad, hábitos no saludables), que trataremos dentro de los criterios del programa de entrenamiento.

\section{Densidad mineral ósea.}

Los resultados del DXA [Anexo 1] indican osteoporosis en columna lumbar con un $T$ Score de -3.7, más acusado hacia los últimos niveles lumbares (L4). Además, el cuello femoral se mantiene en un diagnóstico de osteopenia con -1.4 T Score.

Teniendo en cuenta el historial clínico, es evidente que la menopausia precoz ha jugado un papel fundamental en la pérdida de densidad mineral ósea, pues como ya hemos mencionado anteriormente durante la casuística, las hormonas sexuales femeninas actúan como protector de la salud ósea y cardiovascular.

Además, el consumo de tabaco (contribuyente además del cese de estrógenos temprano), exacerba la pérdida de DMO e interfiere en los procesos fisiológicos de mineralización.

\section{Composición corporal.}

Debido al riesgo cardiovascular que supone la composición corporal (ya justificado en el apartado de evaluación), los resultados que podemos destacar son el $\mathbf{3 5 . 6 \%}$ de porcentaje graso en el límite inferior de "exceso de grasa", así como el índice de cinturacadera $=0$ '8 en el límite superior "alto" (Tabla 9). La masa magra de partida según la bioimpedancia es de $37.5 \mathrm{~kg}$, lo que resultará útil para monitorizar los progresos, teniendo en cuenta los beneficios de los niveles de masa muscular anteriormente descritos. 
Como observamos, estos valores se corresponden con las alteraciones en la distribución de grasa tras la menopausia, predominando un patrón abdominal/visceral que aumenta exponencialmente los riesgos anteriormente mencionados. A pesar de mantenerse por debajo del perímetro de $88 \mathrm{~cm}$ clasificado como obesidad, resulta esencial tener en cuenta este dato por su relación con el posible desarrollo de síndrome metabólico.

Desde el punto de vista de intervención, cobrará importancia el diseño de estímulos más óptimo para disminuir estos niveles de grasa visceral, si bien será más importante reducir el consumo de alcohol que aumenta exponencialmente este porcentaje graso abdominal. La dosis diaria de cerveza durante las comidas puede explicar en parte este resultado, pues la dieta no es muy desequilibrada y los niveles de actividad diarios durante el trabajo son moderados-altos, a pesar de no alcanzar intensidades vigorosas. Estos niveles de actividad constituyen un factor protector, que permite que este parámetro de riesgo no progrese.

Teniendo en cuenta todos estos resultados y en base a la estratificación de riesgos de la NSCA (Tabla 16), podemos concluir que existe un riesgo cardiovascular moderado (Tabla 17), al disponer de dos factores positivos.

\begin{tabular}{|c|c|}
\hline FACTORES DE RIESGO POSITIVOS & CRITERIO DE DEFINICIÓN \\
\hline EDAD & Hombres $\geq 45$ años, mujeres $\geq 55$ años \\
\hline ANTECEDENTES FAMILIARES & $\begin{array}{c}\text { Infarto de miocardio, revascularización croronaria o } \\
\text { muerte súbita antes de los } 55 \text { años del padre biológico u } \\
\text { otro familiar varón de primer grado, o antes de las } 65 \\
\text { años en el caso de la madre biológica u otro familiar } \\
\text { mujer de primer grado }\end{array}$ \\
\hline TABAQUISMO & $\begin{array}{c}\text { Persona que actualmente fuma o que lo ha dejado } \\
\text { durante los últimos } 6 \text { meses, o persona expuesta al } \\
\text { humo del tabaco }\end{array}$ \\
\hline ESTILO DE VIDA SEDENTARIO & $\begin{array}{l}\text { No haber practicado AF de intensidad moderada (40- } \\
60 \% \text { del VO2 de reserva) durante al menos } 30 \text { minutos, } \\
3 \text { días a la semana como mínimo, durante al menos } 3 \\
\text { meses. }\end{array}$ \\
\hline OBESIDAD & $\begin{array}{c}\text { Indice de masa corporal } \geq 30 \mathrm{~kg} / \mathrm{m} 2 \text {, o circuferencia de } \\
\text { cintura }>102 \mathrm{~cm} \text { en hombres y }>88 \mathrm{~cm} \text { en mujeres }\end{array}$ \\
\hline HIPERTENSIÓN & $\begin{array}{c}\text { Presión arterial sistólica } \geq 140 \mathrm{~mm} \mathrm{Hg} \text { y/o distólica } \geq 90 \\
\mathrm{~mm} \mathrm{Hg}, \text { confirmadas por mediciones realizadas en al } \\
\text { menos dos ocasiones distintas, o bien estar tomando } \\
\text { medicación antihipertensiva }\end{array}$ \\
\hline DISLIPIDEMIA & $\begin{array}{c}\text { Colesterol LDL } \geq 130 \mathrm{mg} / \mathrm{dl}\left(3^{\prime} 37 \mathrm{mmol} / \mathrm{l}\right) \text { o bien } \\
\text { colesterol HDL }<40 \mathrm{MG} / \mathrm{DL}\left(1^{\prime} 04 \mathrm{mmol} / \mathrm{l}\right) \text {, o estar } \\
\text { tomando medicación para reducir lípidos. Si el } \\
\text { colesterol sérico total es el único dato del que } \\
\text { disponemos, } \geq 200 \mathrm{mg} / \mathrm{dl}\left(5^{\prime} 18 \mathrm{mmol} / \mathrm{l}\right)\end{array}$ \\
\hline PREDIABETES & $\begin{array}{l}\text { Alteración de la glucosa }=\text { glucosa en plasma en ayunas } \\
\geq 100 \mathrm{mg} / \mathrm{dl}\left(5^{\prime} 50 \mathrm{mmol} / \mathrm{l}\right) \text { pero }<126 \mathrm{mg} / \mathrm{dl}(6.93 \\
\text { mmol/l) o alteración de la glucosa }=\text { valores a las } 2 \mathrm{~h} \text { en } \\
\text { la prueba de tolerancia a la glucosa oral } \geq 140 \mathrm{mg} / \mathrm{dl} \\
\left(7^{\prime} 70 \mathrm{mmol} / \mathrm{l}\right) \text { pero }<200 \mathrm{mg} / \mathrm{dl}(11 \mathrm{mmol} / \mathrm{l}), \\
\text { confirmados por mediciones realizadas en al menos dos } \\
\text { ocasiones distintas. }\end{array}$ \\
\hline $\begin{array}{l}\text { COLESTEROL-HDL SÉRICO ALTO (Factor de } \\
\text { riesgo negativo) }\end{array}$ & $\geq 60 \mathrm{mg} / \mathrm{dl}(1 ' 55 \mathrm{mmol} / \mathrm{l})$ \\
\hline
\end{tabular}

Tabla 16. Factores de riesgo cardiovasculares. En amarillo los hallados positivos durante la evaluación inicial. En verde, hallado positivo y considerado factor de riesgo negativo. Modificado de Coburn \& Malek (2014). 
RIESGO BAJO

RIESGO MODERADO
Hombres y mujeres asintomáticas que tengan uno o ningún factor de riesgo de enfermedad cardiovascular determinados en la tabla anterior

RIESGO ALTO

Hombres y mujeres asintomáticos que tengan dos o más factores de riesgo

Individuos con una enfermedad cardiaca, vascular periférica o cerebrovascular conocida, enfermedad pulmonar obstructiva crónica, asma, enfermedad intersticial pulmonar o fibrosis quística; diabetes mellitus (tipo 1 y 2), trastornos de la tiroides, enfermedad hepática o del riñón, o bien uno o más de los siguientes signos o síntomas:

- Soplo en el corazón

- Fatiga inexplicable

- Mareo o desvanecimiento

- Hinchazón en los tobillos

- Latidos rápidos o irregulares

- Falta de aire inexplicable

- Cojera intermitente o dolor en los gastrocnemios

- Molestias al respirar sin estar en posición erguida o interrupción de la respiración durante la noche

- Dolor o molestias en la mandíbula, el cuello, el pecho, los brazos o en otro lugar que pudiera estar causado por falta de circulación

\section{Tabla 17. Estratificación y clasificación basada en los factores de riesgo} cardiovascular. Modificado de Coburn \& Malek (2014).

\section{Evaluación anatómico-funcional}

En el apartado de "Evaluación Inicial" encontramos la justificación según la evidencia científica de cada uno de los contenidos (¿Por qué?), herramientas (¿Cómo?) y el significado de cada uno de los resultados con la cita de diversos autores. Recordemos, además, que el proceso de toda la evaluación anatómico-funcional se encuentra en [Anexo 6]. Por tanto, en este caso, nos limitaremos a interrelacionar todos estos resultados para entender la evaluación como un todo, en lugar de valorar cada parte como algo aislado.

Debemos destacar antes, que muchos de los tests realizados son algo subjetivos (si bien se han intentado obtener las máximas medidas cuantificables), y requieren de una larga experiencia para detectar ciertas características, por lo que no podemos limitarnos a establecer una causa-efecto exacta e inamovible, teniendo en cuenta la complejidad del organismo. De esta manera, deberemos de tomar con cautela la siguiente reflexión y conclusiones derivadas de los resultados de la evaluación inicial. 
A nivel plantar, encontramos un pie cavo, rígido y especialmente deformado debido a un hallux valgus (más pronunciado en el izquierdo). Esto tiene consecuencias durante su marcha, al no poder finalizar el despegue con un ROM completo debido a la limitación en flexión del dedo gordo. De esta manera, su organismo busca la solución a través de una sobrepronación del antepié, ya que además la dorsiflexión está limitada

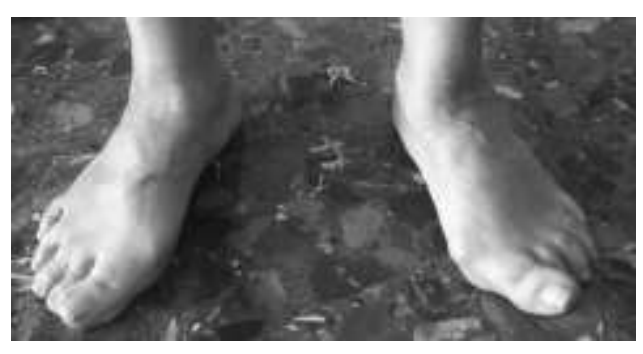

Figura 19. Hallux valgus. por un exceso de tensión notable de la cadena posterior (evaluado a través del Lunge Test), que no deja que la tibia se interiorice y avance en las diferentes fases de la marcha.

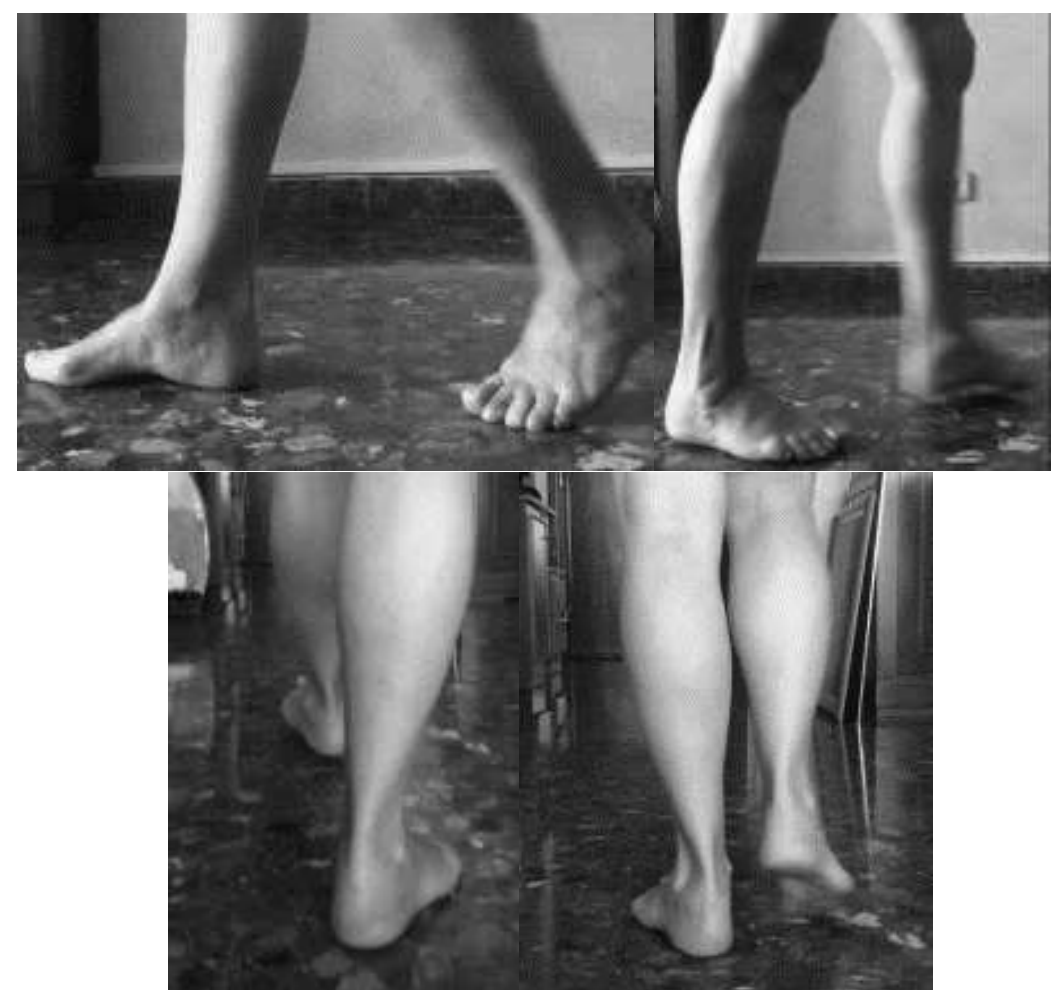

Figura 20. Análisis de la marcha. Arriba: Perdida de contacto temprana en el despegue (izquierda) y máximo ángulo de dorsiflexión durante la marcha (derecha). Abajo: sobrepronación del pié en despegue (izquierda) y en carga (derecha), especialmente pronunciado en el pie izquierdo como podemos ver en el ángulo del tendón de Aquiles.

Debido a ello, la rodilla se ve arrastrada hacia un valgo dinámico, que podemos observar especialmente en patrones complejos de la evaluación como el Overhead Squat Test que ponen en compromiso a su sistema no acostumbrado a estas tareas. A pesar de que durante la marcha esto es menos perceptible en el plano frontal, su caída de la pelvis durante la fase monopodal (conocida como marcha Tredelemburg) sugiere un aumento de la presión articular y mayor desgaste en la rodilla, ya que además podemos observar una ligera rotación interna de la tibia durante la marcha para buscar una ventaja mecánica que permita descargar su peso hacia el borde lateral del pie, como consecuencia de esa limitación del hallux valgus. 
Su complejo coxolumbopélvico mantiene una susceptibilidad a la flexión lumbar, cuya explicación puede hallarse en el exceso de stiffness y limitación del ROM de su cadena posterior (que podemos observar en Knee Extended Test), especialmente a nivel isquiosural. Debido al origen de esta musculatura en la pelvis, su excesiva rigidez arrastra a esta a una retroversión, lo que bloquea su movilidad y control motor, compensando de esta manera con otras estructuras, en este caso a nivel dorsal-torácico. Este desajuste que ha ido perpetuándose debido a la adaptación del sistema, puede explicar de alguna manera esa molestia lumbar de 2/10 constante mencionada en la entrevista inicial, si bien somos conscientes de que el dolor depende de multitud de factores y no solo del estado de la estructura. Sin embargo, considero importante destacar que esta limitación puede tener consecuencias sobre su desgaste vertebral a nivel lumbar debido a su osteoporosis, cuyos niveles de DMO son claramente más bajos en columna lumbar, y que, por tanto, puede llegar a constituir un mayor riesgo de fractura a largo plazo.

Por último, a nivel dorsal encontramos escoliosis y cifosis, así como una protracción de la cabeza, bastante común con el paso de los años y la osteoporosis, que funciona como un intento de mantener el equilibrio de toda su estructura al tener esta limitación pélvica. Esto, junto a una limitación del pectoral menor, repercute especialmente en su movilidad en flexión de hombro, que resulta esencial para sus patrones laborales y de la vida cotidiana. Además de esto, como hemos mencionado anteriormente en la casuística, una cifosis excesiva puede aumentar de nuevo el riesgo de fractura osteoporótica, por lo que es esencial tenerlo en cuenta a la hora de reeducar al sistema.

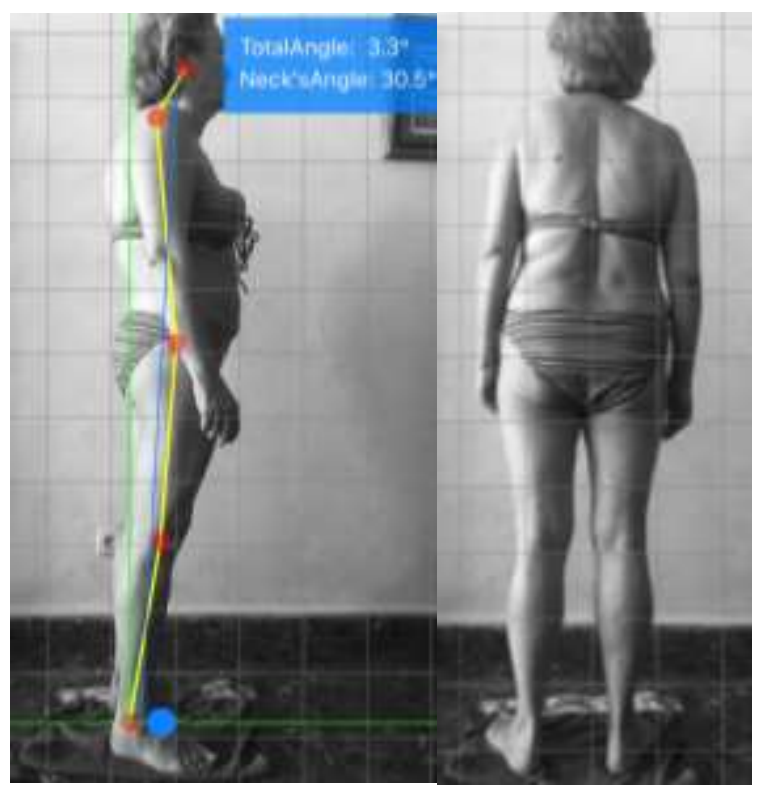

Figura 21. Plomada basada en Kendall et al (2007). Extraída de Posture Checker App iOS. 


\section{Condición física.}

Los resultados de los tests de condición física mantienen un nivel bastante bueno en general para el percentil de los 60 años (Tabla 11 y 14), lo que en parte puede justificarse por el nivel de actividad diaria en el entorno laboral.

- One Leg Test: equilibrio de categoría alta, aunque con disparidad en el pie izquierdo, acorde a su patología plantar descrita anteriormente.

- Y Balance Test. Ligera asimetría en desplazamiento postero-medial, con un rendimiento óptimo en comparación con los datos de los escasos estudios con adulto mayor.

- Chair Stand Test: fuerza resistencia de tren inferior dentro de un rango óptimo para su edad.

- Push-up Test Modificado: fuerza resistencia de tren superior nivel excelente para el rango de su edad.

- Ukk Test $2 \mathrm{~km}$ : capacidad cardiorrespiratoria en el límite inferior de nivel alto para el rango de edad.

Figura 22. Interrelacionado de las características propias anteriormente mencionadas, constituyendo la casuística.

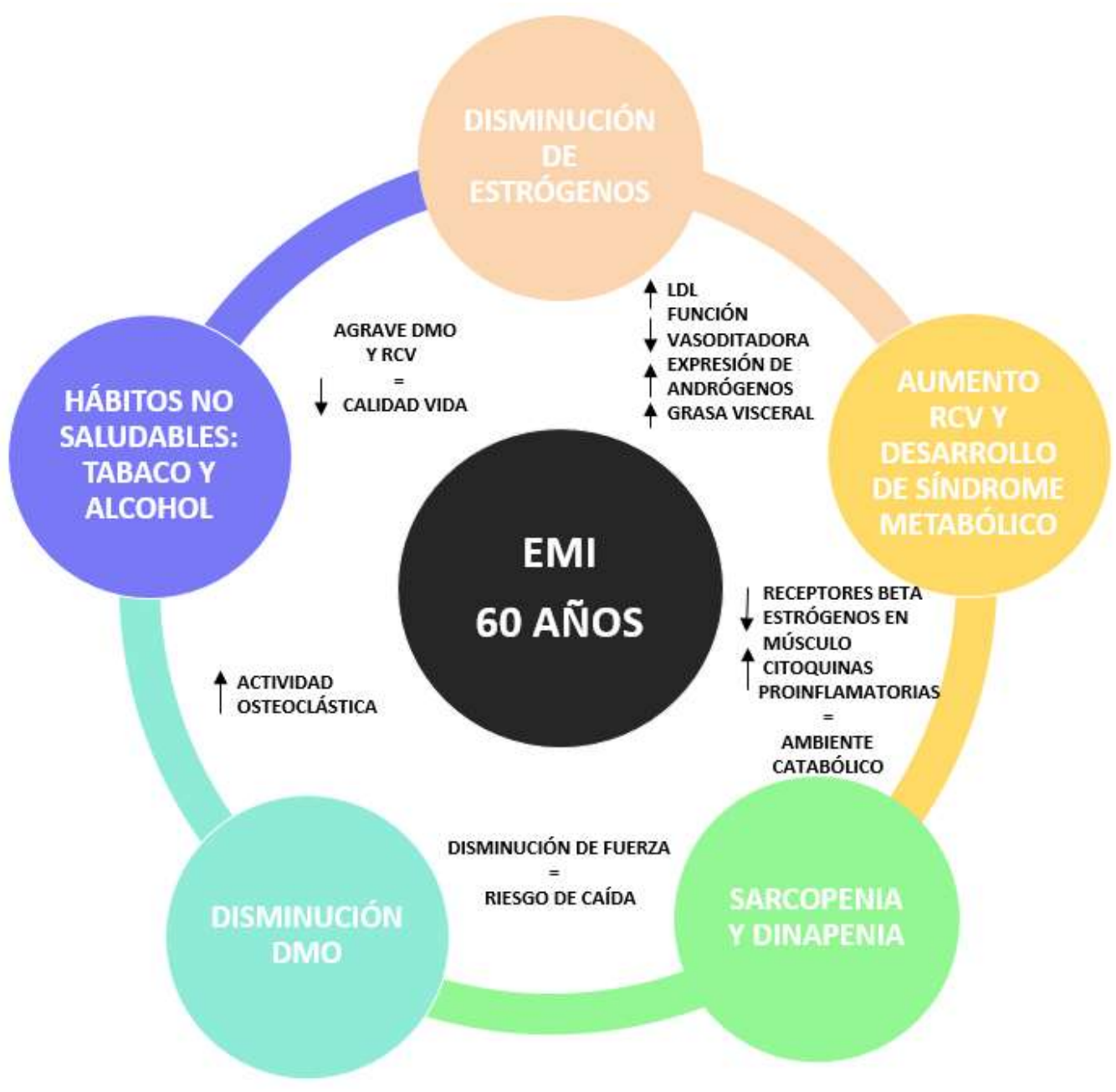




\section{OBJETIVOS DEL PROGRAMA DE INTERVENCIÓN}

Según los resultados obtenidos en la evaluación inicial, y en consenso con las preferencias de nuestra alumna, se establecen los siguientes objetivos:

No evaluable, el siguiente DXA se realiza con margen de 2 años. No

Aumentar la puntuación $T$ Score en cuello del fémur y columna lumbar

Mejorar la salud ósea

DISMINUIR LAS

CONSECUENCIAS

DERIVADAS DE

POSTMENOPAUSIA

Y OSTEOPOROSIS
Evitar el agrave de la sarcopenia y la dinapenia
Potenciar los niveles de masa muscular y fuerza como papel protector ósea

habría cambios significativos hasta

los 18-24 meses, debido a los 3-4

meses que dura cada ciclo de

mineralización. Además, no

proporcionaría información sobre la calidad del tejido.

Método indirecto a través de

bioimpedancia Keito $\mathrm{K} 8$

Método directo a través de dinamometría Rise Pro WH-C3OO

Disminuir el riesgo de fractura

Mejorar la capacidad del sistema para evitar caídas

No evaluable, aunque la mejora de equilibrio y la fuerza disminuyen indirectamente el riesgo de caída

Método directo a través de analítica de sangre

Disminuir las _ - $\quad$ Reducir los niveles de glucosa en sangre posibilidades de $\quad$ - $\quad$ Mejorar los valores de dislipidemia

desarrollo de síndrome _ - Mantener en valores normativos tensión metabólico arterial sistólica y diastólica

Método directo a través de tensiómetro digital VitalControl

\section{MEJORAR LOS \\ PARÁMETROS DE \\ SALUD \\ CARDIOVASCULAR}

Limitar los hábitos no saludables
Tomar conciencia sobre los efectos perjudiciales de tabaco y alcohol y su interferencia en la consecución de objetivos

Intentar reducir su consumo
Medición directa a través de ENS, sesiones educativas y retos semanales.

Estimación indirecta a través de la ecuación cintura-cadera
Reducir los niveles de $\quad-\quad$ Disminuir el perímetro de cintura grasa visceral
Mejorar el índice de cintura-cadera
Medición directa a través de cinta métrica

\section{EVALUACIÓN}

Reducir la sensación de cansancio tras el trabajo

POTENCIAR LOS NIVELES DE CALIDAD DE VIDA

\section{DESARROLLAR LA \\ FUNCIONALIDAD \\ DIARIA Y EL \\ CONTROL MOTOR EN LAS \\ NECESIDADES DE MOVIMIENTO}

Mejorar la calidad de sueño

Favorecer el desempeño en sus patrones laborales, a través de la eficiencia, calidad de movimiento y aumento de los niveles de fuerza-resistencia en ellos
Monitorización indirecta del sueño nocturno a través de Xiaomi Band 4

Evaluación indirecta a través de puntuación en SF-36

Evaluación indirecta gracias a la propia progresión de entrenamiento
Aumentar la vitalidad

Perfeccionar la mecánica de pie-tobillo

Restablecer el control lumbopélvico

- Reducir la rigidez isquiosural

- Corregir el síndrome de flexión

\section{Mejorar el equilibrio en} raquis dorsal
Disminuir la rigidez de pectoral y dorsal

ancho para corregir exceso de cifosis

Aumentar la movilidad en flexión de hombro

Tabla 18. Objetivos principales y secundarios del programa de intervención.

Feedback directo y sensaciones personales durante la progresión del entrenamiento

Medición indirecta a través de goniómetro digital 
Informe de resultados derivados de la evaluación inicial:

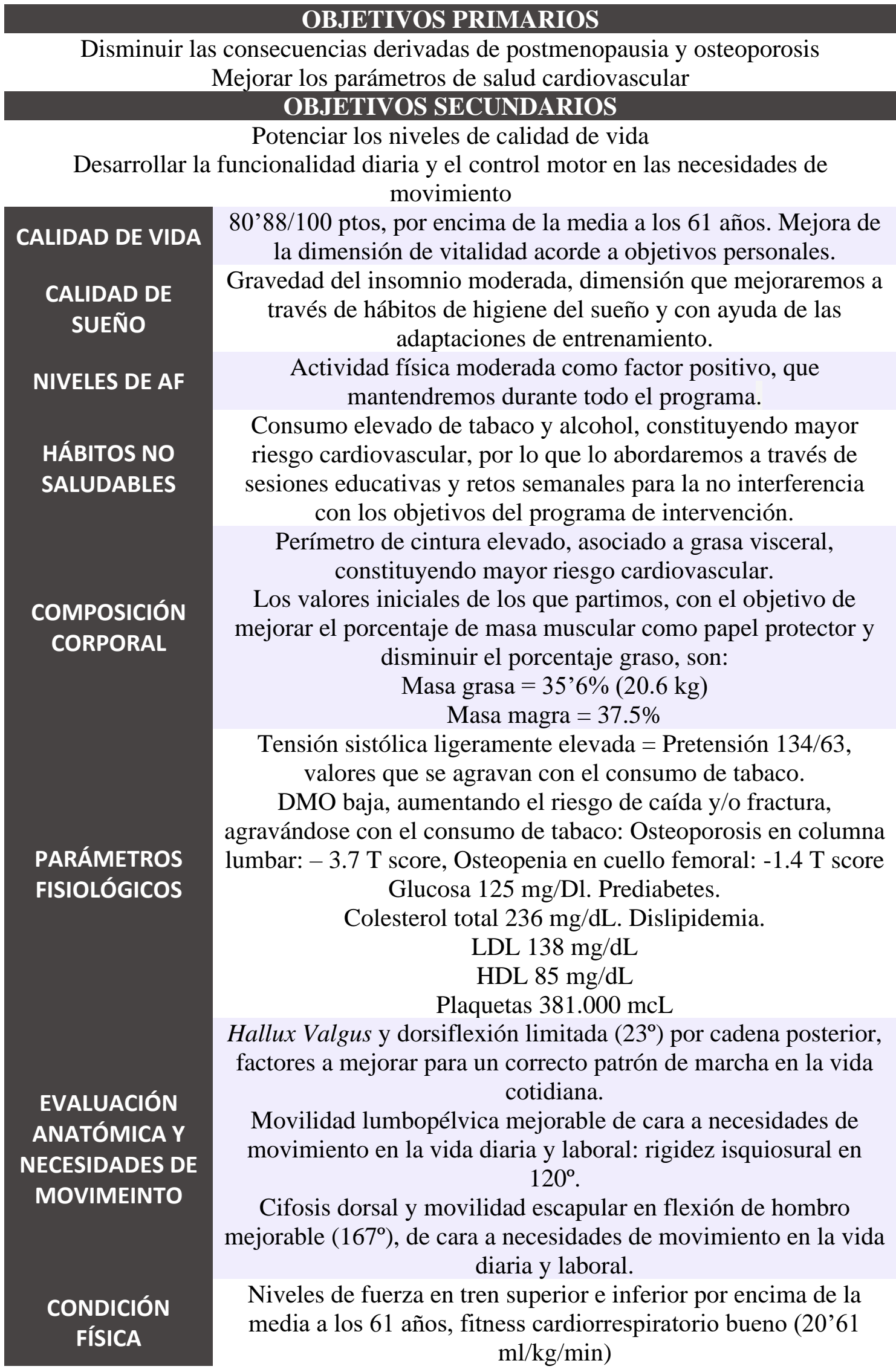




\section{JUSTIFICACIÓN DEL PROGRAMA DE INTERVENCIÓN.}

\subsection{Carga mecánica y movimiento para la mejora de la salud ósea.}

Para comprender cómo actúan los diversos estímulos de entrenamiento en la mejora de la salud ósea, nos basaremos en una de las teorías más apoyadas por la evidencia científica, el mecanostato óseo de dos investigadores referentes como Harold Frost y Jose Luis Ferretti.

\section{Fisiología del ejercicio en la osteogénesis}

Al igual que el resto de tejidos, el hueso conforma un sistema dinámico en constante búsqueda de la homeostasis y adaptación al entorno, para evitar una fractura por falta de rigidez ósea. El estímulo que dispara el funcionamiento de los mecanismos fisiológicos que consiguen esto es la carga mecánica.

Como observamos en la Figura 23, este estímulo mecánico activa una cascada bioquímica y despierta la actividad de los osteocitos. Los osteocitos son aquellos sensores encargados de traducir e interpretar una señal de exceso de rigidez o flexibilidad del hueso. Dependiendo de esto, se activan osteoclastos y osteoblastos con una determinada intensidad (predominando unos $\mathrm{u}$ otros) para favorecer un equilibrio entre rigidezdeformación y una eficiencia ósea para soportar la carga dada a través de las fuerzas reactivas del suelo o la inercia, así como las fuerzas internas del sistema musculoesquelético.

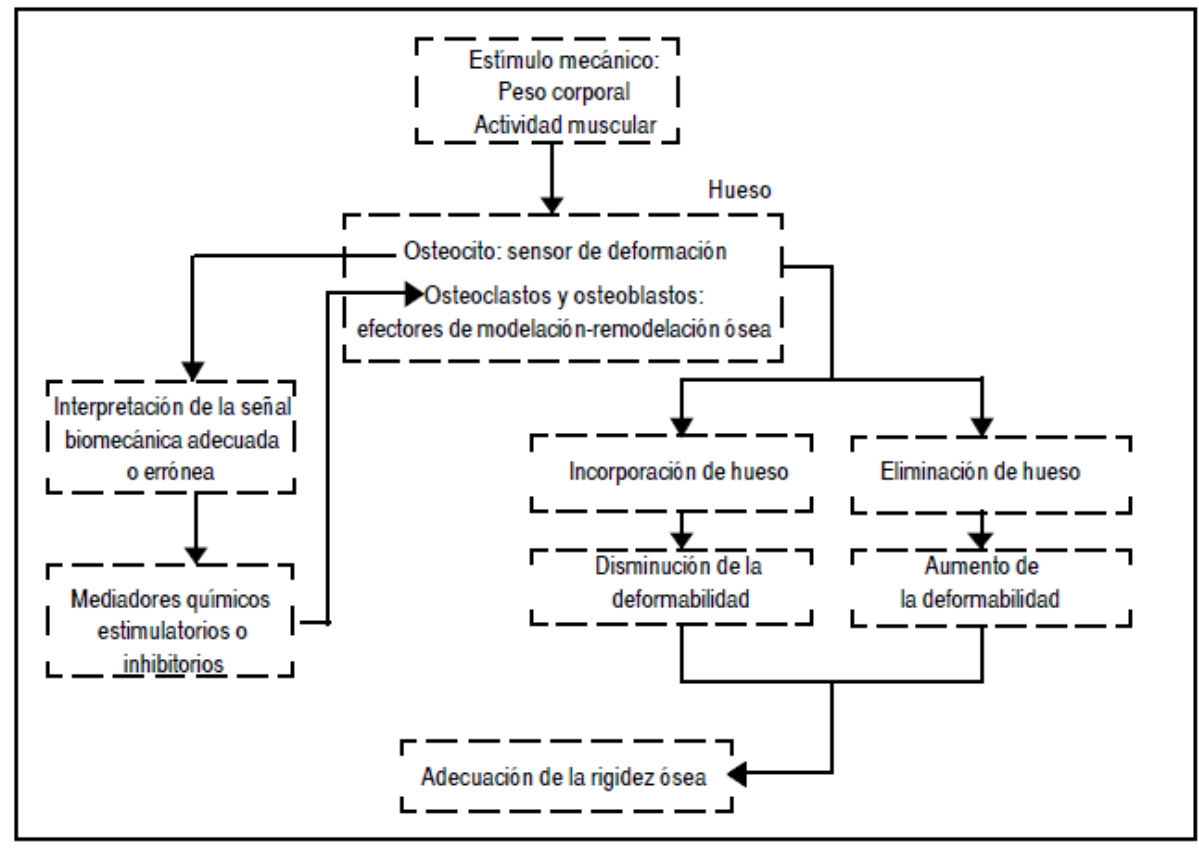

Figura 23. Mecanostato óseo de Frost. Extraído de Pintos et al. (2013)

En este sentido, la contracción muscular se considera la carga fisiológica más importante para el correcto equilibrio, desarrollo y salud ósea (Ferretti et al., 2003), evidencia que corrobora las ideas de la relación músculo-hueso presentadas durante la casuística (pueden consultarse en dicho punto los efectos endocrinos). 
Es decir, más allá de los cambios hormonales que se producen (y siempre y cuando la osteoporosis sea primaria, y no como consecuencia secundaria de otra patología que afectaría a la "interpretación de la señal" representada a la izquierda de la Figura 23), revertir el desuso del sistema sometido a bajas cargas dará lugar a un mejor pronóstico.

Teniendo en cuenta esto, resulta lógico pensar que el entrenamiento es un pilar fundamental tanto en la prevención como en el mantenimiento y el tratamiento de la osteoporosis:

\section{Combinación y progresión: entrenamiento de fuerza y máxima velocidad de ejecución}

Siguiendo con la teoría del mecanostato y la relación músculo-hueso, un incremento de masa muscular (evaluado a través de bioimpedancia), con ello de fuerza máxima de contracción del individuo (evaluado a través de dinamometría), y la propia adaptación progresiva a la carga de entrenamiento, suponen por sí mismas mejoras para la salud muscular y ósea. Es por ello que el entrenamiento de fuerza induce grandes beneficios, que, si bien no vamos a poder observar en este caso tras el programa de intervención a través de DXA u otras herramientas cualitativas como TC mencionadas anteriormente, una progresión en las cargas de entrenamiento a través de nuevos y variables estímulos nos informa de una adaptación del sistema, con lo que también de una mejor resistencia ósea.

Esta concepción constituye en la actualidad multitud de vías de investigación para establecer una dosis-respuesta adecuada, ya que la estandarización resulta complicada teniendo en cuenta la diversidad de características de los sujetos en los diferentes estudios y las dificultades para observar cambios in vivo o a corto plazo (de hecho, para conocer estos cambios en muchas ocasiones se utilizan modelos animales y métodos invasivos; Turner \& Robling, 2003).

Según la evidencia más actual obtenida de RCTs y metaanálisis en relación al tipo de ejercicio (Zhao et al., 2015; Xu et al., 2016; Benedetti et al., 2018; Daly et al., 2019) el entrenamiento de fuerza de moderada-alta intensidad es uno de los estímulos más óptimos para el aumento de masa muscular y DMO en el cuello del fémur especialmente, así como columna lumbar, teniendo siempre en cuenta que la selección de ejercicios cumpla con el principio de especificidad en la zona a estimular (Beck, Daly, Fiatarone, \& Taaffe, 2017) sin diferenciar estímulos entre osteoporosis y osteopenia. Esto hace referencia al uso de una carga gravitacional directa en la articulación, fuerzas reactivas contra el suelo, o bien asegurando una tracción de la musculatura correspondiente.

Para llegar a conseguir dicha intensidad, será esencial establecer una progresión por fases que permita una adaptación a la carga. Resulta lógico pensar que, en la primera toma de contacto, el propio entrenamiento con carga y los diversos patrones de movimiento van a generar una adaptación a todos los niveles, pues el sistema no está habituado. Además, esta fase de adaptación con cargas moderadas es esencial desde el punto de vista de la seguridad, asentando así el control del movimiento y el aprendizaje de la técnica. Sin embargo, si no vamos más allá a través de la sobrecarga progresiva (pues es necesario un trabajo vigoroso), llegará un punto de estancamiento en el que el estímulo no generará adaptaciones, y, por tanto, tampoco una respuesta osteogénica. 
Además, resulta esencial favorecer el movimiento en multitud de planos y direcciones (Lanyon, 1996; Beck et al., 2017), ya que asegura el impacto y tracción en gran parte de las articulaciones. Probablemente por esto, disciplinas como el Tai Chi son muy apoyadas por las principales guías para la mejora de la salud ósea anteriormente mencionadas, por lo que nos basaremos en sus principios multidireccionales para adaptar diversos estímulos.

Por ello, modularemos las principales variables de entrenamiento (que serán desarrolladas en profundidad en la secuenciación de fases) para continuar generando una sobrecarga progresiva, hasta finalizar con la combinación de un entrenamiento con máxima intencionalidad de velocidad en la fase concéntrica, generalmente basado moderadas-bajas repeticiones y alta intensidad, pues según la evidencia (Von Stengel et al., 2007; Hamaguchi et al. 2017.), se postula como el tipo de entrenamiento más adecuado en mujeres posmenopáusicas con osteoporosis. Debemos destacar, que el entrenamiento de fuerza de alta intensidad se ha demostrado como seguro en diferentes rangos de edades, desde la infancia hasta el adulto mayor, registrándose una baja tasa de lesiones durante los programas de intervención (Zhao et al., 2015).

Además de progresivos y variables, los estímulos seleccionados deberán de basarse en la multidireccionalidad en los planos (Vainionpää et al., 2006), siendo especialmente importante este aspecto si no se consigue alcanzar una intensidad elevada de manera segura (Marques, et al., 2012)

De esta manera, conseguiremos que durante todo el periodo haya siempre un estímulo óptimo y novedoso que permita alcanzar un umbral que desencadene la respuesta osteogénica, es decir, mantener una sensibilidad constante de los tejidos a dicha estimulación mecánica, bajo unas condiciones seguras en todo momento (Figura 24).

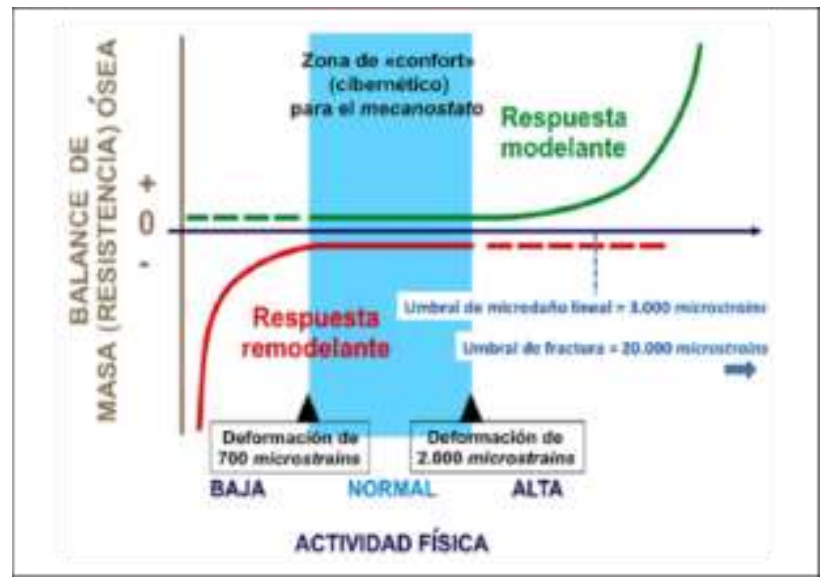

Figura 24. Carga necesaria para inducir una respuesta osteogénica según Ferretti (2003).

Sin embargo, tal y como apuntan muchos de los anteriores autores, debemos destacar que el uso del entrenamiento de fuerza, si bien es primordial para las ganancias de masa muscular y fuerza (con la relación que estas tienen con el riesgo de caída y fractura); sin la combinación de otro tipo de trabajo que desarrollaremos a continuación, resulta insuficiente para obtener los máximos beneficios a nivel de salud ósea. 


\section{Ejercicio de alto impacto para la osteogénesis}

El entrenamiento de alto impacto se basa en estímulos de tipo dinámico, intermitente, con cargas de gran magnitud y realizados a alta velocidad. La actividad por tanto debe de ser vigorosa, ya que es necesario un estrés alto para generar adaptaciones osteogénicas, alcanzando incluso cargas 2 o 3 veces el peso corporal (ACSM, 2004).

Según la evidencia (Beck et al, 2017; Daly et al., 2019), deberemos acumular en torno a 50-100 impactos en cada sesión (ej.: 3-5 series de 10-20 repeticiones) teniendo en cuenta que el intervalo de carga tendrá que dosificarse en periodos cortos con descansos (aproximadamente de 15 segundos), ya que las células óseas cesarían su estimulación ante periodos prolongados en el tiempo (Montgomery et al., 2019). Por eso, jugar con la frecuencia puede permitir adaptar este trabajo al resto de estímulos de entrenamiento, llegando incluso a generar intervalos de carga cortos casi a diario, aunque la dosis mínima es 3-4 días a la semana.

\begin{tabular}{cc}
\hline EJERCICIO & FUERZA DE REACCION \\
\hline Zancada hacia delante & 1.1 \\
Zancada lateral & 1.2 \\
Marcha en el sitio & 1.5 \\
Subida lateral al escalón $(15 \mathrm{~cm})$ & 2.1 \\
Subida frontal al escalón $(15 \mathrm{~cm})$ & 2.2 \\
Correr & 2.6 \\
Salto horizontal monopodal & 3.1 \\
Salto vertical monopodal & 3.4 \\
Elevaciones de talones + excéntrico & 3.6 \\
Sentadilla con salto & 3.8 \\
Saltos laterales & 3.9 \\
Jumping Jacks & 4.3 \\
Pisotones & 4.6 \\
Comba saltos simples & 5.1 \\
Salto desde el cajón $(30 \mathrm{~cm})$ & 5.2 \\
Saltos verticales delante-detrás & 6.3
\end{tabular}

Tabla 19. Multiplicación del pico de fuerza de reacción vertical del suelo relativa al peso corporal en diversos ejercicios. Modificado de Daly et al. (2019)

Para conseguir una alta intensidad, debe de haber una correcta progresión, asegurando así un entorno seguro desde el que comenzar. De esta manera, nos basaremos en progresiones de impacto a ras de suelo, aumentando progresivamente la altura y añadiendo carga durante el ejercicio.

Como hemos comentado en la Figura 24, el estímulo debe considerarse inusual para el sujeto, debido al funcionamiento del mecanostato y las células óseas. Por eso, la evidencia ha demostrado que el simple hecho de caminar no genera adaptaciones óseas.

De hecho, caminar puede llegar a aumentar el riesgo de caída si no se combina con otro tipo de trabajo (Borer et al., 2007) como lo son el entrenamiento de fuerza y alto impacto, así como la intensidad, ya que caminatas por encima de $5 \mathrm{~km} / \mathrm{h}$ si desencadenan una respuesta osteogénica (Pellikaan et al., 2018). 
De esta manera, el criterio de inclusión de la caminata va a ser la intensidad, intentando alcanzar valores cercanos al 75\% VO2Máx, y cuyo objetivo se acerca más a las adaptaciones cardiovasculares deseadas, pues según Swain \& Franklin (2006) altas intensidades derivan en un menor riesgo cardiovascular en comparación con las intensidades moderadas (que además no van a generar una respuesta osteogénica)

\subsection{Contrarrestando los efectos de la sarcopenia y la dinapenia.}

Además, el entrenamiento basado en la velocidad de ejecución constituye una herramienta interesante debido a la pérdida de capacidad neuromuscular durante el envejecimiento, como consecuencia del ambiente oxidativo y catabólico. Con la aparición de la sarcopenia se ven especialmente afectadas fibras de contracción rápida tipo II, disminuyendo entre un 25-60\% (Aagaard et al., 2010), por lo que predominan las fibras tipo I, además de un mayor porcentaje de tejido no contráctil (colágeno, grasa...) y una menor excitabilidad y trasmisión, dando lugar a un deterioro de la capacidad funcional.

Haciendo referencia a lo expuesto durante la casuística, recordemos que todo el sistema neuromuscular contiene receptores de estrógenos, lo que incluye al tendón, que disminuye su stiffness. Por tanto, ante su descenso, el sistema neuromuscular se ve afectado dando lugar no solo a la sarcopenia sino a la dinapenia, objetivos principales que hemos incluido en el programa de entrenamiento.

El entrenamiento con una intencionalidad de máxima velocidad concéntrica requerirá por tanto una mayor interacción neuromuscular, reclutamiento y coordinación de las fibras tipo II, al tener que mantener un control motor en un movimiento a mayor velocidad (Sipilä et al., 2015).

\subsection{Variabilidad de respuestas del sistema para disminuir el riesgo de fractura y caída.}

Como venimos mencionando, el propio trabajo de fuerza va a desarrollar parámetros que influyen directamente en la disminución del riesgo de caída, así como la mejora de la salud ósea a través del alto impacto. Sin embargo, debemos de intentar exponer al sistema a diversos desafíos que favorezcan respuestas emergentes ante situaciones que comprometan la estabilidad, y que pueden desembocar en una posible caída.

En este sentido, existen varios grupos musculares esenciales durante la marcha, cuya debilidad se asocia directamente con un mayor riesgo de caída (Carter el al., 2002; Chien et al., 2005; Teixeira et al., 2010; Hebert-Losier et al. 2017): cuádriceps, psoas, glúteo mayor, glúteo medio, gemelo y soleo (dorsiflexión) y extensores de tronco. Con respecto al trabajo específico de CORE, debemos tener en cuenta que el núcleo central actúa como generador de estabilidad y trasmisor de fuerzas, especialmente en la región pélvica y la columna (Leetun et al., 2004). Por tanto, su co-contracción con el resto de músculos anteriormente mencionados en antiflexión, antiextensión y antirotación dan como resultado unos mayores niveles de fuerza, respuesta, absorción y coordinación durante el movimiento, afectando a las respuestas anticipatorias (Panjabi, 1992) y con ello (aunque este no sea el único factor que determina la causa-efecto) una disminución del riesgo de caída y fractura. 
Por tanto, el trabajo de estos grandes grupos deberá integrarse junto a los patrones cotidianos y funcionales de nuestra alumna. A ello, añadiremos de manera controlada situaciones que perturben al sistema para favorecer un aprendizaje implícito, con el objetivo de obtener una respuesta automatizada ante situaciones propensas a caída, como pueden ser: privación visual, vestibular, kinestesia, trabajo coordinativo, predominio de patrones monopodales (más comunes en la vida diaria) ... que supongan un desafío progresivo (Bilezikian, 2019), variable y a una correcta intensidad.

A su vez, los estímulos que se desarrollan en base a dos tareas, como un ejercicio principal atendiendo a un componente cognitivo o de control motor añadido, mejoran la capacidad funcional del sistema (Silsupadol et al., 2009).

A nivel postural, la hipercifosis dorsal (medida como la distancia entre occipucio y pared) está asociada a un mayor riesgo de caída y fractura por compresión, debido al desequilibrio muscular que genera a todos los niveles, como puede ser el exceso de rigidez en isquiosurales, bajos niveles de fuerza abdominal y paravertebral, menor capacidad ventilatoria, o la anteriorización del centro de masas (Koelé et al., 2020).

Sin embargo, todo esto puede combatirse con entrenamiento de fuerza en los mismos, así como protocolos de movilidad y liberación (que serán detallados en la justificación 5.5 por su relación con dicho objetivo) en la musculatura con exceso de rigidez (en el caso de cifosis dorsal: trapecio superior y pectoral menor), para permitir diversos rangos de movimiento óptimos en los patrones del entrenamiento de fuerza. Según la revisión y metaanálisis de González-Gálvez et al. (2019), los estímulos más usados para revertir esta situación de cifosis dorsal son la predominancia de patrones de tracción durante el entrenamiento de fuerza, con un correcto timing de la musculatura estabilizadora de la escápula (serrato, trapecio medio e inferior), favoreciendo a su vez una buena movilidad de hombro con la liberación de la musculatura implicada (Arshadi et al., 2019; Watson et al., 2019).

\section{Entrenamiento multicomponente}

Uno de los protocolos con mayor evidencia para reducir el riesgo de caída y su relación con fractura se basa en el denominado entrenamiento multicomponente (Zhao et al., 2017; Marín-Cascales et al., 2017; Varahra et al., 2018; Daly et al., 2019). La tipología de ejercicios que compone el entrenamiento multicomponente son el trabajo de fuerza y alto impacto anteriormente mencionados, así como la caminata de alta intensidad y estímulos que ayuden a la anticipación y reacción ante una situación de caída.

Esta metodología de entrenamiento ayuda a mejorar fuerza muscular, potencia, capacidad aeróbica, control motor, equilibrio, coordinación, propiocepción, postura, rango de movimiento... Dichos factores disminuyen notablemente el riesgo de caída debido a la relación de todos sus componentes: las ganancias de masa muscular conllevan un aumento de los niveles de fuerza, que en conjunto con el trabajo de equilibrio, propiocepción y control motor en diversos movimientos, constituyen factores clave para la prevención de caídas (Capozza et al., 2008). Además, una mejor salud ósea a través de este trabajo de impacto incluido conlleva menor posibilidad de fractura. 


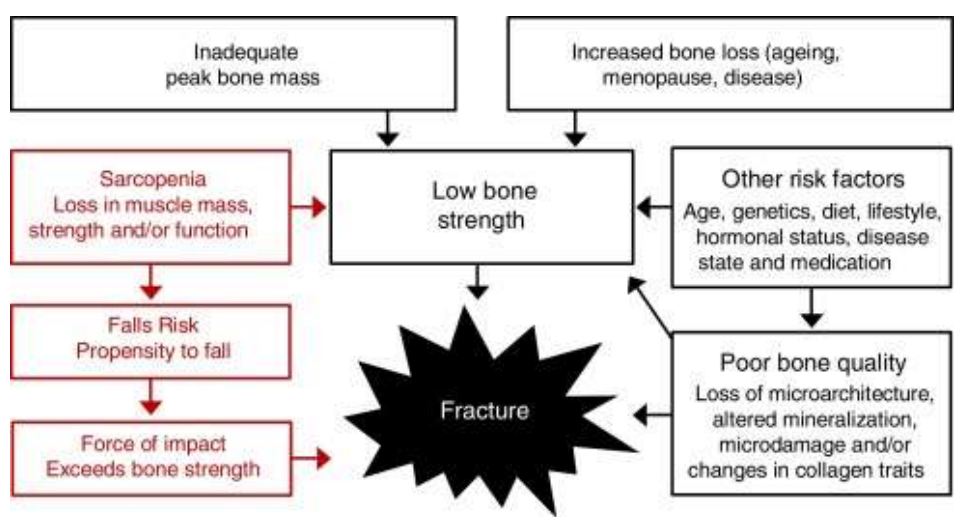

Figura 25. Relación de todos los componentes que generan un riesgo de fractura. El entrenamiento multicomponente es capaz de incidir en todos ellos. Extraído de la guía de prescripción de Daly et al. (2019)

Debido a la heterogeneidad de las muestras, es complicado una vez más establecer una dosis-respuesta clara, pero la variabilidad en este tipo de trabajo parece ser esencial para asegurar un entorno seguro y una alta eficacia en la mejora de los diferentes parámetros. No obstante, la mayoría de autores anteriormente mencionados se mueven en torno a 45-60 min/sesión al menos 3 días a la semana.

Por tanto, la ventaja del entrenamiento multicomponente reside en la capacidad de este para mejorar otros parámetros muy útiles, más allá del riesgo de caída y fractura, en este caso, adaptaciones óseas y cardiovasculares, así como la variabilidad de respuestas ante una posible caída. Esta concepción multifactorial nos permitirá abarcar de forma integral el caso de nuestra alumna, permitiendo la mejora en multitud de aspectos concretados en la casuística, y, por tanto, en la consecución de objetivos.

\subsection{Mejora de los parámetros cardiovasculares.}

En su relación a la salud cardiovascular y el síndrome metabólico, la evidencia muestra que tanto el entrenamiento de fuerza como el aeróbico tienen efectos positivos sobre la regulación de hipertensión, alteración de la glucosa, dislipidemia y niveles de grasa visceral. A pesar de que la dosis-respuesta no está clara, debido a la heterogeneidad de las muestras y origen multifactorial de estas patologías, resulta esencial entender que el ejercicio es el único tratamiento (combinado con unos buenos hábitos) que, en la mayoría de los casos, no genera efectos secundarios (como si ocurre con la farmacología) y del que se obtienen multitud de beneficios en diversas dimensiones.

Teniendo en cuenta esto, la combinación de ambos tipos de ejercicio (entrenamiento concurrente) será integrada dentro del programa de intervención, modificando diversos principios de entrenamiento según el parámetro cardiovascular a mejorar, que desarrollaremos a continuación. Recordemos, que el entrenamiento con orientación aeróbica también se incluye en los programas multicomponente con poblaciones similares a la situación personal de nuestra alumna. Cabe destacar que utilizaremos una concurrencia intrasesión e intersesión sin interferencia (Coffey \& Hawley, 2017), pues al tratarse de un sujeto no entrenado, conseguiremos adaptaciones iniciales con bajas dosis en todos los procesos, tanto aeróbicos (mayor capilarización, bombeo de sangre, aumento de la cantidad de mitocondrias...) como anaeróbicos y relacionados con la hipertrofia muscular. 
Deberemos de tener en cuenta la selección de ejercicios para evitar que la fatiga local provocada por el entrenamiento de fuerza produzca interferencias en la intensidad del entrenamiento de componente aeróbico, y viceversa a nivel neural/técnico afectando a la coordinación inter e intra muscular durante el entrenamiento de fuerza. Llegados a una última etapa de entrenamiento, puede llegar a ser conveniente dividir los estímulos en sesiones diferentes para potenciar las adaptaciones a un mayor nivel según el objetivo, atendiendo así al principio de especificidad.

\section{Hipertensión}

Atendiendo al cambio de paradigma de entrenamiento para el tratamiento de la hipertensión, destacamos el ejercicio isométrico, tradicionalmente contraindicado. Según el metaanálisis más actual (Smart, Gow, Bleile, Van der Touw \& Pearson, 2020), el entrenamiento isométrico genera unos beneficios muy similares al entrenamiento de fuerza, reduciendo TAS hasta 5-10.4 mmHg y TAD 4-6.7 mmHg. En cuanto a contraindicaciones (Campbell et al., 2019), y teniendo en cuenta los niveles de tensión de nuestra alumna, basta con mantener un control previo y post sesión a través del tensiómetro digital ante sesiones de entrenamiento de alta intensidad, evitando así respuestas hipertensivas al ejercicio.

A pesar de que, en la mayoría de los casos, los efectos son agudos y moderados (disminución de TAS 0.5-4 mmHg y TAD 0.4-3 mmHg) tras el ejercicio (Carpio-Rivera et al., 2016), combiene tenerlos en cuenta, pues reducciones durante un par de horas al día acumulan a lo largo del año un tiempo considerable en valores normativos de tensión arterial. Reducciones de $\mathbf{2} \mathbf{~ m m H g}$ generan hasta un $10 \%$ menos de riesgo y muerte cardiovascular. (Lewington et al., 2002)

Los mecanismos por los cuales se obtienen los efectos positivos del entrenamiento isométrico parecen asociarse con la mayor vasodilatación y función endotelial, que ayuda a la biodisponibilidad del óxido nítrico (Goto et al., 2007; Otsuki et al., 2019), que recordemos, se ve reducido por el ambiente de estrés oxidativo de la postmenopausia.

En cualquier caso, al tratarse de un método en desarrollo, se necesita una mayor muestra que maneje una metodología de forma adecuada en relación, por ejemplo, al uso de fármacos antihipertensivos. Sin embargo, desde el punto de vista de la seguridad y viabilidad, la evidencia respalda este tipo de entrenamiento.

Los estímulos más usados consisten en intervenciones de grandes grupos musculares: extensiones de piernas, sentadilla isométrica, prensión manual con pelota... en torno al 30\% de la contracción voluntaria máxima, 4 series de 2 minutos con descansos aproximados intraserie de 1 minuto, 2-3 días a la semana. (Smart, Way, Carlson et al., 2019).

Por la naturaleza multifactorial de los factores del síndrome metabólico, resulta esencial tener en cuenta que el trabajo isométrico tiene efectos contrastados únicamente sobre la presión arterial. Este, suele compararse en los diferentes estudios con resultados también positivos del trabajo aeróbico continuo de moderada intensidad (Cornelissen \& Smart, 2013; Sakamoto, 2020), e interválico de moderada (MIIT)-alta intensidad (HIIT) (Costa et al., 2018), que además actúan sobre otros parámetros de salud cardiovascular (composición corporal, resistencia a la insulina, niveles de colesterol...). 
Por tanto, la inclusión en el programa de ejercicio de trabajo metabólico continuo e interválico (40-60\% VO2Máx, pudiendo llegar a progresar hasta una intensidad elevada entre el 70-90\%), así como estímulos isométricos (30\% CVM) y entrenamiento de fuerza (2-3 series, 10-12 repeticiones, 8-10 ejercicios, 60-80\% RM), será la opción más eficiente y eficaz para la mejora de los diversos parámetros cardiovasculares relacionados con el síndrome metabólico, en concreto en este caso, con la hipertensión (Pescatello et al., 2015)

\section{Dislipidemia.}

En el caso de la hipercolesterolemia, la evidencia indica que debemos de atender más al volumen total que a la intensidad, siendo beneficiosos aquellos programas que incluyen tanto entrenamiento de fuerza como aeróbico (Pedersen \& Saltin, 2015). Si se opta por actividades de intensidad leve-moderada, deberemos de acumular el doble de volumen, que si por el contrario, elegimos actividades de intensidad vigorosa, pudiendo combinar ambos conceptos y progresando en ellos durante el programa de entrenamiento.

De esta manera, el entrenamiento aeróbico continuo al 60-80\% del VO2Máx (Wang \& Xu, 2017) durante la semana es la mejor opción para conseguir este objetivo cardiovascular (recordando además la inclusión del entrenamiento de fuerza en las sesiones, por sus demostrados beneficios en este aspecto), ya que se adecua además a las preferencias (caminatas) y disponibilidad de nuestra alumna. Será esencial establecer unas pautas de intensidad efectiva (FC, velocidad, distancia...) que progresen a lo largo del programa, previa explicación, funcionamiento y aprendizaje de la monitorización para potenciar la autonomía en sesiones no presenciales.

\section{Prediabetes}

La prediabetes está considerada un estado potencialmente reversible a través de la actividad física y el ejercicio, pues el músculo esquelético mantiene un papel fundamental en el metabolismo de la glucosa en sangre, gracias a su función endocrina a través del transportador GLUT-4 (Roher et al., 2008).

Para la mejora de la resistencia a la insulina, cobra especial importancia la intensidad del ejercicio. Es por ello, que el entrenamiento de fuerza al 60-80\% RM (Liu et al., 2019) y el interválico de alta intensidad (Jelleyman et al., 2015; De Nardi et al., 2018) previa progresión de moderada-alta intensidad (MIIT), son el tipo de ejercicio que mayores efectos beneficiosos tiene en este sentido. Como observamos, la tipología e intensidad de los criterios de entrenamiento no interfiere con el resto de parámetros pertenecientes al síndrome metabólico, pudiéndose incorporar fácilmente dentro de las sesiones de entrenamiento presenciales.

\section{Grasa visceral.}

Debemos recordar, que este objetivo se presenta como el menos desarrollado dentro de los riesgos del síndrome metabólico, ya que el perímetro de cintura no llega a determinarse como obesidad abdominal. Sin embargo, es esencial tenerlo en cuenta ya que interfiere en el desarrollo de los diversos factores de riesgo metabólicos, y más aún cuando el entrenamiento de fuerza resulta ser, incluso más importante que la dieta. 
Con respecto a esto último, independientemente de la pérdida de peso, el entrenamiento de fuerza tiene un efecto lipolítico sobre la grasa visceral, pues este tejido adiposo contiene receptores adrenérgicos beta-3, que son activados por las catecolaminas (adrenalina y noradrenalina) secretadas durante el ejercicio ante el estímulo estresor (Horowitz, 2001).

De nuevo, la intensidad del ejercicio (60-80\% $\mathbf{R M})$ resulta esencial, pudiéndose combinar sin interferencia con el HIIT (Idoate et al., 2011).

Este entrenamiento concurrente tiene efectos positivos además sobre factores como la inflamación (Gleeson et al., 2011), que contribuyen indirectamente a la mejora del entorno para otros factores, como la resistencia a la insulina. Además, en diversas publicaciones como la revisión de Coffey \& Hawley (2017), se pone de manifiesto que el HIIT produce menores interferencias en el entrenamiento concurrente cuando quiere mejorarse el Vo2Máx. Los niveles de AF moderada diarios en el entorno laboral actuarán como parámetro protector, evitando que se desarrolle este nivel de grasa visceral.

\subsection{Capacidad funcional, control motor y necesidades de movimiento.}

El objetivo final del programa de intervención radica en la capacidad para trasferir las mejoras alcanzadas a la vida cotidiana, mejorando así la calidad de vida a través de unas necesidades de movimiento controladas.

Para ello, es necesario establecer una correcta progresión de entrenamiento que permita asentar unas bases sólidas en cuanto a patrones de movimiento eficientes se refiere. En relación a esto, observamos como tras la evaluación y el planteamiento de objetivos, existen diversos factores que pueden limitar el aprendizaje, control motor y progresión, como pueden ser la mecánica del pie, el síndrome de flexión, movilidad de hombro... afectando así a las necesidades de movimiento en el entorno laboral y de la vida cotidiana, que debido a la alta repetición diaria deben de forjarse bajo una condición de fuerza y eficiencia.

Muchos de los desequilibrios radican en exceso de stiffness, limitando por tanto el movimiento en diversos patrones. El stiffness, definido como rigidez muscular, representa el estado de los componentes estructurales y las propiedades contráctiles del tejido. El gold standard para obtener datos cuantificables es la tensiomiografía (Granata, Padua \& Wilson, 2002), donde se observa el desplazamiento del músculo por unidad de tiempo. Sin embargo, existen métodos subjetivos como la sensación de tirantez en diversos test indirectos realizados durante la evaluación inicial, así como la medición de rangos de movimiento. Cabe destacar que debe de haber un grado de rigidez/tensión óptimo para cada tejido de nuestro organismo, que en el caso del tejido muscular, pueda garantizar una contracción y trasmisión adecuada de fuerzas, afectando a su vez al sistema fascial, tendinoso y ligamentoso.

Sin embargo, disponemos de herramientas viables y eficaces que permiten preparar el sistema para un adecuado estado del organismo de cara a la sesión de entrenamiento: 


\section{Foam roller y pelotas de automasaje: autoliberación miofascial.}

Proporciona una ayuda como método previo de calentamiento, fragmentando las moléculas de ácido hialurónico, lubricando así todas las fibras musculares como si del aceite de un motor se tratase (Stecco et al., 2011). Además, parece ser que se generan cambios agudos en el rango de movimiento, debido a la modulación de las vías reguladas por el sistema nervioso, que permiten llegar a un mayor ROM al "desechar" aquellos rangos considerados "peligrosos" para la integridad del sistema. (Wiewelhove et al., 2019). Este cambio agudo puede convertirse en un efecto crónico al incorporar movilidad estática y dinámica en este nuevo y transitorio rango que queremos mejorar (Cheatham $\&$ Stull, 2018). Por ejemplo, usando el foam roller en gemelo y soleo, podremos generar ese efecto agudo, para posteriormente realizar un estiramiento estático de la cadena posterior e integrarlo en una movilidad dinámica a través de un Lunge Test, consiguiendo así una mejora crónica de la dorsiflexión en ese nuevo rango.

\section{Carrera externa e inhibición recíproca.}

La carrera externa se basa en una contracción incompleta del músculo y un estiramiento completo. De esta manera, pedimos que se genere una tensión activa (isometría) durante todo el estiramiento, hasta llegar a vencer la articulación del sujeto en el punto de máxima amplitud de elongación.

Esta técnica disminuye el stiffness de la musculatura en cuestión, actuando en los elementos elásticos en serie, debido a ese componente excéntrico y previa pretensión (Kandel et al., 2000; Esnault \& Viel, 2003). La implicación del elemento elástico en serie debida a la pretensión, provoca además una estimulación de los Órganos Tendinosos de Golgi, encargados de informar al sistema nervioso de una relajación refleja de los músculos implicados para prevenir una rotura. Es gracias a esta sinergia muscular por lo que la rigidez de la musculatura tratada disminuye, pudiendo aprovechar este cambio agudo para generar adaptaciones crónicas integrándolo en el movimiento con este nuevo estado/rango.

Además, la inhibición recíproca (Davis et al. 2005) juega un papel fundamental en este caso, pues la contracción del músculo agonista (ej.: cuádriceps), genera una disminución de rigidez en la musculatura antagonista (ej.: isquiosurales) para permitir el movimiento en extensión de rodilla.

\subsection{Papel de la educación en la calidad de vida.}

Para conseguir alcanzar los objetivos personales en cuanto a calidad de vida se refiere, el papel de la educación se torna esencial dentro del abordaje integral del entrenamiento individualizado, pues de nada servirá escoger el mejor estímulo de entrenamiento, si este no se complementa con unos hábitos de vida que permitan las adaptaciones deseadas cronificadas en el tiempo, interfiriendo por tanto en el estado de bienestar que se quiere alcanzar.

Por ejemplo, en el caso del aumento de la vitalidad que afecta a la dimensión social, deberemos de actuar sobre los hábitos de calidad de sueño, así como en los hábitos posturales durante los patrones laborales, mejorando la eficiencia de los mismos. 
Por otro lado, los hábitos de vida relacionados con la alimentación, el tabaco y el alcohol pertenecerán a la dimensión más biomédica de ausencia de enfermedad.

Por último, a pesar de que los episodios de dolor no son severos y nuestra alumna no se ve excesivamente incapacitada en su día a día, una educación sobre el dolor será importante para favorecer una sensación de autoeficacia y empoderamiento ante diversas situaciones, con el objetivo de que esta interfiera lo menos posible en el bienestar físico, social o emocional.

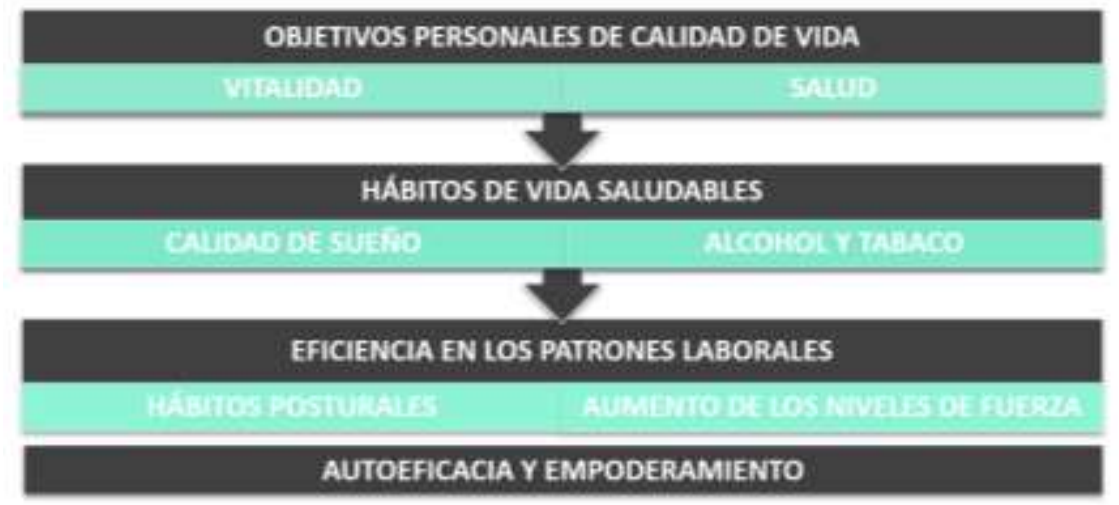

Figura 26. Papel de la educación en el entrenamiento como modulador de los efectos. Situación personal.

\section{PROGRAMA DE INTERVENCIÓN.}

El programa de intervención se llevará a cabo durante los meses de junio, julio y agosto de 2020, con una dosis mínima semanal de entrenamiento presencial de 2 días a la semana alternos. Además, se incorporará trabajo autónomo en las diferentes fases según el objetivo a alcanzar. Los horarios se establecerán a preferencia de la alumna, teniendo en cuenta su jornada laboral y las condiciones climáticas, pues resulta un aspecto esencial en la adherencia al programa, debido a las altas temperaturas alcanzadas durante el verano que generan una sensación de fatiga en su caso.

\subsection{Secuenciación de las fases de entrenamiento del programa de intervención.}

A grandes rasgos, el programa se dividirá en 3 fases fundamentales que permitan generar una progresión correcta y segura mes a mes, a expensas de cualquier modificación según el cumplimiento de los objetivos comprobados durante las evaluaciones.

\begin{tabular}{|c|c|c|c|c|c|c|}
\hline \multicolumn{7}{|c|}{ JUNIO } \\
\hline L & $M$ & $X$ & $J$ & $V$ & $S$ & $D$ \\
\hline 1 & 2 & 3 & 4 & 5 & 6 & 7 \\
\hline 8 & 9 & 10 & 11 & 12 & 13 & 14 \\
\hline 15 & 16 & 17 & 18 & 19 & 20 & 21 \\
\hline 22 & 23 & 24 & 25 & 26 & 27 & 28 \\
\hline 29 & 30 & 1 & 2 & 3 & & \\
\hline
\end{tabular}

\begin{tabular}{|c|c|c|c|c|c|c|}
\hline & \multicolumn{7}{c|}{ JULIO } \\
\hline L & $M$ & $X$ & $J$ & $V$ & $S$ & $D$ \\
\hline & & 1 & 2 & 3 & 4 & 5 \\
\hline 6 & 7 & 8 & 9 & 10 & 11 & 12 \\
\hline 13 & 14 & 15 & 16 & 17 & 18 & 19 \\
\hline 20 & 21 & 22 & 23 & 24 & 25 & 26 \\
\hline 27 & 28 & 29 & 30 & 31 & & \\
\hline
\end{tabular}

\begin{tabular}{|c|c|c|c|c|c|c|}
\hline \multicolumn{1}{c|}{ AGOSTO } \\
$\mathrm{L}$ & $\mathrm{M}$ & $\mathrm{X}$ & $\mathrm{J}$ & $\mathrm{V}$ & $\mathrm{S}$ & $\mathrm{D}$ \\
\hline & & & & & 1 & 2 \\
\hline 3 & 4 & 5 & 6 & 7 & 8 & 9 \\
10 & 11 & 12 & 13 & 14 & 15 & 16 \\
17 & 18 & 19 & 20 & 21 & 22 & 23 \\
24 & 25 & 26 & 27 & 28 & 29 & 30 \\
\hline
\end{tabular}

Figura 27. Secuenciación de las fases durante los meses de junio, julio y agosto. En amarillo, fase 1: adaptación. En naranja, fase 2: desarrollo. En rojo, fase 3: potenciación y autonomía. Evaluaciones del progreso destacadas en negro. 


\section{Metodología general de la intervención.}

La metodología de las diferentes sesiones y fases puede variar según el objetivo a alcanzar y los diferentes contenidos, que serán detallados posteriormente. Sin embargo, en general, el programa de intervención se basará en:

- Estructura de la sesión. Dividida en calentamiento, parte principal y vuelta a la calma. En primer lugar, la elección de esta estructura radica en la importancia del calentamiento por sus mecanismos neurales (Aagaard et al., 2002), tales como el aumento de la velocidad de conducción en las fibras musculares, mejor rendimiento de las neuronas motoras, aumento de la actividad eléctrica que media los reflejos espinales, mayor excitabilidad cortical... Todo ello, actúa especialmente como mediador y potenciador del aprendizaje y predisposición al movimiento de la sesión (también a nivel psicológico) y sus adaptaciones deseadas, más allá de los efectos térmicos conocidos del calentamiento, pues recordemos nos encontramos en un clima cálido y húmedo.

Durante el calentamiento se focalizará el trabajo en aquellos factores limitantes intervinientes en los movimientos de la sesión (ej.: uso de foam roller y estiramiento dinámico en cadena posterior para favorecer la dorsiflexión en sentadilla), así como la movilidad y activación de aquella musculatura necesaria para el correcto desarrollo de la parte principal (ej.: movilidad escapular y activación de la zona media).

Por último, la vuelta a la calma se basará en liberación miofascial y conciencia en respiración, ayudando así a una regulación del sistema nervioso parasimpático para volver a un estado basal y la mejora de la musculatura inspiratoria (teniendo en cuenta su casuística de fumadora). El ejercicio constituye un estímulo estresor para el organismo del que recuperarse, influyendo en aspectos como el posterior descanso, factor personal limitante en la vida diaria de nuestra alumna. El uso de estas herramientas, especialmente la respiración diafragmática controlada, activará las vías parasimpáticas por la regulación de secreción de cortisol (Ma et al., 2017), disminuyendo la FC, presión arterial y azúcar en sangre, así como favoreciendo la oxigenación y eliminación de sustancias de desecho.

- Duración de la sesión. Las sesiones de entrenamiento de fuerza presencial tendrán una duración aproximada de 1h, mientras que las sesiones autónomas de carácter cardiovascular irán en progresión de 20 minutos a 1 hora. El criterio de modificación y adaptación de esta duración dependerá del estado y predisposición inicial a cada día y sesión, así como por la consecución de objetivos planteados. De esta manera, fomentaremos la eficiencia y la adherencia al programa, evitando así sesiones muy largas que no se identifican con las preferencias y el modo de vida de nuestra alumna.

Cuando sea necesario un carácter educativo para determinadas tareas no presenciales no se establecerá un tiempo determinado, sino que finalizarán cuando se hayan comprendido todos los conceptos y alcanzados los objetivos según la fase. 
- Medios y control de la recuperación inter e intra sesión. Durante la sesión, utilizaremos la escala de percepción subjetiva del esfuerzo (RPE) como método de autorregulación por su alta viabilidad y fiabilidad (Haddad et al., 2017; Crawford et al., 2018), que será detallado posteriormente además como método de monitorización durante las distintas fases.

De esta manera, la duración de descansos entre ejercicios dependerá del grado de esfuerzo en las tareas en las diferentes fases, asegurando una buena intensidad y técnica de ejecución. Deberá de haber al menos 1 día de descanso intersesiones. Controlaremos estas variables a través de una planilla [Anexo 8] en la que encontramos una Escala de Percepción de Recuperación Inicial (PRS) 1-10 para conocer la predisposición inicial de la sesión basada en Laurent et al. (2011), cuyos datos nos informan del cansancio o fatiga previa provocada por la jornada laboral, así como las adaptaciones al entrenamiento a nivel fisiológico y psicoemocional (siendo 1 muy cansada y 10 muy bien recuperada). A su vez, se recogerá en dicha planilla la RPE final de la sesión, que nos informará de la intensidad. Esta planilla incorporará además el sueño previo y posterior al entrenamiento, así como la sensación de dolor muscular al día siguiente.

No deberemos olvidar medios esenciales como la hidratación o alimentación, así como el uso de diferentes herramientas intra e inter sesiones que ayuden a generar una menor sensación de fatiga, como pueden ser el foam roller y las pelotas de automasaje. El principal método de recuperación serán las 24h/48h intersesión.

- Educación. Con el objetivo de modificar los estilos de vida no saludables y trabajar en las diferentes dimensiones que componen la calidad de vida anteriormente detalladas en el punto 5.6, previa sesión educativa con diversidad de contenidos según la temática, se establecerán retos semanales durante las diferentes fases, buscando así una vía motivacional y de autosuperación que genere adherencia.

- Comunicación e interacción. El uso de comunicación verbal y no verbal se seleccionará de forma variada con el objetivo de potenciar el aprendizaje, a través de diferentes tipos de feedback verbal y kinestésico (que serán detallados posteriormente), así como el uso de medios audiovisuales. Además, y lo que es más importante, se generará una interacción alumna-entrenadora bidireccional, basándonos en la empatía y la gestión emocional. No debemos olvidar que, a pesar de establecer una planificación sobre el papel, trabajamos con personas, por lo que será necesario realizar modificaciones que consigan que el entrenamiento ayude a nivel integral a nuestra alumna según su situación diaria.

- Entorno y equipamiento. El entorno deberá favorecer un ambiente cómodo y seguro, de cara a conseguir la mayor adherencia posible al programa. Deberemos tener en cuenta especialmente las altas temperaturas al encontrarnos en verano, pues además es un aspecto fundamental en la sensación de fatiga de nuestra alumna. Por eso, estableceremos un horario hecho a medida, generalmente a última hora de la tarde. A su vez, aprovecharemos la disposición del ático del domicilio y la cercanía del Paseo Marítimo y otros entornos para entrenar al aire libre. 


\subsection{Fase 1 del programa de intervención: adaptación.}

La primera fase del programa de intervención consistirá en una adaptación inicial, en la que priorizaremos todo un proceso de aprendizaje y control motor de los patrones básicos de movimiento, estableciendo así una base sólida a partir de la cual progresar en carga para conseguir los diferentes objetivos. Para ello, será necesario corregir de manera transversal aquellos factores más limitantes en el movimiento: dorsiflexión y rigidez isquiosural; ya que de lo contrario reducirá el progreso en el aprendizaje motriz.

Desde el punto de vista educativo, desarrollaremos el uso y aprendizaje de las escalas subjetivas para el control del entrenamiento, así como la introducción de modificaciones en los hábitos de vida no saludables a través de las diferentes sesiones educativas y retos semanales.

\subsubsection{Objetivos específicos y contenidos de entrenamiento de la Fase 1.}

\begin{tabular}{|c|c|c|}
\hline OBJETIVOS GENERALES & OBJETIVOS ESPECIFICOS & CONTENIDOS DE ENTRENAMIENTO \\
\hline $\begin{array}{l}\text { Evitar el agrave de la sarcopenia y la } \\
\text { dinapenia }\end{array}$ & $\begin{array}{l}\text { Potenciar los niveles de masa muscular y fuerza } \\
\text { como papel protector. }\end{array}$ & $\begin{array}{l}\text { Introducción al entrenamiento de fuerza: } \\
\text { patrones básicos de movimiento }\end{array}$ \\
\hline Disminuir el riesgo de fractura & Mejorar la capacidad del sistema para evitar caídas. & $\begin{array}{c}\text { Introducción al entrenamiento de fuerza: } \\
\text { potenciación de los principales grupos } \\
\text { musculares durante la marcha } \\
\end{array}$ \\
\hline $\begin{array}{l}\text { Disminuir las posibilidades de } \\
\text { desarrollo de síndrome metabólico }\end{array}$ & $\begin{array}{l}\text { Reducir los niveles de glucosa en sangre. } \\
\text { Mejorar los valores de dislipidemia. } \\
\text { Mantener en valores normativos tensión arterial } \\
\text { sistólica y diastólica. }\end{array}$ & $\begin{array}{c}\text { Progresión hacia Entrenamiento Interválico de } \\
\text { Alta Intensidad: MIIT, incorporando además } \\
\text { impacto. } \\
\text { Entrenamiento Continuo } \\
\text { Entrenamiento de Fuerza } \\
\end{array}$ \\
\hline Limitar los hábitos no saludables & $\begin{array}{c}\text { Tomar conciencia sobre los efectos perjudiciales de } \\
\text { tabaco y alcohol y su interferencia en la consecución } \\
\text { de objetivos. } \\
\text { Reducir el consumo de alcohol. }\end{array}$ & $\begin{array}{l}\text { Sesiones educativas } \\
\text { Retos }\end{array}$ \\
\hline $\begin{array}{l}\text { OBJETIVOS SECUNDARIOS } \\
\text { (TRANSVERSAL) }\end{array}$ & OBJETIVOS ESPECIFICOS & CONTENIDOS DE ENTRENAMIENTO \\
\hline Perfeccionar la mecánica de pie-tobillo & $\begin{array}{l}\text { Aumentar el ángulo de dorsiflexión. } \\
\text { Disminuir la limitación de gemelo y soleo. }\end{array}$ & \multirow{3}{*}{$\begin{array}{l}\text { Calentamiento: autoliberación miofascial, } \\
\text { carrera externa e inhibición recíproca para la } \\
\text { reducción de stiffness, movilidad dinámica } \\
\text { integrada en el movimiento a alcanzar. }\end{array}$} \\
\hline Restablecer el control lumbopélvico & Reducir la rigidez isquiosural y síndrome de flexión. & \\
\hline Mejorar el equilibrio en raquis dorsal & Disminuir la rigidez de pectoral y dorsal ancho & \\
\hline Reducir la sensación de cansancio & Introducción a la mejora de la calidad de sueño & Educación en higiene del sueño \\
\hline
\end{tabular}

Tabla 20. Objetivos generales y específicos detallados en el apartado $n^{\circ} 4$ y su relación con los contenidos de entrenamiento de la fase 1 de adaptación.

De esta manera, atendiendo al orden de prioridad de la Tabla 20, trataremos de conseguir dichos objetivos a través de los siguientes contenidos de entrenamiento:

- Aprendizaje de patrones básicos de movimiento, cuyo control asentará las bases del entrenamiento de fuerza y la sobrecarga progresiva, permitiendo alcanzar una mejor salud ósea, muscular y metabólica. 
- En relación a estos patrones, y de manera trasversal en el calentamiento clasificándose como objetivo secundario, será necesario mejorar la capacidad de dorsiflexión para evitar limitaciones en los patrones de triple flexión-extensión, disminuir la rigidez isquiosural para conseguir un control lumbopélvico en los distintos patrones, y mejorar la movilidad escapular favoreciendo la liberación de pectoral y dorsal ancho.

- Potenciación de los principales músculos durante la marcha a través del entrenamiento de fuerza, que, además, introducirá un trabajo dirigido a evitar el riesgo de caída y fractura.

- Mejora de los parámetros cardiovasculares, evitando un desarrollo de todos los factores relacionados con el síndrome metabólico. Para ello, el trabajo continuo e interválico será esencial durante el programa (más allá del entrenamiento de fuerza).

Además, se introducirá trabajo de impacto moderado, por la fácil incorporación al entrenamiento interválico con orientación cardiovascular dentro de las sesiones, ayudando por tanto a conseguir los objetivos de mejora de salud ósea.

- Uso y aprendizaje de escalas de percepción subjetiva del esfuerzo (RPE) como método de control de entrenamiento.

- Modificación de malos hábitos: alcohol e higiene del sueño, a través sesiones educativas y retos.

\subsubsection{Metodología específica de los contenidos de entrenamiento de la fase 1.}

\section{Patrones básicos: entrenamiento de fuerza.}

Consideraremos patrones básicos aquellos movimientos que nuestro sistema musculo-esquelético es capaz de realizar, y de los que derivarán el resto de estímulos escogidos según el objetivo a alcanzar, por lo que su control y automatización para la generación de movimiento resulta esencial. Además, desde el punto de vista de la funcionalidad, muchos de estos ejercicios multiarticulares se asemejan en gran medida a los patrones realizados durante la jornada laboral, cuya eficiencia lleva plasmándose en los objetivos del programa.

La tipología y progresión de ejercicios pasará de un control bilateral a unilateral de patrones dominantes de rodilla, dominantes de cadera, tracción y empuje vertical y horizontal con multitud de variantes y variabilidad de vectores. Previo a ello, será necesario un aprendizaje integrado del control del complejo coxolumbopélvico a través de la estabilidad central (bracing) y el control antiextensión, antiflexión y antirotación. Prestaremos especial atención al estímulo de aquellos músculos esenciales durante la marcha y la vida cotidiana y laboral (glúteo mayor, glúteo medio, cuádriceps, gemelo y sóleo, musculatura intrínseca del pie...), de cara a introducir un trabajo de prevención de caída y fractura. Además, recordemos que, con el paso de los años, la principal pérdida de masa muscular se centra en el tren inferior, por lo que priorizamos predominantemente dichos estímulos.

Con el objetivo de asentar una base sólida, la primera toma de contacto con el entrenamiento de fuerza se basará en la repetición y variabilidad de movimiento a partir de estos patrones básicos a alcanzar. 
De esta manera, conseguiremos que el aprendizaje se produzca a través del ensayo-error, manteniendo un reto constante y construyendo un amplio mapa motor con multitud de respuestas (Harbourne \& Stergiou, 2009).

Además, incluiremos tanto un foco interno (mind muscle conexión, feedback táctil, percepción) como externo, a través de medios como el uso de vídeo, espejo, factores limitantes o facilitadores (miniband, silla de referencia...). Escogeremos uno u otro según sea necesario, teniendo en cuenta para su elección siempre la respuesta ante cada uno de ellos, pues ambos son útiles durante el proceso de entrenamiento, muy dependientes del objetivo a alcanzar y con una respuesta individual. Lo más importante será diseñar una relación entorno-estímulo óptima para que se genere la respuesta deseada.

Por ejemplo, considerando la falta de experiencia en el entrenamiento, es probable que en el caso de nuestra alumna haya diversos "mapas motores borrosos" que el cerebro no está acostumbrado a procesar ni a responder con precisión. Por eso, el uso de un foco basado en la percepción de las sensaciones internas (ej.: activación de glúteo) puede ser útil durante el estímulo escogido, lo que no quita que pueda integrarse junto a un foco externo que ayude al sistema a generar la respuesta emergente deseada (ej.: mantén la miniband tensa en todo momento).

Teniendo en cuenta la justificación del programa de intervención, en términos de intensidad, esta se irá desarrollando poco a poco con el paso de las sesiones presenciales de forma segura, ya que en un inicio habrá un predominio de volumen (repeticiones), cesando la serie ante una pérdida repetida de control motor (más de 2 veces seguidas). Posteriormente, generaremos una sobrecarga progresiva esencial que alcanzará en esta fase en torno al 60\% RM (RPE 6) en los 8-10 ejercicios seleccionados (Daly et al. 2019), adaptando progresivamente los principios de entrenamiento a la revisión de las diversas recomendaciones presentadas durante la casuística y la justificación del programa, a expensas de cualquier modificación según la respuesta de nuestra alumna a los diferentes estímulos. Los descansos entre las 2-3 series será autorregulado, de forma que permita realizar la siguiente serie con una calidad de movimiento óptima.

$\begin{array}{cccc}\text { VOLUMEN } & \text { INTENSIDAD } & \text { FRECUENCIA } & \text { MONITORIZACION } \\ \begin{array}{c}\text { Predominante en } \\ \text { repeticiones para el }\end{array} & \text { Progresión hasta el } & \text { 2 días a la semana, } & \text { Pérdida de control motor } \\ \text { aprendizaje, cesando el } & 60 \% \text { RM. } & \text { repetida más de } 2 \text { veces. } \\ \text { ejercicio antes de la } & \text { Recuperación } & \text { alrededor de } 60 \text { min } & \text { Percepción subjetiva del } \\ \text { pérdida repetida de } & \text { autorregulada. } & & \text { esfuerzo, RPE } 6 \\ \text { control motor. Uso de } 2- & & & \\ 3 \text { series, 8-10 ejercicios. } & & & \end{array}$

Tabla 21. Principios de entrenamiento para el contenido de entrenamiento de fuerza en la Fase 1 de adaptación.

\section{Trabajo metabólico.}

Para abordar los objetivos de salud cardiovascular, y tal y como hemos justificado anteriormente, utilizaremos dos medios: 
- Trabajo autónomo continuo. Se realizará de forma no presencial, progresando en intervalos de intensidad moderada-vigorosa controlados a través de la frecuencia cardiaca (previa sesión presencial de aprendizaje del uso de la herramienta). Atendiendo a la síntesis de los principios de entrenamiento mencionados durante la justificación, comenzaremos con periodos alternos de 10 minutos a una intensidad moderada del $40 \%$ de la FC reserva y 10 minutos de moderada-vigorosa al $60 \% \mathrm{FC}$ reserva, hasta progresar semana a semana a una sesión completa de mayor intensidad cuyo criterio de modificación será la respuesta y adaptación a los diferentes estímulos.

- Trabajo interválico de moderada-alta intensidad (MIIT) en sesiones presenciales, con el objetivo de progresar posteriormente a HIIT, justificados sus beneficios en este aspecto.

El trabajo interválico se incorporará en la segunda mitad de la sesión presencial para evitar pequeñas interferencias por fatiga durante el entrenamiento de fuerza con objetivo de disminución del riesgo de caída (en el que se requiere gran control motor), añadiendo además ejercicios que generen impacto inusual (Tabla 19) para introducir los objetivos de salud ósea. Se realizará una progresión en los intervalos de trabajo y descanso para alcanzar la intensidad deseada en torno al 60\% de la FC reserva, con un RPE correspondiente de 6-7, coincidiendo con las recomendaciones presentadas durante la justificación para la mejora de los parámetros cardiovasculares, y teniendo muy presente las respuestas individuales para cualquier modificación.

\begin{tabular}{|c|c|c|c|c|}
\hline TIPO & VOLUMEN & INTENSIDAD & FRECUENCIA & MONITORIZACIÓN \\
\hline $\begin{array}{c}\text { Continuo (trabajo no } \\
\text { presencial) }\end{array}$ & $\begin{array}{l}\text { Intervalos progresivos } \\
\text { hasta completar } 30-45 \\
\text { minutos a la intensidad } \\
\text { determinada }\end{array}$ & $\begin{array}{l}\text { Progresión en } \\
\text { periodos de } 40-60 \% \\
\text { FC de reserva }\end{array}$ & 1 día a la semana & $\begin{array}{c}\text { FC a través de Xiaomi } \\
\text { Band } 4\end{array}$ \\
\hline TIPO & VOLUMEN & INTENSIDAD & FRECUENCIA & MONITORIZACIÓN \\
\hline $\begin{array}{l}\text { Interválico MIIT, } \\
\text { progresión previa a } \\
\text { HIIT, incluyendo } \\
\text { impacto }\end{array}$ & $\begin{array}{c}4 \text { series de } 3-4 \text { ejercicios } \\
\text { por intervalos } \\
\text { progresivos de tiempo } \\
\text { trabajo-descanso. }\end{array}$ & $\begin{array}{l}\text { 60\% FC de reserva. } \\
\text { Descanso 1-3 } \\
\text { minutos según } \\
\text { intensidad. }\end{array}$ & $\begin{array}{c}2 \text { días a la semana, } \\
\text { incorporado en las } \\
\text { sesiones } \\
\text { presenciales }\end{array}$ & $\begin{array}{c}\text { FC a través de Xiaomi } \\
\text { Band } 4 \\
\text { RPE 6-7 en MIIT }\end{array}$ \\
\hline
\end{tabular}

Tabla 22. Principios de entrenamiento de los contenidos de trabajo continuo e interválico en Fase 1 de adaptación.

\section{Herramientas para la reducción de stiffness}

Teniendo en cuenta los beneficios expuestos durante la justificación del programa, incorporaremos durante el calentamiento las siguientes herramientas, de cara a conseguir una mejor predisposición al movimiento de la sesión:

- Autoliberación miofascial. A través del uso del foam roller y pelotas de automasaje. La metodología usada consistirá en unos 20 segundos por cada músculo durante los primeros 3-5 minutos del calentamiento. Una vez afianzado el aprendizaje, se pedirá cierta velocidad en la fricción durante el calentamiento. Si se usa este método durante la vuelta a la calma, esta velocidad disminuirá, aumentando por tanto el tiempo de aplicación en torno a unos 50 segundos. 
- Inhibición recíproca, carrera externa y neurodinámica. Acumulando 2 series de unas 10 repeticiones con cada extremidad, acorde a la mayoría de metodologías de los autores mencionados durante la justificación, a expensas de las sensaciones de la alumna y sus posibles modificaciones

- FNP. Manteniendo el rango de estiramiento unos 10 segundos con una contracción isométrica durante unas 4-5 repeticiones (Areeudomwong \& Buttagat, 2019).

- Posteriormente, se integrará la movilidad dinámica enfocada al patrón a alcanzar. Por ejemplo, tras el uso del foam roller en musculatura isquiosural, inhibición recíproca y/o neurodinámica con gliding en extensión de rodilla, realizaremos Rocking Backwards con un volumen de unas 15-20 repeticiones, para integrar y conseguir un control lumbopélvico sin limitaciones en cadena posterior.

\section{Educación en relación a los hábitos no saludables e higiene del sueño.}

Al principio de cada fase, realizaremos una pequeña sesión educativa en la que expongamos los riesgos de los hábitos no saludables y su interferencia con los objetivos a alcanzar. De esta manera, y en consenso, se establecerán una serie de retos semanales para la limitación de cada hábito. En esta primera fase, escogeremos la reducción del consumo de alcohol diario. El contenido de cada sesión y las plantillas de retos pueden consultarse en su totalidad en [Anexo 7].

Además, en esta primera fase optaremos por establecer unas pautas de higiene del sueño, acostándose 1 o 2 horas antes y limitando el previo uso de pantallas durante los últimos 45 minutos antes de ir a la cama. El progreso será monitorizado a través de Xiaomi Band 4, generando unos retos diarios con el objetivo de aumentar la motivación para cumplir dichos hábitos.

\subsubsection{Secuenciación de contenidos.}

La distribución de sesiones se ejecuta según la disponibilidad horaria de nuestra alumna, configurándose en esta fase de la siguiente manera:

\begin{tabular}{|c|c|c|c|c|c|c|}
\hline \multicolumn{7}{|c|}{ JUNIO } \\
\hline L & $M$ & $x$ & $\mathrm{~J}$ & V & $S$ & D \\
\hline 1 & 2 & 3 & 4 & 5 & 6 & 7 \\
\hline 8 & 9 & 10 & 11 & 12 & 13 & 14 \\
\hline 15 & 16 & 17 & 18 & 19 & 20 & 21 \\
\hline 22 & 23 & 24 & 25 & 26 & 27 & 28 \\
\hline 29 & 30 & 1 & 2 & 3 & 4 & \\
\hline
\end{tabular}

Tabla 23. Secuenciación de sesiones del mes de junio. En Amarillo: sesiones presenciales de fuerza y MIIT. En verde: sesiones no presenciales de trabajo continuo al aire libre. En azul: sesión educativa y establecimiento de retos semanales. En negro: evaluación final del progreso en la fase 1.

De esta manera, las sesiones presenciales abordarán los contenidos relacionados con el entrenamiento de fuerza e interválico-impacto (incluyendo las herramientas usadas durante el calentamiento). Las sesiones no presenciales, por su parte, se centrarán el contenido de trabajo continuo de carácter cardiovascular. 
Por tanto, la distribución de los diversos estímulos diarios a través de una progresión que favorezca el aprendizaje y la adaptación progresiva para la consecución final de objetivos, queda de la siguiente forma:

\begin{tabular}{|c|c|}
\hline FECHA & ESTIMULO DE ENTRENAMIENTO \\
\hline 03 -jun & Aprendizaje de activación abdominal y patrones básicos bilaterales \\
\hline 06-jun & Aprendizaje de patrones básicos bilaterales \\
\hline 07-jun & $1 \times 10 \min 40 \%$ FC reserva, $1 \times 10 \min 60 \%$ FC reserva, $1 \times 10$ min $40 \% \mathrm{FC}$ reserva \\
\hline 10 -jun & Aprendizaje de patrones básicos unilaterales \\
\hline 11 -jun & $1 \times 10 \min 40 \%$ FC reserva, $1 \times 15 \min 60 \%$ FC reserva, $1 \times 10$ min $40 \% \mathrm{FC}$ reserva \\
\hline 12-jun & Introducción de carga bilateral. Básicos unilaterales. Introducción interválico metabólico-impacto. \\
\hline 15 -jun & Progresión en bilaterales. Respuesta CORE. Interválico metabólico-impacto. \\
\hline 18 -jun & $1 \times 10 \min 40 \% \mathrm{FC}$ reserva, $1 \times 20$ min $60 \% \mathrm{FC}$ reserva \\
\hline 19 -jun & Progresión en unilaterales. Predominancia de tracciones. Interválico metabólico-impacto \\
\hline 22-jun & Sobrecarga dominante de rodilla. Respuesta CORE. Interválico metabólico-impacto \\
\hline 25 -jun & $1 \times 5 \min 40 \% \mathrm{FC}$ reserva, $1 \times 25 \min 60 \% \mathrm{FC}$ reserva \\
\hline 26-jun & Sobrecarga dominante de cadera unilateral. Interválico metabólico-impacto \\
\hline 29-jun & Sobrecarga dominante de rodilla y cadera unilateral. Respuesta CORE. Interválico metabólico-impacto \\
\hline 02-jul & Isometría, movilidad integrada, trabajo analítico: sesión modificada por sensación de fatiga. \\
\hline 03-jul & $1 \times 30 \min 60 \% \mathrm{FC}$ reserva \\
\hline S & $\begin{array}{l}\text { Tabla 24. Estímulos pertenecientes a cada sesión para la consecución de objetivos } \\
\text { través de cada contenido de entrenamiento, detallado anteriormente. En blanco: } \\
\text { esiones presenciales de entrenamiento de fuerza e interválico-impacto. En verde: } \\
\text { sesiones autónomas de carácter aeróbico con objetivo cardiovascular. }\end{array}$ \\
\hline
\end{tabular}

\subsubsection{Sesiones.}

A continuación, se presentan varias sesiones tipo correspondientes a la fase 1, relacionando el estímulo de entrenamiento con el objetivo a alcanzar, así como la metodología empleada en cada uno de ellos, acorde a la detallada anteriormente. Recordemos que estas sesiones pertenecen a la modalidad presencial, cuyos contenidos de entrenamiento son predominantemente la introducción al entrenamiento de fuerza y el trabajo interválico de moderada-alta intensidad (MIIT), necesario para progresar en las siguientes fases a un trabajo de alta intensidad (HIIT). Además, durante los calentamientos se incorporan las herramientas que permiten mejorar los diversos factores limitantes del movimiento

03/07 SESIÓN 1: activación, aprendizaje, concienciación y control del movimiento previo a patrones

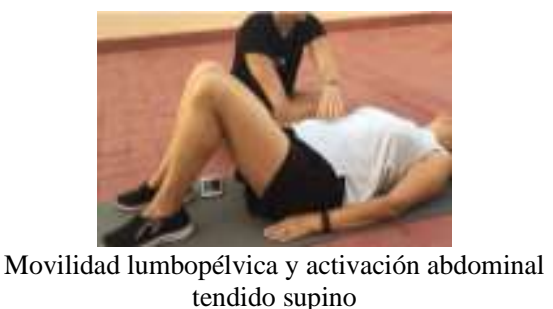




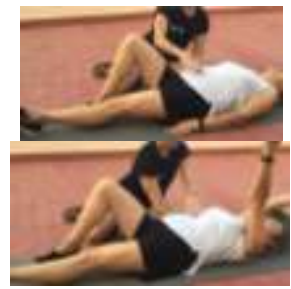

Control lumbopélvico (LP) ante desafío en flexión de hombro y extensión de rodilla
$2 \times$ Repeticiones hasta la pérdida de control motor LP

Dead bug modificado, progresión previa

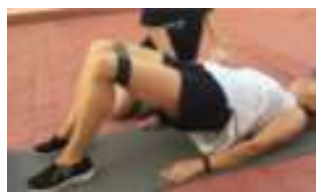

Integración control LP + bracing en sinergia con glúteo
Foco externo miniband rodillas para evitar aducción. $2 \mathrm{x}$ repeticiones hasta la pérdida de control motor o RPE 6

Puente de glúteo

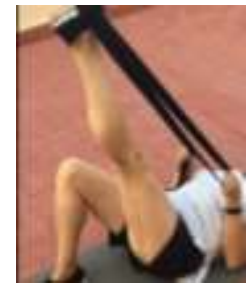

Disminución de stiffness cadena posterior

evitando la limitación en el aprendizaje motor de los siguientes patrones

$2 \times 10$ cada pierna

Inhibición recíproca Q-H y neurodinámica tendido supino

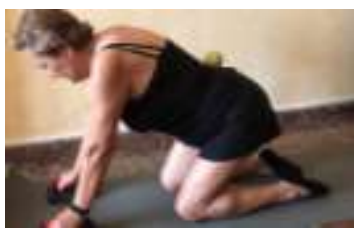

Concienciación y control LP evitando síndrome de flexión
$2 \times 12$ repeticiones

Foco externo pelota raquis lumbar

Rocking backwards

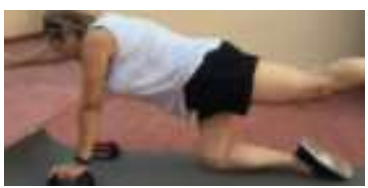

Estabilización sagital. Control LP + activación abdominal antirotación.
$2 \times 15$ por cada lado o RPE 6 Foco externo pelota raquis lumbar

Bird dog

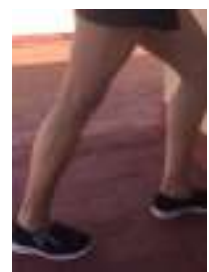

Reducción de stiffness cadena posterior en estático para favorecer la dorsiflexión en el siguiente patrón

$1 \mathrm{x} 10$ repeticiones 15 " con cada pierna

Estiramiento estático cadena posterior desde Lunge

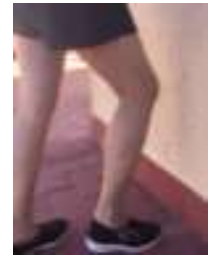

Favorecer la dorsiflexión aplicada e integrada al movimiento

$1 \mathrm{x} 15$ repeticiones por cada pierna

Movilidad dinámica cadena posterior 


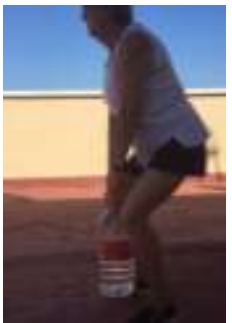

Patrón squat

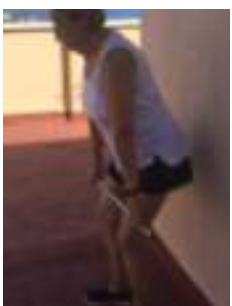

Aprendizaje patrón dominante de rodilla bilateral

Aprendizaje patrón dominante de cadera bilateral
3 series hasta pérdida de control motor repetida

Uso de espejo

Foco externo silla

Introducción de distintos elementos ante respuestas de la alumna:

Foco externo pica para neutralidad del raquis Foco interno instrucción activación plantar, evitando colapso plantar en sobrepronación y valgo dinámico de rodilla

Patrón hinge

3 series hasta pérdida de control motor repetida Uso de espejo

Foco externo pared

10/07 SESIÓN 3: aprendizaje patrones básicos unilaterales

\begin{tabular}{|c|c|c|}
\hline ESTÍMULO & $\begin{array}{l}\text { CALENTAMIIENTO } \\
\text { OBJETIVO }\end{array}$ & METODOLOGÍA Y MODIFICACIONES \\
\hline Foam Roller & Autoliberación miofascial & $\begin{array}{l}\text { 15-20 repeticiones cada grupo muscular con } \\
\text { cierta velocidad }\end{array}$ \\
\hline Carrera externa cadena posterior & Disminución de rigidez en cadena posterior & $1 \times 10$ repeticiones cada pierna \\
\hline Estiramiento estático cadena posterior desde Lunge & $\begin{array}{l}\text { Reducción stiffness estático cadena } \\
\text { posterior para favorecer la dorsiflexión }\end{array}$ & $1 \mathrm{x} 10$ repeticiones 15 " con cada pierna \\
\hline Movilidad dinámica cadena posterior & $\begin{array}{l}\text { Favorecer la dorsiflexión aplicada al } \\
\text { movimiento }\end{array}$ & $1 \times 15$ repeticiones por cada pierna \\
\hline Rocking backwards & Control LP, evitando síndrome de flexión & Foco externo pelota raquis lumbar \\
\hline FNP pectoral & Disminución de rigidez en cadena anterior & $1 \times 10$ repeticiones 15 "cada brazo \\
\hline
\end{tabular}

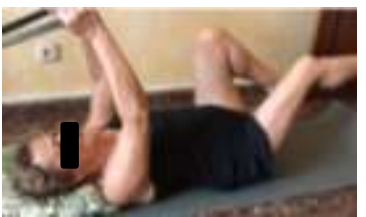

Afianzar control LP y curva neutra ante demanda y control en antiextensión.

3x hasta RPE 6

Dead bug antiextensión

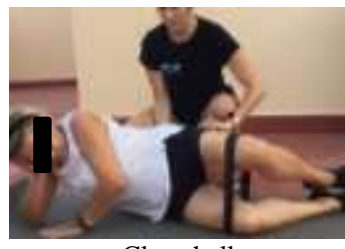

Activación analítica previa de glúteo medio para la correcta ejecución de los patrones monopodales 2x hasta RPE 6

Mind muscle conexión, feedback táctil.

Clamshell

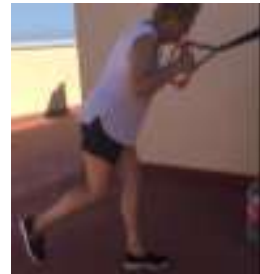

Aprendizaje de patrón dominante de cadera monopodal, contribuyente a la disminución de rigidez de cadena posterior

\section{3x hasta RPE 6}

Apoyo gliding y TRX facilitando el movimiento Bisagra de cadera en rango de control LP (percepción cadena posterior) 


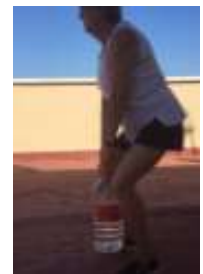

Afianzar patrón dominante de rodilla sin referencia ni uso de miniband

3x hasta RPE 6-7

Sentadilla con carga

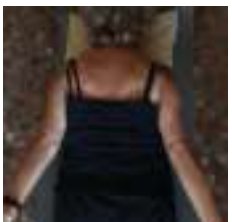

Mejora de la activación y propiocepción previa a tracciones, ya que tiene dificultad para la integración de la retracción escapular en las anteriores sesiones.

$2 \times 15$ repeticiones Mind muscle conexión, feedback táctil movimiento escapular

Cierre escapular

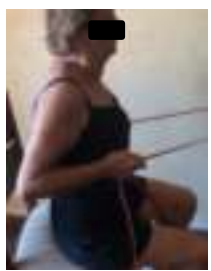

$3 \mathrm{x}$ hasta pérdida de control repetida

Afianzar patrón de tracción Silla de apoyo para aislar al sistema de atención a estímulos en bipedestación.

Tracción horizontal sentada

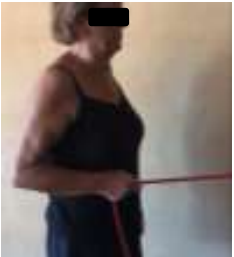

Afianzar patrón de tracción con componente rotacional. Paso a

3x hasta RPE 6 bipedestación.

Tracción horizontal unilateral

\begin{tabular}{|c|c|c|}
\hline ESTÍMULO & $\begin{array}{l}\text { VUELTA A LA CALMA } \\
\text { OBJETIVO }\end{array}$ & METODOLOGÍA Y MODIFICACIONES \\
\hline FNP Pectoral & \multirow{2}{*}{ Disminución de rigidez de cadena anterior } & $1 \times 10$ repeticiones 15 " con cada brazo \\
\hline Autoliberación pelota & & 15-20 repeticiones a velocidad lenta \\
\hline Respiraciones torácico diafragmáticas & $\begin{array}{c}\text { Estado basal, disminución FC, musculatura } \\
\text { inspiratoria }\end{array}$ & $2 \times 12$ repeticiones \\
\hline
\end{tabular}

15/07 SESIÓN 5: progresión bilateral, respuesta CORE ante diferentes movimientos, interválico-impacto

\section{ESTIMMULO}

Liberación miofascial rodillo y pelota

Neurodinámica gliding desde zancada

Estiramiento estático cadena posterior desde Lunge

Movilidad dinámica cadena posterior

FNP pectoral

ESTÍMULO

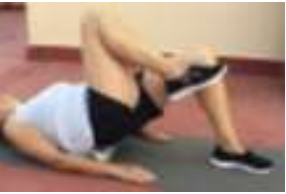

Sobrecarga progresiva en extensión de

cadera con fase monopodal, musculatura

esencial durante la marcha
METODOLOGIA Y MODIFICACIONES

Autoliberación miofascial

Cambio de foam por molestias

Movilización neural para preparar al sistema

Reducción de rigidez posterior

Concienciación control LP

Reducción stiffness estático cadena posterior para favorecer la dorsiflexión

Favorecer la dorsiflexión aplicada al movimiento

Reducción stiffness cadena anterior

PARTE PRINCIPAL OBJETIVO

\section{5-20 repeticiones cada grupo muscular con} cierta velocidad

$1 \mathrm{x} 10$ repeticiones cada pierna
Foco externo pelota raquis lumbar

$1 \times 10$ repeticiones 20 " con cada pierna

$1 \mathrm{x} 15$ repeticiones por cada pierna

1x 15 repeticiones por cada brazo

METODOLOGÍA Y MODIFICACIONES

Bridge con fase monopodal 


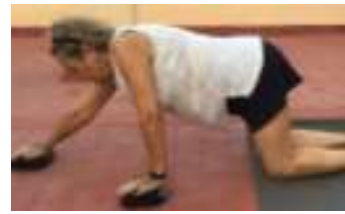

Activación abdominal y control LP ante demanda antiextensión.

3x hasta RPE 6-7

Plancha deslizante

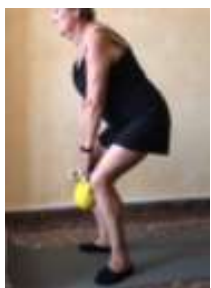

Afianzar patrón dominante de rodilla, sin referencia ni foco externo. Superar el patrón con carga.

3x hasta RPE 6-7

Squat kettlebell

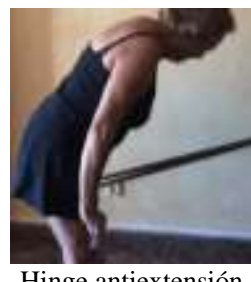

Afianzar patrón dominante de cadera junto

a estímulo antiextensión. Contribuye a la

diminución de rigidez de la cadena

3x hasta RPE 6-7 posterior.

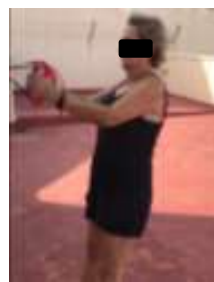

Sobrecarga en patrón de tracción con demanda de suspensión, contribuyendo a la estabilidad central.

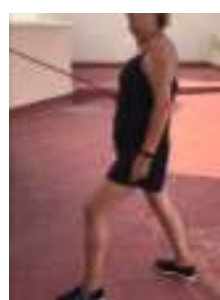

Tracción unilateral desde zancada isométrica

Subida frontal al step (instrucción: hacer ruido para mayor pico de impacto)

Batir botellas

Escalera de coordinación, variedad de desplazamiento

Boxing

\begin{tabular}{|c|c|c|}
\hline FNP Pectoral & \multirow{2}{*}{ Disminución de rigidez de cadena anterior } & $1 \times 10$ repeticiones 15 " con cada brazo \\
\hline Autoliberación pelota & & $15-20$ repeticiones a velocidad lenta \\
\hline Respiraciones torácico diafragmáticas & $\begin{array}{c}\text { Estado basal, disminución FC, musculatura } \\
\text { inspiratoria }\end{array}$ & $2 \times 12$ repeticiones \\
\hline
\end{tabular}




\subsubsection{Control y monitorización del entrenamiento.}

En relación al control de la carga, tanto en el entrenamiento de fuerza como el interválico, la principal herramienta utilizada (previa explicación y continuo aprendizaje) es la percepción subjetiva del esfuerzo (Tabla 25). Esta escala de Borg modificada constituye una herramienta eficaz, fiable, no invasiva y muy viable (Haddad et al., 2017; Crawford et al., 2018), que permite monitorizar el entrenamiento de forma sencilla aún en sujetos no experimentados. Además, tendremos un control exhaustivo de los valores de carga interna de entrenamiento, es decir, conoceremos el estrés fisiológico que constituyen los diferentes estímulos en nuestra alumna. Para ello, usaremos la medida de unidades arbitrarias (UA) (Gabbet 2016), resultado de la multiplicación de la RPE*minutos de la sesión.

\begin{tabular}{|l|l|c|}
\hline & 0 & Reposo \\
\cline { 2 - 3 } & 1 & Muy suave \\
\cline { 2 - 3 } & 2 & Suave \\
\hline & 3 & Ligero, empieza a aumentar mi ventilación. \\
\hline & 4 & Medio, pero puedo mantener una conversación estable. \\
\hline & 5 & Duro, me cuesta respirar y mantener una conversación estable. \\
\hline & 6 & Duro, he sobrepasado mi límite de comodidad. Solo puedo mantener un par de \\
\cline { 2 - 3 } & 7 & frases. \\
\hline
\end{tabular}

Tabla 25. Escala visual subjetiva de percepción del esfuerzo utilizada durante el programa de entrenamiento.

De cara a ajustar la carga día a día según el estado inicial, predisposición y capacidades de nuestra alumna, se llevará el registro en una planilla [Anexo 8] de la Escala de Percepción de Recuperación Inicial, la RPE final de la sesión y la carga interna de entrenamiento (UA), así como el sueño de la noche anterior, pues estos parámetros afectarán a la percepción de esfuerzo. Además, será incorporado el sueño posterior y la sensación de DOMS para entender que adaptaciones está generando el entrenamiento.

Para el entrenamiento aeróbico continuo e interválico usaremos los datos de \% de intensidad de la FC de reserva deseados, monitorizados en vivo a través de Xiaomi Band 4, moviéndonos en este caso en torno a 115-133 lpm según la elección de intensidad moderada o vigorosa.

Por último, de cara a evitar respuestas hipertensivas al ejercicio, tomaremos la tensión antes y después de la sesión de entrenamiento, pudiendo modificar o cesar el ejercicio en caso de encontrarnos con valores no normativos.

\subsubsection{Evaluación del progreso.}

\section{Introducción al entrenamiento de fuerza: patrones básicos.}

El criterio de progresión para la siguiente fase consiste en superar y dominar los patrones básicos de movimiento, de cara a poder manejar mayores cargas sin que suponga un riesgo en posteriores fases. Por tanto, observamos los cambios con respecto a la evaluación inicial: 


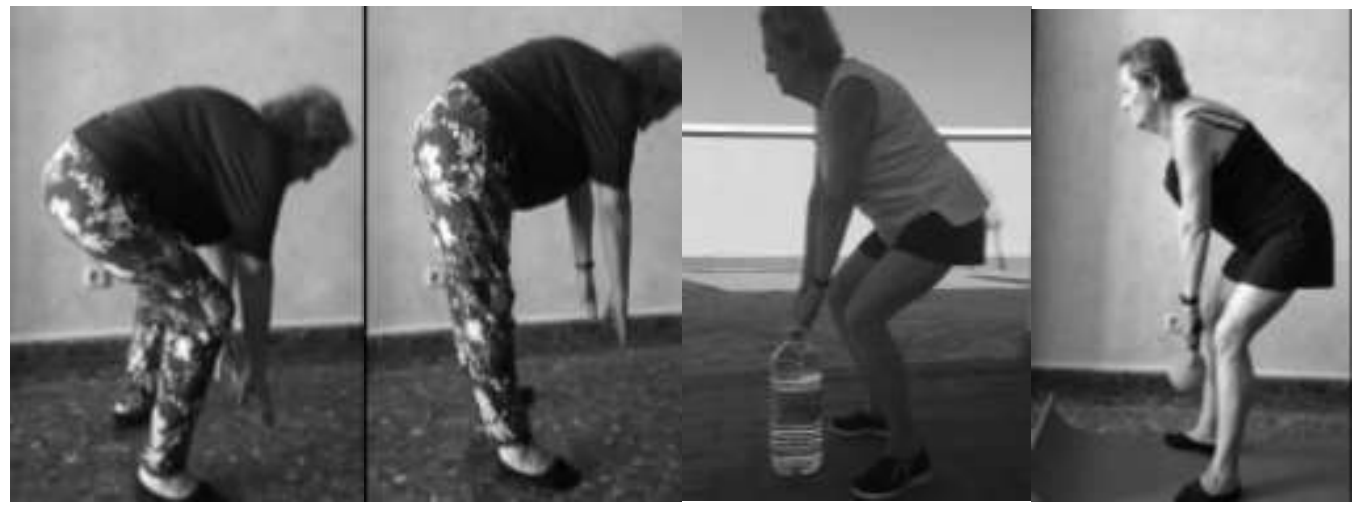

Figura 28. Respuesta ante la orden de coger algo del suelo con mayor y menor flexión de rodilla. En las dos primeras imágenes a la izquierda, observamos el movimiento previo al programa de intervención, con nula movilidad y control lumbopélvico, exceso de tensión en la cadena posterior, hiperextensión de rodilla y compensación torácica. A la derecha, destaca la integración de la neutralidad del raquis lumbar, así como un mayor equilibrio en raquis dorsal, con mayor dominancia de rodilla (tercera imagen) y cadera (cuarta imagen), a pesar de que existe cierta limitación de la cadena posterior en patrones dominantes de cadera (cuarta imagen).

\section{Disminución de los parámetros relacionados con el síndrome metabólico}

Realizando el promedio de todas las tomas durante la fase 1, observamos como la presión arterial ha disminuido notablemente a $\mathbf{1 2 9 / 7 0} \mathbf{~ m m H g}$ (Figura 29), a pesar de no haber alcanzado aún las intensidades marcadas por la evidencia para la optimización de estos parámetros.

Figura 29. Cambios en la presión arterial diastólica y sistólica de la Fase 1 con respecto a la evaluación inicial

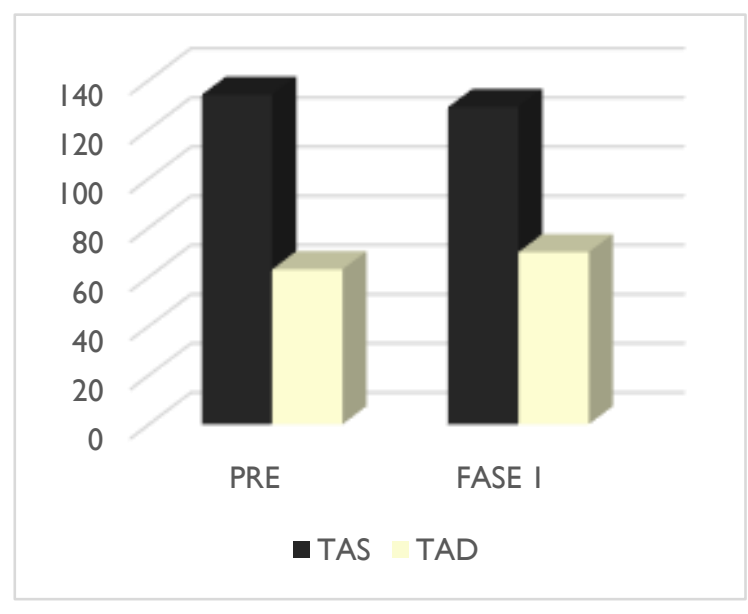

\section{Reducción de los hábitos no saludables}

El cumplimiento de los retos semanales [Anexo 7] refleja una clara disminución del consumo diario de alcohol, optando así por la sustitución de la cerveza sin alcohol, así como el consumo de agua durante las comidas, y disminuyendo a un máximo de 2 cervezas con alcohol el fin de semana.

\section{Objetivos trasversales}

A pesar de ser un objetivo secundario, dentro de la dimensión de la calidad de sueño únicamente nos hemos limitado en esta fase a introducir unos hábitos previos a la hora de ir a la cama, sin escoger un tipo de entrenamiento específico. 
Gracias al registro llevado a cabo [Anexo 8], podemos observar como este parámetro ha mejorado notablemente, lo que nos indica además una buena adaptación del sistema al programa de intervención. Como observamos en la Figura 30, la media pre intervención se encontraba en 66 puntos mientras que tras la Fase 1, la media se encuentra en 83 puntos.

Figura 30. Promedio de la calidad del sueño pre y post Fase 1, monitorizado a través de Xiaomi Band 4.

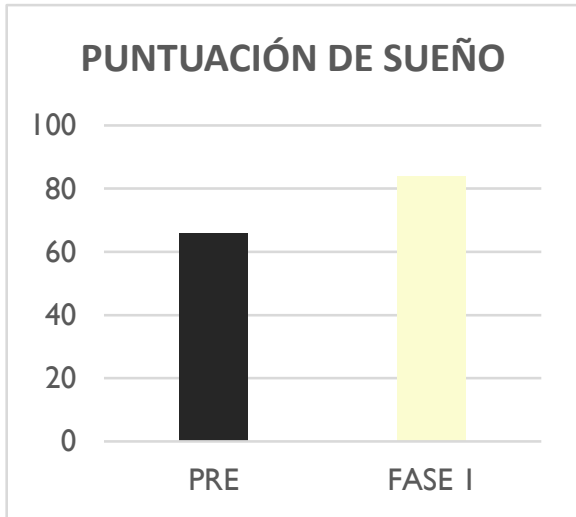

Por último, realizamos un seguimiento de los valores de dinamometría y ángulos de los factores limitantes durante el movimiento:

- Dinamometría en relación a los contenidos de entrenamiento enfocados a la mejora de los niveles de fuerza en los principales músculos durante la marcha, en extensión de rodilla y extensión de cadera, así como tracción unilateral. A pesar de comprobar los progresos en los niveles de fuerza, destacamos que en esta fase hemos optado por la calidad de movimiento previa. Observamos ligeras mejoras en todos los datos (Figura 31).

- Ángulo de dorsiflexión, rigidez isquiosural y flexión de hombro, factores limitantes durante el movimiento. Observamos un aumento en los 3 tests (Figura 32).

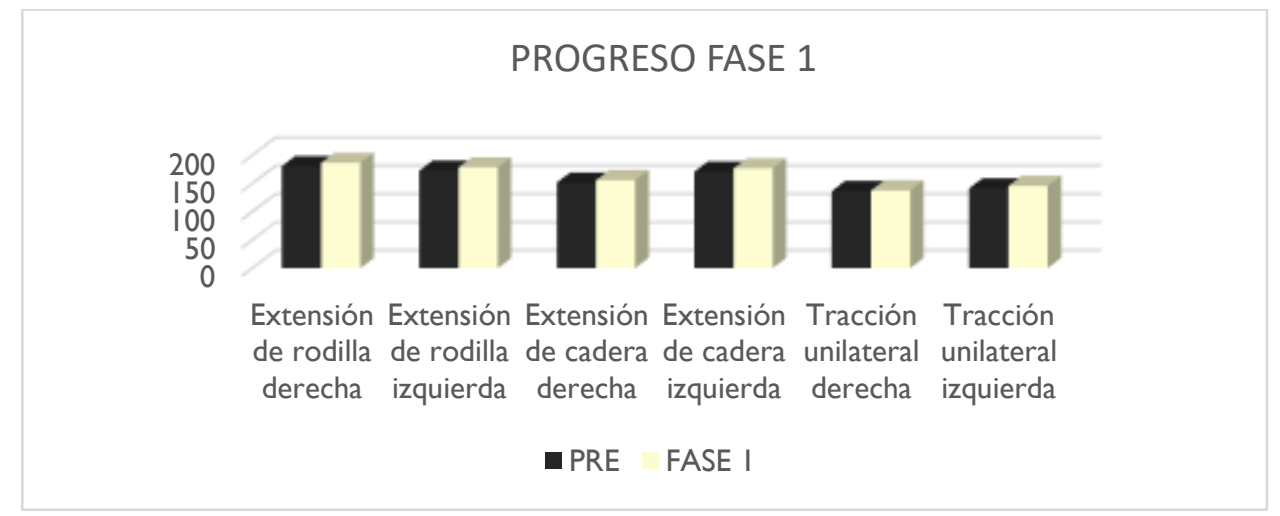

Figura 31. Ligeros progresos en los niveles de fuerza en la fase 1.

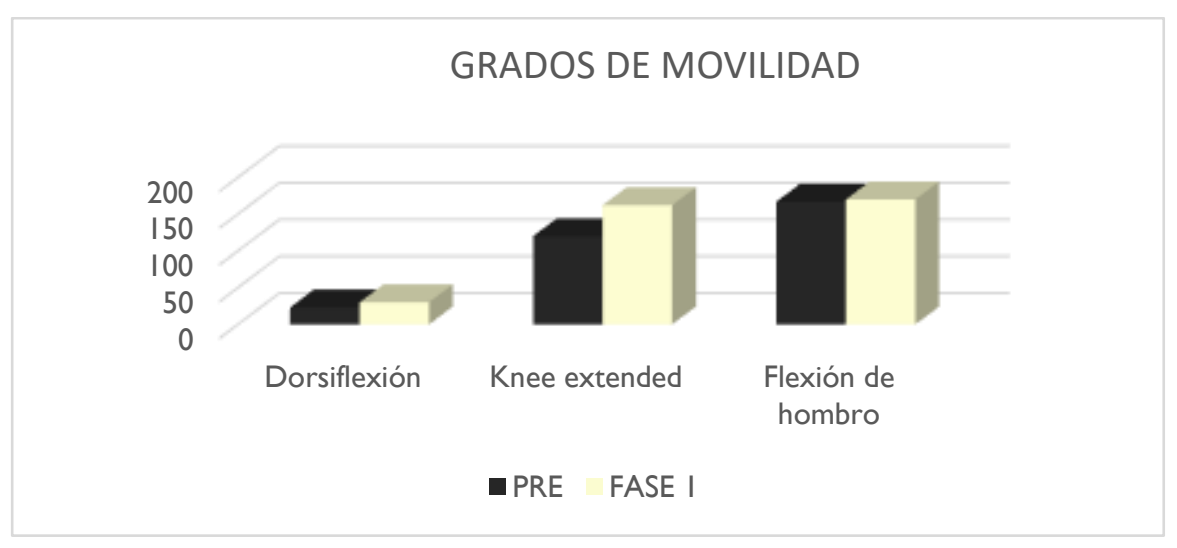

Figura 32. Mejora de la rigidez en los 3 tests, aun sin incluir trabajo específico para la mejora de la movilidad de hombro en la fase 1. 


\subsection{Fase 2 del programa de intervención: desarrollo.}

Una vez asentadas las bases sólidas de movimiento, podremos aumentar los niveles de carga en el entrenamiento de fuerza (sobrecarga progresiva). Generado este entorno seguro, introduciremos la combinación de un entrenamiento con una intencionalidad máxima de velocidad concéntrica, una vez justificados sus beneficios anteriormente. La orientación de los estímulos en el entrenamiento de fuerza tendrá como objetivo la integración de la eficiencia en los diversos patrones laborales cada vez más complejos, potenciando así la funcionalidad, disminuyendo la sensación de fatiga tras la jornada laboral y continuando con la mejora de aquellos factores limitantes del movimiento en raquis dorsal, raquis lumbar y pie-tobillo.

Por otro lado, progresaremos en el control motor en situaciones complejas con predominancia de patrones monopodales, mejorando así la capacidad del sistema ante una posible caída. Además, añadiremos en estas situaciones un componente cognitivo, conformando una doble tarea y modificaciones visuales, vestibulares y kinestésicas.

\subsubsection{Objetivos específicos y contenidos de entrenamiento de la fase 2.}

\begin{tabular}{|c|c|c|}
\hline OBJETIVOS GENERALES & OBJETIVOS ESPECIFICOS & $\begin{array}{l}\text { CONTENIDOS DE } \\
\text { ENTRENAMIENTO }\end{array}$ \\
\hline $\begin{array}{c}\text { Evitar el agrave de la sarcopenia y } \\
\text { la dinapenia }\end{array}$ & $\begin{array}{l}\text { Potenciar los niveles de masa muscular y } \\
\text { fuerza como papel protector. }\end{array}$ & $\begin{array}{c}\text { Progresión en el entrenamiento de fuerza } \\
\text { Introducción al entrenamiento con } \\
\text { máxima velocidad intencional } \\
\text { concéntrica }\end{array}$ \\
\hline Disminuir el riesgo de fractura & $\begin{array}{c}\text { Mejorar la capacidad del sistema para evitar } \\
\text { caídas. }\end{array}$ & $\begin{array}{c}\text { Potenciación del sistema con nuevos } \\
\text { estímulos, control motor en situaciones } \\
\text { complejas y doble tarea }\end{array}$ \\
\hline Mejorar la salud ósea & $\begin{array}{l}\text { Aumentar la puntuación } T \text { Score en cuello del } \\
\text { fémur y columna lumbar } \\
\text { Mejorar la calidad de la microestructura ósea }\end{array}$ & $\begin{array}{c}\text { Progresión en el entrenamiento de } \\
\text { impacto } \\
\text { Entrenamiento de fuerza e } \\
\text { intencionalidad de máxima velocidad } \\
\text { concéntrica }\end{array}$ \\
\hline $\begin{array}{l}\text { Disminuir las posibilidades de } \\
\text { desarrollo de síndrome metabólico }\end{array}$ & $\begin{array}{l}\text { Reducir los niveles de glucosa en sangre. } \\
\text { Mejorar los valores de dislipidemia. } \\
\text { Mantener en valores normativos tensión } \\
\text { arterial sistólica y diastólica. }\end{array}$ & $\begin{array}{l}\text { Continuo e Interválico } \\
\text { Entrenamiento de Fuerza } \\
\text { Trabajo isométrico }\end{array}$ \\
\hline Limitar los hábitos no saludables & $\begin{array}{l}\text { Establecer como hábito la reducción del } \\
\text { consumo de alcohol } \\
\text { Intentar reducir el consumo de tabaco }\end{array}$ & $\begin{array}{l}\text { Sesiones educativas } \\
\text { Retos }\end{array}$ \\
\hline $\begin{array}{l}\text { OBJETIVOS SECUNDARIOS } \\
\text { (TRANSVERSAL) }\end{array}$ & OBJETIVOS ESPECIFICOS & $\begin{array}{l}\text { CONTENIDOS DE } \\
\text { ENTRENAMIENTO }\end{array}$ \\
\hline $\begin{array}{c}\text { Reducir la sensación de cansancio } \\
\text { tras el trabajo }\end{array}$ & $\begin{array}{c}\text { Favorecer el desempeño en sus patrones } \\
\text { laborales, a través de la eficiencia, calidad de } \\
\text { movimiento y aumento de los niveles de } \\
\text { fuerza-resistencia en ellos }\end{array}$ & $\begin{array}{c}\text { Integración de patrones laborales en el } \\
\text { entrenamiento de fuerza } \\
\text { Mantenimiento de hábitos de higiene del } \\
\text { sueño }\end{array}$ \\
\hline $\begin{array}{c}\text { Mejorar el equilibrio en raquis } \\
\text { dorsal }\end{array}$ & $\begin{array}{l}\text { Corregir exceso de cifosis } \\
\text { Aumentar la movilidad en flexión de hombro }\end{array}$ & $\begin{array}{c}\text { Trabajo específico en rotación y } \\
\text { extensión torácica } \\
\text { Uso de vibración } \\
\end{array}$ \\
\hline $\begin{array}{l}\text { Perfeccionar la mecánica de pie- } \\
\text { tobillo }\end{array}$ & $\begin{array}{l}\text { Aumentar el ángulo de dorsiflexión. } \\
\text { Disminuir la limitación de gemelo y soleo. }\end{array}$ & Calentamiento: autoliberación miofascial, \\
\hline $\begin{array}{l}\text { Restablecer el control } \\
\text { lumbopélvico }\end{array}$ & $\begin{array}{c}\text { Reducir la rigidez isquiosural y síndrome de } \\
\text { flexión. }\end{array}$ & movilidad dinámica integrada \\
\hline
\end{tabular}

Tabla 26. Objetivos generales y específicos detallados en el apartado $n^{\circ} 4$ y su relación con los contenidos de entrenamiento de la fase 2 de desarrollo 
Haciendo referencia a la Tabla 26, observamos como:

- Se establecerá una progresión en carga y dificultad del entrenamiento de fuerza para continuar con los objetivos de sarcopenia, dinapenia y disminución del riesgo de fractura. Con respecto a este último, además, se incluyen retos cognitivos que aumentan la complejidad de la tarea motora.

- Para mejorar en la dimensión laboral y su influencia en la fatiga, la elección de los estímulos se orientará a la similitud de los patrones laborales y su progresión en complejidad. A su vez, se incorpora trabajo específico para la mejora de los grados en flexión de hombro.

- Se mantienen los contenidos relacionados con la diminución del desarrollo de síndrome metabólico, cuya metodología se basará en la progresión de los mismos.

- Por otro lado, se incorpora un trabajo específico isométrico para la mejora de los parámetros de presión arterial.

- A nivel educativo, continuaremos con el establecimiento de la reducción del consumo de alcohol para convertirlo en hábito, así como la introducción de la reducción del tabaco diario.

\subsubsection{Metodología específica de los contenidos de entrenamiento de la fase 2}

\section{Entrenamiento de fuerza con máxima intencionalidad concéntrica}

Interaccionando con los objetivos de sarcopenia, dinapenia y mejora de la DMO, el entrenamiento de fuerza continuará en base a una sobrecarga progresiva. Para ello, modularemos las variables de carga e intensidad, así como la variabilidad a través de los diferentes planos para asegurar un estímulo óptimo y novedoso. Teniendo en cuenta los beneficios a nivel neuromuscular anteriormente mencionados en la justificación, introduciremos en esta fase el entrenamiento con máxima intencionalidad de velocidad en la fase concéntrica, junto a recuperaciones completas para garantizar esta metodología.

La selección de estímulos orientados a la vida laboral se desarrollará más que en la anterior fase de adaptación, con el objetivo de mejorar la eficiencia y reducir la sensación de cansancio tras el trabajo. La metodología de aprendizaje ensayo-error y el uso de foco interno y externo se mantendrá con los mismos principios detallados en la fase 1 (consultar punto 6.2.2. en "Entrenamiento de fuerza")

Teniendo en cuenta las horquillas recomendadas obtenidas de la revisión detallada durante la justificación, y observando el funcionamiento y adaptación de nuestra alumna como criterio de progresión, avanzamos con respecto a la fase 1 de la siguiente manera (Tabla 27). Cabe destacar que, en ocasiones, se hará uso de biseries que no comprometan la calidad entre ambos ejercicios (grupos musculares diferentes o antagonistas) para un mayor aprovechamiento del tiempo de la sesión.

\begin{tabular}{|c|c|c|c|}
\hline VOLUMEN & INTENSIDAD & FRECUENCIA & MONITORIZACIÓN \\
\hline $\begin{array}{l}\text { Aumento de la intensidad con } \\
\text { respecto al volumen anterior } \\
\text { en repeticiones. } \\
\text { Cese del ejercicio antes de la } \\
\text { pérdida repetida de control } \\
\text { motor. Uso de } 2-3 \text { series, } 8 \text { - } \\
10 \text { ejercicios. }\end{array}$ & $\begin{array}{l}\text { Combinación entre el 60- } \\
\text { 75\% RM regulado por } \\
\text { RPE. Recuperación } \\
\text { autorregulada, descanso } \\
\text { completo }\end{array}$ & $\begin{array}{c}2 \text { días a la semana, sesiones } \\
\text { presenciales de alrededor de } \\
60 \mathrm{~min}\end{array}$ & $\begin{array}{l}\text { Pérdida de control motor } \\
\text { repetida más de } 2 \text { veces. } \\
\text { Percepción subjetiva del } \\
\text { esfuerzo, predominante RPE } \\
7 \text { sobre RPE } 6\end{array}$ \\
\hline
\end{tabular}




\section{Control motor en situaciones complejas y de doble tarea}

Abordando el objetivo de disminución del riesgo de caída, y como complemento al entrenamiento de fuerza e impacto, diseñaremos estímulos predominantemente unilaterales $y$ con perturbaciones, incertidumbre $y$ toma de decisiones. Esta variabilidad ayudará al sistema a anticiparse y reaccionar en situaciones reales ante una posible caída. Como hemos mencionado en el punto 5.3., los músculos diana serán los protagonistas durante el patrón de marcha, y la metodología a llevar a cabo para este tipo de tareas se basará en modificaciones en el sistema visual y vestibular, así como en estímulos kinestésicos y coordinativos que comprometan y saturen ligeramente al sistema. La pérdida de control motor repetida más de 2 veces seguidas será el criterio de cese del ejercicio.

Una vez superado este nivel, introduciremos además tareas cognitivas como operaciones matemáticas o reacción ante diversas señales visuales o auditivas para fomentar la toma de decisiones.

\section{Mejora de parámetros cardiovasculares: combinación con trabajo isométrico}

Acorde a la justificación de su utilidad y uso en el punto 5.4. en "Hipertensión", incorporaremos un trabajo específico isométrico en los descansos interserie de ciertos ejercicios para el mayor aprovechamiento del tiempo de sesión, a través de 3-4 series de alrededor de $\mathbf{2}$ minutos de trabajo al $30 \%$ de CVM. La herramienta de monitorización será una escala con puntuación de 3 sobre 10, siendo 10 "lo más fuerte que puedas apretar/empujar/tirar..." con variabilidad de actuación de grandes grupos musculares.

Recordemos, como mencionamos durante todo el punto 5.4, que la naturaleza que compone el síndrome metabólico es multifactorial, por lo que el entrenamiento de fuerza, continuo e interválico actúan tanto en la presión arterial como en el resto de factores de riesgo cardiovascular. Esta adaptación ya ha sido visible en la anterior fase, donde no hemos realizado específicamente un trabajo isométrico para la mejora de la tensión arterial, y aun así sus valores han disminuido notablemente. La opción más eficiente para la mejora de los parámetros cardiovasculares es la combinación de estos 4 tipos de trabajo, integrados durante todo el programa de intervención en el denominado entrenamiento multicomponente.

Por tanto, observando las adaptaciones de la anterior fase como criterio de progresión y manteniendo la misma metodología, los principios de entrenamiento metabólico continuo e interválico se desarrollarán un paso más de la siguiente manera:

\begin{tabular}{|c|c|c|c|c|}
\hline TIPO & VOLUMEN & INTENSIDAD & FRECUENCIA & MONITORIZACIÓN \\
\hline $\begin{array}{l}\text { Continuo (trabajo } \\
\text { no presencial) }\end{array}$ & $\begin{array}{l}\text { Intervalos progresivos hasta } \\
\text { completar } 45 \mathrm{~min}-1 \mathrm{~h} \text {, } \\
\text { predominando los de mayor } \\
\text { duración a mayor intensidad }\end{array}$ & $\begin{array}{l}\text { Alternancia y } \\
\text { progresión de } \\
\text { periodos al } 50-70 \% \\
\text { FC de reserva }\end{array}$ & 1 día a la semana & $\begin{array}{c}\text { FC a través de Xiaomi } \\
\text { Band } 4\end{array}$ \\
\hline TIPO & VOLUMEN & INTENSIDAD & FRECUENCIA & MONITORIZACIÓN \\
\hline $\begin{array}{c}\text { Introducción HIIT } \\
\text { con combinación } \\
\text { MIIT }\end{array}$ & $\begin{array}{c}4 \text { series de } 3-4 \text { ejercicios por } \\
\text { intervalos progresivos de } \\
\text { tiempo con ratio trabajo- } \\
\text { descanso. }\end{array}$ & $\begin{array}{l}\text { Alrededor de } 70 \% \\
\text { FC de reserva. } \\
\text { Descanso 1-3 } \\
\text { minutos según } \\
\text { intensidad. }\end{array}$ & $\begin{array}{l}2 \text { días a la semana, } \\
\text { incorporado en las } \\
\text { sesiones } \\
\text { presenciales }\end{array}$ & $\begin{array}{c}\text { FC a través de Xiaomi } \\
\text { Band } 4 \\
\text { RPE } 7 \text { con intervalos } \\
\text { puntuales en RPE } 6\end{array}$ \\
\hline
\end{tabular}

Tabla 28. Principios de entrenamiento de los contenidos de trabajo continuo e interválico en Fase 2 de desarrollo. 
Por tanto, destaca la progresión en volumen e intensidad del trabajo continuo, así como la predominancia de una mayor intensidad en el trabajo interválico con respecto a la Fase 1, a expensas de la respuesta individual a este desarrollo.

\section{Mejora de la salud ósea: impacto-interválico.}

Junto con la metodología del entrenamiento de fuerza anteriormente mencionada, el entrenamiento de impacto progresará en intensidad, acorde al aumento de las fuerzas de reacción en los estímulos detallados en la Tabla 19. La metodología aplicada en cuanto a la inclusión de este trabajo dentro de la sesión presencial se mantendrá del mismo modo que en la fase 1, dentro del entrenamiento interválico por la naturaleza intermitente de la respuesta osteogénica (consultar dentro 6.2.2. "Trabajo metabólico" "Interválico")

\section{Educación en hábitos no saludables e higiene del sueño.}

Una vez reducido el consumo de alcohol en diversas acciones puntuales, intentaremos establecerlo como hábito. A su vez, y previa sesión educativa en la que expongamos los riesgos del consumo de tabaco y su interferencia con los objetivos a alcanzar, trataremos de reducir su consumo. Para ello, estableceremos una serie de retos semanales en consenso. El contenido de cada sesión y las plantillas de retos pueden consultarse en su totalidad en [Anexo 7].

Con respecto a la higiene del sueño, seguiremos manteniendo las pautas establecidas durante la fase 1 (consultar punto 6.2.2. "Educación") por su simplicidad y efectividad, convirtiéndolas en un hábito. No obstante, si no se desarrollara la respuesta deseada, optaríamos por técnicas más avanzadas de relajación.

\section{Aplicación al entorno laboral para la mejora de la eficiencia}

Como hemos mencionado anteriormente durante los criterios de progresión en el entrenamiento de fuerza, la mayoría de estímulos irán orientados a la similitud con los diversos patrones de la vida laboral. Con respecto al raquis dorsal, durante la Fase 1 nos hemos limitado a mejorar su equilibrio, escogiendo estímulos que reviertan el exceso de cifosis para mejorar la mecánica de la escápula (predominantemente tracciones en multitud de vectores) junto a una diminución de la rigidez en cadena anterior durante el calentamiento, lo que ha dado como resultado una mejora en el rango de movimiento en flexión de hombro, tal y como observamos en la evaluación de final de fase 1.

Continuaremos con esta metodología, sin embargo, para potenciar esta mejora movilizaremos el raquis dorsal en rotación y extensión torácica, mecánicas clave para el correcto funcionamiento de la cintura escapular. La metodología será muy similar a la utilizada para el complejo lumbopélvico durante la fase 1, es decir, incorporada dentro del calentamiento y desarrollada durante la sesión a través de la progresión en tracciones.

Además, haremos uso de un sistema de vibración de unos $30 \mathrm{~Hz}$ junto a una isometría al 30\% CVM (Escala 3 sobre 10) en 3 x 45" y descanso de 15" acorde a los protocolos observados en la evidencia (a pesar de que la mayoría contienen una muestra con tren inferior o musculatura fina) (Pamukoff et al., 2014). Esta herramienta es capaz de provocar una mayor excitabilidad cortical que aumenta la predisposición al aprendizaje motor en la musculatura aplicada (steadiness) (Schabrun \& Chipchase, 2012). 
En este caso será aplicado en el vientre muscular de serrato y bíceps braquial, sinergistas durante la flexión de hombro, desde una posición de flexión de hombro a $90^{\circ}$ con ligera protracción, así como una flexión de codo, respectivamente.

\subsubsection{Secuenciación de contenidos.}

\begin{tabular}{|c|c|c|c|c|c|c|}
\hline \multicolumn{7}{|c|}{ JULIO } \\
\hline L & $\mathrm{M}$ & $X$ & & V & S & D \\
\hline & & 1 & 2 & 3 & 4 & 5 \\
\hline 6 & 7 & 8 & 9 & 10 & 11 & 12 \\
\hline 13 & 14 & 15 & 16 & 17 & 18 & 19 \\
\hline 20 & 21 & 22 & 23 & 24 & 25 & 26 \\
\hline 27 & 28 & 29 & 30 & 31 & $\begin{array}{r}1 \\
1\end{array}$ & 2 \\
\hline
\end{tabular}

Tabla 29. Secuenciación de sesiones del mes de julio. En Amarillo: sesiones presenciales de fuerza y MIIT-HIIT. En verde: sesiones no presenciales de trabajo continuo al aire libre. En azul: sesión educativa y establecimiento de retos semanales. En negro: evaluación final del progreso en la fase 2.

\begin{tabular}{|c|c|}
\hline FECHA & ESTIMULO DE ENTRENAMIENTO \\
\hline 06-jul & Introducción máxima intencionalidad de velocidad concéntrica (MIVC) desde básicos bilaterales. \\
\hline 09-jul & Introducción MIVC desde básicos unilaterales. \\
\hline $11-\mathrm{jul}$ & 1x5 min 50\% Vo2Máx, 1x 30min 60\% Vo2Máx, 1x5 min 50\% Vo2Máx, \\
\hline 13-jul & MIVC bilateral y multiplanar. Introducción isométrico interserie. Interválico metabólico- impacto. \\
\hline $16-j u l$ & Estimulación propioceptiva para evitar caída. Fuerza y mov hombro. Iso. MIVC. Interválico met-imp. \\
\hline $18-\mathrm{jul}$ & 1x5 min 50\% Vo2Máx, 1x 30min 60\% Vo2Máx, 1x5 min 50\% Vo2Máx, 1x5 min 70\% Vo2Máx, \\
\hline 20-jul & MIVC bilateral y unilateral multiplano. Isometrías. Interválico metabólico- impacto. \\
\hline 23-jun & Modificación por esfera emocional: Mayor componente lúdico y estímulos favoritos. \\
\hline 25-jul & 1x40 min 60\% Vo2Máx, 1x5 min 50\% Vo2Máx, 1x5 min 70\% Vo2Máx, 1x5 min 60 \% Vo2Máx \\
\hline 27-jul & MIVC y control glúteo medio. Fuerza y mov en rotación externa y flexión hombro. Interválico met-imp. \\
\hline 30- jul & MIVC e impacto integrados en entrenamiento de fuerza junto a patrones laborales. Interválico met-imp. \\
\hline $1-$ ago & 1x 50 min 60\%Vo2Máx, 1x5 min 70\% Vo2Máx, 1x 50 min 50 \% Vo2Máx \\
\hline
\end{tabular}

Tabla 30. Estímulos pertenecientes a cada sesión para la consecución de objetivos a través de cada contenido de entrenamiento, detallado anteriormente. En blanco: sesiones presenciales de entrenamiento de fuerza e interválico-impacto. En verde: sesiones autónomas de carácter aeróbico con objetivo cardiovascular

\subsubsection{Sesiones.}

A continuación, se presentan varias de las sesiones que reflejan los cambios en la progresión de la fase 2: uso de vibración para la mejora del aprendizaje motor en rotación y extensión torácica, flexión de hombro y movilidad escapular, entrenamiento de fuerza multiplanar y multivectorial con uso de máxima intencionalidad de velocidad concéntrica y aplicación laboral, introducción de mayor número de empujes en tren superior para la ganancia de movilidad y fuerza en flexión de hombro, progresión de patrones monopodales en carga y dificultad (doble tarea y retos cognitivos), modificación de la planificación por esfera emocional (Sistemas Dinámicos Complejos). 
13/07 SESIÓN 13: MIVC, isometrías interseries, control y respuesta en multiplano, interválico-impacto

\begin{tabular}{|c|c|c|}
\hline ESTÍMULO & OBJETIVO & METODOLOGÍA Y MODIFICACIONES \\
\hline Foam Roller & Autoliberación miofascial & $\begin{array}{c}15-20 \text { repeticiones cada grupo muscular con } \\
\text { cierta velocidad }\end{array}$ \\
\hline Estiramiento estático cadena posterior desde Lunge & $\begin{array}{l}\text { Reducción stiffness estático cadena } \\
\text { posterior para favorecer la dorsiflexión }\end{array}$ & $1 \mathrm{x} 10$ repeticiones 15 " con cada pierna \\
\hline Movilidad dinámica cadena posterior & $\begin{array}{c}\text { Favorecer la dorsiflexión aplicada al } \\
\text { movimiento }\end{array}$ & $1 \times 15$ repeticiones por cada pierna \\
\hline Rocking backwards & Control LP, evitando síndrome de flexión & Foco externo pelota raquis lumbar \\
\hline Extensión torácica en foam & \multirow{2}{*}{$\begin{array}{l}\text { Mejora de la movilidad escapular para } \\
\text { favorecer un correcto equilibrio en raquis } \\
\text { dorsal y ROM en flexión de hombro }\end{array}$} & \multirow[b]{2}{*}{$1 \mathrm{x} 15$ repeticiones } \\
\hline Rotación torácica desde zancada & & \\
\hline Wall slide supino & $\begin{array}{l}\text { Inhibición recíproca de cadena anterior } \\
\text { aplicada al ritmo escapular }\end{array}$ & 1x 15 repeticiones \\
\hline
\end{tabular}

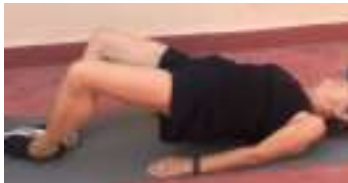

Frog bridge
MIVC en actividad de glúteo medio

2x hasta RPE 6

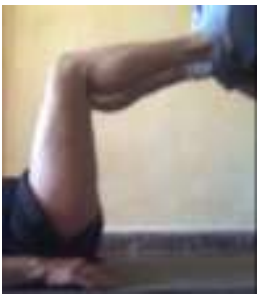

Disminución TAS/TAD

$2 \times 2$ ' al 30\% CVM (3/10), en descanso entre series del ejercicio anterior para un mayor aprovechamiento del tiempo de sesión

Isometría extensión de cadera

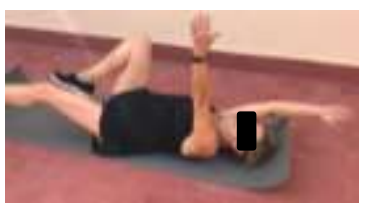

Bicho muerto completo
Control del complejo coxolumbopélvico ante demanda de antiextensión, alcanzando el patrón completo del ejercicio por primera vez.
3 x hasta RPE 6
Disminución TAS/TAD

Isometría prensión manua
$2 \times 2$ ' al 30\% CVM (3/10) en descanso entre series del ejercicio anterior para un mayor aprovechamiento del tiempo

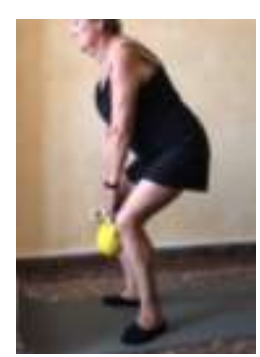

MIVC en patrón dominante de rodilla,

afianzado con una mayor carga.

Mejora de fuerza para patrón de carga

3x hasta RPE 7

laboral.

Sentadilla MIVC kettlebell 


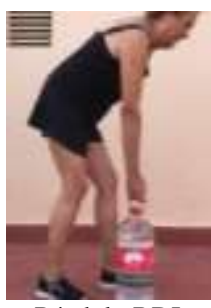

Trasmisión de fuerzas a través de la línea fascial posterior superficial para la mejora de la dorsiflexión y capacidad de la cadena posterior, junto con integración en patrón dominante de cadera unilateral.
2 con cada pierna $\mathrm{x}$ hasta pérdida de control motor repetida más de 2 veces
Capacidad de generar fuerzas en varios planos y vectores

Mejora de la respuesta del sistema ante privación visual y diferencia entre órdenes visuales y auditivas. 3x hasta RPE 7

Perturbación con variante de ojos cerrados o cambio de señal auditiva

Zancada multiplano ante orden (variedad de vectores)

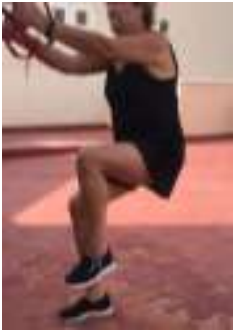

Control de la cadena cruzada posterior en demanda de inestabilidad. Potenciación del sistema en situaciones más complicadas a

la realidad (posible caída), tras fatiga al final de la sesión acorde a estados comunes de la vida diaria
$2 \mathrm{x}$ hasta pérdida de control motor repetida más de 2 veces

Remo-squat progresado a apoyo monopodal

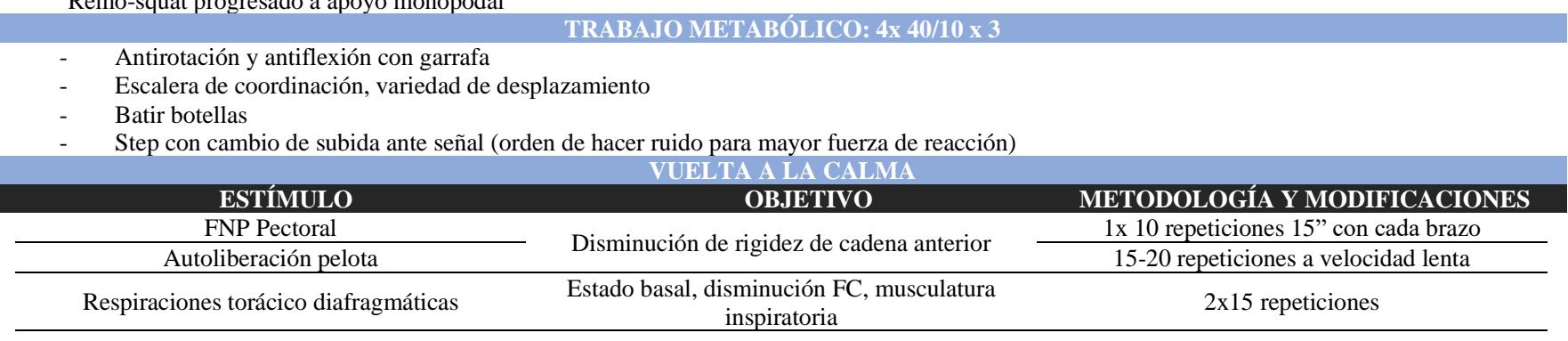

16/07 SESIÓN 15: Estimulación neuromuscular y propioceptiva para evitar caídas, fuerza y movilidad de hombro, iso interseries, MIVC

\section{ESTÍMULO}

Liberación miofascial rodillo y pelota

\begin{tabular}{r}
\hline Carrera externa cadena posteri \\
\hline Rocking backwards \\
\hline Estiramiento estático cadena posterior d \\
\hline Movilidad dinámica cadena post \\
\hline Vibración serrato y bíceps braqu \\
ESTÍMULO \\
\end{tabular}

Propiocepción en cuerda

\section{OB JETIVO}

Autoliberación miofascial

Cambio de foam por molestias

Disminución de rigidez en cadena posterior

Control LP previo a la sesión

Reducción stiffness estático cadena posterior para favorecer la dorsiflexión

Favorecer la dorsiflexión aplicada al movimiento

Activación sinergias en flexión de hombro

\section{PARTE PRINCIPAL} OBJETIVO

\section{METODOLOGÍA Y MODIFICACIONES}

15-20 repeticiones cada grupo muscular con cierta velocidad

$1 \times 10$ repeticiones cada pierna Foco externo pelota raquis lumbar

$1 \mathrm{x} 10$ repeticiones 20 " con cada pierna

$1 \mathrm{x} 15$ repeticiones por cada pierna

$3 \times 45$ " trabajo/15" descanso alterno entre brazos METODOLOGÍA Y MODIFICACIONES
Estimulación de receptores propioceptivos desde el pie.

Desafío neuromuscular para el sistema ante disminución de la base de sustentación y desplazamientos poco comunes.
2 ida y vuelta al circuito 


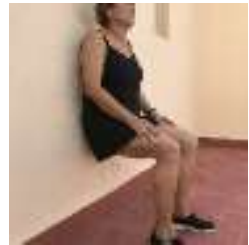

Disminución TAS/TAD

$2 \times 2$ ' al 30\% CVM (3/10) en descanso entre series del ejercicio anterior para un mayor aprovechamiento del tiempo.

Sentadilla isométrica

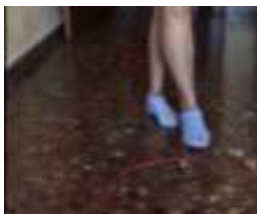

Estimulación de receptores propioceptivos desde el pie con privación visual, alterando la respuesta emergente

Desafío neuromuscular para el sistema ante

2 ida y vuelta al circuito disminución de la base de sustentación y

desplazamientos poco comunes

Propiocepción en cuerda con ojos cerrados

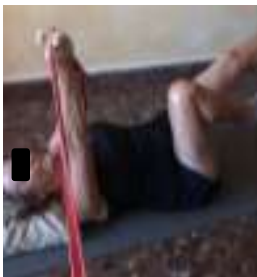

Control abdominal ante demanda

antiextension y antirotación

$2 x$ hasta RPE 6-7

Dead bug antirotación

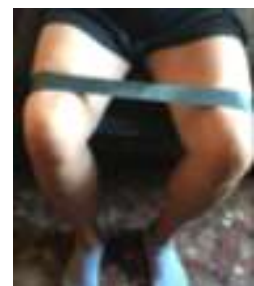

Serie de activación de glúteo medio previa al siguiente ejercicio

1x hasta RPE 7

Abducción de cadera con miniban

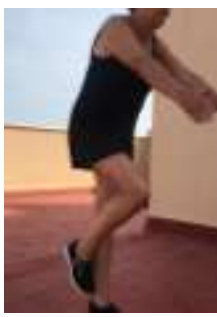

Respuesta del sistema ante la desestabilización provocada por el movimiento en flexión de hombro, generando un desplazamiento del CG
2 con cada pierna $\mathrm{x}$ pérdida de control motor repetida más de 2 veces

RDL con perturbación del CG

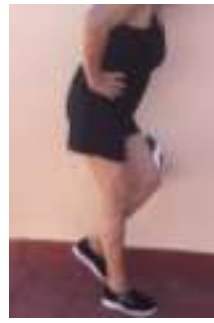

Fuerza y control glúteo medio.

Estimulación en mayor medida de fibras tipo II durante la extensión de cadera

2x hasta RPE 7 unilateral

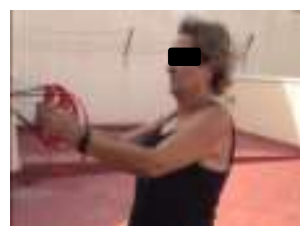

Énfasis en control de fase excéntrica de la cintura escapular y CORE 


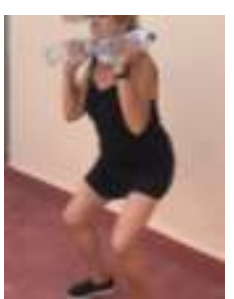

Mejora de los niveles de fuerza resistencia

en tren inferior junto a patrón de empuje

vertical necesario para los patrones

2x hasta RPE 6

overhead durante la jornada labora

Biserie, ejercicio 2: Sentadilla thruster MIVC

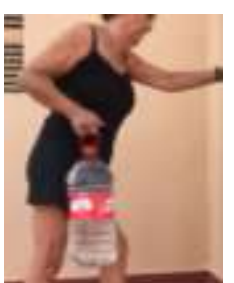

Variabilidad de vector en patrón de tracción

unilateral para la mejora del equilibrio en raquis dorsal

2x hasta RPE 6

Biserie, ejercicio 1: Remo inclinado unilateral

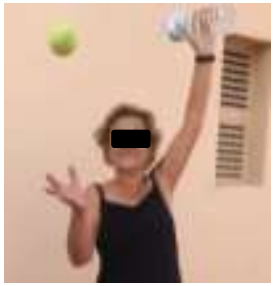

Mejora de la fuerza resistencia en patrón de empuje/flexión de hombro (muy repetido durante el trabajo) a través de juego
$2 \times$ hasta un tercio de pérdida de rango en flexión de hombro como consecuencia de la fatiga

Biserie, ejercicio 2: flexión de hombro mantenida con carga y foco externo

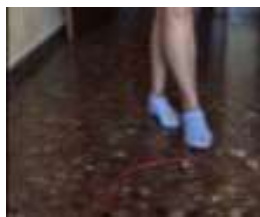

Coordinación cuerda ojos cerrados
Estimulación de receptores propioceptivos desde el pie con privación visual, alterando la respuesta emergente.

Desafío neuromuscular para el sistema ante $\quad 1 x$ ida y vuelta al circuito

disminución de la base de sustentación y desplazamientos poco comunes.

Simulación de condiciones de fatiga tras todo el desarrollo de la sesión.

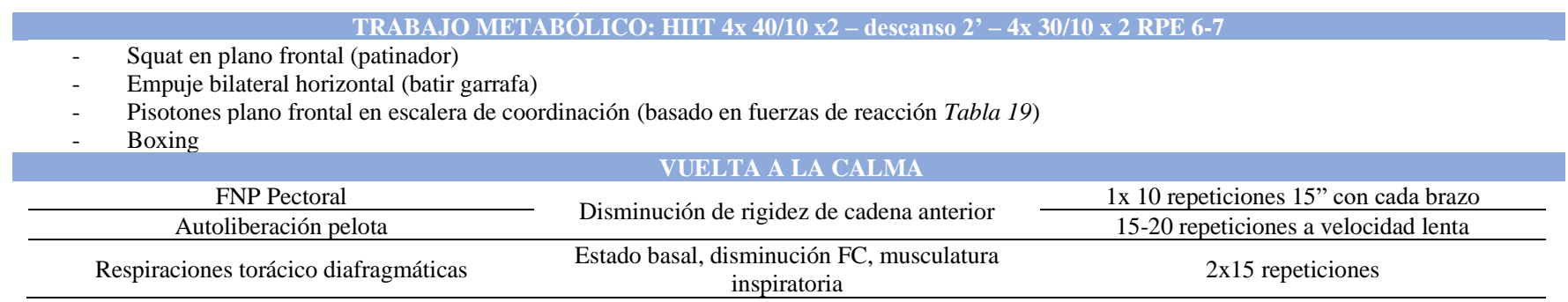

23/07 SESIÓN 16: Sistemas dinámicos complejos, modificación por esfera emocional: estímulos favoritos y predominancia de componente lúdico.

\section{ESTÍMULO}

Liberación miofascial rodillo y pelota

Extensión torácica en foam

Rotación torácica desde zancada

Wall slide supino

\section{OB.}

Autoliberación miofascial

Cambio de foam por molestias

Mejora de la movilidad escapular para

favorecer un correcto equilibrio en raquis

dorsal y ROM en flexión de hombro

Inhibición recíproca de cadena anterior aplicada al ritmo escapula
METODOLOGÍA Y MODIFICACIONES

15-20 repeticiones cada grupo muscular con cierta velocidad

$1 \mathrm{x} 15$ repeticiones

$1 \mathrm{x} 15$ repeticiones 


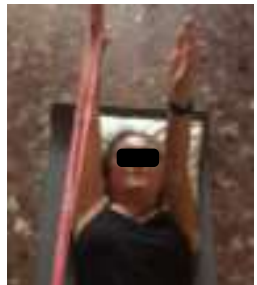

Activación abdominal ante demanda antiextensión de tronco

Isometría en máximo rango de flexión de

3x hasta RPE 6 hombro

Bicho muerto con isometría en flexión de hombro

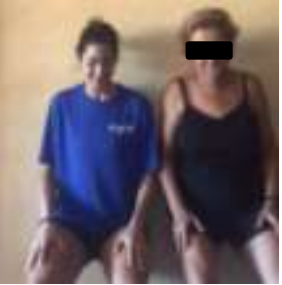

Disminución TAS/TAD

Componente lúdico ante ejercicio analítico
$2 \times 2$ ' al 30\% CVM (3/10) en descanso entre series del ejercicio anterior para un mayor aprovechamiento del tiempo

Guerra en pareja sentadilla isométrica

Mejora de movilidad y ritmo escapular.

Aumento de los niveles de fuerza en cintura

$$
\text { escapular. }
$$

Mejora del equilibrio en raquis dorsal,

revirtiendo postura cifótica

3x hasta RPE 6

Introducción del ejercicio en la

planificación por preferencia personal,

siente que le alivia las molestias en raquis dorsal.

Remo vertical goma

Mejora de la movilidad y fuerza en rotación externa y extensión torácica

2x hasta RPE 6

Mejora de fuerza y control escapular unilateral

Control antirotación de CORE ante perturbaciones en pareja

3x hasta RPE 6

Componente lúdico en un ejercicio analítico

Guerra remo horizontal goma en pareja

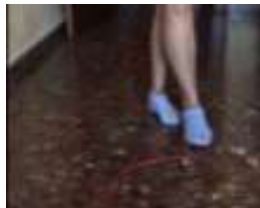

Coordinación cuerda con foco externo pelota y doble tarea cognitiva

\section{TRABAJO MITABÓLICO: HIIIT 3x 40/10 x2 - descanso 2' - 3x 30/10 x 2 RPE 6}

\begin{tabular}{|c|c|c|}
\hline $\begin{array}{ll}\text { - } & \text { Step foco externo pelota } \\
\text { - } & \text { Lanzamiento antirotación } \\
- & \text { Boxing }\end{array}$ & & \\
\hline & VUELTA A LA CALMA & \\
\hline $\begin{array}{c}\text { FNP Pectoral } \\
\text { Autoliberación pelota }\end{array}$ & Disminución de rigidez de cadena anterior & $\frac{1 \times 10 \text { repeticiones } 15 \text { " con cada brazo }}{15-20 \text { repeticiones a velocidad lenta }}$ \\
\hline Respiraciones torácico diafragmáticas & $\begin{array}{c}\text { Estado basal, disminución FC, musculatura } \\
\text { inspiratoria }\end{array}$ & $2 \times 15$ repeticiones \\
\hline
\end{tabular}


27/07 SESIÓN 17: MIVC, control glúteo medio, fuerza y movilidad hombro, metabólico-impacto

CALENTIMULO OBJETIVO
OBIO

Liberación miofascial rodillo y pelota

Wall slide supino

ESTÍMULO

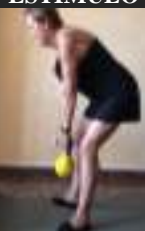

Peso muerto MIVC kettlebell

laboral integrado monopodal
METODOLOGÍA Y MODIFICACIONES

15-20 repeticiones cada grupo muscular con cierta

Autoliberación miofascial velocidad

Inhibición recíproca de cadena anterior aplicada
al ritmo escapular

PARTE PRINCIPAL OBJETIVO

MIVC en patrón dominante de cadera, patrón

Activación precia al siguiente ejercicio

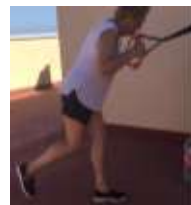

MIVC en patrón dominante de rodilla, afianzado

$$
\text { con una mayor carga. }
$$

4x hasta RPE 7

Mejora de fuerza para patrón de carga laboral.

RDL monopodal MIVC

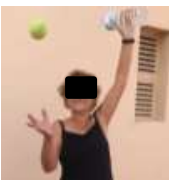

Mejora de la fuerza resistencia en patrón de empuje/flexión de hombro (muy repetido durante el trabajo) a través de juego

4x hasta RPE 7

Flexión de hombro mantenida con foco externo

\section{TRABAJO MIETABÓLICO: HIIT 3x 40/10 x2 - descanso 2' - 3x 30/10 x 2 RPE 6}

Elevación de talones + excéntrico (impacto acorde a Tabla 29)

Batir botellas

Skipping en el sitio ( impacto acorde a Tabla 19)

VUELTA A LA CALMA

Respiraciones torácico diafragmáticas

Estado basal, disminución FC, musculatura inspiratoria

$2 \times 12$ repeticiones

30/07 SESIÓN 18: MIVC, patrones laborales integrados, metabólico-impacto CALENTAMIENTO

\section{OBJETIVO}

Autoliberación miofascial

Cambio de foam por molestias

Inhibición recíproca de cadena anterior aplicada

al ritmo escapular

PARTE PRINCIPAL OBJETIVO

MIVC en patrón dominante de cadera junto a empuje bilateral
METODOLOGÍA Y MODIFICACIONES

15-20 repeticiones cada grupo muscular con cierta velocidad

$1 \mathrm{x} 15$ repeticiones
ESTIMULO

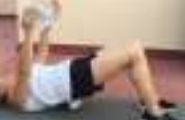

Bridge con empuje
MIVC en patrón dominante de rodilla, afianzado

$$
\text { con una mayor carga. }
$$

Mejora de fuerza para patrón de carga laboral. 4x hasta RPE 7

Sentadilla MIVC ketllebell

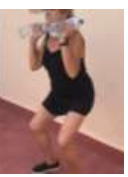

MIVC en patrón dominante de rodilla + empuje bilateral

4x hasta RPE 7

Sentadilla MIVC Thruster

Elevación de talones + excéntrico (impacto acorde a Tabla 29)

Batir botellas

Skipping en el sitio ( impacto acorde a Tabla 19) 


\subsubsection{Control y monitorización del entrenamiento.}

La escala RPE (Tabla 25) se seguirá usando con la misma metodología que en la anterior fase (consultar 6.2.5) durante el entrenamiento de fuerza, si bien el progreso en esta fase nos hace mantener una intensidad de RPE 7 en mayor medida que en la fase 1. La propia progresión en carga en kg y en términos de volumen también nos permite observar un cumplimiento de la progresión establecida, para ello nos ayudaremos además de la PRS registrada al inicio de la sesión y el cálculo de la carga interna en UA [Anexo 8]

Para el entrenamiento aeróbico continuo e interválico usaremos los datos de \% de intensidad de FC de reserva deseados, monitorizados en vivo a través de Xiaomi Band 4, moviéndonos en este caso en torno a $\mathbf{1 2 5 - 1 4 0 ~ l p m ~ s e g u ́ n ~ l a ~ e l e c c i o ́ n ~ d e ~ l o s ~ i n t e r v a l o s ~}$ de intensidad moderada o vigorosa entre el 50-70\% Vo2Máx detallados en la Tabla 28. Con respecto a la fase anterior, predominarán los de mayor intensidad, en concreto alcanzados durante el entrenamiento interválico (intervalos de trabajo más largos con menor descanso, o intervalos cortos más intensos), debido a que durante el entrenamiento aeróbico continuo no se llega a trotar y existe fatiga local en tren inferior que dificulta llegar a una intensidad mayor.

\subsubsection{Evaluación del progreso.}

\section{Integración de patrones laborales y disminución de fatiga.}

El diseño de los estímulos similares a los patrones realizados de manera repetitiva y prolongada durante la jornada laboral, tenía como objetivo principal en esta fase disminuir la sensación de fatiga tras la misma, al mejorar los niveles de fuerza y eficiencia en los mismos. De esta manera, observamos el valor de PRS de la sesión (Escala de Percepción del Estado de Recuperación) en la planilla recogida en [Anexo 8], en la que obtenemos un promedio de 4'8 en la fase $\mathbf{2}$ con respecto al valor de 5'5 en la fase 1 (Figura 33, en la derecha)

Figura 33. Comparación del promedio de la PRS inicial de la sesión entre Fase 1 y 2. Observamos la disminución de la sensación de cansancio y predisposición inicial)

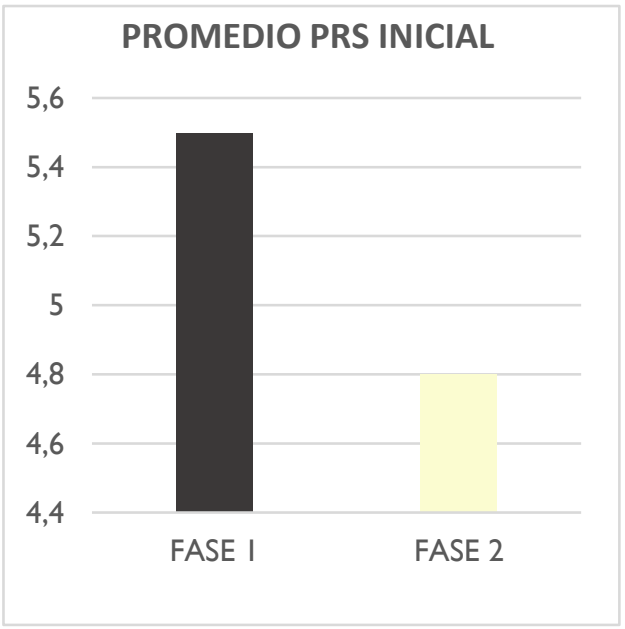

De igual modo, la calidad de sueño medida a través de Xiaomi Band se mantiene estable con respecto a la fase inicial y la fase 1 , con una media de 85 puntos con respecto a la ya mejorada puntuación de 84 en la fase 1 . 
Con el objetivo de evaluar el progreso en la capacidad neuromuscular y respuesta del sistema ante una posible caída, y teniendo presente las limitaciones por la complejidad de esta medida, volvemos a realizar el $Y$ Balance Test (que recordemos se relaciona con fuerza de cadera y parámetros funcionales como la velocidad de marcha) en el que observamos una mejoría en el rendimiento de alcance de todas las distancias (Figura 34).

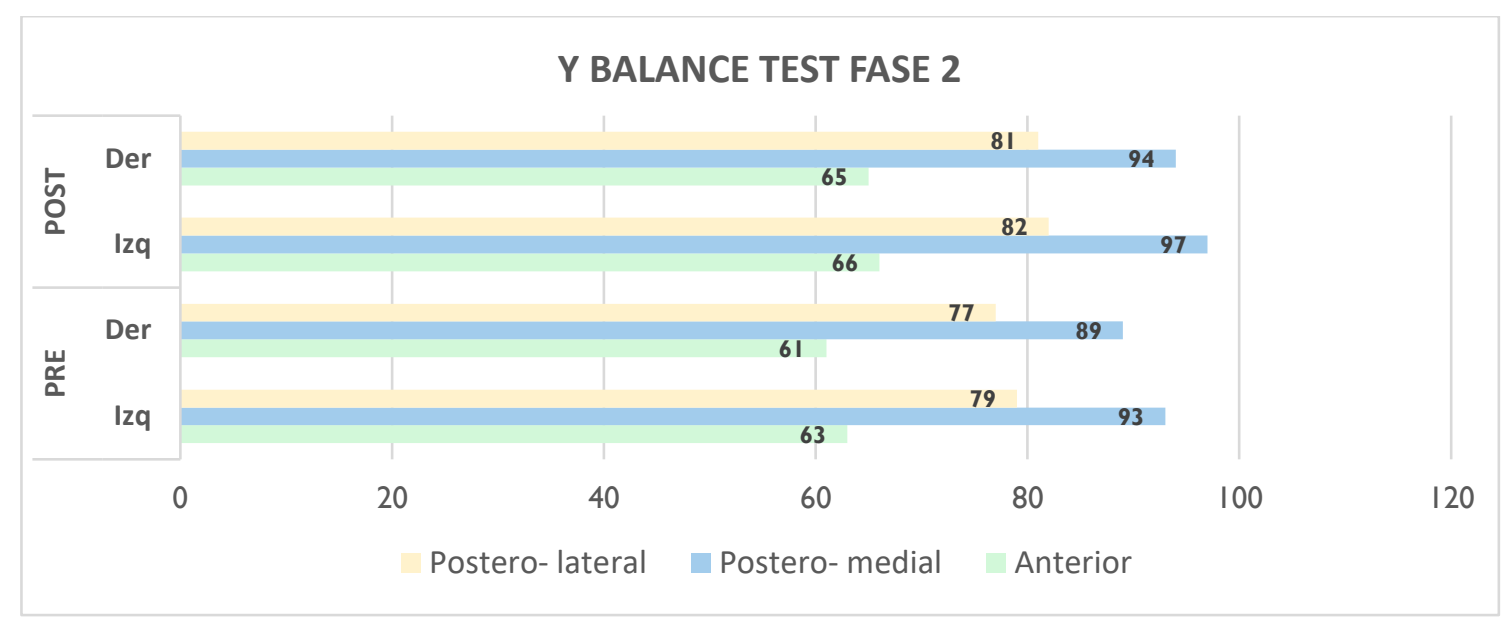

Figura 34. Comparación de resultados pre test y post fase 2 en la capacidad neuromuscular de cada extremidad.

Disminución de parámetros de riesgo cardiovascular

Ante la imposibilidad de medir a través de analítica todos los parámetros establecidos en los objetivos relacionados con el síndrome metabólico, continuamos observando el promedio entre fases de los valores de TAS/TAD tras el trabajo isométrico específico para su reducción, observando de nuevo claras mejorías entre la fase 1 y la fase 2 (Figura 35) con 121/73 $\mathbf{~ m m H g . ~}$

Figura 35, en la derecha. Comparación de los niveles de presión arterial entre fases del programa de intervención.

\section{Reducción de los hábitos no saludables}

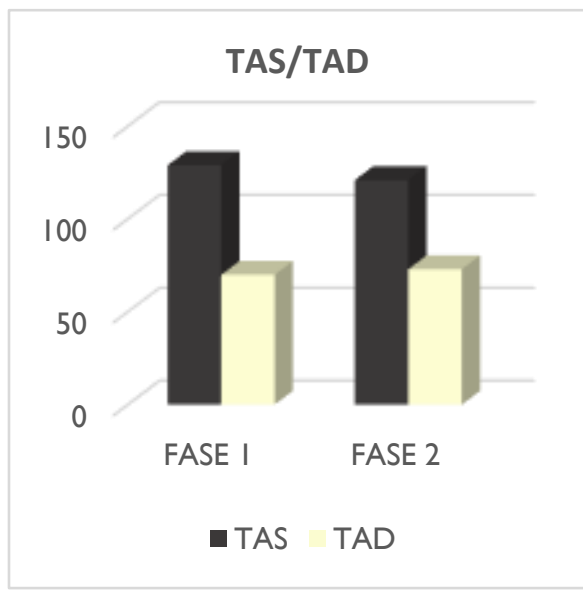

El cumplimiento de los retos semanales [Anexo 7] refleja un establecimiento de los hábitos relacionados con la disminución del consumo diario de alcohol. Además, hay un ligero descenso del consumo de tabaco, observando como este constituye una dificultad mucho mayor para nuestra alumna.

\section{Mejora del rango de movimiento en flexión de hombro}

Tras el trabajo y herramientas específicas para la mejora de rango de movimiento en flexión de hombro y fuerza en empuje (especialmente vertical), acorde a los patrones realizados durante la jornada laboral, observamos la ganancia de hasta $5^{\circ}$ de angulación en la fase 2 con respecto a la fase 1 (Figura 36), constituyendo $\mathbf{8}^{\mathbf{0}}$ de mejora comparándolo con la evaluación inicial. 
La diferencia entre derecha e izquierda en esta fase no constituye un riesgo por asimetría, y probablemente se deba a la elevación de su hombro izquierdo acorde a su escoliosis observada durante la evaluación inicial, así como a la dominancia de su brazo derecho con respecto al izquierdo (diestra).

Figura 36. Comparación del rango de movimiento medido en ${ }^{\circ}$ entre fases, con $170^{\circ}$ en fase 1 y $172^{\circ}$ izq $/ 175^{\circ}$ derecha.

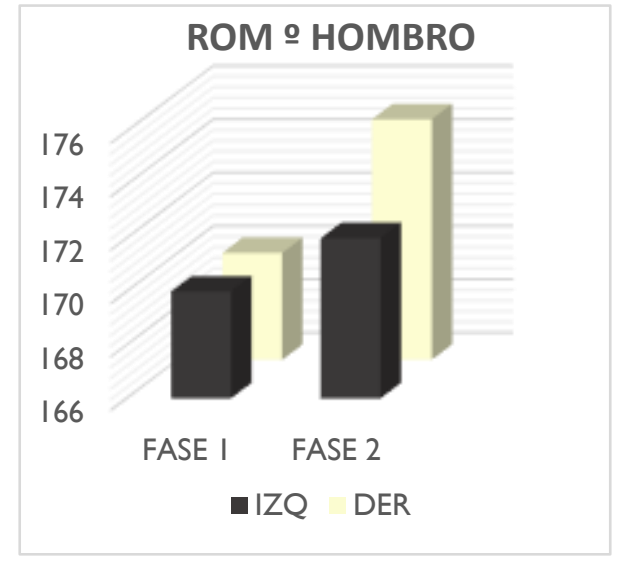

\section{Control sobre sarcopenia y dinapenia}

Como método de control de los objetivos relacionados con la ganancia de masa muscular y fuerza como papel protector, así como para la modificación de la carga para la última fase, volvemos a realizar la dinamometría. De igual modo, debemos tener en cuenta que la propia progresión en carga-volumen-intensidad monitorizada a través de RPE durante y tras la sesión [Anexo 8], nos informa de una adaptación y progreso de nuestra alumna

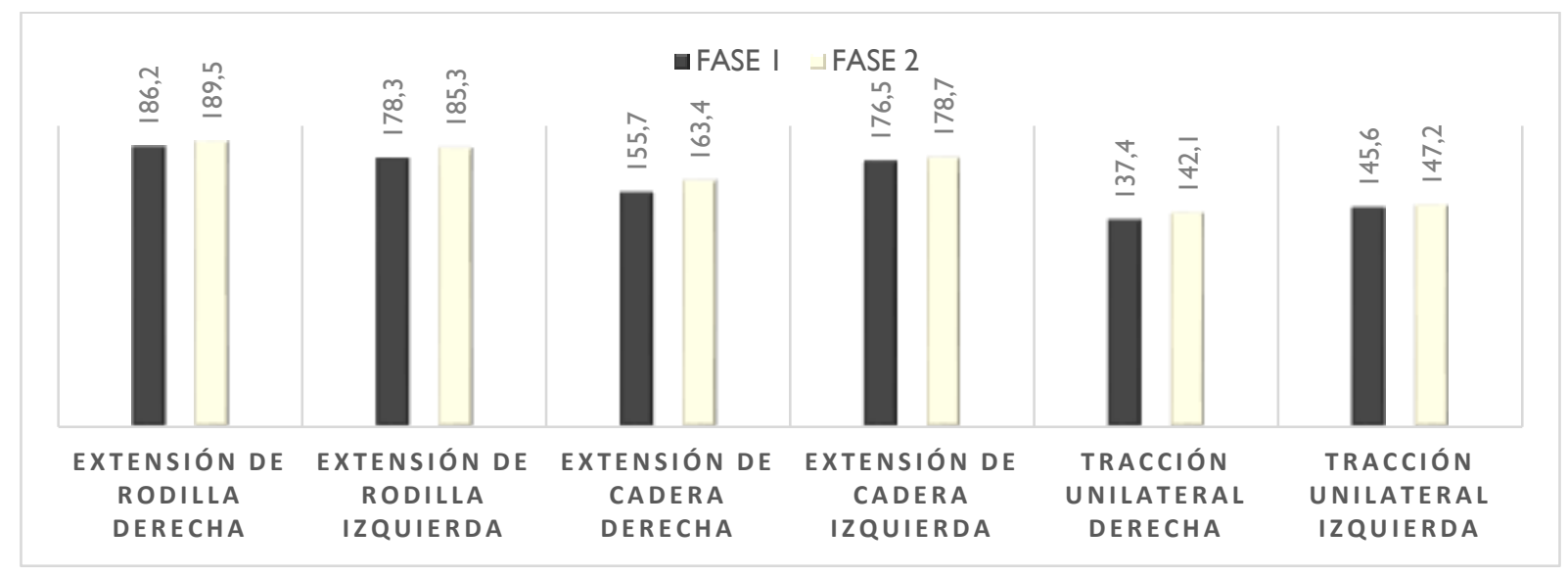

Figura 37. Comparación de los valores de dinamometría en ambas extremidades entre fase 1 y fase 2.

\subsection{Fase 3 del programa de intervención: potenciación y autonomía.}

La última fase de intervención mantendrá en gran medida el desarrollo de los objetivos y el progreso en la metodología llevada a cabo durante las anteriores fases, especialmente la 2 , debido a la necesidad de una prolongación de diversos principios de entrenamiento que permitan obtener una mayor experiencia a nuestra alumna (pues recordemos, es su primer contacto con el ejercicio físico).

Con respecto a esto último, uno de los principales fines de este programa es conseguir una adherencia al ejercicio junto a un estilo de vida activo y saludable, para lo que es necesario que las acciones "puntuales" que hemos llevado a cabo se conviertan en hábitos con una motivación intrínseca extra. Por ello, durante esta fase trataremos de potenciar la autonomía de nuestra alumna, que será necesaria una vez finalice el programa de intervención, a través de una mayor flexibilidad y responsabilidad durante las sesiones de entrenamiento. 
Además, aprovecharemos esta metodología para desarrollar el modo de entrenamiento online tan en auge por la situación de pandemia, con la posibilidad de que sea una herramienta más a largo plazo a la que nuestra alumna pueda acudir cuando sea necesario, con el fin de mantener este estilo de vida. Junto a ello se asentará la reducción del consumo de tabaco con el objetivo de poder prescindir de el mismo en un futuro.

\subsubsection{Objetivos específicos y contenidos de entrenamiento.}

\begin{tabular}{|c|c|c|}
\hline OBJETIVOS GENERALES & OBJETIVOS ESPECIFICOS & CONTENIDOS DE ENTRENAMIENTO \\
\hline $\begin{array}{c}\text { Evitar el agrave de la sarcopenia y } \\
\text { la dinapenia }\end{array}$ & $\begin{array}{l}\text { Potenciar los niveles de masa muscular y } \\
\text { fuerza como papel protector. }\end{array}$ & $\begin{array}{l}\text { Progresión en el entrenamiento de fuerza } \\
\text { y máxima velocidad intencional concéntrica }\end{array}$ \\
\hline Disminuir el riesgo de fractura & $\begin{array}{c}\text { Mejorar la capacidad del sistema para } \\
\text { evitar caídas. }\end{array}$ & $\begin{array}{l}\text { Progresión y combinación de entrenamiento de } \\
\text { fuerza y situaciones complejas a nivel motor, } \\
\text { cognitivo y coordinativo }\end{array}$ \\
\hline Mejorar la salud ósea & $\begin{array}{c}\text { Aumentar la puntuación } T \text { Score en } \\
\text { cuello del fémur y columna lumbar } \\
\text { Mejorar la calidad de la microestructura } \\
\text { ósea }\end{array}$ & $\begin{array}{c}\text { Progresión en el entrenamiento de impacto } \\
\text { Progresión en el entrenamiento de fuerza e } \\
\text { intencionalidad de máxima velocidad } \\
\text { concéntrica }\end{array}$ \\
\hline $\begin{array}{c}\text { Reducir los niveles de grasa } \\
\text { visceral }\end{array}$ & Disminuir el perímetro de cintura & Entrenamiento de fuerza y HIIT \\
\hline $\begin{array}{l}\text { Disminuir las posibilidades de } \\
\text { desarrollo de síndrome metabólico }\end{array}$ & $\begin{array}{l}\text { Reducir los niveles de glucosa en sangre. } \\
\text { Mejorar los valores de dislipidemia. } \\
\text { Mantener en valores normativos tensión } \\
\text { arterial sistólica y diastólica. }\end{array}$ & $\begin{array}{l}\text { Continuo e Interválico } \\
\text { Entrenamiento de Fuerza } \\
\text { Trabajo isométrico }\end{array}$ \\
\hline Limitar los hábitos no saludables & Intentar reducir el consumo de tabaco & $\begin{array}{l}\text { Sesiones educativas } \\
\text { Retos }\end{array}$ \\
\hline $\begin{array}{l}\text { OBJETIVOS SECUNDARIOS } \\
\text { (TRANSVERSAL) }\end{array}$ & OBJETIVOS ESPECIFICOS & CONTENIDOS DE ENTRENAMIENTO \\
\hline $\begin{array}{c}\text { Mejorar el equilibrio en raquis } \\
\text { dorsal }\end{array}$ & $\begin{array}{c}\text { Corregir exceso de cifosis } \\
\text { Aumentar la funcionalidad en flexión de } \\
\text { hombro }\end{array}$ & $\begin{array}{c}\text { Mejora de la fuerza en nuevos rangos a través } \\
\text { de la isometría } \\
\text { Uso de vibración }\end{array}$ \\
\hline $\begin{array}{l}\text { Perfeccionar la mecánica de pie- } \\
\text { tobillo }\end{array}$ & $\begin{array}{l}\text { Favorecer la mecánica del flexor del } \\
\text { dedo gordo } \\
\text { Aumentar el ángulo de dorsiflexión. } \\
\text { Disminuir la limitación de gemelo y } \\
\text { soleo. }\end{array}$ & $\begin{array}{l}\text { Tarea semanal: liberación fascial, flexión y } \\
\text { abducción asistida del dedo gordo. } \\
\text { Calentamiento: autoliberación miofascial, }\end{array}$ \\
\hline $\begin{array}{l}\text { Restablecer el control } \\
\text { lumbopélvico }\end{array}$ & $\begin{array}{c}\text { Reducir la rigidez isquiosural y síndrome } \\
\text { de flexión. }\end{array}$ & dinámica integrada \\
\hline
\end{tabular}

Tabla 31. Objetivos generales y específicos detallados en el apartado $n^{\circ} 4$ y su relación con los contenidos de entrenamiento de la fase 3 de potenciación y autonomía

Como observamos en la Tabla 31, los contenidos continúan bajo un principio de progresión, con el fin de alcanzar los objetivos planteados al inicio del programa, que deberán mantenerse en un futuro teniendo en cuenta la casuística de nuestra alumna.

Sin embargo, destacamos en esta fase el tratamiento del objetivo de reducción de los niveles de grasa visceral y su relación con el perímetro de cintura, ya justificado durante la evaluación inicial como factor de riesgo cardiovascular. Su inclusión dentro de las anteriores fases no ha aparecido hasta ahora para evitar la búsqueda de un fin estético, más propenso a desembocar en abandono por un foco de motivación extrínseco más allá de la mejora de salud, así como por una ausencia de resultados inmediatos. Además, durante la entrevista inicial no constituía uno de los objetivos principales de nuestra alumna, ni se encontraba dentro de los valores considerados como obesidad abdominal (aunque si con valores mejorables). 
Los resultados estéticos llegarán como consecuencia del conjunto de acciones y planes llevados a cabo, sin necesidad de abordarlo como objetivo principal, el resultado se verá reflejado en la bioimpedancia. Por último, desde el punto de vista de herramientas de entrenamiento, tal y como hemos mencionado en la justificación (consultar punto 5.4. "Grasa visceral") el entrenamiento más óptimo y eficaz para abordar este objetivo es la combinación de fuerza y entrenamiento interválico de alta intensidad, para lo que es necesario un progreso a través de la moderada intensidad (MIIT) trabajada durante las anteriores fases para poder abordar un HIIT de manera segura en esta última.

\subsubsection{Metodología.}

\section{Desarrollo de la Optimal Theory: un paso hacia la autonomía.}

El proceso de autonomía se desarrollará a través del entrenamiento online 1 día a la semana, cuyo proceso no difiere apenas de la otra sesión semanal presencial. Para ello, utilizaremos la herramienta de Google Meet, desarrollando las sesiones bajo estímulos ya controlados por nuestra alumna y sus preferencias, potenciando así la confianza en ella misma a través de las experiencias exitosas de movimiento.

Durante las sesiones online será esencial mantener un feedback y un lenguaje breve y de calidad que no sature al sistema, a través de una feedback de resultado (efecto/objetivo deseado a través del movimiento) más que de rendimiento, así como una retroalimentación siempre en positivo (dando menor peso a las ejecuciones negativas).

En relación a esto, la denominada Optimal Theory (Wulf \& Lewthwaite, 2016), 1leva plasmándose durante todo el trabajo, inclusive dentro de los objetivos que fomentan la autoeficacia en el desempeño físico y social, así como dentro de las sesiones (elección según preferencias, lenguaje, feedback, foco externo...). Sin embargo, se va a desarrollar en mayor medida durante esta fase 3 , cuando nuestra alumna tiene un cierto bagaje motor, experiencia y concienciación sobre la importancia del ejercicio, tras observar multitud de mejoras en su estado de salud. Otra ventaja de darle mayor peso ahora en lugar de en las anteriores fases, radica en haber usado diversos focos, lenguaje, instrucciones o diseños que permiten conocer ahora el más óptimo para la situación personal y única de nuestra alumna. A pesar de que en la teoría el uso de este sistema favorece el aprendizaje, recordemos que, debido a la heterogeneidad de las muestras, estas respuestas no siempre se corresponden con la realidad personal.

La metodología de una sesión a distancia con mayor autonomía nos permite potenciar y asentar una base de motivación que permita prolongar y adherirse a los hábitos, pues tras la finalización del programa deberá de llevarse a cabo una necesidad de desempeño independiente y autosuficiente que dependerá de estas experiencias previas. A nivel fisiológico, las vías dopaminérgicas se desencadenan a través de los sistemas de recompensa generados por el apoyo a la autonomía, confianza y motivación (Schultz, 2013), fomentando una autoeficacia al alcanzar una experiencia positiva. De esta manera, la dopamina disponible desarrolla un ambiente de predisposición neural para la memoria y el aprendizaje motor. 


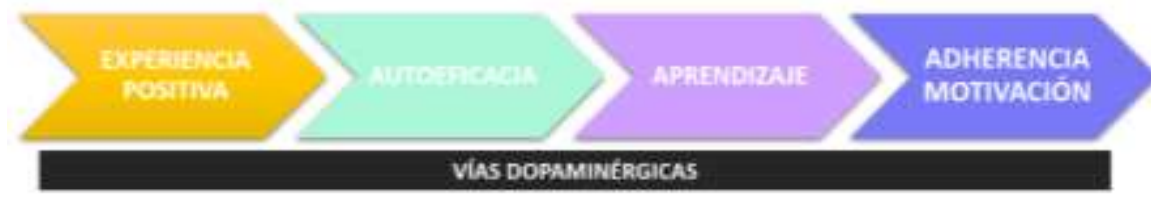

Figura 38. Modelo de aprendizaje basado en Optimal Theory (Wulf \& Lewthwaite, 2016)

Teniendo en cuenta esta metodología, se exponen a continuación los principios de entrenamiento que progresan ligeramente en volumen y/o intensidad en esta fase. Cabe destacar que los contenidos de alto impacto (progresando en fuerzas de reacción basadas en Tabla 19), MIVC, anticipación del sistema (mayor dificultad por menor base de sustentación, perturbaciones, doble tarea y componente cognitivo...), trabajo isométrico y hábitos saludables (reducción del consumo de tabaco) mantienen la misma metodología anteriormente expuesta (consultar 6.2.2 y 6.3.2).

\section{Entrenamiento de fuerza}

Realizaremos pequeños ajustes en la intensidad, predominando aquellas intensidades elevadas en torno a 70-85\% RM por encima de las de 60\% RM. Mantendremos cierta intensidad moderada ante la imposibilidad de usar únicamente altas intensidades con altas carga, debido a la poca experiencia de nuestra alumna y la falta de material. Sera necesario trabajar durante varios meses más con altas cargas para poder ir un paso más allá. Aun así, nos encontramos dentro la horquilla mínima de intensidad de trabajo efectivo para los diversos objetivos de salud ósea, muscular y metabólica (consultar en punto 5 de "justificación").

$\begin{array}{cccc}\text { VOLUMEN } & \text { INTENSIDAD } & \text { FRECUENCIA } & \text { MONITORIZACIÓN } \\ \text { Volumen variable según la } & \text { Combinación entre el } & \text { 2 días a la semana, sesión } & \text { Pérdida de control motor } \\ \text { intensidad escogida. } & \text { repetida más de 2 veces. } \\ \text { Cese del ejercicio antes de } & \text { 60-85\% RM regulado } & \text { andine de } & \text { Percepción subjetiva del } \\ \text { la pérdida repetida de } & \text { por RPE. Recuperación } & \text { alrededor de 60 min } & \text { esfuerzo, predominante } \\ \text { control motor. Uso de 2-3 } & \text { autorregulada. } & & \text { RPE 7-8 sobre RPE 5-6 } \\ \text { series, 8-10 ejercicios. } & & & \end{array}$

Tabla 32. Principios de entrenamiento para el contenido de entrenamiento de fuerza en la Fase 3 de potenciación y autonomía.

\section{Entrenamiento aeróbico continuo}

Aumentamos la frecuencia de entrenamiento continuo autónomo al aire libre, favoreciendo la progresión a través del aumento de la dosis (volumen) en 2 días, alcanzando la hora de trabajo y con intervalos más intensos, puesto que el valor superior de intensidad dentro de la horquilla recomendada en términos de \% Vo2Máx resulta difícil de alcanzar, como consecuencia de la imposibilidad de trotar y la fatiga local en gemelo y sóleo. 
Tabla 33. Principios de entrenamiento del contenido de trabajo continuo en Fase 3.

\begin{tabular}{|c|c|c|c|c|}
\hline TIPO & VOLUMEN & INTENSIDAD & FRECUENCIA & MONITORIZACIÓN \\
\hline $\begin{array}{l}\text { Continuo } \\
\text { (trabajo no } \\
\text { presencial) }\end{array}$ & $\begin{array}{l}\text { Intervalos progresivos hasta } \\
\text { completar } 1 \text { hora, } \\
\text { predominando los de mayor } \\
\text { duración con mayor intensidad }\end{array}$ & $\begin{array}{l}\text { Alternancia y progresión } \\
\text { de periodos al } 50-70 \% \\
\text { FC de reserva }\end{array}$ & 2 días a la semana & $\begin{array}{c}\text { FC a través de Xiaomi } \\
\text { Band } 4\end{array}$ \\
\hline
\end{tabular}

\section{Entrenamiento interválico de alta intensidad (HIIT)}

Una vez hemos progresado a través del MIIT, diseñaremos intervalos más intensos a través del ratio trabajo:descanso. Para ello, estableceremos especialmente intervalos de un menor tiempo de trabajo y menor descanso, lo que nos permitirá mantener una intensidad elevada durante todo el intervalo de trabajo. De igual modo, según las capacidades fisiológicas o emocionales de cada sesión, haremos uso de intervalos más prolongados en el tiempo, bajando así ligeramente la intensidad, pero manteniéndonos dentro de la horquilla de recomendaciones para la mejora de los parámetros cardiovasculares de nuestra alumna. Recordemos, que las intensidades alcanzadas tienen como objetivo en esta fase el entrenamiento más eficiente y eficaz para la reducción del perímetro de cintura como factor de riesgo cardiovascular.

Tabla 34. Principios de entrenamientointerválico en Fase 3 de potenciación y autonomía.

\begin{tabular}{|c|c|c|c|c|}
\hline TIPO & VOLUMEN & INTENSIDAD & FRECUENCIA & MONITORIZACIÓN \\
\hline $\begin{array}{l}\text { Predominancia de } \\
\text { HIIT sobre MIIT }\end{array}$ & $\begin{array}{l}4 \text { series de } 3-4 \text { ejercicios } \\
\text { por intervalos intesos de } \\
\text { tiempo trabajo-descanso. }\end{array}$ & $\begin{array}{l}\text { Predominancia del 75- } \\
85 \% \text { sobre el } 60-70 \% \\
\text { FC de reserva. } \\
\text { Descanso 1-3 minutos } \\
\text { según intensidad. }\end{array}$ & $\begin{array}{c}2 \text { días a la semana, } \\
\text { incorporado al final } \\
\text { de las sesiones de } \\
\text { fuerza }\end{array}$ & $\begin{array}{c}\text { FC a través de Xiaomi } \\
\text { Band } 4 \\
\text { RPE 7-8 con intervalos } \\
\text { puntuales en RPE } 6\end{array}$ \\
\hline
\end{tabular}

\subsubsection{Secuenciación de contenidos.}

\begin{tabular}{|c|c|c|c|c|c|c|}
\hline \multicolumn{7}{|c|}{ AGOSTO } \\
\hline$L$ & $\mathrm{M}$ & $x$ & $\mathrm{~J}$ & V & $S$ & $\mathrm{D}$ \\
\hline & & & & & 1 & 2 \\
\hline 3 & 4 & 5 & 6 & 7 & 8 & 9 \\
\hline 10 & 11 & 12 & 13 & 14 & 15 & 16 \\
\hline 17 & 18 & 19 & 20 & 21 & 22 & 23 \\
\hline 24 & 25 & 26 & 27 & 28 & 29 & 30 \\
\hline 31 & 1 & 2 & 3 & & & \\
\hline
\end{tabular}

Tabla 35. Secuenciación de sesiones del mes de agosto. En Amarillo: sesiones online de fuerza y MIIT-HIIT. En rojo: sesiones presenciales de fuerza y MIIT-HIIT. En verde: sesiones no presenciales de trabajo continuo al aire libre. En azul: sesión educativa y establecimiento de retos semanales. En negro: evaluación final del programa de intervención. 
3 y 8 -ago

6-ago

9-ago

10 y 15 -ago

13-ago

16-ago

17 y 22 -ago

20-ago

23-ago

24 y 29 -ago

27-ago

30-ago

31-ago

1-sept

1x 60 min $60 \%$ Vo2Máx

Adaptación al online, patrones controlados MIVC, autoeficacia. Interválico metabólico- impacto.

Condiciones de saturación del sistema: apoyo monopodal, perturbaciones, doble tarea. Impacto-HIIT.

1x 50 min 60\% Vo2Máx, 1x5 min 70\% Vo2Máx

Variabilidad en empuje-tracción basado en las necesidades de movimiento. HIIT con impacto.

Sobrecarga y control de patrones monopodales de cadera. Perturbaciones en el sistema. Impacto-MIIT. 1x 50 min 60\% Vo2Máx, 1x5 min 70\% Vo2Máx, 1x 5 min 50\% Vo2Máx

Sobrecarga y MIVC en patrones controlados, autoeficacia. HIIT con impacto.

Modificación por dolor inespecífico zona lumbar: posible relación con carga emocional semanal. 1x 3 min 50\% Vo2Máx, 1x 7 min 70\% Vo2Máx, 1x 50 min 60\% Vo2Máx

Tabla 36. Estímulos pertenecientes a cada sesión para la consecución de objetivos a través de cada contenido de entrenamiento, detallado anteriormente. En amarillo: sesiones online. En blanco: sesión presencial de entrenamiento de fuerza e interválico-impacto. En verde: sesiones autónomas de carácter aeróbico con objetivo cardiovascular.

\subsubsection{Sesiones.}

13/08 SESIÓN 21(ONLINE): Variabilidad full body de forma lúdica basada en necesidades de movimiento. HIIT con impacto

\begin{tabular}{|c|c|c|}
\hline ESTÍMULO & $\begin{array}{l}\text { CALENTAMIENTO } \\
\text { OBJETIVO }\end{array}$ & METODOLOGIA Y MODIFICACIONES \\
\hline Liberación miofascial rodillo y pelota & $\begin{array}{c}\text { Autoliberación miofascial } \\
\text { Cambio de foam por molestias }\end{array}$ & $\begin{array}{l}\text { 15-20 repeticiones cada grupo muscular con } \\
\text { cierta velocidad }\end{array}$ \\
\hline Extensión torácica en foam & \multirow{2}{*}{$\begin{array}{l}\text { Mejora de la movilidad escapular para } \\
\text { favorecer un correcto equilibrio en raquis } \\
\text { dorsal y ROM en flexión de hombro }\end{array}$} & \multirow{2}{*}{ 1x 15 repeticiones } \\
\hline Rotación torácica desde zancada & & \\
\hline Wall slide supino & $\begin{array}{l}\text { Inhibición recíproca de cadena anterior } \\
\text { aplicada al ritmo escapular }\end{array}$ & 1x 15 repeticiones \\
\hline ESTÍMULO & OBJETIVO & METODOLOGÍA Y MODIFICACIONES \\
\hline
\end{tabular}

Control LP y activación abdominal ante demanda antirotación, cadenas cruzadas
2 con cada brazo-pierna $\mathrm{x}$ hasta pérdida de control repetida

Bird dog con resistencia y foco externo pelota

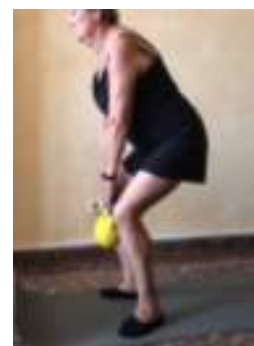

Fomentar la variabilidad y creatividad de la respuesta ante una elección propia de cambio de posición continua (adelantar un pie sobre otro, desplazarse y ejecutar, girarse, coger la kettlebell con una sola mano...) previa a la ejecución de sentadilla (con la única premisa de no repetir más de 2 veces seguidas la misma acción) 


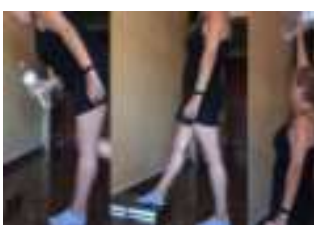

RDL al escalón con impacto + empuje vertical
Fuerza y control en cadena cruzada posterior en patrón monopodal

Impacto generado durante la señal de "pisotón al escalón" acorde a progreso en

las fuerzas de reacción de la Tabla 19

Mejora de la fuerza en ROM completo en flexión de hombro 3x hasta RPE 7

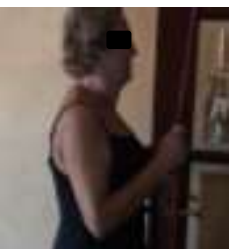

Integración de extensión torácica y retracción de la cintura escapular para la mejora del equilibrio en raquis dorsal 3x hasta RPE 6 o pérdida de control motor repetida por sobreactivación de trapecio superior

Remo vertical bilateral

$$
\text { TRABAJO MIETABÓLICO: HIITT 3x 40/10 x2 - descanso 2" - 3x 30/10 x } 2 \text { RPE 7-8 }
$$

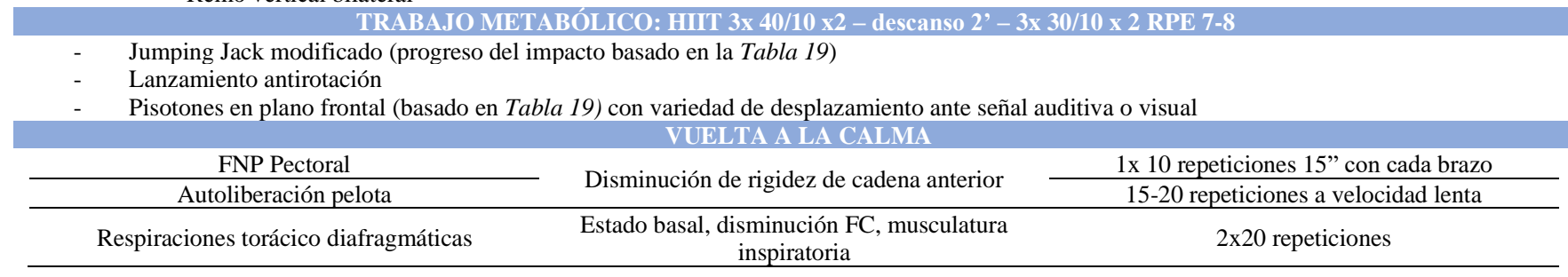

16/08 SESIÓN 22(PRESENCIAL): sobrecarga en dominantes de cadera unilaterales. Perturbaciones del sistema evitando caída. Met-imp.

\begin{tabular}{|c|c|c|}
\hline ESTÍMULO & OBJETIVO & METODOLOGÍA Y MODIFICACIONES \\
\hline Liberación miofascial rodillo y pelota & $\begin{array}{c}\text { Autoliberación miofascial } \\
\text { Cambio de foam por molestias }\end{array}$ & $\begin{array}{c}\text { 15-20 repeticiones cada grupo muscular con } \\
\text { cierta velocidad }\end{array}$ \\
\hline Rotación torácica desde zancada & $\begin{array}{l}\text { Mejora de la movilidad escapular para } \\
\text { favorecer un correcto equilibrio en raquis } \\
\text { dorsal y ROM en flexión de hombro }\end{array}$ & $1 \times 15$ repeticiones \\
\hline Wall slide supino & $\begin{array}{l}\text { Inhibición recíproca de cadena anterior } \\
\text { aplicada al ritmo escapular }\end{array}$ & $1 \times 15$ repeticiones \\
\hline \multicolumn{3}{|c|}{ PARTE PRINCIPAL } \\
\hline
\end{tabular}

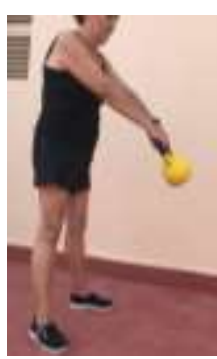

Patrón dominante de cadera con mayor carga generada con la inercia 4x hasta RPE 7 primero de forma bilateral y después unilateral ( 2 y 2 series)

Swing bilateral y unilatera

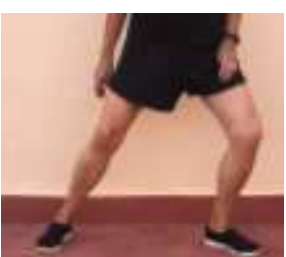

Capacidad de generar fuerzas en varios planos y vectores

Mejora de la respuesta del sistema ante privación visual y diferencia entre órdenes 3x hasta RPE 7

Perturbación con variante de ojos cerrados $\mathrm{y}$ cambio de señal auditiva o visual 

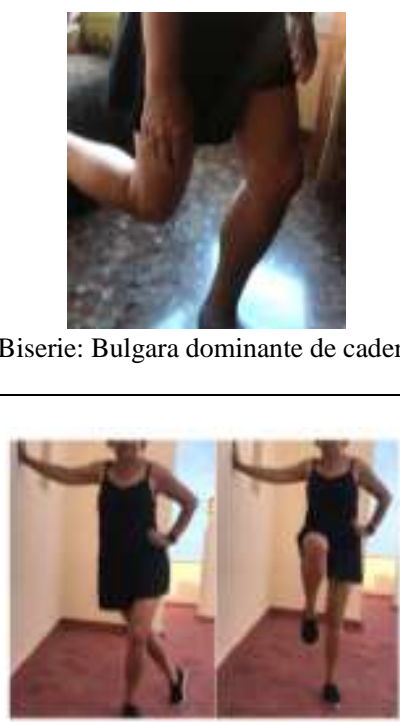
poco común

Wall drill latera

Jumping Jack, progresión en impacto (basado en Tabla 19)

"Limpia suelos" con variedad de desplazamiento arriba-abajo o lateral

Step lateral (mayor impacto basado en Tabla 19 a través de un cambio al plano frontal)

Apoyo monopodal con perturbaciones y doble tarea cognitiva para la mejora de la anticipación del sistema ante condiciones de fatiga

\begin{tabular}{|c|c|c|}
\hline FNP Pectoral & & $1 \times 10$ repeticiones 15 " con cada brazo \\
\hline Autoliberación pelota & Disminución de rigidez de cadena anterıor & $15-20$ repeticiones a velocidad lenta \\
\hline
\end{tabular}

\subsubsection{Control y monitorización del entrenamiento.}

La escala RPE (Tabla 25) se seguirá usando con la misma metodología que en las anteriores fases (consultar 6.2.5) durante el entrenamiento de fuerza con una predominancia de RPE 7 en las sesiones presenciales. En el caso de las sesiones online, mantendremos la mayoría del tiempo una RPE 6, prestando especial atención en la pérdida de control motor repetida, anteriormente mencionada. Todo el registro puede consultarse en su totalidad junto a la Escala PRS y los valores de sueño en la planilla del [Anexo 8].

Para el entrenamiento aeróbico continuo e interválico usaremos los datos de \% de intensidad de FC de reserva deseados, monitorizados en vivo a través de Xiaomi Band 4, moviéndonos de nuevo en torno a 125-140 lpm según la elección de los intervalos de intensidad moderada o vigorosa entre el 50-70\% Vo2Máx detallados en la (Tabla 33 y $34)$. 


\subsubsection{Evaluación del progreso.}

Potenciada la autonomía durante esta fase 3, pasamos a reevaluar todos los parámetros iniciales para observar los resultados y la consecución de objetivos a modo de evaluación final, que se expone a continuación.

\section{RESULTADOS Y DISCUSIÓN}

\subsection{Resultados de la evaluación final}

Objetivos primarios reflejados en la Tabla 18

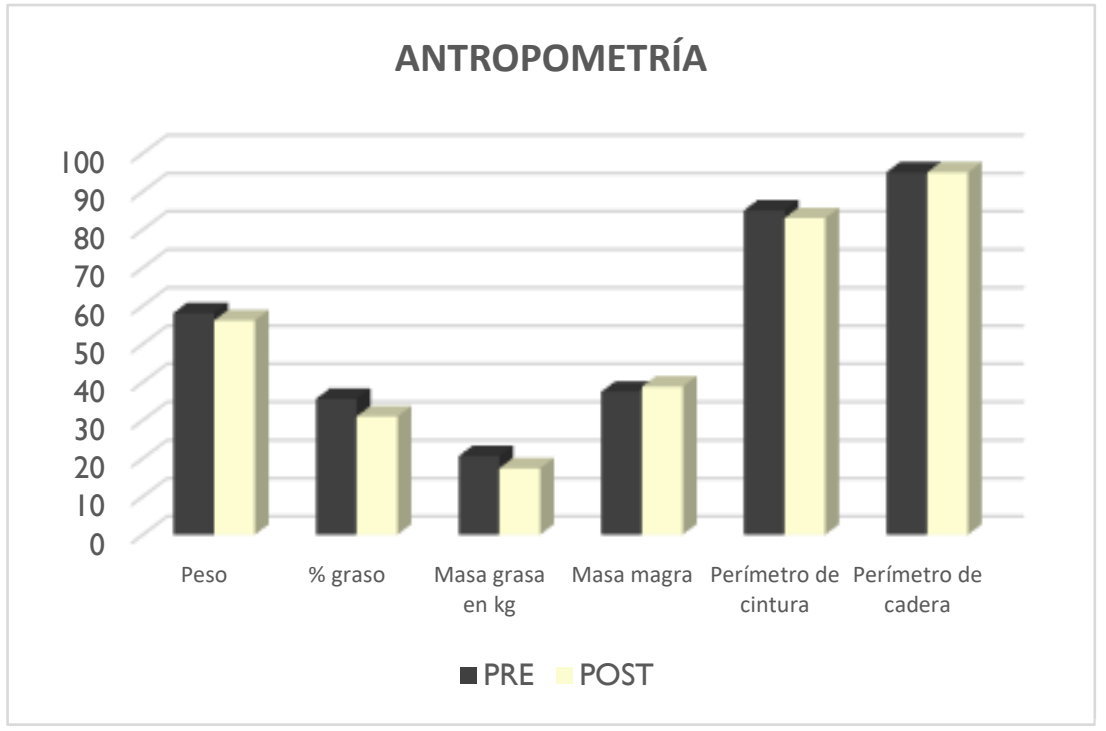

Figura 39. Disminución de los valores relacionados con el riesgo cardiovascular. Aumento de la masa muscular como papel protector.

\section{PARÁMETROS FISIOLÓGICOS}

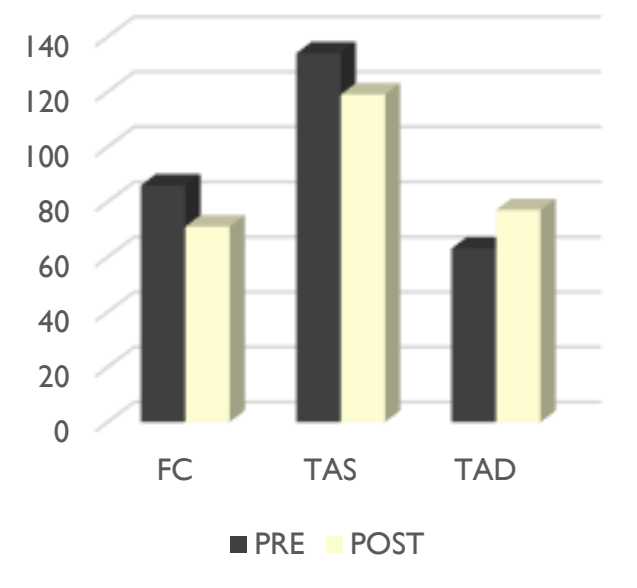

Figura 40. Disminución de la FC y los valores de presión arterial, mejorando los parámetros de salud cardiovascular

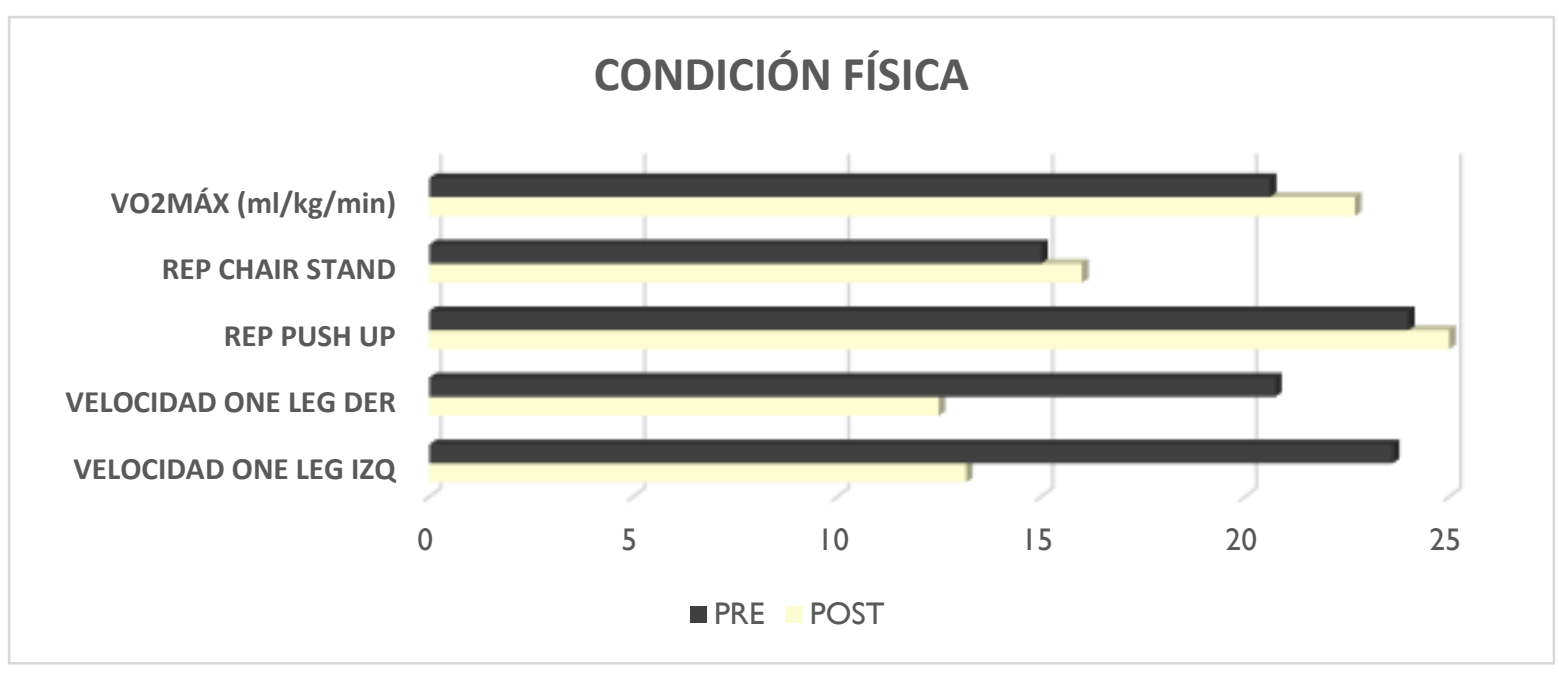

Figura 41. Mejora en los distintos test de condición física, relacionándose especialmente con el aumento de los niveles de fuerza como papel protector y la capacidad del sistema para evitar caída y/o fractura, a través de la mejora del equilibrio (One Leg Test, Figura 42). El Vo2máx representa la mejora de la capacidad cardiorrespiratoria como factor de salud cardiovascular. 
Figura 42. Estabilograma One Leg pre-test (izquierda) y post test (derecha).

Disminución del área recorrida y menor velocidad.
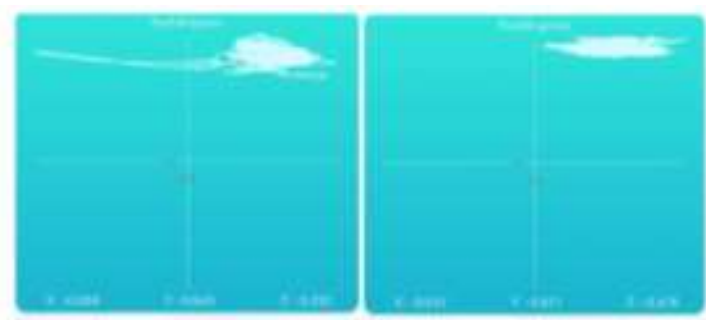

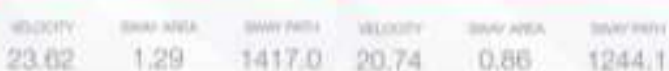

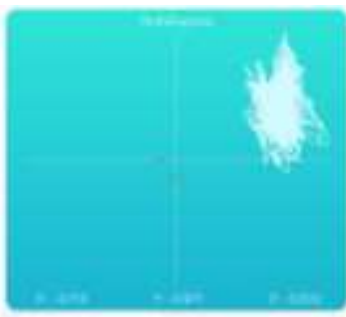

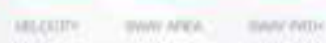
1316
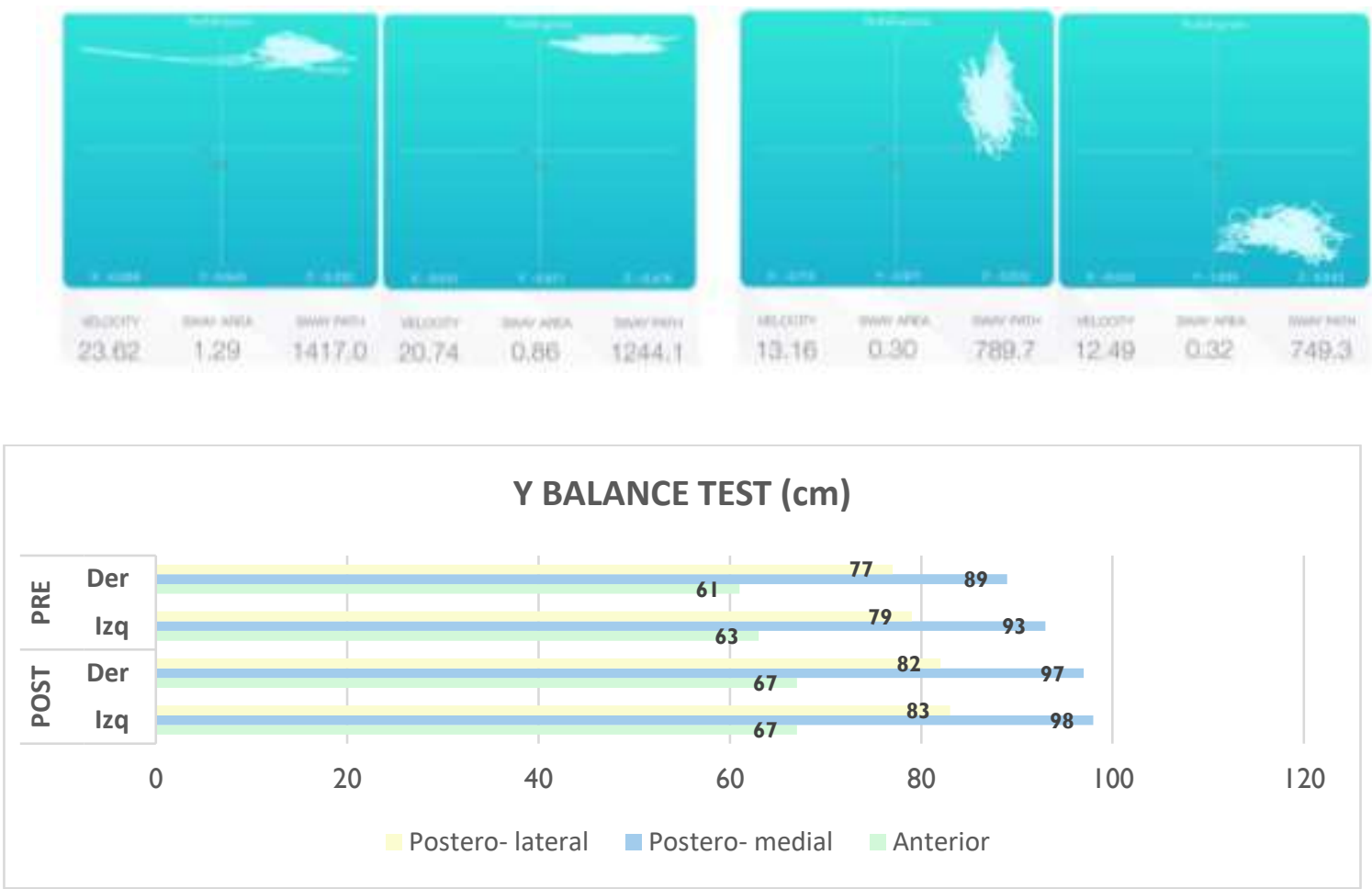

Figura 43. Diferencias pre y post de la distancia recorrida en centímetros en Y Balance Test, reflejando un aumento de la capacidad neuromuscular, relacionándose con la mejora del sistema para evitar una caída y fractura.

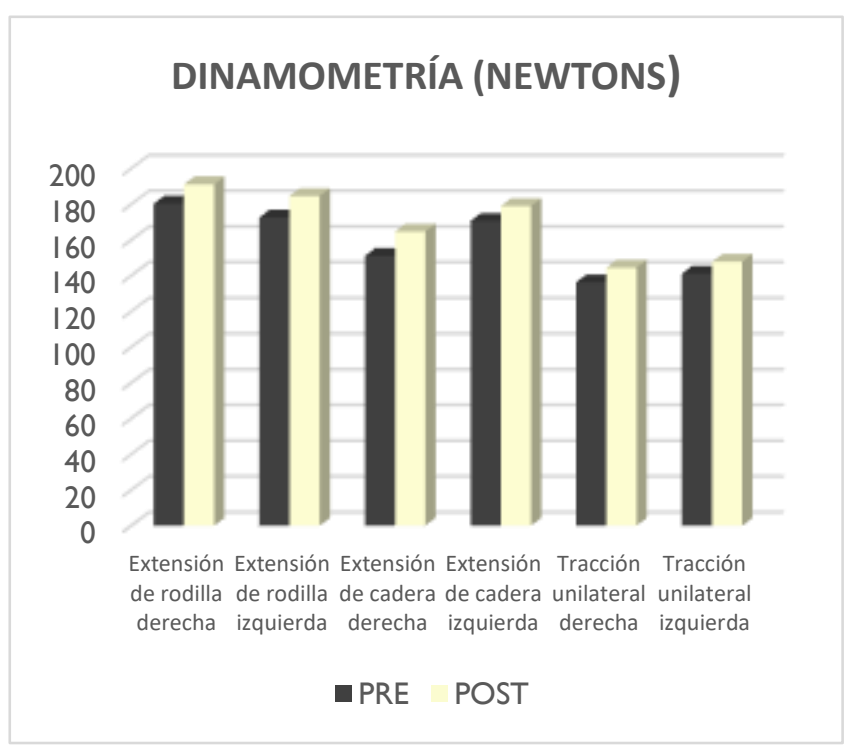

Figura 44. Mejora de los niveles de fuerza en todos los tests, relacionándose con el papel de fuerza y masa muscular como papel protector, evitando el agrave de la sarcopenia, la dinapenia y una mejor salud ósea. A su vez, un aumento de estos valores genera una mayor capacidad del sistema para evitar una caída y/o fractura. 


\section{Objetivos trasversales reflejados en la Tabla 18}
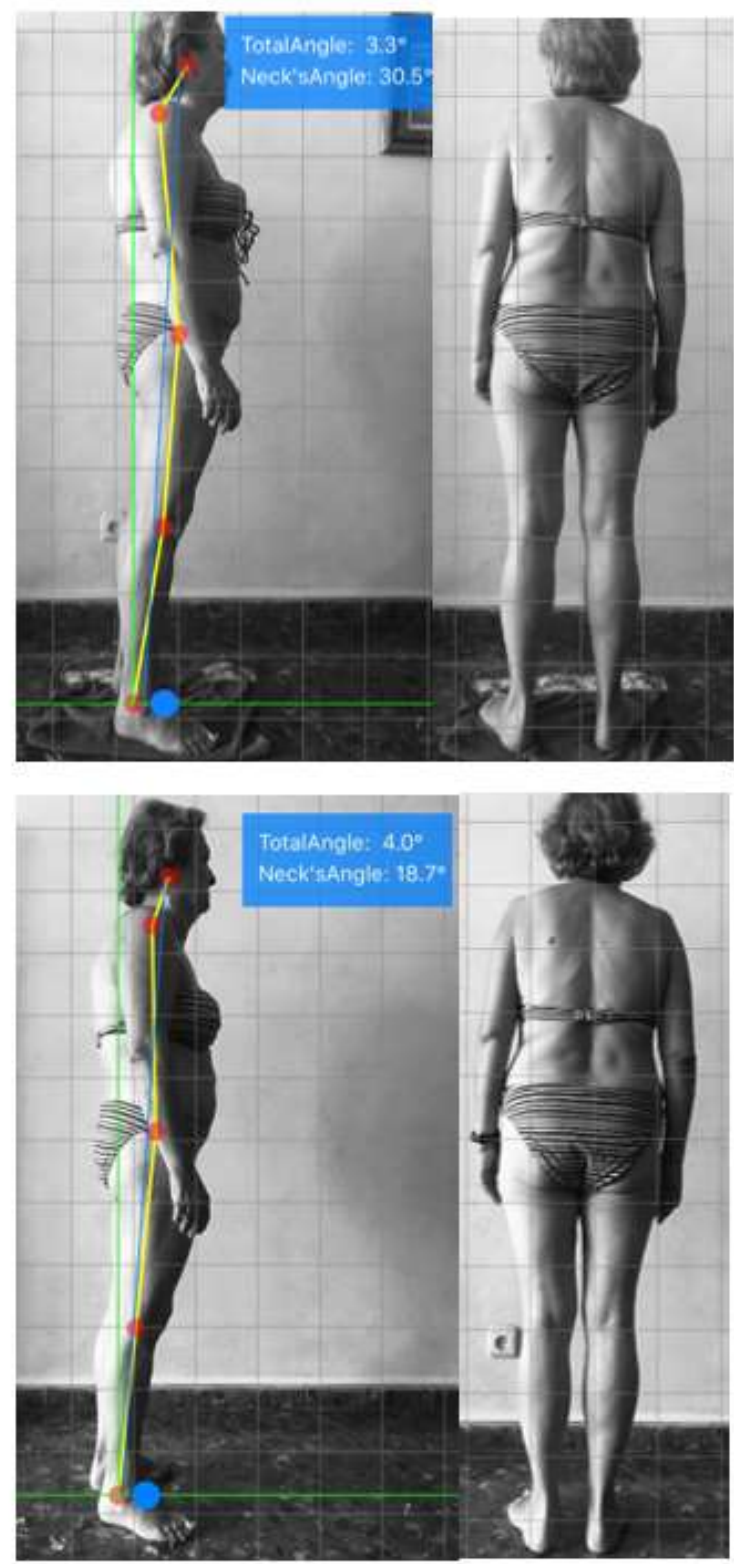

Figura 45. Mejora postural en el post test (abajo) en vista lateral y posterior, lo que se refleja en la mejora de ROM de los diferentes test (Figura 46). Observamos una menor posición adelantada de la cabeza (disminución en el valor en ${ }^{\circ}$ cuello) con lo que también una disminución del ángulo de cifosis dorsal, así como menor sobrepronación en ambos pies. A su vez, existe una leve mejoría a nivel de volumen abdominal, lo que ratificamos con la disminución del perímetro de cintura (Figura 39).

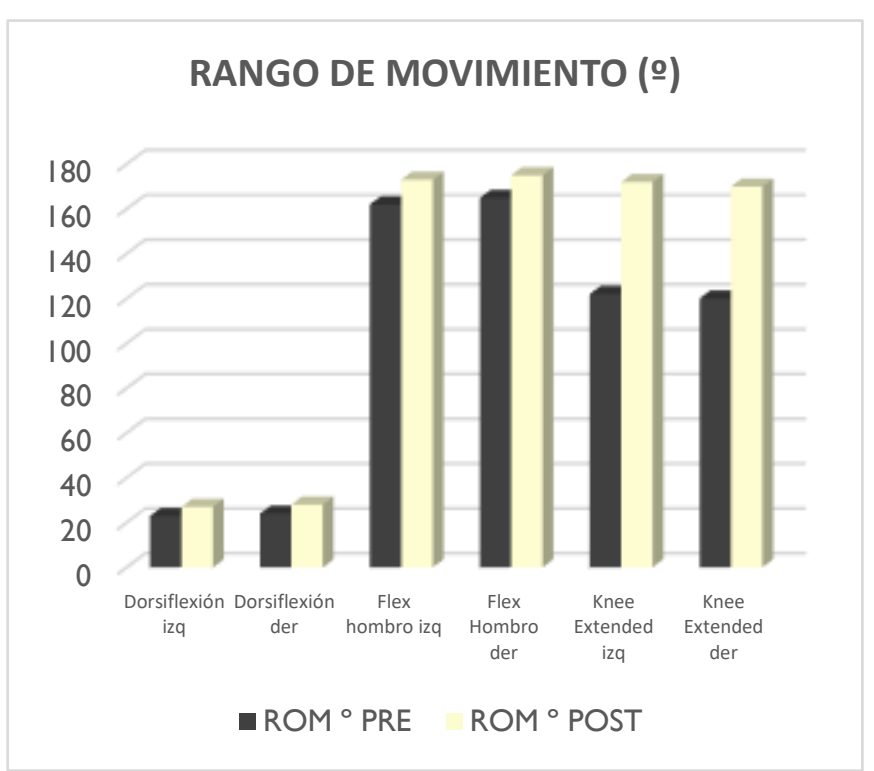

Figura 46. Aumento del rango de movimiento en todos los test realizados durante la evaluación inicial

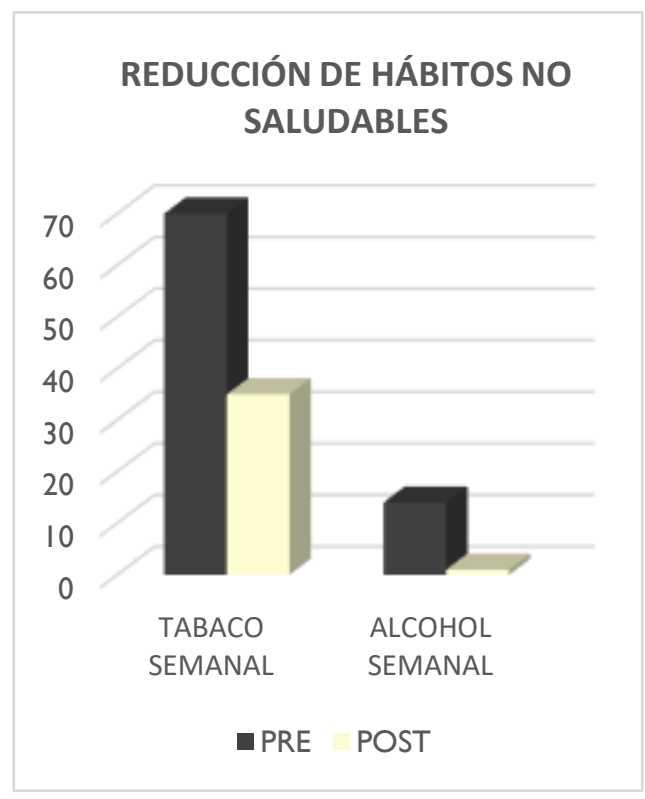

Figura 47. Reducción del consumo semanal de tabaco y alcohol, destacando la supresión casi absoluta de este último. 


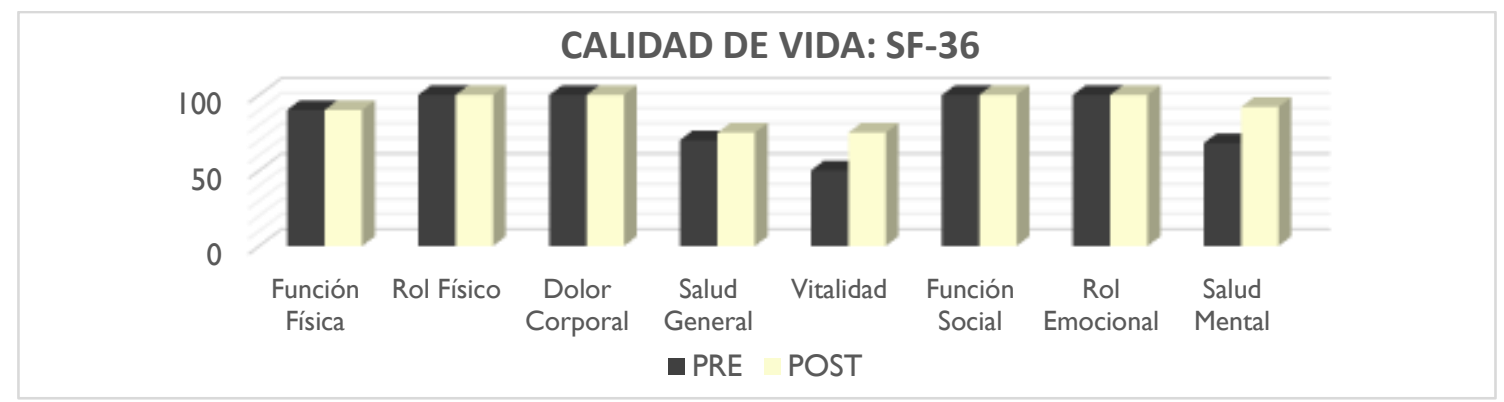

Figura 48. Mantenimiento y mejora de la calidad de vida en las dimensiones incluidas dentro de los objetivos secundarios del programa de intervención (vitalidad, disminución de cansancio)

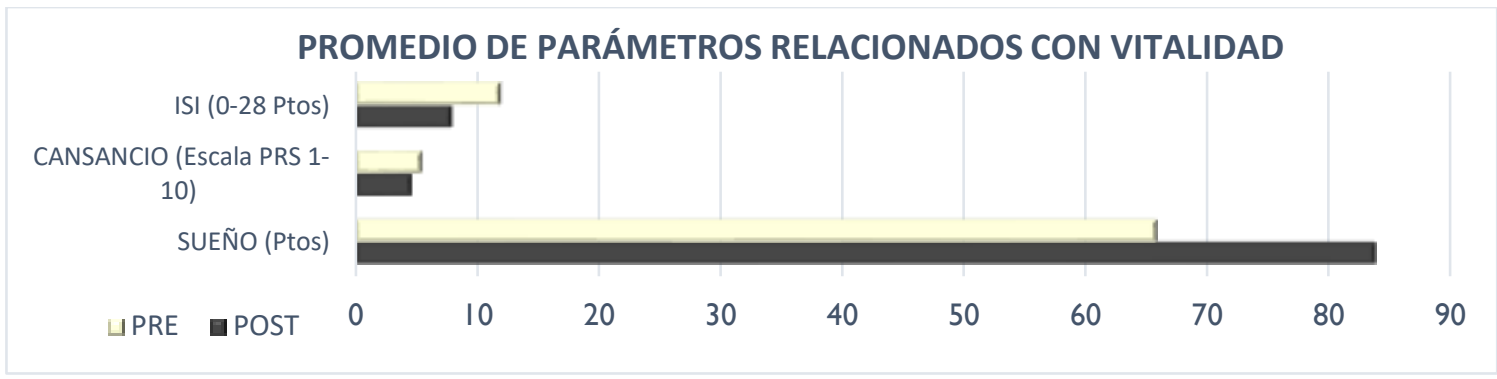

Figura 49. Mejora de los valores relacionados el objetivo de vitalidad. Disminución ISI y sensación de cansancio a través del cálculo del promedio de la escala PRS inicial a cada sesión

(siendo 1 muy cansada, poco recuperada; y 10 en perfectas condiciones, muy recuperada).

Aumento de la puntuación en Xiaomi, relacionándose con la mejora de la calidad de sueño.

\section{Informe final de los resultados: Emilia S.}

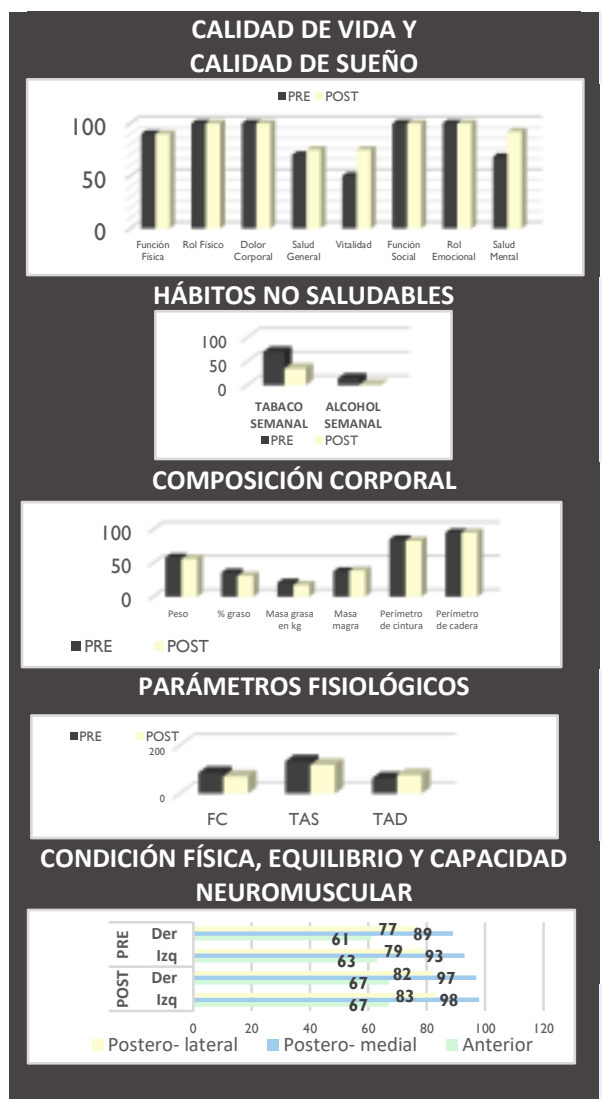

Mejora de la dimensión de vitalidad de 50 puntos a 75 puntos, acorde a objetivos personales.

Traduciéndose en mejoras de la calidad de sueño y descanso.

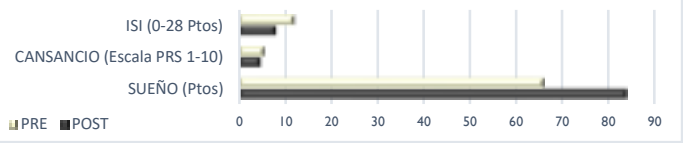

Disminución del consumo de alcohol en un $98 \%$ y tabaco en un $50 \%$, lo que se extrapola a una mejora de la salud cardiovascular y composición corporal.

Disminución del porcentaje de grasa de un $35^{\prime} 6 \%$ al $31 \%$, encontrándose ahora en valores normativos para los 60 años y constituyendo menor riesgo cardiovascular.

Aumento de la masa muscular en 1'3 kg como papel protector contra la sarcopenia y la dinapenia.

Mejora de TAS/TAD a 119/77, alcanzando valores normativos y constituyendo menor riesgo cardiovascular.

Mayores niveles de fuerza en dinamometría y en los diferentes tests de $\mathrm{CF}$, con consecuencias en la disminución del riesgo de sarcopenia y posible caída, relacionado a su vez con el aumento de la masa magra.

Mejora en la capacidad neuromuscular para evitar caídas, y por consiguiente con menor riesgo de fractura. 


\section{Discusión del grado de consecución de los objetivos planteados y posibles causas.}

\section{Salud ósea y disminución del riesgo de caída y/o fractura}

Tal y como hemos mencionado durante la revisión bibliográfica, la prueba diagnóstica DXA se realiza aproximadamente cada 2 años (NIH, 2001), entre otras razones, por la dificultad para hallar cambios significativos hasta ese periodo de tiempo, atendiendo de esta manera a los procesos de resorción y mineralización ósea que duran varios meses. Sin embargo, sí que podemos observar cambios en los factores de masa muscular (Figura 39, masa magra pre 37'5; post 38'8 kg) y fuerza durante la progresión de entrenamiento (Figuras 41 y 44), afectado así de manera directa a la salud ósea a través de la mecanotransducción generada durante la tracción de la musculatura implicada. La propia adaptación a las cargas y fuerzas de reacción estimadas durante el entrenamiento de impacto nos indican una progresión en este aspecto.

De manera indirecta, tenemos información de mejora en los valores de equilibrio gracias a One Leg Test (Área recorrida izq/dcha pre: 23'62/20'74, velocidad izq/dcha pre: 1'29/0'86; área izq/dcha post: 13'16/12'49; velocidad izq/dcha post: 0’30/0'32) constituyendo un aumento del rendimiento en un $44 \%$ en pierna izquierda y un $40 \%$ en derecha, teniendo en cuenta los valores de velocidad media (Figura 42), habiendo disminuido a su vez el área recorrida. Además, la capacidad neuromuscular estimada a través de $Y$ Balance Test (rendimiento en cm pre: izq 79/93/63, dcha 77/89/61; post: izq 83/98/67, dcha 82/97/67) (Figura 43), representa una mejora del $75 \%$ de la asimetría en el desplazamiento postero medial, teniendo en cuenta el objetivo de disminución por debajo de 4cm, que constituía según Smith et al. (2015) mayor riesgo de lesión.

El resultado de estos test se relaciona como hemos mencionado anteriormente con la disminución del riesgo de caída y/o fractura, si bien debemos de tener en cuenta que esta dimensión es multifactorial. La adaptación a la progresión de entrenamiento, así como la selección de estímulos específicos según la evidencia, tales como el predominio de apoyo monopodal con doble tarea o privación de sentidos, explican en cierto modo la mejora en estos parámetros, afectando indirectamente a una mejor salud ósea.

\section{Sarcopenia y dinapenia}

Otra de las principales consecuencias derivadas de la postmenopausia es la disminución del porcentaje de masa muscular y consiguiente fuerza, debido al entorno hormonal (Kaji, 2013). El papel protector de la masa muscular se ha manifestado como esencial durante toda la justificación y programa de intervención (Fonseca et al., 2014), cuyas mejoras (Figura 39 y 44) se han visto reflejadas en los resultados finales con un aumento de 1'3 kg de masa magra, que deberá seguir progresando a largo plazo para aumentar lo máximo posible este valor tan esencial. El entrenamiento de fuerza ha cobrado un papel fundamental, del que deriva la progresión de carga e intensidad detalladas durante las diferentes fases, constituyendo la principal causa de mejora en estos parámetros, siendo necesario su mantenimiento en el tiempo para conseguir una mejora sustancial en el futuro debido a la inexperiencia aún de nuestra alumna. 


\section{Salud cardiovascular: disminución del desarrollo de síndrome metabólico}

A pesar de no disponer de una analítica final debido a la situación de crisis sanitaria nacional, que permita observar los valores de resistencia a la insulina y dislipidemia, si tenemos constancia de las mejoras en los parámetros de grasa visceral (evaluación indirecta a través de perímetro de cintura; pre $85 \mathrm{~cm}$, post $83 \mathrm{~cm}$ ) y tensión arterial (TAS TAD pre 134/63, post 119/77) (Figuras 39 y 40). De esta manera, teniendo como referencia los valores normativos 120/80, hemos mejorado en un 101\% TAS y un 96\% TAD. En cuanto a la composición corporal, partíamos de un porcentaje graso del 35 ' $6 \%$ clasificado como "exceso de grasa", cuyo resultado final es de un $\mathbf{3 1 \%}$ de masa grasa, constituyendo una consecución del objetivo del $100 \%$ para la reducción a valores normativos (30-32\% masa grasa). Por otro lado, gracias a un menor perímetro de cintura, el índice de cintura-cadera ha disminuido (pre 0'89 cm, post 0'87) (Figura 39). Sin embargo, nos encontramos aún por encima de los valores normativos (0'790’ $83 \mathrm{~cm}$ ), por lo que el grado de consecución del objetivo se queda en un $\mathbf{2 4 \%}$.

De igual manera, el marcador de Vo2Máx, que se encontraba con un rendimiento por encima de la media para la edad de 60 años, ha mejorado de 20 '61 a 22'69 ml/kg/min (Figura 41), estimando una mejor salud cardiovascular debido a la capacidad del organismo para procesar y usar el oxígeno de manera más eficiente.

Observando estos cambios, la reducción de hábitos no saludables (50\% tabaco, 98\% alcohol) reflejados durante el programa (Figura 47) se torna como una herramienta eficaz y muy viable en la que seguir progresando, junto a la combinación de entrenamiento de fuerza y entrenamiento continuo e interválico.

\section{Calidad de vida, funcionalidad y desempeño social.}

La principal dimensión a mejorar manifestada durante la entrevista inicial era la de vitalidad, afectando al desempeño social de la vida de nuestra alumna, cuyo objetivo personal era el de encontrarse menos cansada para poder realizar cualquier plan sin impedimentos. A pesar de la dificultad para evaluar este parámetro tan subjetivo y multifactorial, tal y como observamos en la Figura 48, encontramos una mejora sustancial en esta dimensión de vitalidad (pre 50 ptos; post 75 ptos.) y una mejor percepción de salud general (pre 70 ptos; post 75 ptos.). Por tanto, la consecución del objetivo es de un $129 \%$, teniendo en cuenta que los valores normativos para 60 años en la dimensión de vitalidad eran de $58^{\prime} 8$ puntos. Con respecto a la mejora de la dimensión del umbral de insomnio (Figura 49), los valores normativos de no insomnio se encontraban entre 0-7 puntos, por lo que la puntuación de 8 nos sitúa en la consecución del objetivo del $86 \%$.

A su vez, podemos relacionar que una mejor calidad de sueño (Figura 49) ha ayudado a conseguir un descanso más reparador, menor cansancio en la jornada y una mejora en la eficiencia de los patrones laborales incluidos durante el entrenamiento de fuerza, mediados en cierto modo por aquellos factores limitantes que también han mejorado ligeramente (Figura 46), siendo necesario un abordaje a largo plazo de estos para conseguir un mayor margen de mejora, a pesar de que con estos ligeros cambios ya existe una mejor percepción de salud y rol social. Todo esto, ha permitido mejorar la dimensión psicosocial del modelo multifactorial plasmado durante la metodología de todo el trabajo, más allá de una perspectiva puramente biomédica. 
Además, observamos como en la plomada (Figura 45) existe especialmente una disminución del ángulo de cifosis dorsal y protracción de cabeza, si bien desequilibrios como la sobrepronación del pie, torsión tibial, rotación de tronco y elevación de hombro izquierdo han progresado en menor medida, lo que podemos atribuir a que constituyen principalmente problemas estructurales más difíciles de revertir. Sin embargo, a nivel funcional, las adaptaciones generadas durante el paso de los años han permitido un desempeño óptimo para el movimiento sin episodios recurrentes de dolor, lo que hemos visto reflejado en la progresión del programa de intervención, por lo que nuestro papel es que estos factores no se desarrollen afectando a la funcionalidad, evitando así una hipervigilancia o kinesiofobia.

\subsection{Puntos fuertes y débiles del programa de intervención.}

Como puntos fuertes, destacamos:

- Adherencia final al programa de entrenamiento individualizado. A pesar de comenzar la intervención con una actitud reticente hacia el ejercicio físico, el trascurso de la misma ha permitido hallar aquellas actividades y estímulos preferentes de nuestra alumna.

Además, se ha otorgado cierta autonomía de cara a un mantenimiento del entrenamiento y los hábitos saludables, que a largo plazo es lo que generará verdaderos beneficios y adaptaciones.

- Relación familiar directa. Aunque en algunos momentos ha llegado a constituir una desventaja desde el punto de vista de autoridad (especialmente al inicio del programa), en general, la relación cercana ha permitido establecer una mayor disponibilidad a prácticamente cualquier hora del día, especialmente importante durante la evaluación inicial y el entrenamiento online.

- Abordaje integral y consecución de objetivos. Partiendo de una nula experiencia y predisposición de nuestra alumna, se ha alcanzado una mejora de la salud desde un punto de vista integral. Es decir, no solo a nivel biomédico teniendo en cuenta las patologías de osteoporosis y síndrome metabólico, sino también a nivel de desempeño social, autoeficacia y autonomía, estableciéndose incluso claros hábitos saludables aparentemente difíciles de eliminar en un comienzo. Además, la consecución de objetivos se ha alcanzado casi en su totalidad, especialmente los denominados principales, únicamente destacando en menor medida algunos secundarios relacionados con la estructura (pie, escoliosis), que deberán de mantener una intervención a largo plazo de hasta 1-2 años según la evidencia para conseguir mejoras significativas.

Por otro lado, consideramos los siguientes puntos débiles con sus respectivas soluciones y alternativas elegidas:

- Uso de herramientas y material casero. Al no disponer de muchos de los gold standard de evaluación, así como por el uso de ciertos materiales usados durante el programa, la rigurosidad de ciertos factores de medición o monitorización disminuye, si bien se ha optado por mantener un claro protocolo que afecte lo menos posible a la fiabilidad de los mismos, atendiendo a las posibilidades y disponibilidad de medios materiales, espaciales y temporales. 
- Inexperiencia profesional propia y personal de nuestra alumna. Ambas han ralentizado ciertos procesos durante el programa. Por un lado, durante la evaluación en términos de recursos temporales y fiabilidad por mi falta de experiencia. Por otro lado, durante la primera fase en la que predominaba un aprendizaje motor básico por parte de nuestra alumna, necesario para progresar en los principios de entrenamiento basados en la evidencia. En este aspecto, ciertas intensidades recomendadas han sido imposibles de alcanzar, trabajando desde un punto de vista de la seguridad, y teniendo en cuenta de nuevo los recursos materiales.

- Disponibilidad de un equipo interdisciplinar. Las competencias y el trabajo en equipo con un nutricionista y un fisioterapeuta, así como una mayor comunicación y seguimiento por parte del médico (con imposibilidad por la situación de crisis sanitaria), habría enriquecido notablemente el abordaje y los consiguientes resultados.

- Evaluación final DMO y analítica. La imposibilidad de conocer en detalle algunas adaptaciones generadas para los objetivos de salud ósea y cardiovascular limitan la consecución de ciertas metas, si bien teniendo en cuenta las mejoras en multitud de aspectos interrelacionados nos informan de un progreso similar.

- Metodología y periodización del entrenamiento. Debido a la naturaleza del caso práctico en un contexto de salud, ciertos parámetros y metodologías de entrenamiento son más difusos según la evidencia, en comparación por ejemplo al paradigma de rendimiento. Sin embargo, para solventar este problema se ha optado por una individualización en todo momento, fomentando además la adaptación de nuestra alumna debido a su inexperiencia de entrenamiento.

\subsection{Limitaciones, dificultades y soluciones.}

- Situación actual por COVID-19. La situación sanitaria ha afectado tanto a los recursos materiales, por la imposibilidad de adquirir especialmente implementos de sobrecarga para fases más avanzadas; así como la dificultad para la realización de algunas actividades de carácter aeróbico continuo con el uso de mascarilla (mayor RPE, FC, sensación de fatiga, temperatura...). Se ha intentado solucionar este problema a través de la continua adaptación a los recursos disponibles más fiables.

- Factores externos no modificables. Destacando especialmente la temperatura y humedad en el ambiente, afectando a la sensación de fatiga antes, durante y después del entrenamiento. Por ello, se han adaptado los horarios a última hora de la tarde, teniendo en cuenta el nivel de cansancio inicial. Además, las restricciones de movimiento para actividades al aire libre no permitieron, por ejemplo, el uso de algunos puntos de calistenia fuera del domicilio previstos en un comienzo con el objetivo de variabilidad y adherencia al entrenamiento.

- Diagnóstico clínico. La falta de uso en el sistema sanitario español de técnicas de diagnóstico y seguimiento de la calidad de la estructura (TC) limitan la comprobación de objetivos a corto plazo para la salud ósea, ya que cada DXA se realiza en un espacio de tiempo de 2 años, en el caso de nuestra alumna.

A su vez, debido a la situación sanitaria surgida durante el programa, no tenemos datos finales sobre los parámetros de dislipidemia y resistencia a la insulina. 
- Recursos temporales. La incompatibilidad horaria mutua por trabajo ha sido una de las principales limitaciones del programa, constituyendo una barrera para muchos factores y actividades deseadas. Para solventar este problema se han ido desarrollando estrategias eficientes y efectivas como el entrenamiento online, potenciando así la autonomía de nuestra alumna.

- Falta de evidencia de dosis-respuesta y sesgo de muestras. En relación a todos los objetivos, existe un claro vacío en el conocimiento de la dosis-respuesta, teniendo en cuenta la heterogeneidad de las muestras, especialmente en este caso con una mayoría de hombres jóvenes en los diferentes estudios. Estas limitaciones generan una incertidumbre en la respuesta deseada.

Por suerte, siguiendo y adaptando las recomendaciones a los medios disponibles, nuestra alumna no ha constituido una clara no respondedora a las dosis establecidas en la evidencia científica.

- Giro de la casuística según los resultados tardíos de la analítica. Al no disponer de una analítica reciente, y tras no hacer referencia a nada en la entrevista inicial, se desconocía la existencia por parte de nuestra alumna de valores no normativos en los parámetros de resistencia a la insulina. Por tanto, una vez finalizada la evaluación inicial (al no disponer de fecha reciente para la analítica por la situación sanitaria) y ya casi en el planteamiento del programa de intervención, se tuvieron que modificar ciertos aspectos constituyendo un giro en la casuística, evitando así un potencial sesgo.

\section{CONCLUSIONES.}

En definitiva, el balance de consecución de objetivos principales y secundarios planteados al inicio del programa ha sido bastante positivo, teniendo en cuenta además las preferencias de nuestra alumna.

Por un lado, desde el paradigma más biomédico hemos conseguido disminuir las consecuencias derivadas de la postmenopausia y la osteoporosis diagnosticada desde un punto de vista multifactorial, evitando un agrave de la sarcopenia y dinapenia propias de este entorno hormonal.

Teniendo en cuenta esto, la disminución del riesgo de caída y posible fractura se ve respaldado por los niveles de fuerza y masa muscular, así como la preparación del sistema en situaciones motoras complejas y de doble tarea.

La naturaleza a corto plazo del programa de intervención no nos permite conocer los resultados exactos en cuanto a salud ósea se refiere, sin embargo, la progresión de entrenamiento de impacto basado en la evidencia científica, permite afianzar una correcta selección de estímulos novedosos que desencadenan la respuesta osteogénica a largo plazo.

Desde el punto de vista cardiovascular, de nuevo carecemos de datos clínicos finales que ratifiquen una mejora sustancial en la disminución del desarrollo de los factores de dislipidemia y resistencia a la insulina. Sin embargo, dentro del síndrome metabólico, observamos una clara mejoría en los valores de TAS/TAD controlados durante todo el programa de intervención, así como el perímetro de cintura y los resultados de la bioimpedancia. 
En este sentido, la educación para la reducción de los hábitos no saludables ha jugado un papel fundamental para la mejora de la salud cardiovascular, lo que nos permite asegurar este estado a largo plazo.

Desde el punto de vista biopsicosocial, modelo claramente referenciado durante todo el programa, no solo hemos abordado una esfera patológica sino un estado de salud integral que ha permitido a nuestra alumna percibir una mejor calidad de vida, entendida para ella como un desempeño social basado en la vitalidad, autoeficacia, autonomía y empoderamiento. Es por estos factores por los que probablemente se haya conseguido una adherencia a un estilo de vida más saludable (en el que seguir progresando) y al ejercicio físico, cuyo mantenimiento generará los verdaderos beneficios a largo plazo.

\section{Opinión personal del caso práctico.}

El contexto desarrollado durante la realización de este TFM ha sido muy complicado en muchas ocasiones en términos de recursos materiales, temporales y espaciales, tanto por la crisis sanitaria, como por la incompatibilidad entre ambas jornadas laborales. Sin embargo, esto me ha permitido mejorar en la organización y gestión del tiempo, el establecimiento y cumplimiento de metas a corto plazo, así como la constancia y disciplina. Por otro lado, valoro y doy gracias especialmente a la coordinación de este máster por ayudarme en mi desarrollo personal y profesional a través de todos los procesos involucrados en este caso práctico. Ante casos similares en un futuro, considero fundamental la integración y comunicación entre un equipo interdisciplinar afianzado en un entorno viable para el cliente, que permita así obtener una mejor experiencia a las personas con las que tratamos, facilitando el trabajo y la consecución de objetivos.

\section{LÍNEAS FUTURAS DE INTERVENCIÓN.}

- Evaluación de DMO, glucosa y lípidos en sangre para el establecimiento de nuevos objetivos.

- Progresión del entrenamiento de fuerza a intensidades del 85\%RM de manera segura y controlada, con una mayor disponibilidad de material de sobrecarga.

- Progresión en el desarrollo de estímulos novedosos basados en las fuerzas de reacción para desencadenar una respuesta osteogénica.

- Desarrollo de estrategias de intervención a largo plazo en un equipo interdisciplinar para la mejora del equilibrio en raquis dorsal y pie, acorde a las necesidades de movimiento.

- Mantenimiento de la reducción o supresión de los hábitos no saludables relacionados con el alcohol y el tabaco, especialmente este último. 


\section{BIBLIOGRAFÍA.}

Aagaard, P., Simonsen, E., Andersen, J., Magnusson, P. \& Dyhre-Poulsen, P. (2002). Neural adaptation to resistance training: changes in evoked $\mathrm{V}$-wave and H-reflex responses. Journal of Applied Physiology, 92(6), 2309-2318.

Aagaard, P., Suetta, C., Caserotti, P., Magnusson, S. \& Kjær, M. (2010). Role of the nervous system in sarcopenia and muscle atrophy with aging : strength training as a countermeasure. Scandinavian Journal of Medicine \& Science in Sports 20, 49-64.

Abdulnour, J., Doucet, E. \& Brochu, M. (2012). The effect of the menopausal transition on body composition and cardiometabolic risk factors: a Montreal-Ottawa New Emerging Team group study. Menopause, 19: pp. 760-767.

Ahlborg, H., Johnell, O. \& Turner, C. (2003). Bone loss and bone size after menopause. $N$ Engl J Med, 349: pp. 327-334.

Ammann, P. \& Rizzoli, R. (2003) Bone strength and its determinants. Osteoporos Int, $14 ; 13-18$.

American College of Sports Medicine (ACSM). (2015). ACSM's Guidelines for Exercise Testing and Prescription. Paises Bajos: Wolters Kluwer.

American College of Sports Medicine (ACSM). (2004). Position Stand: Physical Activity and Bone Health. Medicine \& Science in Sports \& Exercise 36 (11), 1985-1996.

Areeudomwong, P. \& Buttagat, V. (2019). Proprioceptive neuromuscular facilitation training improves pain-related and balance outcomes in working-age patients with chronic low back pain: a randomized controlled trial. Brazilian Journal of Physical Therapy, 23(5), 428-436.

Arshadi, R., Ghasemi, G. \& Samadi, H. (2019). Effects of an 8-week selective corrective exercises program on electromyography activity of scapular and neck muscles in persons with upper crossed syndrome: Randomized controlled trial. Physical Therapy in Sport 37, 113-119.

Ashwell, M., Gunn, P., \& Gibson, S. (2012). Waist-to-height ratio is a better screening tool than waist circumference and BMI for adult cardiometabolic risk factors: Systematic review and meta-analysis. Obesity Reviews, 13(3), 275-286.

ATP III: Expert Panel on Detection, Evaluation, and Treatment of High Blood Cholesterol in Adults (2001). Executive summary of the third report of the National Cholesterol Education Program (NCEP) expert panel on detection, evaluation, and treatment of high blood cholesterol in adults (adult treatment panel III). Journal of the American Medical Association 285(19), 2486-2497.

Bartl, R. \& Bartl, C. (2019). The Osteoporosis Manual: Prevention,diagnosis and management. Suiza: Springer, 93-95.

Bastien C., Vallières A., Morin, C. (2001). Validation of the Insomnia Severity Index as an outcome measure for insomnia research. Sleep Medicine. 2, 297-307.

Beck, B., Daly, R., Fiatarone, M. \& Taaffe, D. (2017). Journal of Science and Medicine in Sport Exercise and Sports Science Australia ( ESSA ) position statement on exercise prescription for the prevention and management of osteoporosis. Journal of Science and Medicine in Sport, 20(5), 438-445. 
Benedetti, M., Furlini, G., Zati, A. \& Mauro, G. (2018). The Effectiveness of Physical Exercise on Bone Density in Osteoporotic Patients. Hindawi BioMed Research International 4, 1-10

Bennell, K., Talbot, R., Wajswelner, H., Techovanich, W., Kelly, D., \& Hall, A. J. (1998). Intra-rater and inter-rater reliability of a weight-bearing lunge measure of ankle dorsiflexion. Australian Journal of physiotherapy, 44(3), 175-180.

Bilezikian, J. (2019). Primer on the Metabolic Bone Diseases and Disorders of Mineral Metabolism. USA: The American Society for Bone and Mineral Research 517--525.

Black, D., \& Rosen, C. (2016). Clinical Practice. Postmenopausal Osteoporosis. The New England journal of medicine, 374(3), 254-262.

Borer, K., Fogleman, K., Gross, M., La New, J. \& Dengel, D. (2007). Walking intensity for postmenopausal bone mineral preservation and accrual. Bone 41(4):713-721.

Bortolozo, E., Santos, C., Pilatti, L., Canteri, M. (2017). Validity of International Questionnaire of Physical Activity by Correlation with Pedometer. Revista Internacional de Medicina y Ciencias de la Actividad Física y el Deporte, vol. 17 (66) pp. 397-414.

Bredin, S., Gledhill, N., Jamnik, V., Warburton, D. (2013). PAR-Q+ and ePARmed-X+: New risk stratification and physical activity clearance strategy for physicians and patients alike. The official Journal of the Collegue of family Physicians of Canada 59, 273-277.

Brown, J. \& Josse, R. (2002). Clinical practice guidelines for the diagnosis and management of osteoporosis in Canada. CMAJ 167(Suppl): S1-34.

Buysse, D., Reynolds C., Monk, T., Berman, S. \& Kupfer, D. (1989). The Pittsburgh Sleep Quality Index: A new instrument for psychiatric practice and research. Psychiatry Research. 28, 193-213.

Campbell, W., Kraus, W., Powell, K., Haskell, W., Janz, K., Jakicic, J., ... \& Bartlett, D.(2019). High-Intensity Interval Training for Cardiometabolic Disease Prevention. Medicine and Science in Sports and Exercise 51(6), 1220-1226.

Campodónico, I., Blümel, J., Arteaga, E., Vallejo, M. \& Valdivia, M. (2018). Low bone mineral density in middle-aged women: A red flag for sarcopenia. Menopause, 25(3), 324-328.

Capozza, R., Cure-Cure, C., Cointry, G., Meta, M., Cure, P., Rittweger, J. \& Ferretti, L. (2008). Association between low lean body mass and osteoporotic fractures after menopause. Menopause: The Journal of The North American Menopause Society15(5), 905-913.

Carpio-Rivera, E., Moncada-Jiménez, J., Salazar-Rojas, W. \& Solera-Herrera, A. (2016). Acute effects of exercise on blood pressure: A meta-analytic investigation. Arquivos Brasileiros de Cardiologia 106(5), 422-433.

Carter, N., Khan, K. \& Mallinson, A. (2002). Knee extension strength is a significant determinant of static and dynamic balance as well as quality of life in older community- dwelling women with osteoporosis. Gerontology 48, 36-38. 
Catalá-López, F., Sanfélix-Gimeno, G., García-Torres, C., Ridao, M. \& Peiró, S. (2012). Control of arterial hypertension in Spain: A systematic review and meta-analysis of 76 epidemiological studies on 341632 participants. Journal of Hypertension 30(1), 168-176.

Cerda, L.A. (2014). Manejo del trastorno de marcha del adulto mayor. Revista Médica Clínica Las Condes, 25(2), 265-275.

Cervellati, C. \& Bergamini, C. (2016). Oxidative damage and the pathogenesis of menopause related disturbances and diseases. Clin. Chem. Lab. Med., 54: 739-753.

Cheatham, S. \& Stull, K. (2018). Comparison of a foam rolling session with active joint motion and without joint motion: A randomized controlled trial. Journal of Bodywork and Movement Therapies 22(3), 707-712.

Chiacchio Sieira, M., Omar Ricart, A., \& Suau Estrany, R. (2010). Respuesta de la tensión arterial a la prueba de esfuerzo. Apunts Medicina de l'Esport, 45(167), 191-200.

Chien, M., Yang, R. \& Tsauo, J. (2005). Home-based trunk strengthening exercise for osteoporotic and osteopenic postmenopausal women without fracture - a pilot study. Clin Rehabil 19, 28-36.

Chun, K. J. (2011). Bone densitometry. Seminars in Nuclear Medicine, 41(3), 220-228.

Coburn, J., \& Malek, M. (2014). Manual NSCA: Fundamentos del Entrenamiento Personal ( $2^{a} E d$.) Badalona: Paidotribo.

Coffey, V. \& Hawley, J. (2017). Concurrent exercise training: do opposites distract? Journal of Physiology, 595(9), 2883-2896.

Colegio Oficial de Licenciados en Educación Física y en Ciencias de la Actividad Física y del Deporte de Andalucía. (2019). Código Deontológico de la profesión de la Educación Física y Deportiva. León: Acta Sede Plenaria XC.

Cook, G., Burton, L. \& Hoogenboom, B.J. (2006). The use of fundamental movements as an assessment of function-Part 1. N Am J Sports Phys Ther, 1(2):62-72.

Cornelissen, V., Smart, N (2013). Exercise training for blood pressure: a systematic review and meta-analysis. J Am Heart Assoc 2: e004473.

Costa, E., Hay, J., Kehler, D., Boreskie, K., Arora, R., Umpierre, D., ... \& Duhamel, T.(2018). Effects of High-Intensity Interval Training Versus Moderate-Intensity Continuous Training On Blood Pressure in Adults with Pre- to Established Hypertension: A Systematic Review and Meta-Analysis of Randomized Trials. Sports Medicine 48(9), 2127-2142.

Craig, C. L., Marshall, A. L., Sjöström, M., Bauman, A. E., Booth, M. L., Ainsworth, B. E., ... Oja, P. (2003). International physical activity questionnaire: 12-Country reliability and validity. Medicine and Science in Sports and Exercise, 35(8), 13811395.

Crawford, D., Drake, N., Carper, M., DeBlauw, J. \& Heinrich, K. (2018). Validity, Reliability, and Application of the Session-RPE Method for Quantifying Training Loads during High Intensity Functional Training. Sports 6(3), 84. 
Cuspidi, C., Sala, C., Tadic, M., Gherbesi, E., Grassi, G. \& Mancia, G. (2018). Association of metabolic syndrome with carotid thickening and plaque in the general population: A meta-analysis. Journal of Clinical Hypertension 20(1), 4-10.

Daly, R., Dalla, J., Duckham, R., Fraser, S. \& Wulff, E. (2019). Exercise for the prevention of osteoporosis in postmenopausal women: an evidence-based guide to the optimal prescription. Brazilian Journal of Physical Therapy, 23(2), 170-180.

Davis, R., Bull, C., Roscoe, J., Roscoe, D. (2005). Physical Education \& the Study of Sport. UK: Mosby.

De Mutsert, R., Gast, K., Widya, R., De Koning, E., Jazet, I., Lamb, H., .. \& \& Den Heijer, M. (2018). Associations of Abdominal Subcutaneous and Visceral Fat with Insulin Resistance and Secretion Differ between Men and Women: The Netherlands Epidemiology of Obesity Study. Metabolic Syndrome and Related Disorders 16(1), 54-63.

De Nardi, A., Tolves, T., Lenzi, T., Signori, L. \& Silva, A. (2018). High-intensity interval training versus continuous training on physiological and metabolic variables in prediabetes and type 2 diabetes: A meta-analysis. Diabetes Research and Clinical Practice 137, 149-159.

Donato, K. (1998). Executive summary of the clinical guidelines on the identification, evaluation, and treatment of overweight and obesity in adults. Archives of Internal Medicine, 158(17), 1855-1867.

Duque, G. (2019). Osteosarcopenia: bone, muscle and fat interactions. Suiza: Springer Nature.

Ekelund, U., Steene-Johannessen, J., Brown, W. J., Fagerland, M. W., Owen, N., Powell, K. E., ... Yi-Park, S. (2016). Does physical activity attenuate, or even eliminate, the detrimental association of sitting time with mortality? A harmonised meta-analysis of data from more than 1 million men and women. The Lancet, 388(10051), 13021310 .

Engel, G. (1977). The need for a New Medical Model: A Challenge for Biomedicine. Science Journal, 196(4286): 129-136.

Esnault, M. \& Viel, E. (2003). Streching: Estiramientos de las cadenas musculares. Barcelona: Masson.

Ferland, M., Despres, J., Tremblay, A. \& Pinault, S. (1989). Assessment of adipose tisue distribution by computed axial tomography in obese women. British Journal of Nutrition: 61 (2), 139-148.

Ferretti, JL., Cointry, G., Capozza, R. \& Frost, H. (2003). Bone mass, bone strength, muscle-bone interactions, osteopenias and osteoporoses. Mech Ageing Dev 124: 269-79.

Fichtlscherer, S., Breuer, S. \& Zeiher, A. (2004). Prognostic value of systemic endothelial dysfunction in patients with acute coronary syndromes. Further evidence for the existence of the vulnerable patient. Circulation 110(14), 1926-32.

Freund, J., Stetts, D., Oostindie, A., Shepherd, J. \& Vallabhajosula, S. (2018). Lower Quarter Y-Balance Test in healthy women 50-79 years old. Journal of Women \& Aging 31 (6), 475-491. 
Fonseca, R., Roschel, H. \& Tricoli,V. (2014). Changes in exercises are more effective than in loading schemes to improve muscle strength. J Strength Cond Res 28: 30853092.

Gabbett, T. (2016). The training — injury prevention paradox : should athletes be training smarter and harder?. Br J Sports Medicine 50, 273-280.

García, Hector (2020). Manual avanzado de reparación postural: Columna cervicotorácica y hombro. Granada: Ponencia en IX MEP 2019-2020.

Gami, A., Witt, B., Howard, D., Erwin, P., Gami, L., Somers, V. \& Montori, V. (2007). Metabolic Syndrome and Risk of Incident Cardiovascular Events and Death. A Systematic Review and Meta-Analysis of Longitudinal Studies. Journal of the American College of Cardiology, 49(4), 403-414.

Glechner, A., Keuchel, L., Affengruber, L., Titscher, V., Sommer, I., Matyas, N., ... Gartlehner, G. (2018). Effects of lifestyle changes on adults with prediabetes: A systematic review and meta-analysis. Primary Care Diabetes 12(5), 393-408.

Gleeson, M., Bishop, N., Stensel, D., Lindley, M., Mastana, S. \& Nimmo, M. (2011). The anti-inflammatory effects of exercise: Mechanisms and implications for the prevention and treatment of disease. Nature Reviews Immunology 11(9), 607-610.

Gomarasca, M., Banfi, G. \& Lombardi, G. (2020). Myokines: The endocrine coupling of skeletal muscle and bone. Advances in Clinical Chemistry, 94; 155-218.

Gonzalez-Gálvez, N., Gea-García, G. \& Marcos-Pardo, P.(2019). Effects of exercise programs on kyphosis and lordosis angle: A systematic review and meta- analysis. PLOS ONE 14(4), 1-18.

Goto, C., Nishioka, K., Umemura, T., Jitsuiki, D., Sakagutchi, A., Kawamura, M., ... \& Higashi, Y. (2007). Acute Moderate-Intensity Exercise Induces Vasodilation Through an Increase in Nitric Oxide Bioavailiability in Humans. American Journal of Hypertension 20(8), 825-830.

Granata, K., Padua, D. \& Wilson, S. (2002). Gender differences in active musculoskeletal stiffness. Part II. Quantification of leg stiffness during functional hopping tasks. Journal of Electromyography and Kinesiology, 12(2), 127-135.

Haddad, M., Stylianides, G., Djaoui, L., Dellal, A. \& Chamari, K. (2017). Session-RPE method for training load monitoring: Validity, ecological usefulness, and influencing factors. Frontiers in Neuroscience, 11.

Hamaguchi, K., Kurihara, T., Fujimoto, M., Iemitsu, M., Sato, K., Hamaoka, T. \& Sanada, K. (2017). The effects of low-repetition and light-load power training on bone mineral density in postmenopausal women with sarcopenia: a pilot study. BMC Geriatrics, 17(1), 1-7.

Harbourne, R. \& Stergiou, N. (2009). Movement Variability and the Use of Nonlinear Tools: Principles to Guide Physical Therapist Practice. Physical Therapy 89(3), 267282.

Harris, S., Kendler, D., Kessel, B., \& Mcclung, M. (2006). Management of osteoporosis in postmenopausal women: 2006 Position statement of The North American Menopause Society. Menopause, 13(3), 340-367. 
Hasegawa, R., Islam, M., Lee, S. (2008). Threshold of lower body muscular strength necessary to perform ADL independently in community-dwelling older adults. Clinical Rehabilitation, 22: 902-910.

Herbert, D.L. (2014). Aspectos legales del entrenamiento personal. En Coburn, J.W. \& Malek, M.H. (2 ${ }^{a}$ Ed.) Manual NSCA: Fundamentos del Entrenamiento Personal (pp. 623-641). Badalona: Paidotribo.

Hebert-Losier, K., Wessman, C., Alricsson, M., Svatesson, U. (2017). Updated reliability and normative values for the standing heel-rise test in healthy adults. Physiotherapy. Dec;103(4):446-452.

Hernlund, E., Svedbom, A., Ivergard, M., Compston, J. Cooper, C. \& Stenmark, J. (2013). Osteoporosis in the European Union: Medical management, epidemiology andeconomic burden. Arch Osteoporos, 8: 136.

Horowitz, J. (2001). Regulation of lipid mobilization and oxidation during exercise in obesity. Exercise and Sport Sciences Reviews 29(1), 42-46.

Huang, Y., Cai, X., Mai, W., Li, M. \& Hu, Y. (2016). Association between prediabetes and risk of cardiovascular disease and all cause mortality: Systematic review and meta-analysis. $B M J, 355$.

Idoate, F., Ibañez, J., Gorostiaga, E., García-Unciti, M., Martínez-Labari, C. \& Izquierdo, M. (2011). Weight-loss diet alone or combined with resistance training induces different regional visceral fat changes in obese women. International Journal of Obesity 35(5), 700-713.

Imboden, M., Harber, M., Whaley, M., Finch, W. Bishop, D. \& Kaminsky, L. (2018). Cardiorespiratory Fitness as a Quantitative Predictor of All-Cause Mortality and Cardiovascular Events in Healthy Men and Women. Journal of American College of Cardiology 301(19):2024-2035.

James, P., Oparil, S., Carter, B., Cushman, W., Dennison-Himmelfarb, C., Handler, J., ... Ortiz, E. (2014). 2014 Evidence-based guideline for the management of high blood pressure in adults: Report from the panel members appointed to the Eighth Joint National Committee (JNC 8). JAMA - Journal of the American Medical Association, 311(5), 507-520.

Jelleyman, C., Yates, T., O’Donovan, G., Gray, L., King, J., Khunti, K., \& Davies, M. (2015). The effects of high-intensity interval training on glucose regulation and insulin resistance: A meta-analysis. Obesity Reviews 16(11), 942-961.

Kaji, H. (2013). Linkage between muscle and bone: Common catabolic signals resulting in osteoporosis and sarcopenia. Current Opinion in Clinical Nutrition and Metabolic Care, 16(3), 272-277.

Kandel, E. Schwartz, J. \& Jesell, T. (2000). Principles of neural science. USA: McGrawHill

Kanis J., Borgstrom, F. \& De Laet, C. (2005). Assessment of fracture risk. Osteoporosis Int, 16: pp. 581-589 
Kamei, Y., Suzuk, M., Miyazaki, H., Tsuboyama-Kasaoka, N., Wu, J., Ishimi, Y. \& Ezaki, O. (2005). Ovariectomy in mice decreases lipid metabolism-related gene expression in adipose tissue and skeletal muscle with increased body fat. J. Nutr. Sci. Vitaminology, 51:110-117.

Kapuš, O., Gába, A. \& Lehnert, M. (2020). Relationships between bone mineral density, body composition, and isokinetic strength in postmenopausal women. Bone Reports, 12(February).

Karlamangla, A., Burnett-Bowie, S. \& Crandall, C. (2018). Bone Health During the Menopause Transition and Beyond. Obstetrics and Gynecology Clinics of North America, 45(4), 695-708.

Karvonen, J. \& Vuorimaa, T. (1988). Heart rate and exercise intensity during sports activities. practical application. Sports Medicine 5(5), 303.

Kendall, F. P., Mc Creary, E. K. \& Provance, P. (2007). Músculos pruebas funcionales, postura y dolor ( $4^{a}$ Edición). Madrid: Marban.

Khamis, S., Dar, G., Peretz, C., Yizhar, Z. (2015). The relationship between foot and pelvic alignment while standing. Journal of Human Kinetics. Vol 46, 85-97.

Ko, S. H., \& Kim, H. S. (2020). Menopause-associated lipid metabolic disorders and foods beneficial for postmenopausal women. Nutrients, 12(1).

Koelé, M., Lems, W. \& Willems, H. (2020). The Clinical Relevance of Hyperkyphosis: A Narrative Review. Frontiers in Endocrinology 11, 1-7.

Kubala, A. G., Barone Gibbs, B., Buysse, D. J., Patel, S. R., Hall, M. H., \& Kline, C. E. (2019). Field-based Measurement of Sleep: Agreement between Six Commercial Activity Monitors and a Validated Accelerometer. Behavioral Sleep Medicine, 1-16.

Kwon, Y., Lim, H., Lee, Y., Lee, H., Linton, J., Lee, J. \& Kang, H. (2017). Associations between high-risk alcohol consumption and sarcopenia among postmenopausal women. Menopause, 24(9), 1022-1027.

Landgren, B., Collins, A., Csemiczky, G., Burger, H., Baksheev, L. \& Robertson, D. (2004). Menopause transition: Annual changes in serum hormonal patterns over the menstrual cycle in women during a nine-year period prior to menopause. J. Clin. Endocrinol. Metab, 89. 2763-2769.

Lanyon, L (1996). Using functional loading to influence bone mass and architecture: objectives, mechanisms, and relationship with estrogen of the mechanically adaptive process in bone. Bone $18,37 \mathrm{~S}-43$

Laukkanen, R., Kukkonen-Harjula, K., Oja, P., Rasanen, M. \& Vuori, I. (2000). Prediction of change in maximal aerobic power by the 2-km Walk Test after walking training in middle-aged adults. International Journal of Sports Medicine; 20: 113116 .

Laurent, C., Green, J., Obispo, P., Sjökvis, J., Schumacker, R., Richardson, M. \& Curtner-Smith, M. (2011). A Practical Approach to Monitoring Recovery: Development of a Perceived Recovery Status Scale. Journal of Strength and Conditioning Research 25 (3) 620-628. 
Lee, D., Kang, M., Lee, T. \& Oh, J.(2015). Relationships among the Y balance test, Berg Balance Scale, and lower limb strength in middle-aged and older females. Brazilian Journal of Physical Therapy, 19(3), 227-234.

Leetun, D., Ireland, M., Willson, J., Ballantyne, B. \& Davis, I. (2004). Core stability measures as risk factors for lower extremity injury in athletes. Medicine and Science in Sports and Exercise, 36(6), 926-934.

Levinson, R. (2014). Metabolyc sindrome ePoster. Nature Medicine.

Lewington, S., Clarke, R., Qizilbash, N., Peto, R. \& Collins, R. (2002). Age-specific relevance of usual blood pressure to vascular mortality: A meta-analysis of individual data for one million adults in 61 prospective studies. The Lancet 360: 1903-1913

Li, R., Xia, J., Zhang, X., Gathirua-Mwangi, W. G., Guo, J., Li, Y., ... Song, Y. (2018). Associations of Muscle Mass and Strength with All-Cause Mortality among US Older Adults. Medicine and Science in Sports and Exercise, 50(3), 458-467.

Liu, Y., Ye, W., Chen, Q., Zhang, Y., Kuo, C. \& Korivi, M. (2019). Resistance exercise intensity is correlated with attenuation of HbA1c and insulin in patients with type 2 diabetes: A systematic review and meta-analysis. International Journal of Environmental Research and Public Health, 16(1).

Lupsa, B. \& Insogna, K. (2015). Bone Health and Osteoporosis. Endocrinology and Metabolism Clinics of North America, 44(3), 517-530.

Ma, X., Yue, Z., Gong, Z., Zhang, H., Duan, N., Shi, Y., ... Li, Y. F. (2017). The effect of diaphragmatic breathing on attention, negative affect and stress in healthy adults. Frontiers in Psychology, 8 Jun, 1-12.

Marín-Cascales, E., Alcaraz, P., Ramos-Campo, D. \& Rubio-Arias, J. (2017). Effects of multicomponent training on lean and bone mass in postmenopausal and older women: a systematic review. Menopause: The Journal of The North American Menopause Society 25(3), 346-356.

Menéndez, E., Delgado, E., Fernández-Vega, F., Prieto, M. A., Bordiú, E., Calle, A., ... Soriguer, F. (2016). Prevalencia, diagnóstico, tratamiento y control de la hipertensión arterial en España. Resultados del estudio Di@ bet.es. Revista Espanola de Cardiologia 69(6), 572-578.

Marques, E., Mota, J. \& Carvalho, J. (2012). Exercise effects on bone mineral density in older adults : a meta-analysis of randomized controlled trials. Age (34), 1493-1515.

Messier, V., Rabasa-Lhoret, R., Barbat-Artigas, S., Elisha, B., Karelis, A. D., \& AubertinLeheudre, M. (2011). Menopause and sarcopenia: A potential role for sex hormones. Maturitas, 68(4), 331-336.

Ministerio de Sanidad, Consumo y Bienestar Social. (2017). Encuesta Nacional de Salud (ENSE). Madrid: Gobierno de España.

Ministerio de Sanidad, Consumo y Bienestar Social, (2019). Informe de la Subdirección General de Ordenación Profesional sobre competencias de Educadores/as Físico Deportivos/as. Madrid: Gobierno de España. 
Montgomery, G., Abt, G., Dobson, C., Smith, T., Evans, W. \& Ditroilo, M. (2019). The mechanical loading and muscle activation of four common exercises used in osteoporosis prevention for early postmenopausal women. Journal of Electromyography and Kinesiology, 44: 124-131.

Muka, T., Oliver-Williams, C., Kunutsor, S., Laven, J., Fauser, B., Chowdhury \& Franco, O. (2016). Association of age at onset of menopause and time since onset of menopause with cardiovascular outcomes, intermediate vascular traits, and all-cause mortality: A systematic review and meta-analysis. JAMA Cardiology, 1(7): 767-776.

Myers, Thomas W. (2010). Vías anatómicas: Meridianos miofasciales para terapeutas manuales y del movimiento. Barcelona: Elsevier Masson.

Nagai, M., Hoshide, S., \& Kario, K. (2010). Sleep Duration as a Risk Factor for Cardiovascular Disease- a Review of the Recent Literature. Current Cardiology Reviews, 6(1), 54-61.

Naranjo Hernández, A., Diaz del Campo, P., Aguado, M. \& Casado, E. (2018). Recomendaciones de la Sociedad Espanola de Reumatología sobre osteoporosis. Reumatol Clin 515 (4): 188-210

Narula, J., Nakano, M., Virmani, R., Kolodgie, F., Petersen, R. \& Newcomb, R. (2013). Histopathologic Characteristics of Atherosclerotic Coronary Disease and Implications of the Findings for the Invasive and Noninvasive Detection of Vulnerable Plaques. J Am Coll Cardiol. 61(10), 1041-51002.

National Institutes of Health, NIH (2001). NIH Consensus Development Program: Osteoporosis prevention, diagnosis, and therapy. JAMA, 285: 785-795.

Nelson, M., Rejeski, W., Blair, S. et al. (2007). Physical activity and public health in older adults: recommendation from the American College of Sports Medicine and the American Heart Association. AHA J 116:1094-1105, 2007.

Orueta, R., \& Gómez-Caro, S. (2010). Interpretación de la densitometría ósea. Semergen, $36(1), 27-30$.

Otsuki, T., Nakamura, F. \& Zempo-Miyaki, A. (2019). Nitric Oxide and Decreases in Resistance Exercise Blood Pressure With Aerobic Exercise Training in Older Individuals. Frontiers in Physiology, 10, 1-9.

Panjabi, M (1992). The stabilizing system of the spine. Part I. Function, dysfunction, adaptation, and enhancement. Journal of Spinal Disorders 5 (4) 383-389

Pamukoff, D., Ryan, E. \& Troy Blackburn, J. (2014). The acute effects of local muscle vibration frequency on peak torque, rate of torque development, and EMG activity. Journal of Electromyography and Kinesiology, 24(6), 888-894.

Pedersen, B. \& Saltin, B. (2015). Exercise as medicine-evidence for prescribing exercise as therapy in 26 different chronic diseases. Scandinavian Journal of Medicine \& Science in Sports, 1-72.

Pellikaan, P., Giarmatzis, G., Vander Sloten, J., Verschueren, S. \& Jonkersl, I. (2018). Ranking of osteogenic potential of physical exercises in postmenopausal women based on femoral neck strains. PLoS One 13(4). e0195463.55. 
Perumareddi, P. (2019). Prevention of Hypertension Related to Cardiovascular Disease. Primary Care - Clinics in Office Practice 46(1), 27-39.

Pescatello, L., MacDonald, H., Lamberti, L. \& Johnson, B. (2015). Exercise for Hypertension: A Prescription Update Integrating Existing Recommendations with Emerging Research. Current Hypertension Reports 17(11).

Peterson, S. \& Braunschweig, C. (2016) Prevalence of sarcopenia and associated outcomes in the clinical setting. Nutr Clin Pract, 31: 40-48.

Pintos, P., Esteban, L., Bozzini, C., Friedman, S. \& Boyer, P. (2013). Modificación del mecanismo operacional del mecanostato óseo en un modelo de estrés nutricional por efecto del propanolol. Revista de Investigación Clínica 65 (1), 39-51

Plowman, S., \& Meredith, M. (2013). Fitnessgram/Activitygram Reference Guide (4th Edition). Dallas, Texas: The Cooper Institute, 8-55.

Powden, C., Dodds, T. \& Gabriel, E. (2019). The reliability of the Star Excursion Balance Test and lower quarter Y-Balance Test in healthy adultos: a systematic review. International Journal Sports and Physical Therapy, 14(5); 683-694.

Prado, C. M., Purcell, S. A., Alish, C., Pereira, S. L., Deutz, N. E., Heyland, D. K., ... Heymsfield, S. B. (2018). Implications of low muscle mass across the continuum of care: a narrative review. Annals of Medicine, 50(8), 675-693.

Ramos, S., Hervás, M., Morales, E., García, M. \& Cervera, R. (2008). Presión arterial: ¿esfigmomanómetro manual o digital?. Enfermería global, 13. 5-7.

Remor, E. (2001). Psychometric properties of a European Spanish version of the Perceived Stress Scale (PSS). Ansiedad y estrés 7(2-3):195-201

Rikli, R. \& Jones, C (1999). Development and validation of a functional fitness test for community-residing older adults. JAPA (7) 2: 155-160.

Roher, N., Samokhvalov, V., Díaz, M., MacKenzie, S., Klip, A., \& Planas, J. (2008). The proinflammatory cytokine tumor necrosis factor- $\alpha$ increases the amount of glucose transporter-4 at the surface of muscle cells independently of changes in interleukin6. Endocrinology 149(4), 1880-1889.

Rubin, K., Friis-Holmberg, T., Hermann, A., Abrahamsen, B. \& Brixen, K. (2013). Risk assessment tools to identify women with increased risk of osteoporotic fracture: Complexity or simplicity? A systematic review. Journal of Bone and Mineral Research, 28(8), 1701-1717.

Rubio, M., Moreno, C. \& Cabrerizo, L. (2004). Guías para el tratamiento de las dislipemias en el adulto: Adult Treatment Panel III (ATP-III). Endocrinología y Nutrición, 51(5), 254-265.

Sahrmann, Shirley A. (2002). Diagnóstico y tratamiento de las alteraciones del movimiento. Badalona: Paidotribo.

Sakamoto, S. (2020). Prescription of exercise training for hypertensives. Hypertension Research 43(3), 155-161.

Schabrun, S. \& Chipchase, L. (2012). Priming the brain to learn: The future of therapy? Manual Therapy, 17(2), 184-186. 
Schultz, W. (2013). Updating dopamine reward signals. Current Opinion in Neurobiology, 23(2), 229-238.

Shcherbina, A., Mikael Mattsson, C., Waggott, D., Salisbury, H., Christle, J. W., Hastie, T., ... Ashley, E. A. (2017). Accuracy in wrist-worn, sensor-based measurements of heart rate and energy expenditure in a diverse cohort. Journal of Personalized Medicine, 7(2), 1-12.

Shen, X., Wu, Y., \& Zhang, D. (2016). Nighttime sleep duration, 24-hour sleep duration and risk of all-cause mortality among adults: A meta-analysis of prospective cohort studies. Scientific Reports, 6(38), 1-8.

Shin, J., Lee, J., Lim, S., Ha, H., Kwon, H., Park, Y., ... Son, H. Y. (2013). Metabolic syndrome as a predictor of type 2 diabetes, and its clinical interpretations and usefulness. Journal of Diabetes Investigation, 4(4), 334-343.

Silsupadol, P., Shumway-cook, A., Lugade, V., Van Donkelaar, P., Chou, L., Mayr, U. \& Woollacott, M. (2009). Effects of Single-Task Versus Dual-Task Training on Balance Performance in Older Adults : A Double-Blind, Randomized Controlled Trial. Arch Phys Med Rehabil 90(3), 381-387.

Sipilä, S., Finni, T. \& Kovanen, V. (2015). Estrogen Influences on Neuromuscular Function in Postmenopausal Women. Calcif Tissue Int, 96; 222-233.

Smart, N., Gow, J., Bleile, B., Van der Touw, T. \& Pearson, M.(2020). An evidencebased analysis of managing hypertension with isometric resistance exercise - are the guidelines current? Hypertension Research 43(4), 249-254.

Smart, N., Way, D., Carlson, D., Millar, P., McGowan, C., Swaine, I., ... \& Bleile, B. (2019). Effects of isometric resistance training on resting blood pressure: Individual participant data meta-Analysis. Journal of Hypertension 37(10), 1927-1938.

Smith, C., Chimera, N. \& Warren, M. (2015). Association of y balance test reach asymmetry and injury in division I athletes. Med Sci Sports Exerc, 47(1), 136-141.

Sosa, M (2004). Protocolos Osteoporosis. Sociedad Española de Medicina Interna, 3738.

Stearns, K., Keim, R., Powers, C. (2013). Influence of relative hip and knee extensor muscle strength on landing biomechanics. Medicine \& Science in Sport \& Exercise 45 (5) 953-41.

Stecco, A., Stern, R., Fantoni, I., De Caro, R. \& Stecco, C. (2015). Fascial Disorders: Implications for Treatment. $P M \& R$ 8: 161-168.

Stecco, C., Stern, R., Porzionato, A., MacChi, V., Masiero, S., Stecco, A. \& De Caro, R. (2011). Hyaluronan within fascia in the etiology of myofascial pain. Surgical and Radiologic Anatomy, 33(10), 891-896.

Stefanska, A., Bergmann, K. \& Sypniewska, G. (2015). Metabolic Syndrome and Menopause: Pathophysiology, Clinical and Diagnostic Significance. Adv. Clin. Chem, 72:1-75. 
Suni, J., Husu, P., \& Rinne, M. (2009). Fitness for health: the ALPHA-FIT test battery for adults aged 18-69. Tester's Manual. Tampare, Finland: European Union DS, UKK Institute for Health Promotion Research.

Swain, D. \& Franklin, B. (2006) Comparison of cardioprotective benefits of vigorous versus moderate intensity aerobic exercise. Am J Cardiol, 97; 141-147. doi:10.1016/j.amjcard.2005.07.130

Takahashi, T. \& Johnson, K. (2015) Menopause. Med. Clin. N. Am., 99 521-534.

Teixeira, L., Silva, K., Imoto, A., Teixeira, T., Kayo, A., Montenegro-Rodrigues, R., Peccin, M. \& Trevisani, V. (2010) Progressive load training for the quadriceps muscle associated with proprioception exercises for the prevention of falls in postmenopausal women with osteoporosis: a randomized controlled trial. Osteoporos Int 21(4), 589-596.

Thaung Zaw, J., Howe, P. \& Wong, R. (2018) Postmenopausal health interventions: Time to move on from the Women's Health Initiative? Ageing Res. Rev., 48: 79-86.

Thompson, W. (2019). Worldwide survey of fitness trends for 2020. ACSM's Health \& Fitness Journal, 23 (6): 10-18.

Thompson, W., Gordon, N. \& Pescatello, L. (2014). Manual ACSM para la valoración y prescripción del ejercicio. Badalona, España: Paidotribo.

Turner, C. \& Robling, A. (2003). Designing Exercise Regimens to Increase Bone Strength, Exercise and Sports Sciences Review 31 (1), 45-50.

Vainionpää, R., Korpelainen, E., Vihriälä, A., Rinta-Paavola, J. \& Jämsä, A. (2006). Intensity of exercise is associated with bone density change in premenopausal women, Osteopososis International (17), 455-463.

Varahra, A., Rodrigues, I., MacDermid, J., Bryant, D. \& Birmingham, T.(2018). Exercise to improve functional outcomes in persons with osteoporosis : a systematic review and meta-analysis. Osteoporosis International 29, 265-286

Vilagut, G., Ferrer, M., Rajmil, L., Rebollo, P., Permanyer-Miralda, G., Quintana, J. M., . . . Domingo-Salvany, A. (2005). El cuestionario de salud SF-36 español: Una década de experiencia y nuevos desarrollos. Gaceta Sanitaria. 19, 135-150.

Von Stengel, S., Kemmler, W., Lauber, D., Kalender, W. \& Engelke, K. (2007). Differential effects of strength versus power training on bone mineral density in postmenopausal women: a 2-year longitudinal study. British Journal of Sports Medicine 41 (10), 649-655.

Wang, F., Han, L. \& Hu, D. (2017). Fasting insulin, insulin resistance and risk of hypertension in the general population: A meta-analysis. Clinica Chimica Acta 464(1), 57-63.

Wang, Y., \& Xu, D. (2017). Effects of aerobic exercise on lipids and lipoproteins. Lipids in Health and Disease 16(1), 1-8.

Watson, S., Weeks, B., Weis, L., Harding, A., Horan, S. \& Beck, B. (2019). Highintensity exercise did not cause vertebral fractures and improves thoracic kyphosis in postmenopausal women with low to very low bone mass: the LIFTMOR trial. Osteoporosis International 30(5), 957-964. 
Watts, N., Adler, R., Bilezikian, J., Drake, M., Eastell, R., Orwoll, E., \& Finkelstein, J. (2012). Osteoporosis in men: An Endocrine Society clinical practice guideline. Journal of Clinical Endocrinology and Metabolism, 97(6), 1802-1822.

Whelton, P., Carey, R. \& Aronow, W. (2018) ACC/AHA/AAPA/ABC/ACPM/AGS/APhA/ASH/ASPC/NMA/PCNA guideline for the prevention, detection, evaluation, and Management of High Blood Pressure in adults: a report of the American College of Cardiology/American Heart Association task force on clinical practice guidelines. Hypertension 71(6):1269324.

Wiewelhove, T., Döweling, A., Schneider, C., Hottenrott, L., Meyer, T., Kellmann, M., Pfeiffer, M. \& Ferrauti, A. (2019). A meta-analysis of the effects of foam rolling on performance and recovery. Frontiers in Physiology 10, 1-15.

Wulf, G. \& Lewthwaite, R. (2016). Optimizing performance through intrinsic motivation and attention for learning: The OPTIMAL theory of motor learning. Psychonomic Bulletin and Review, 23(5), 1382-1414.

Xie, J., Wen, D., Liang, L., Jia, Y., Gao, L., \& Lei, J. (2018). Evaluating the validity of current mainstream wearable devices in fitness tracking under various physical activities: Comparative study. JMIR mHealth and uHealth, 6(4).

Xu, J., Lombardi, G., Jiao, W. \& Banfi, G. (2016). Effects of Exercise on Bone Status in Female Subjects, from Young Girls to Postmenopausal Women : An Overview of Systematic Reviews and Meta-Analyses. Sports Medicine, 46(8), 1165-1182.

Youdas, J., Krause, D. \& Hollman, J. (2015). The influence of gender and age on hamstring muscle length in healthy adults. Journal of orthopaedic \& Sports Physical Therapy 35 (4), 246-252.

Young, D. R., Hivert, M. F., Alhassan, S., Camhi, S. M., Ferguson, J. F., Katzmarzyk, P. T., ... Yong, C. M. (2016). Sedentary behavior and cardiovascular morbidity and mortality: A science advisory from the American Heart Association. Circulation, 134(13), e262-e279.

Zacarías-Flores, M., Sánchez-Rodríguez, M. A., García-Anaya, O. D., Correa-Muñoz, E., \& Mendoza-Núñez, V. M. (2018). Relationship between oxidative stress and muscle mass loss in early postmenopause: an exploratory study. Endocrinologia, Diabetes y Nutricion, 65(6), 328-334.

Zhao, R., Feng, F., \& Wang, X. (2017). Exercise interventions and prevention of fallrelated fractures in older people: A meta-analysis of randomized controlled trials. International Journal of Epidemiology, 46(1), 149-161.

Zhao, R., Zhao, M. \& Xu, Z. (2015). The effects of differing resistance training modes on the preservation of bone mineral density in postmenopausal women : a metaanalysis. Osteoporosis International, 26; 1605-1618.

Zhao, R., Zhang, M. \& Zhang, Q. (2017). The Effectiveness of Combined Exercise Interventions for Preventing Postmenopausal Bone Loss: A Systematic Review and Meta-analysis. Journal of Orthopaedic \& Sports Physical Therapy 47(4), 241-251. 
ANEXOS 
DXA 2019

\section{POLICLÍNICA DE ALMERIAA GRUPO HLA \\ Avda. Federico Garcia Lorca, 50 \\ Almeria 04005}

Sexo: Mujer

Raza: Blanca

Edad de menopausia: 4

ID del paciente:
Fecha de nacimiento: II Septiembre 1959

Médico remitente:

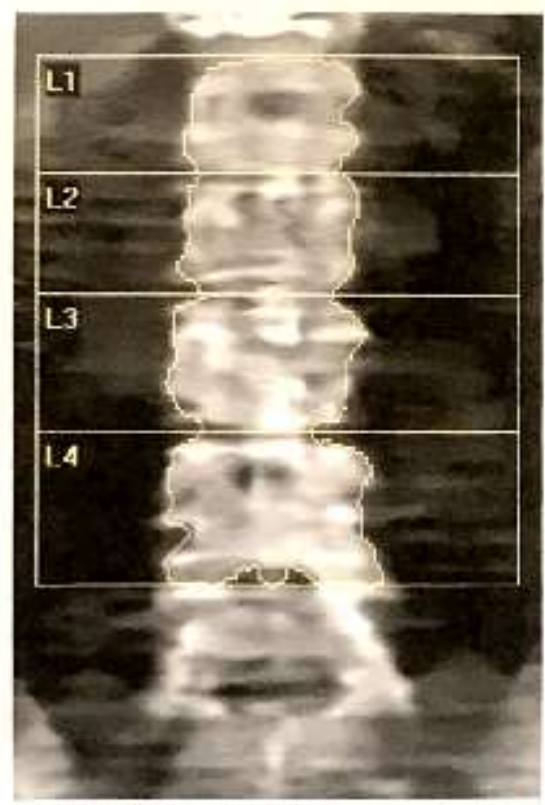

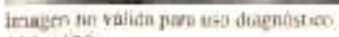
$116 \times 128$

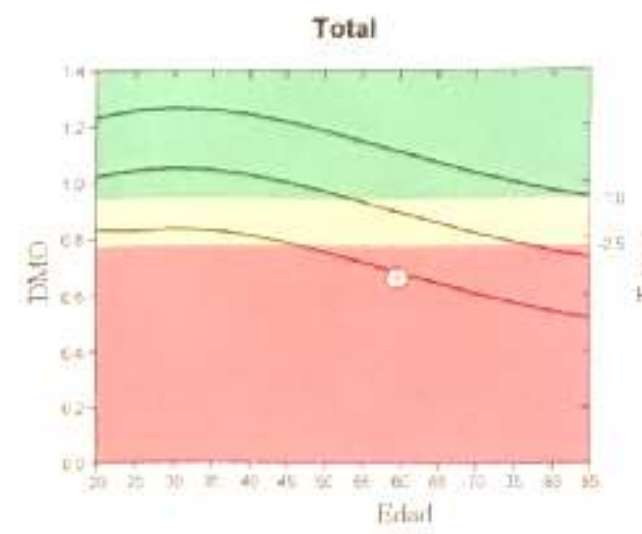

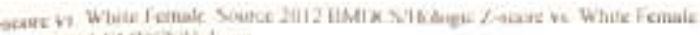

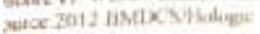

\section{Comentario:}

\section{Información de la exploración:}

Fecha exploración: 23 Mayo 2019 ID: A0523190D

Tipo exploración: a Columns vertebral lumbar

Análisis: 23 Mayo 2019 16:25 Versión 13.6.0.5

Columna vertebral lumbar

Operasur:

Modelo: Horizon Wi (S/N 301904M)

Connentario:

Resumen de resultados DEXA:

\begin{tabular}{|lrrrrr|}
\hline Region & $\begin{array}{r}\text { Area } \\
\left(\mathrm{em}^{2}\right)\end{array}$ & $\begin{array}{r}\text { CMO } \\
(\mathrm{g})\end{array}$ & $\begin{array}{r}\text { DMO } \\
\left(\mathrm{g} / \mathrm{cm}^{2}\right)\end{array}$ & $\begin{array}{r}\text { T- } \\
\text { score }\end{array}$ & $\begin{array}{r}\boldsymbol{Z} \text { - } \\
\text { score }\end{array}$ \\
$\mathrm{L} .1$ & 10.22 & 5.85 & 0.572 & -3.2 & -2.0 \\
$\mathrm{~L} 2$ & 11.78 & 7.21 & 0.612 & -3.8 & -2.4 \\
$\mathrm{~L} 3$ & 13.78 & 9.52 & 0.691 & -3.6 & -2.1 \\
$\mathrm{~L} 4$ & 13.05 & 12.10 & 0.710 & -3.7 & -2.2 \\
Tota1 & $\mathbf{5 2 . 8 3}$ & $\mathbf{3 4 . 6 8}$ & $\mathbf{0 . 6 5 6}$ & -3.6 & -2.2 \\
\hline
\end{tabular}

$10 \% \mathrm{dec}$ de Dewn xital

Clasificación de ia OMS: Osteoporosis.

Riesgo de fractura: Alto 


\section{POLICLÍNICA DE ALMERIAA GRUPO HLA \\ Avda. Federico Garcia Lorca, 50 \\ Almeria 04005}

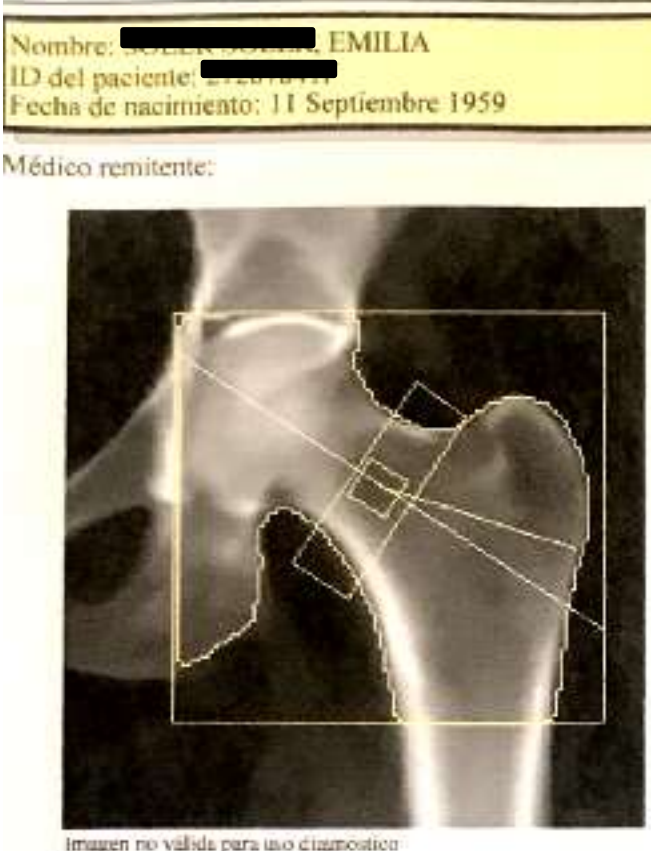

Sexo: Mujer

Raca: Blanca

Edad de menopausia: 41

Height: $153.0 \mathrm{~cm}$

Peso: $56.9 \mathrm{~kg}$

Bdad: 59

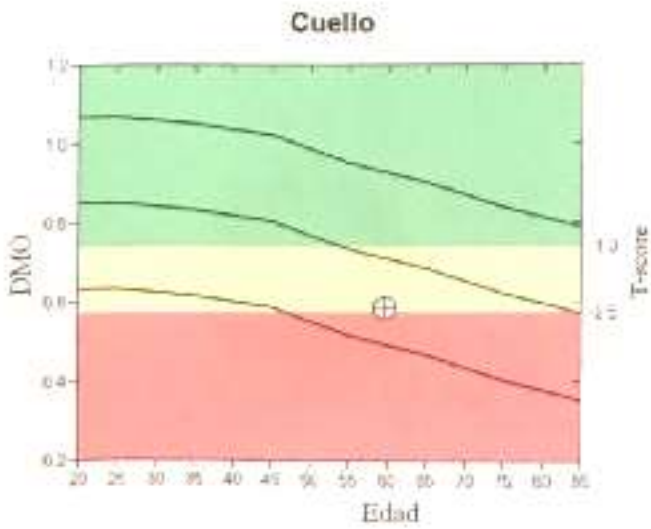

\section{Información de la exploración:}

Fecha exploración: 23 Mayo 2019 ID: Aus23190E

Tipu exploración: a Cadera izquierda

Análisis: $\quad 23$ Muyo 2019 16:24 Versión [3.6.0.5

Cadera izyuierda

Operador:

Modelo: florizon Wi (S/N 301904M)

Comentario:

Resumen de resultados DEXA:

\begin{tabular}{|c|c|c|c|c|c|}
\hline Regínı & $\underset{\left(\mathrm{cm}^{2}\right)}{\text { Arca }}$ & $\begin{array}{r}\text { CMO } \\
\text { (g) }\end{array}$ & $\underset{\left(g^{\prime} i \mathrm{~cm}^{2}\right)}{\text { DMO }}$ & $\begin{array}{c}\text { T- } \\
\text { score }\end{array}$ & $\begin{array}{r}\text { Z- } \\
\text { score }\end{array}$ \\
\hline Cuello & 4.96 & 2.91 & 0.586 & -2.4 & -1.1 \\
\hline Trocánter & 9.61 & 4.89 & 0.509 & -19 & -1.1 \\
\hline Inter & 16.92 & 13.93 & 0.823 & -1.8 & -1.1 \\
\hline Total & 31.49 & $2 t, 72$ & 0.690 & -2.1 & -1.1 \\
\hline Triàngulo de & Waes & 0.37 & 0.363 & -3.2 & -1.2 \\
\hline
\end{tabular}

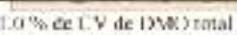

Clasificación de la OMS: Osteopenia

\section{Riesgo de fractura durante 10 años}

No se informó FRAX porque:

Algunos T-scores para columna vertebral total, cadera total o cuello fernonat menores que -2.5 .

\section{Comentario:}


DXA 2020

\section{POLICLÍNICA DE ALMERÍA GRUPO HLA \\ Avda. Federico Garcia Lorca, 50 \\ Almería 04005}

\begin{tabular}{|c|c|c|}
\hline $\begin{array}{l}\text { ambre } \\
\text { Y dol paciente } \\
\text { phal de nacimiento: } 1 \text { I Septicmbre } 1959\end{array}$ & $\begin{array}{l}\text { Sexo: Mujer } \\
\text { Raza: Blanca } \\
\text { Edaut de menopausia: } 41\end{array}$ & $\begin{array}{l}\text { Height: } 154.0 \mathrm{~cm} \\
\text { Peso: } 57,7 \mathrm{~kg} \\
\text { Edad: } 60\end{array}$ \\
\hline
\end{tabular}

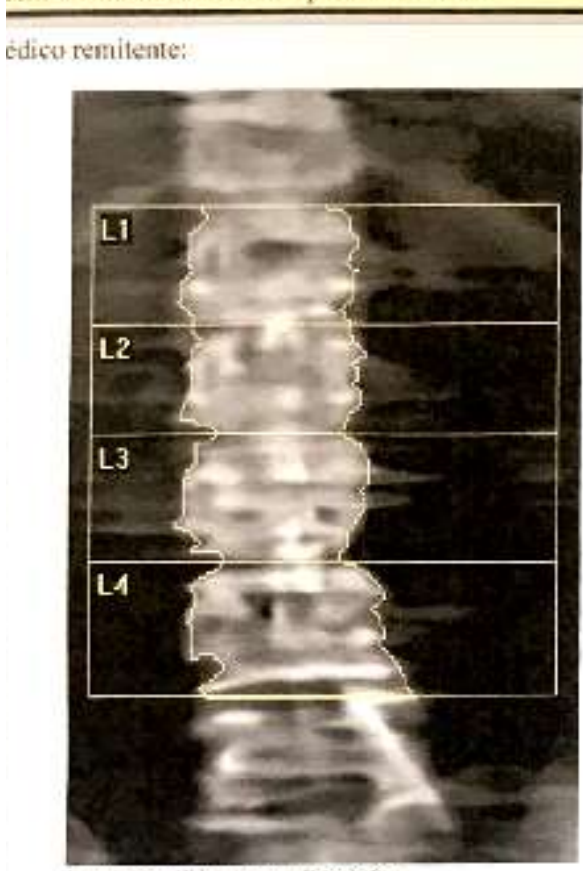

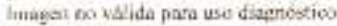

Información de la exploración:

Fecha exploración: 03 Junio 2020 ID: A06032006

Tipo exploración: a Columna vertebral lumbar

Analisis: 03 Junio $202016: 35$ Versión 13.6.0.5

Operador:

Modelo: Horizon Wi (S.N 301904M)

Curtentario:

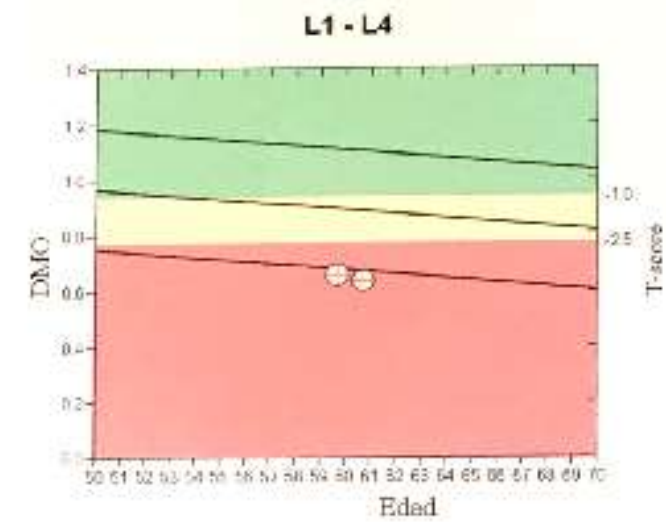

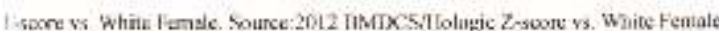
Soune 2012 HMIX SH Hologic

sumen de resultados DEXA: L1 - L4

\begin{tabular}{|c|c|c|c|c|c|}
\hline cha exploracion & Edad & $\underset{\left(\mathrm{g}^{\prime} / \mathrm{cm}^{7}\right)}{\text { DMO }}$ & $\begin{array}{l}\text { T - } \\
\text { score }\end{array}$ & $\begin{array}{l}\text { Cam } \\
\text { sersus tinea hasal }\end{array}$ & $\begin{array}{l}\text { DMO } \\
\text { versus previo }\end{array}$ \\
\hline 06.2020 & 60 & 0.6 .36 & -3.7 & $-3,1 \% \sigma^{\prime \prime}$ & $-3,1^{11 / 14}$ \\
\hline 05.2019 & 59 & 0.656 & -3.6 & & \\
\hline
\end{tabular}

motes siynificance at $95 \%$ confidence level, $1.5 \mathrm{SC}$ is $0.022 \mathrm{~g} / \mathrm{cm}^{\prime}$ presia métodos de análisis o tipos de exploraciones diferentes. 


\section{POLICLÍNICA DE ALMERIAA GRUPO HLA \\ Avda. Fedorico Garcia Lorca, 50 Almeria 04005}

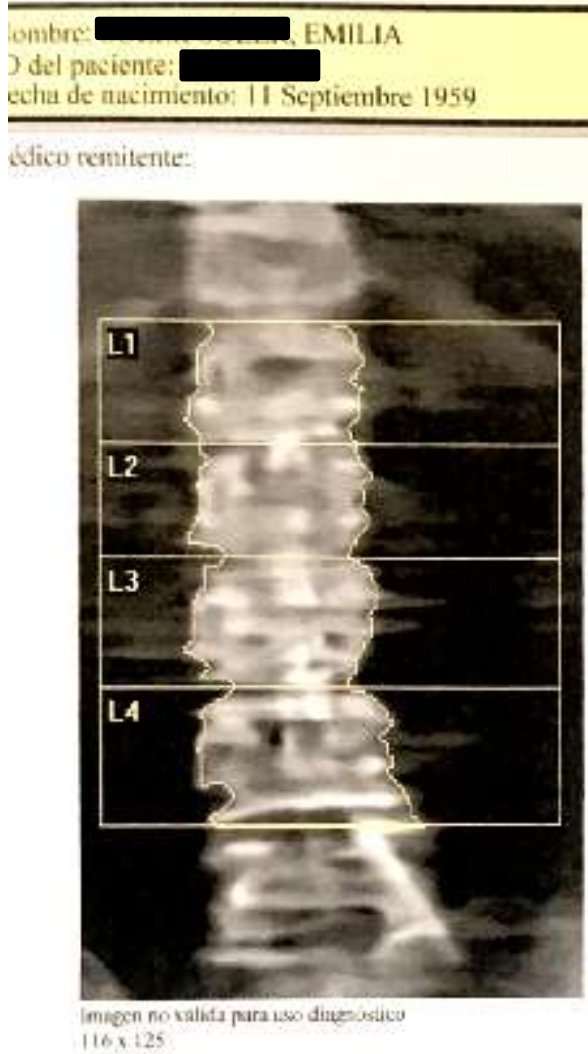

Sexo: Mujer

Height: $154.9 \mathrm{~cm}$

Raza: Blanca

Edad de menopausia: 41

Peso: $57.7 \mathrm{~kg}$

Edad: 60

\section{Información de la exploración:}

Fecha expleración: 03 Junio 2020 ID: A06032606:

Tipo exploración: a Columna vertebral lumbar

Análisis: $\quad 03$ Junio 2020 16:35 Versión 13.6.0.5

Lumbar Spine (auto low density)

Operador:

Modclo: Harizon Wi (SN 301904M)

Comentario:

Resumen de resultados DEXA:

\begin{tabular}{|lrrrrr|}
\hline Region & $\begin{array}{r}\text { Area } \\
\left(\mathrm{cm}^{2}\right)\end{array}$ & $\begin{array}{r}\text { CMO } \\
(\mathrm{g})\end{array}$ & $\begin{array}{r}\text { DMO } \\
\left(\mathrm{g} / \mathrm{cm}^{2}\right)\end{array}$ & $\begin{array}{r}\text { T- } \\
\text { score }\end{array}$ & $\begin{array}{r}\mathbf{Z}- \\
\text { scure }\end{array}$ \\
$\mathrm{LI}$ & 12.24 & 6.29 & 0.514 & -3.7 & -2.4 \\
$\mathrm{~L} 2$ & 11.58 & 7.18 & 0.620 & -3.7 & -2.3 \\
$\mathrm{~L} 3$ & 13.58 & 9.44 & 0.695 & -3.5 & -2.0 \\
$\mathrm{~L} 4$ & 16.36 & 11.27 & 0.689 & -3.9 & -2.3 \\
Total & $\mathbf{5 3 . 7 5}$ & $\mathbf{3 4 . 1 8}$ & $\mathbf{0 . 6 3 6}$ & $-\mathbf{3 . 7}$ & $-\mathbf{2 . 3}$ \\
\hline
\end{tabular}

$111 \%$ de CV de DWh ond

Clasilizacion de la OSIS: Osteoporosis

Riesgo de tractura: Alto

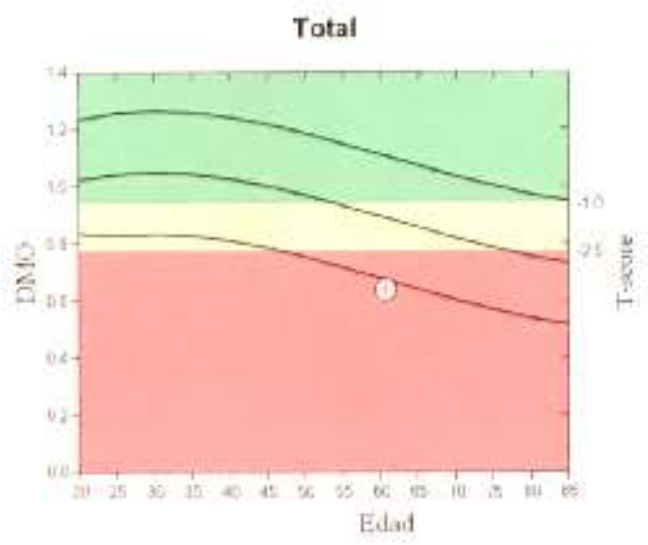

Comentario:

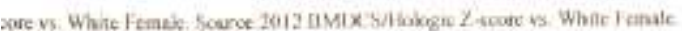

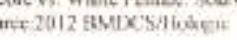




\section{POLICLÍNICA DE ALMERIA GRUPO HLA \\ Avda. Federico Garcia Lorca, 50 \\ Almeria 04005}

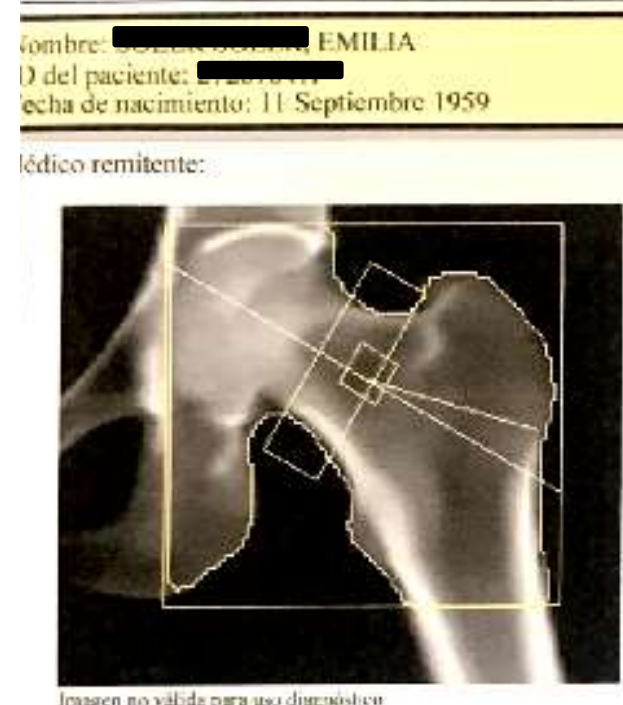

Sexo: Mujer

Height: $154.0 \mathrm{~cm}$

Raza: Blance

Edad de menopausiu: 41

Peso: $57.7 \mathrm{~kg}$

echa de nacimiento: I I Septiembre 1959

Información de la exploración:

Irangen no vatide para uso diagriolicu

$90 \times 87$

(c) $1110204 \times 13$

HeAl $97 \mathrm{mis}$
Fecha exploración: 03 Junio 2020 TD: A0603200H

Tipo exploración: a Cadera izquierda

Análisis: $\quad 03$ Junio 2020 16:34 Versión 13.6.0.5

$$
\text { Cadera izquitenda }
$$

Operadur:

Modelo; Horizon Wi (SN 301904M)

Comentario:

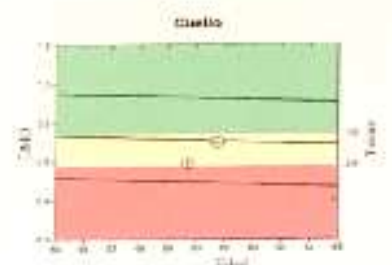

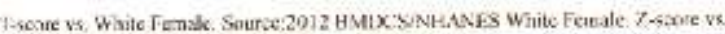
Whire Female Saure:2012 DMDCSTSHLNES Whide temale.

\section{Riesgo de fractura durante 10 an̉os}

No se infurmó FRAX porque:

Algunus T-scores para columba verteloral total, cadera total o cleilo femoral menores que - 2.5

Isumen de resultados DEXA:

\begin{tabular}{|c|c|c|c|c|c|}
\hline \multirow{2}{*}{ cha exploracuón } & \multirow{2}{*}{ Edad } & \multirow{2}{*}{$\underset{\left(g^{\prime} / \mathrm{ca}^{2}\right)}{\text { DNO }}$} & \multirow{2}{*}{$\begin{array}{c}\text { T- } \\
\text { scare }\end{array}$} & \multicolumn{2}{|c|}{ Cambio de DMO } \\
\hline & & & & yersus limea basal & versus previo \\
\hline 06.2020 & 60 & 0.698 & -1.4 & $19.2 \% 0^{+}$ & $102 \%$ \\
\hline 05.2010 & 59 & 0.586 & -24 & & \\
\hline
\end{tabular}

enotes significance at $95 \%$ confidence tevel, LSC is $0.029 \mathrm{~g}^{\prime} \mathrm{cm}^{2}$ 


\section{POLICLÍNICA DE ALMERIAA GRUPO HLA \\ Avda. Federico Garcia Lorca, 50 \\ Almeria 04005}

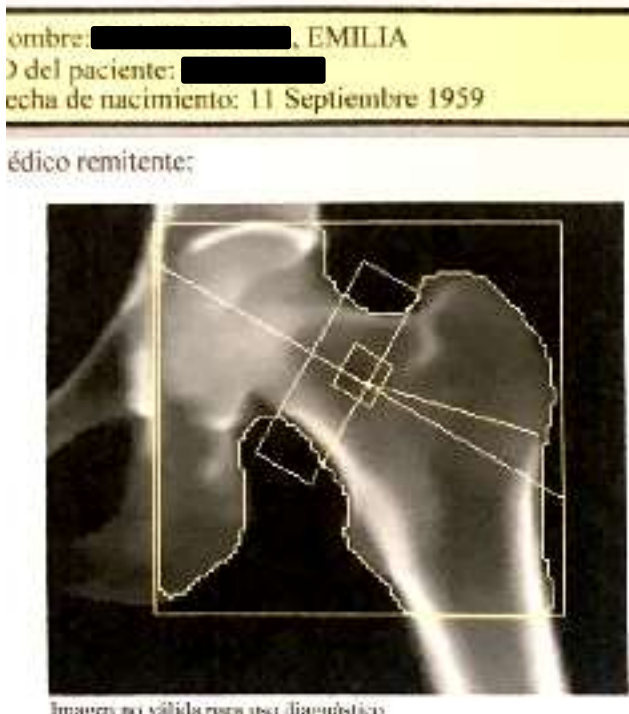

Sexo: Mujer

Raza: Blancat

Edad de menopausia: 41

Height: $154.0 \mathrm{~cm}$

Peso: $57.7 \mathrm{~kg}$

Edad: 60

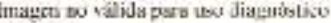

$91 \times 87$

CULLLO $49 \times 15$

H.N. $-197 \mathrm{~mm}$

\section{Cuello}

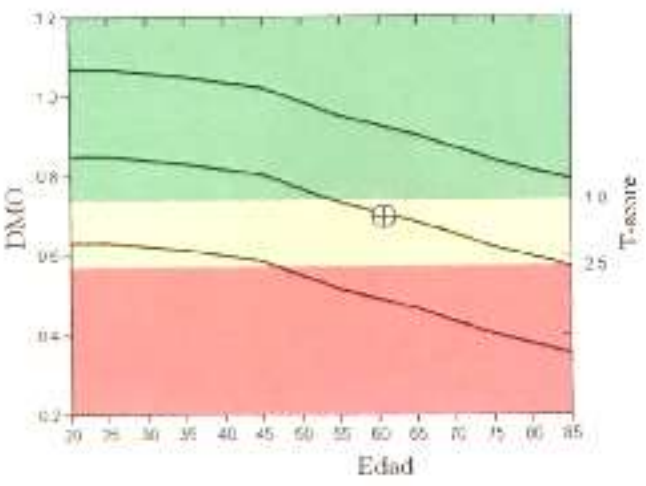

Información de la exploración:

Fecha exploración: 03 Junio 2020 ID: A0603200H

Tipo exploración: a Cadera izquierda

Análisis: $\quad 03$ Junio 2020 16:34 Versión 13.5.0.5

Cadera izquienda

Operador:

Modelo: Horizon Wi (S/N 30t904M)

Comentario:

\section{Resumen de resultados DEXA:}

\begin{tabular}{|c|c|c|c|c|c|}
\hline Rcgión & $\begin{array}{l}\text { Aren } \\
\left(\mathrm{um}^{2}\right)\end{array}$ & C:MO & $\underset{\left(\mathrm{g}^{\prime} / \mathrm{em}^{2}\right)}{\text { DMO }}$ & $\underset{\text { score }}{T}$ & $\begin{array}{r}\text { Z- } \\
\text { score }\end{array}$ \\
\hline Cuello & 4.66 & 3.25 & 0.698 & -1.4 & -0.1 \\
\hline Trucuinter & 10.05 & 5.27 & 0.525 & -1.8 & -0.9 \\
\hline Inter & 18.04 & 14.88 & 0.825 & -1.8 & -1.0 \\
\hline Toxil & 32.75 & 23.40 & 0.715 & -1.9 & -0.9 \\
\hline Triangualo de & W:At & 0.48 & $0.4 \cdot 12$ & -2.5 & -0.5 \\
\hline
\end{tabular}

10\$ Secv ife merome

Clasificación de la OMS: Osteopenia

\section{Riesgo de fractura durante 10 años \\ No se informó FRAX porque:}

Alguwos T-scores para columna vertobral total, cadera toral o cuello femoral menores qua -2.5 .

\section{Comentario:}


ANALÍTICA.

SYNLAB /

www.syralab.es

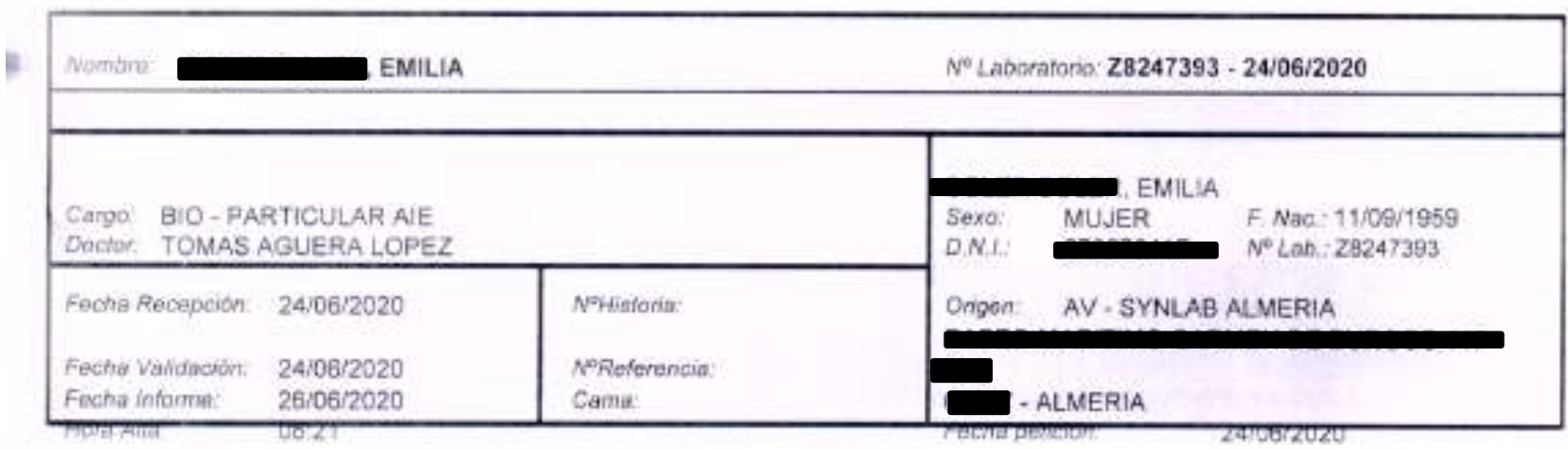

Hemograma

sungereteal LDTh

Serie eritrocitaria

Hermaties

Hemogbobina

Hematocrito

Volumen corpuscular media (VCM)

Hemogiobina corpuscular media (HCM)

Conc de hgh corpusculat media ( $\mathrm{CHCM}$ )

Indice de anisocitosis (RDW)

$\begin{array}{rl}4,67 & \times 10^{5} / \mathrm{mm}^{2} \\ 14,6 & 9 / d L \\ 43,8 & \text { \% } \\ 94 & \text { fl } \\ 31.2 & \text { og } \\ 33.3 & \text { g/dL } \\ 13.5 & \text { \% }\end{array}$

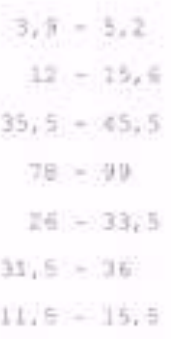

Serie leucocitaria

Leucocitos
Neutrofilos $\%$
Linfocitos \%
Manocitos \%
Eosinófilas \%
Basofilos \%
LuC \%
Neutrofilos
Linfocitos
Monocitos
Eosinofilos
Basofios
LUC

$\begin{array}{ll}10,0 & \times 10^{3} \mathrm{~mm}^{2} \\ 57,8 & \% \\ 31,4 & \% \\ 5,9 & \% \\ 2,7 & \% \\ 0,8 & \% \\ 1,3 & \% \\ 5,8 & \times 10^{2} / \mathrm{mm}^{2} \\ 3,1 & \times 10^{5} \mathrm{~mm}^{2} \\ 0,6 & \times 10^{3} \mathrm{~mm}^{2} \\ 0,3 & \times 10^{3} \mathrm{~mm}^{2} \\ 0,1 & \times 10^{3} \mathrm{~mm}^{2} \\ 0,1 & \times 10^{2} / \mathrm{mm}^{*}\end{array}$

$3,9-10,3$

$42-77$

$20-14$

$1,5-3,3$

$3,5-5$,

$9=3,75$

$4.5-7,7$

$1,2-4,2$

$0,2=0,95$

$0,02=0,3$

$0=0 ; 2$

$<.0 .4$

Serie plaquetaria

Plaquetas

Volumen plaquetario medio (VPM)
$381 \cdot \times 10^{2} / \mathrm{mm}^{2}$

$7.7 \mathrm{iL}$
$158-370$

$7-12$ 
Metabolismo hidrocarbonado Giucosa (suero/plasma)

Trigliceridos

Pruebas de función renal (suero) Urato

Creatinina

Metabolismo del hierro (suero)

Hierro

Hormonas Tiroideas (suero)

Hormona estimulante del tiroides (TSH)

valores de referencia en embarazadas:

- ler trimestre: hasta 2,5 mu/t

- $2^{\circ}$ y Jer trimestre: hasta $3.5 \mathrm{mu} / \mathrm{L}$

Tiroxina Libre (T4L)

$$
\begin{array}{r}
125 \cdot \mathrm{mg} / \mathrm{dL} \\
236^{*} \mathrm{mg} / \mathrm{dL} \\
85 \mathrm{mg} / \mathrm{dL} \\
138 \cdot \mathrm{mg} / \mathrm{dL} \\
64 \mathrm{mg} / \mathrm{dL}
\end{array}
$$

$\begin{array}{cc}3.6 & \mathrm{mg} / \mathrm{dL} \\ 0.58 & \mathrm{mgidL} \\ & \\ 21 & \mathrm{U} / \mathrm{L} \\ 25 & \mathrm{U} / \mathrm{L} \\ 24 & \mathrm{U} / \mathrm{L}\end{array}$

73. $\mu \mathrm{g} / \mathrm{dt}$

No Laboratorio: Z8247393 - 24/06/2020

$0,40 \quad \mathrm{mu} / \mathrm{L}$

$1,15 \mathrm{ng} / \mathrm{dL}$

$0.89-1,76$

INFORME VALIDADO POR MGG 


\subsection{Anexo 2. Cuestionarios autoadministrados en la entrevista inicial.}

\section{PAR-Q}

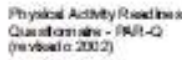

\section{PAR-Q \& YOU}

(Un Cuestionario para Personas de 15 a 69 años)

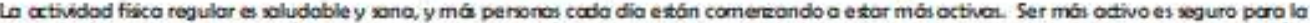

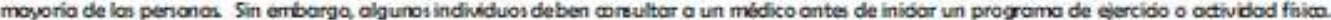

Si uted etá pbenificando portiopar en programes de ejercibo o de octividod fisca, lo recamendado es que rewonda a ba siete preguntos dexcritas

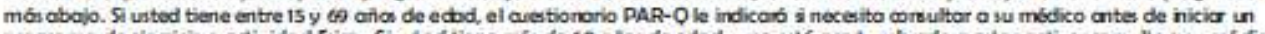
progroma de ejericio o octividod fuim. Si uted tiene mós de 69 ahos de edod, y no estó acostumbrcibo a estar octivo, coreulte a su médias.

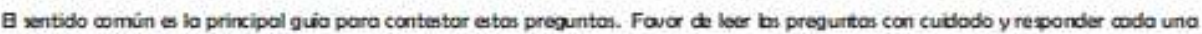
honestomerte: Marave SI O NO.

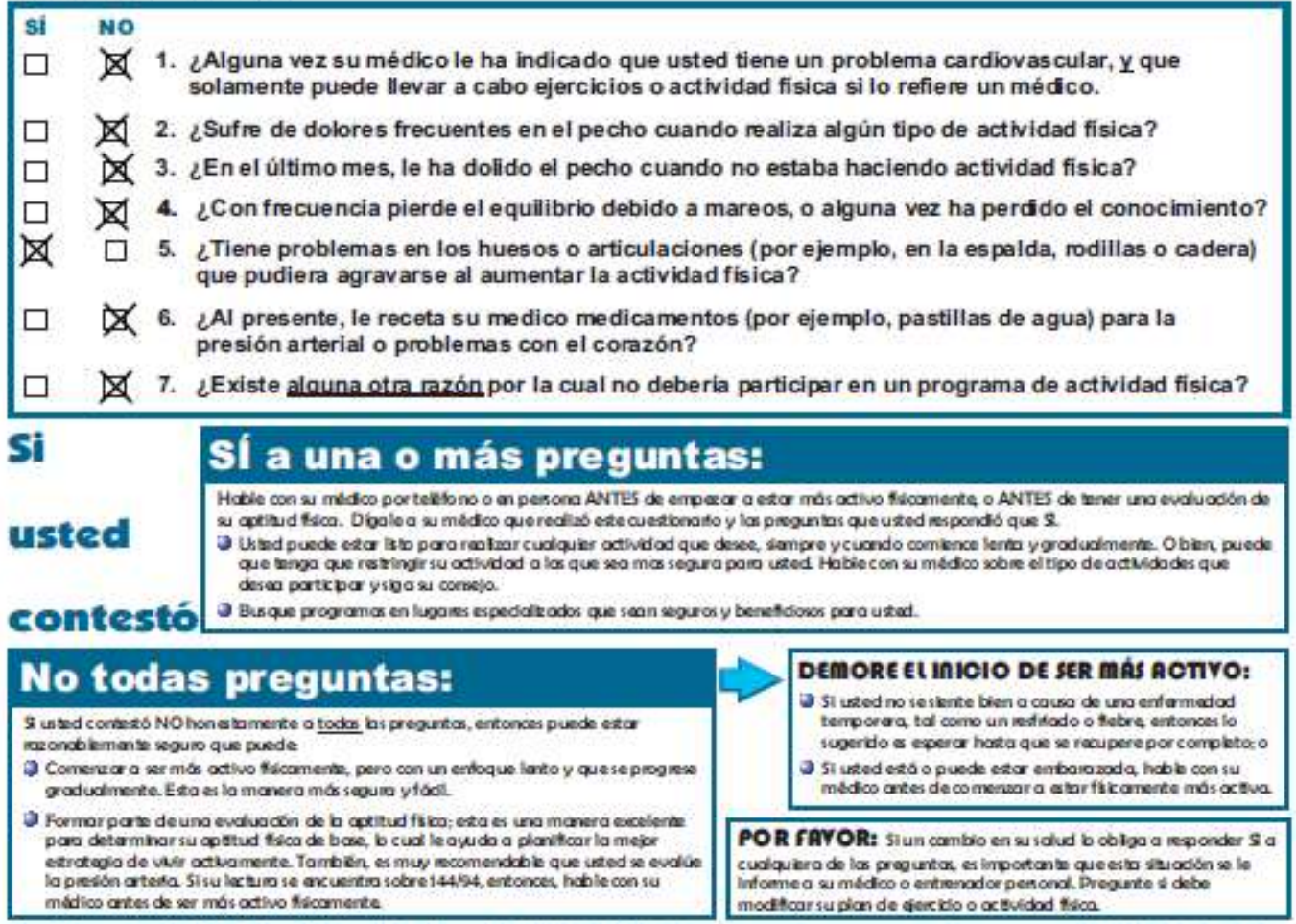

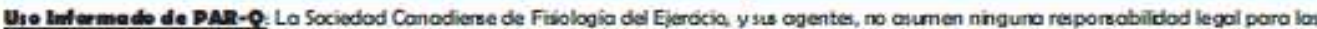
personos que realizan ejerócio o actividod fiaca; en coso de duda despuét de completar este ciestionaria, consulte primero a su módion.

No so permiten cambios. Se puedo fotocopiar el PAR-Q, únicamente si se emplea todo ol formulario.

NOTA Si se requiere odministrar el PAR-Q antes que al participante se incorpore a un programa de ejercicio/actlvidod física, 0 e someta a pruebos de aptitud f́sica, esta sección se puede utiliz cr para propósitos administrativos o legales:

Yo he leido, entendido y completado el cuestionar ia. Todas las preguntas fuer on respondidas a mi enter a satisfacción." Nombre: EMILIA S

Firma EMILLAS

Fecha $01 / 03 / 2020$

\section{PAR-Q+}

FOLLOW-UP QUESTIONS ABOUT YOUR MEDICAL CONDITION(S)

1. Do you have Arthritis, Osteoporosis, or Back Problems?

If the above conditionid is/are present, anmwer questions ta-ic

if No 0 go to question 2

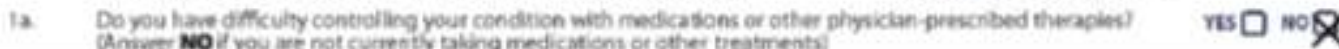

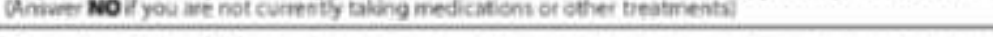

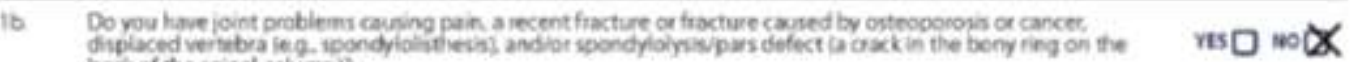
bockef the ipinal colvm

ic. Hove you had stetoid hiections of taken neioid tabless regulaily for more than 3 months?

ns 100 
Encuesta Nacional de Salud

\section{V.- CONSUMO DE TABACO Y EXPOSICIÓN AL HUMO DE TABACO}

Introducción P.121: Entrevistador/a, léale al informante: "Las siguientes preguntas se refieren al consumo de tabaco y a la exposición al humo de tabaco."

121. ¿Podría decirme si fuma?

Sí, fumo a diario 丈1

Sí fumo, pero no a diario

No fumo actualmente pero he fumado antes

No fumo ni he fumado nunca de manera habitual

No sabe

No contesta

Si P. $121=3,4,8,9 \rightarrow$ Ir a P.126

122. ¿Qué tipo de tabaco fuma con mayor frecuencia?

Cigarrillos (incluido el tabaco de liar) _............................ $\not 1$

Puros

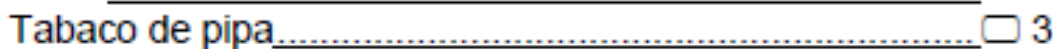

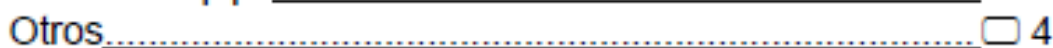

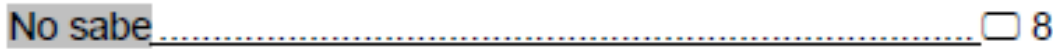

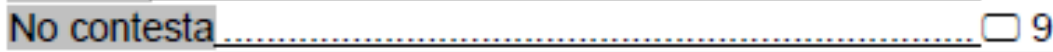

Nota P.122: Entrevistador/a, solamente es posible una respuesta.

Si $P .121=1$ y $P .122=1 \rightarrow$ Ir a P. 123

Si $P .121=1$ y $P .122<>1 \rightarrow$ Ir a P.124

En otro caso $\rightarrow$ Ir a P.126

123. Por término medio, ¿cuántos cigarrillos fuma usted al día?

Número de cigarrillos: $\quad$ 19.ـ $\quad$ NS $\square 98 \quad \mathrm{NC} \square 99$

124. ¿A qué edad empezó a fumar?

Edad en años: $\quad$ |21ㄴ $\quad$ NS $\square 98 \quad$ NC $\square 99$ 
125. Durante los últimos 12 meses, ¿cuántos intentos serios de dejar de fumar ha realizado en los que consiguiera estar al menos 24 horas sin fumar?

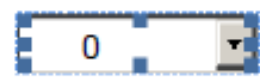

$\mathrm{NS} \square 8 \quad \mathrm{NC} \square 9$

Aparecerá un desplegable con los valores " 0 ", " 1 ", " 2 ", " 3 ", " 4 ", " 5 ó más".

126. ¿Con qué frecuencia está (đexpuesto/a al humo del tabaco en lugares cerrados? Considere solo aquellas situaciones en las que son otras personas las que están fumando.

Nunca o casi nunca ................................... $\searrow_{1}$

Menos de una hora al día $\ldots \ldots \ldots \ldots \ldots \ldots \ldots \ldots \ldots \ldots \ldots \ldots . \ldots 2$

Entre 1 y 5 horas al día_................................ $\square 3$

Más de 5 horas al día_.................................. $\square 4$

No sabe ................................................... $\square 8$

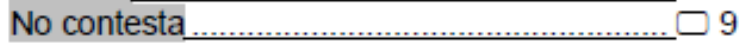

Nota P.126: Entrevistador/a, se refiere a la exposición al humo del tabaco en casa, en el trabajo, lugares públicos, restaurantes.

\section{W.- CONSUMO DE ALCOHOL}

Introducción P.127: Entrevistador/a, léale al informante: "Las siguientes preguntas se refieren al consumo de bebidas alcohólicas durante los últimos 12 meses."

127. Durante los últimos 12 meses, ¿con qué frecuencia ha tomado bebidas alcohólicas de cualquier tipo (es decir, cerveza, vino, licores, bebidas destiladas y combinados $u$ otras bebidas alcohólicas)?

A diario o casi a diario

5-6 dias por semana

3-4 días por semana

1-2 días por semana

2-3 días en un mes....

Una vez al mes.

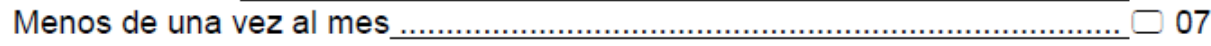

No en los últimos 12 meses, he dejado de tomar alcohol ........................... $\square 08$

Nunca o solamente unos sorbos para probarlo a lo largo de toda la vida ...... $\square 09$

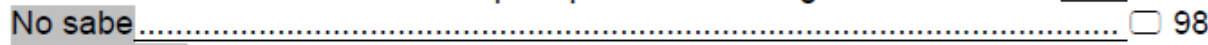

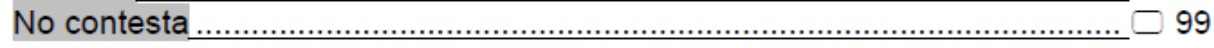

Si P.127 = 05, 06, $07 \rightarrow$ Ir a Introducción P.129

Si P.127 = 08, 09, 98, $99 \rightarrow$ Ir a Introducción P.130 
128. Durante los últimos 12 meses, en una semana en que desarrolló su actividad habitual, ¿cuántas bebidas que contengan alcohol consumió a lo largo de la semana?

\begin{tabular}{|c|c|c|c|c|c|c|}
\hline & 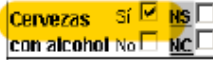 & 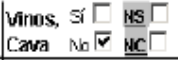 & $\begin{array}{l}\text { Vermuts, si } \square \text { NS } \square \\
\text { fino, jerez No } \sqrt{V} \text { MC } \Gamma\end{array}$ & 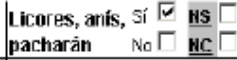 & $\begin{array}{l}\text { Whisky, contac, SI } \square \text { US } \square \\
\text { combinados ... }\end{array}$ & 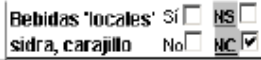 \\
\hline Lunes & [0] Corvezas & $7 v_{a s o s, c o p a s}$ & $\nabla_{\text {Copas }}$ & D copas & $\nabla_{\text {copas }}$ & चasos, copas \\
\hline Martes & [0] Cervezas & Tysos,copas & $\nabla_{\text {Capas }}$ & 回 $\mathrm{Copas}$ & $\nabla_{\text {Copas }}$ & IVasos, copas \\
\hline Miércoles & [0] Cervezas & IVasos,copas & $\nabla_{\text {Copas }}$ & D. copas & $\exists$ Copas & I Uasos, copas \\
\hline Jueves & [1] Correzas & IVasos,copas & 7 capas & 回 copas & $\nabla_{\text {copas }}$ & Iasos, copas \\
\hline Viernes & [0 Cervezas & Vasos,copas & $\nabla_{\text {Copas }}$ & 回 copas & $\nabla_{\text {Copos }}$ & $\nabla_{\text {Vasos, copas }}$ \\
\hline Sábado & [D Cervezas & Yasos,copas & $\nabla_{\text {Copas }}$ & 0 - Copss & $\exists$ Cooas & 7 Vasos, copas \\
\hline Dormingo & [0 cervezas & IVasos,copas & $\nabla_{\text {Capas }}$ & $0-$ copas & $\nabla_{\text {Copos }}$ & IVasos, copas \\
\hline
\end{tabular}

A diario, 2 quintos de cerveza al día, uno en almuerzo y otro en la cena.

\section{PSS-14}

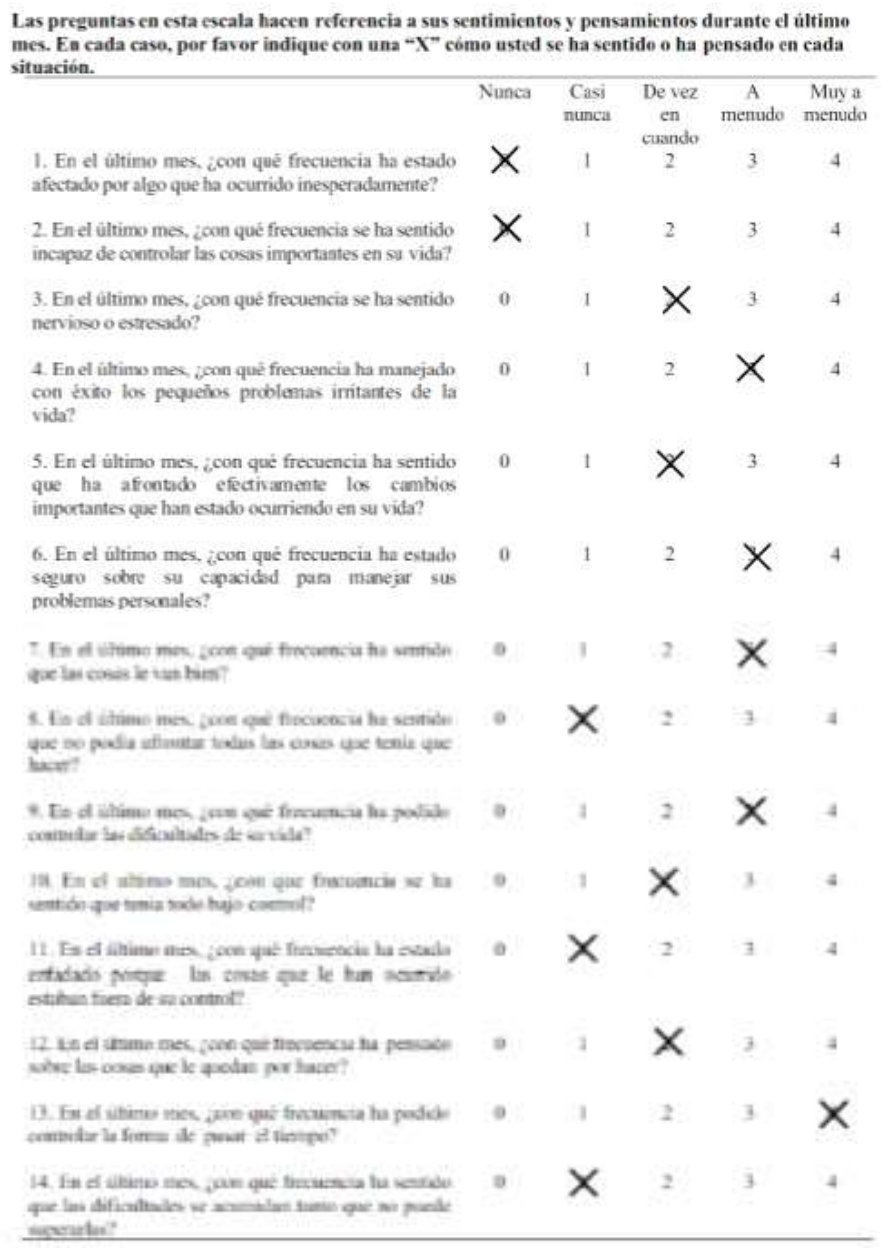


ISI

PENNSTIE HERSHEY

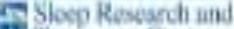

MR\#:

Tresinwinc Cenier

Date:

\section{ISI}

(Morin, 1998; Bastien et al, 2001; Femandez-Mendoza et al, 2012)

1. Por favor indique la GRAVEDAD de su actual (p.ej, durante las últimas 2 semanas) problema(s) de sueño:

Nada Leve Moderado Grave Muy grave

\begin{tabular}{llllll} 
Dificultad para quedarse dormido/a: & 0 & 1 & $\mathbb{X}$ & 3 & 4 \\
\hline Dificultad para permanecer dormido/a: & 0 & 1 & 2 & $\mathbb{X}$ & 4 \\
\hline Despertarse muy temprano: & 0 & 1 & $\searrow$ & 3 & 4 \\
\hline
\end{tabular}

2. ¿Cómo está de SATISFECHO/A en la actualidad con su sueño?

Muy satisfecho Satisfecho Neutral No muy Muy satisfecho insatisfecho

$\begin{array}{lllll}0 & 1 & 2 & \times & 4\end{array}$

3. ¿En qué medida considera que su problema de sueño INTERFIERE con su funcionamiento diario (por ejemplo, fatiga durante el dia, capacidad para las tareas cotidianas/trabajo, concentración, memoria, estado de ánimo etc.)?
Nada
Un poco
Algo
Mucho
Muchisimo

\begin{tabular}{lllll}
\hline$\times$ & 1 & 2 & 3 & 4
\end{tabular}

4. ¿En qué medida cree que LOS DEMAS SE DAN CUENTA de su problema de sueño por lo que afecta a su calidad de vida?

\begin{tabular}{ccccc} 
Nada & Un poco & Algo & Mucho & Muchísimo \\
\hline$X$ & 1 & 2 & 3 & 4
\end{tabular}

5. ¿Cuán PREOCUPADO/A está por su actual problema de sueño?

\begin{tabular}{ccccc} 
Nada & Un poco & Algo & Mucho & Muchísimo \\
\hline 0 & 1 & X & 3 & 4
\end{tabular}




\section{PSQUI}

\section{ÍNDICE DE CALIDAD DE SUEÑO DE PITTSBURGH}

(PSQI)

APELLIDOSY NOMBRE:- $N \mathrm{H}^{\circ} \mathrm{C}$

SEXO:

ESTADO CIVIL:
FDAD:

FECHA:

\section{INSTRUCCIONES:}

Las siguientes preguntas hacen referencia a cómo ha dormido Vd. normalmente durante el último mes. Intente ajustarse en sus respuestas de la manera más exacta posible a lo ocurrido durante la mayor parte de los días y noches del último mes. Muy Importantel CONTESTE A TODAS LAS PREGUNTAS

1. Durante el último mes, ¿Cuál ha sido, normalmente, su hora de acostarse? APUNTE SU HORA HABITUAL DE ACOSTARSE:

2. ¿Cuánto tiempo habrá tardado en dormirse, normalmente, las noches del íltimo mes? APUNTE EL TIEMPO EN MINUTOS:

20 minutos

3. Durante el último mes, ¿a qué hora se ha levantado habitualmente por la mañana?
APUNTE SU HORA HABITUAL DE LEVANTARSE:

4. ¿Cuántas horas calcula que habrá dormido verdaderamente cada noche durante el último mes? (El tiempo puede ser diferente al que Vd. permanezca en la cama).

APUNTE LAS HORAS QUE CREA HABER DORMIDO:

$5.5 \mathrm{~h}$

Para cada una de las siguientes preguntas, elija la respuesta que más se ajuste a su caso. Intente contestas a TODAS las preguntas.

5. Durante el último mes, cuántas veces ha tenido Vd. problemas para dormir a causa de:

a) No poder conciliar el sueno en la primera media hora:

Ninguna vez en el último mes

Menos de una vez a la scmana

Una o dos veces a la semana

Tres o más veces a la semana

b) Despertarse durante la noche o de madrugada:

Ninguna vez en el ultimo mes

Menos de una vez a la semana

Una o dos veces a la semana

Tres o más veces a la semana

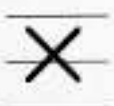

c) Tener que levantarse para ir al servicio:

Ninguna vę en el último mes

Menos de una ver a la scmana

Una o dos veces a la semana

Tres o más veces a la semana

d) No poder respirar bien:

Ninguna vez en el último mes

Menos de una vez a la semana

Una o dos veces a la semana

Tres o más veces a la semana c) Toser o roncar ruidosamente:

Ninguna vez en el último mes

Menos de una vez a la semana

Una o dos veces a la scmana

Tres o más veces a la semana

f) Sentir frio:

Ninguna vez en el último mes

Menos de una vez a la semana

Una o dos veces a la semana

Tres o más veces a la semana
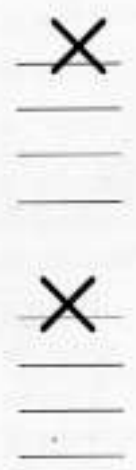

g) Sentir demasiado calor:

Ninguna vez en el último mes

Menos de una ver a la semana

Una o dos reces a la semana

Tres o más veces a la semana

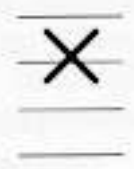

h) Tener pesadillas o «malos sucños:

Ninguna vez en el ultimo mes

Menos de una vez a la semana

Una o dos veces a la semana

Tres o més veces a la semana 
i) Sufrir dolores:

Ninguna vez en el último mes

Menos de una vez a la semana

Una o dos veces a la semana

Tres o más veces a la semana

j) Otras razones (por favor, describalas a continuacion):

Ninguna vez en el úlimo mes

Menos de una vez a la semana

Una o dos veces a la semana

Tres o más veces a la semana

6. Durante el último mes, ¿cómo valoraría, en conjunto, la calidad de su sueño?

Bastante buena

Buena

Mala

Bastante mala

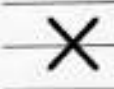

7. Durante el último mes, ceuantas veces habrá tomado medicinas (por su cuenta o recetadas por el médicol para dormir?

Ninguna vez en el último mes

Menos de una vez a la semana

Una o dos veces a la semana

Tres o más veces a la semana

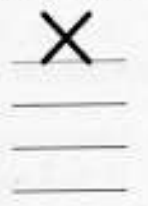

8. Durante el último mes, ¿cuántas veces ha sentido somnolencia mientras conducia, comia, o desarrollaba alguna otra actividad?

Ninguna ver en el último mes

Menos de una vez a la semana

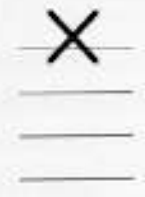

Una o dos reces a la semana

Tres o más veces a la semana

9. Durante el último mes, iha representado para Vd. mucho problema el «tenet ánimos para realizar alguna de las actividades detalladas en la pregunta anterior?

Ningún problema

Sólo un leve problema

Un problema

Un grave problema
10. Ducsuc Vd. solo o acompañado?

Solo

Con alguien en otra habitación

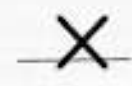

En la misma habitacion, pero en

otra cama

En la misma cama

POR FAVOR. SÓLO CONTESTE A LAS

SIGUIENTES PREGUNTAS EN EL CASO DE QUE DUERMA ACOMPAÑADO.

Si Vd. tiene pareja o compañero de habitación. pregúntele si durante el último mes Vd. ha tcnido:

a) Ronquidos ruidosos.

Ninguna vez en el último mes

Menos de una vez a la semana

Una o dos veces a la semana

Tres o más veces a la semana

b) Grandes pausas entre respiraciones mientras duerme.

Ninguna ver en el último mes

Menos de una vez a la semana

Una o dos reces a la semana

Tres o más veces a la semana

c) Sacudidas o espasmos de piernas mientras ducrme.

Ninguna vez en el último mes

Menos de una ver a la semana

Una o dos veces a la semana

Tres o más veces a la semarta

d) Episodios de desorientación o confusión mientras ducrme.

Ninguna vez en el ultimo mes

Menos de una vez a la semana

Una o dos veces a la semana

Tres o más veces a la semana

c) Otros inconvenientes mientras Vd. duerme (Por favor, describalos a continuación):

Ninguna vez en el último mes Menos de una vez a la semana Una o dos veces a la semana Tres o más veces a la semana 
IPAQ

1. ¿Tiene usted actualmente un trabajo o hace algún trabajo no pago fuera de su casa?

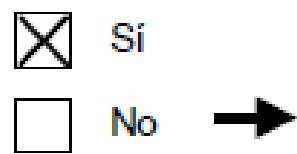

Pase a la PARTE 2: TRANSPORTE

Las siguientes preguntas se refieren a todas las actividades físicas que usted hizo en los últimos 7 días como parte de su trabajo pago o no pago. Esto no incluye ir y venir del trabajo.

2. Durante los últimos 7 días, ¿Cuántos días realizó usted actividades físicas vigorosas como levantar objetos pesados, excavar, construcción pesada, o subir escaleras como parte de su trabajo? Piense solamente en esas actividades que usted hizo por lo menos 10 minutos continuos.

dias por semana

Ninguna actividad física vigorosa relacionada con el trabajo Pase a la pregunta 4

$\square$ No sabe/No está seguro(a)

3. ¿Cuánto tiempo en total usualmente le toma realizar actividades físicas vigorosas en uno de esos días que las realiza como parte de su trabajo?

horas por día minutos por día

$\square$ No sabe/No está seguro(a)

4. Nuevamente, piense solamente en esas actividades que usted hizo por lo menos 10 minutos continuos. Durante los últimos 7 días, ¿Cuántos días hizo Usted actividades físicas moderadas como cargar cosas ligeras como parte de su trabajo? Por favor no incluya caminar.

5 dias por semana

No actividad física moderada relacionada con el trabajo Pase a la pregunta 6

5. ¿Cuánto tiempo en total usualmente le toma realizar actividades físicas moderadas en uno de esos dias que las realiza como parte de su trabajo?

1 horas por día minutos por día

$\square$ No sabe/No está seguro(a) 
6. Durante los últimos 7 días, ¿Cuántos días caminó usted por lo menos 10 minutos continuos como parte de su trabajo? Por favor no incluya ninguna caminata que usted hizo para desplazarse de o a su trabajo.

5 dias por semana

Ninguna caminata relacionada con trabajo

Pase a la PARTE 2: TRANSPORTE

7. ¿Cuánto tiempo en total pasó generalmente caminado en uno de esos días como parte de su trabajo?

\section{3 horas por día minutos por día \\ $\square$ No sabe/No está seguro(a)}

\section{PARTE 2: ACTIVIDAD FISICA RELACIONADA CON TRANSPORTE}

Estas preguntas se refieren a la forma como usted se desplazó de un lugar a otro, incluyendo lugares como el trabajo, las tiendas, el cine, entre otros.

8. Durante los últimos 7 días, ¿Cuántos días viajó usted en un vehículo de motor como un tren, bus, automóvil, o tranvía?

5 días por semana

No viajó en vehículo de motor

Pase a la pregunta 10

9. Usualmente, ¿Cuánto tiempo gastó usted en uno de esos días viajando en un tren, bus, automóvil, tranvía u otra clase de vehículo de motor?

15-20 horas por día minutos por día

$\square$ No sabe/No está seguro(a)

Ahora piense únicamente acerca de montar en bicicleta o caminatas que usted hizo para desplazarse a o del trabajo, haciendo mandados, o para ir de un lugar a otro.

10. Durante los últimos 7 días, ¿Cuántos días montó usted en bicicleta por al menos 10 minutos continuos para ir de un lugar a otro? días por semana

No montó en bicicleta de un sitio a otro

11. Usualmente, ¿Cuánto tiempo gastó usted en uno de esos días montando en bicicleta de un lugar a otro?

horas por día minutos por día

No sabe/No está seguro(a) 
12. Durante los últimos 7 dias, ¿Cuảntos dias camino usted por al menos 10 minutos continuos para ir de un sitio a otro?

2 dias por semana

No caminatas de un sitio a otro $\rightarrow$ Pase a la PARTE 3: TRABAJO

DE LA CASA,

MANTENIMIENTO DE LA

CASA, Y CUIDADO DE LA

FAMILIA

13. Usuaimente, ¿Cuánto tiempo gasto usted en uno de esos dias caminando de un sitio a otro?

horas por dia

$\overline{20-30}$ minutos por dia

No sabe/No esta seguro(a)

\section{PARTE 3: TRABAJO DE LA CASA, MANTENIMIENTO DE LA CASA, $Y$} CUIDADO DE LA FAMILIA

Esta sección se refiere a algunas actividades físicas que usted hizo en los últimos 7 días en y alrededor de su casa tal como como arreglo de la casa, jardinería, trabajo en el césped, trabajo general de mantenimiento, y el cuidado de su familia.

14. Piense únicamente acerca de esas actividades físicas que hizo por lo menos 10 minutos continuos. Durante los últimos 7 días, ¿Cuántos días hizo usted actividades físicas vigorosas tal como levantar objetos pesados, cortar madera, palear nieve, o excavar en el jardín o patio?

\section{días por semana}

Xinguna actvidad física vigorosa en el jardín o patio Pase a la pregunta 16

15. Usualmente, ¿Cuánto tiempo dedica usted en uno de esos dias haciendo actividades físicas vigorosas en el jardín o patio?

horas por día

minutos por día

$\square$ No sabe/No está seguro(a)

16. Nuevamente, piense únicamente acerca de esas actividades físicas que hizo por lo menos 10 minutos continuos. Durante los últimos 7 días, ¿Cuántos días hizo usted actividades físicas moderadas tal como cargar objetos livianos, barrer, lavar ventanas, y rastrillar en el jardín o patio?

dias por semana

Ninguna actvidad física moderada en el jardín o patio Pase a la pregunta 18

17. Usualmente, ¿Cuánto tiempo dedica usted en uno de esos dias haciendo actividades físicas moderadas en el jardín o patio?

horas por día minutos por día

No sabe/No está seguro(a) 
18. Una vez más, piense únicamente acerca de esas actividades físicas que hizo por lo menos 10 minutos continuos. Durante los últimos 7 días, ¿Cuántos días hizo usted actividades físicas moderadas tal como cargar objetos livianos, lavar ventanas, estregar pisos y barrer dentro de su casa?

4 días por semana

Ninguna actvidad física moderada dentro de la casa-

Pase a la PARTE 4:

ACTIVIDADES FÍSICAS DE RECREACIÓN, DEPORTE Y TIEMPO LIBRE

19. Usualmente, ¿Cuánto tiempo dedica usted en uno de esos días haciendo actividades físicas moderadas dentro de su casa?

horas por día

$30-45$ minutos por día

No sabe/No está seguro(a)

\section{PARTE 4: ACTIVIDADES FÍSICAS DE RECREACIÓN, DEPORTE Y TIEMPO LIBRE}

Esta sección se refiere a todas aquellas actividades físicas que usted hizo en los últimos 7 días únicamente por recreación, deporte, ejercicio o placer. Por favor no incluya ninguna de las actividades que ya haya mencionado.

20. Sin contar cualquier caminata que ya haya usted mencionado, durante los últimos 7 días, ¿Cuántos días caminó usted por lo menos 10 minutos continuos en su tiempo libre?

1 días por semana

Ninguna caminata en tiempo libre

Pase a la pregunta 22

21. Usualmente, ¿Cuánto tiempo gastó usted en uno de esos días caminando en su tiempo libre?

1 horas por día minutos por día

No sabe/No está seguro(a)

22. Piense únicamente acerca de esas actividades físicas que hizo por lo menos 10 minutos continuos. Durante los últimos 7 días, ¿Cuántos dias hizo usted actividades físicas vigorosas tal como aeróbicos, correr, pedalear rápido en bicicleta, o nadar rápido en su tiempo libre?

días por semana

X Ninguna actividad física vigorosa en tiempo libre Pase a la pregunta 24

23. Usualmente, ¿Cuánto tiempo dedica usted en uno de esos días haciendo actividades físicas vigorosas en su tiempo libre?

horas por día minutos por día 
24. Nuevamente, piense únicamente acerca de esas actividades físicas que hizo por lo menos 10 minutos continuos. Durante los últimos 7 días, ¿Cuántos días hizo usted actividades físicas moderadas tal como pedalear en bicicleta a paso regular, nadar a paso regular, jugar dobles de tenis, en su tiempo libre?

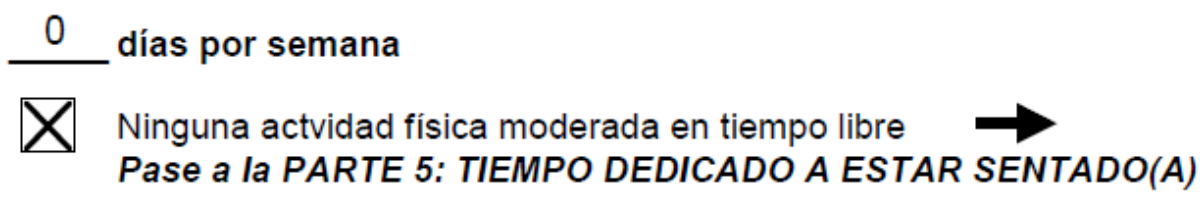

25. Usualmente, ¿Cuánto tiempo dedica usted en uno de esos días haciendo actividades físicas moderadas en su tiempo libre? horas por día minutos por día

$\square$ No sabe/No está seguro(a)

\section{PARTE 5: TIEMPO DEDICADO A ESTAR SENTADO(A)}

Las últimas preguntas se refieren al tiempo que usted permanence sentado(a) en el trabajo, la casa, estudiando, y en su tiempo libre. Esto incluye tiempo sentado(a) en un escritorio, visitando amigos(as), leyendo o permanecer sentado(a) o acostado(a) mirando television. No incluya el tiempo que permanence sentado(a) en un vehículo de motor que ya haya mencionado anteriormente.

26. Durante los últimos 7 días, ¿Cuánto tiempo permaneció sentado(a) en un día en la semana?

4-5 h horas por día minutos por día

No sabe/No está seguro(a)

27. Durante los últimos 7 días, ¿Cuánto tiempo permaneció sentado(a) en un día del fin de semana?

$7 \mathrm{~h}$ horas por día minutos por día

No sabe/No está seguro(a)

Este es el final del cuestionario, gracias por su participación. 


\section{Actitud NSCA}

¿Qué predisposición tiene a practicar ejercicio?

1. Me estresa pensar en practicar ejercicio.

2. Lo hago porque sé que resulta beneficioso, pero no disfruto haciéndolo.

3. Sé que es beneficioso y no me molesta practicarlo.

4. Me siento muy motivado para hacerlo

¿Cuál es su actitud para conseguir objetivos?

1. Veremos a ver que ocurre, de momento ya se irá viendo.

2. Suelo establecer unos objetivos que me ayudan a lo que debo hacer y me dan control sobre los resultados.

3. Establezco objetivos y pienso que es fundamental para determinar mi rendimiento y logros futuros.

4. Escribo mis objetivos y los reviso frecuentemente. Pienso que soy capaz de conseguir cualquier cosa que me plantee y establecer objetivos es findamental para ello.

¿Es importante para usted el concepto de salud y bienestar

1. No tengo que hacer nada para mejorar mi salud.

2. Normalmeate dedico tiempo para verme mejor fisicamente.

3. Me he comprometido a trabajar para mantener y mejorar mi estado de salud y bienestar fisico.

4. Es por lo que decido practicar ejercicio, son la base de mis logros y seguirán siendo mis prioridades.

¿Cuál es su deseo de mejorar?

1. Me siento bien como me encuentro. No tengo ningün deseo especial en mejorar.

2. Me gustaria mejorar pero no se si todo el trabajo que realizaré valdrá la pena.

3. Me gusta sentir que mejoro y estoy predispuesto a cualquier consejo con el fin de mejorar.

4. Busco la perfección y estoy comprometido en mejorar continuamente.

¿Como te ves respecto a ti mismo y tus capacidades?

1. No me gusta mi apariencia ni como me siento la mayor parte de las veces.

2. Quisiera cambiar muchas cosas de mi, aunque me gusta ser como soy.

3. Me considero bueno en las cosas que hago y siento felicidad cuando alcanao mas objetivos y me raelo manejar bien en diversas situaciones

4. Me siento fuerte, orgulloso y capaz de afroutar cualquier reto.

¿Cual es su percepción de condición física actual respecto a sa apariencia fisica?

i. Me gustaria cambuar mu cuerpo por completo

2. No me siento comodo cuando me mito al espejo.

3. Por lo general mi apecto es bueno, y con las prendas adecuadas mi aspecto puede ser realmente bueno, aunque quisien cambuar alguans cosas sobre mi apariencia fisica

4. Estoy orgullose de mi cuerpo y me siento comodo con cualquier tipe de prenda.

¿Cual es su pereepción de condición fisica achual en relación a su salud general?

1. Querria sentimue sano.

2. Me siento sano para mi edad en relación a las demis personas que conozco.

3. Mi estado de salud es bueno

4 Mi salud es extremadamente buena

Cual es su percepción de cosdución fisica actual en relación a sa rendumiento en cualquer contexto deportivo (deporte, entrenamuento,....)?

1. Pienso que mi forma fisica es pobre $y$ no me siento comodo al enfrentarme a un reto deportive.

2. Pienso que ma rendimieato no es óptimo, pero cuando entreno para mejorir me siento cómodo

3. Me siento bien en relación a mi capacidad fisica, aunque me gustaria mejorar.

4. Tengo un gran aivel fisico $y$ disfruto demostrundo mi potencial.

¿Está convencido de que puede mejorar fisicamente en todos los aspectos?

1. Realizar esfierzo para untentar cambiar es una pérdida de tieapo ya que todo es genético

2. He visto a mucha gente que ha cambiado sa cuerpo y si me esfuerzo podré conseguirto también.

3. Pienso que la combinacién de ejercicio junto con una alimentación adecuada conllevara alguna mejora.

4. Estoy convencido al $100 \%$ que la combunación de ejercicio fisico de forma regular y una alamentacióa adecuada se traducirin ea resultados dristicos.

Cada vez que empieza un programa de entrenamiento, aque posibuidades hay de que lo acabe?

1. Numca be teminado las cosas que be empezado.

2. Si tengo una adecuada motivación y empiezo a ver resultados, creo que podré seguir el programa.

3. Me comprometo con los programas y tengo capacidad de paciencia.

4. Cada vez que fijo un objetivo, no puede detenerme nada. 


\subsection{Anexo 3. Documentos legales y jurídicos.}

Colegiación en Ilustre Colegio Oficial de Graduados en Ciencias de la Actividad Física y el Deporte en Andalucía.

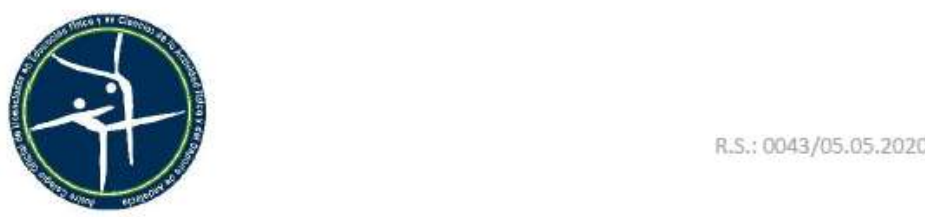

JOSÉ CARLOS GÓMEZ TEBA, SECRETARIO DEL ILUSTRE COLEGIO OFICIAL DE UICENCIADOS EN EDUCACIÓN FÍSICA Y EN CIENCIAS DE LA ACTIVIDAD FÍSICA Y DEL DEPORTE DE ANDALUCIA

\section{CERTIFICO}

QUe Da. IRENE MANZANO SOLER CON N.I.F. se encuentra inscrita desde el dos de marzo de 2020 en el ILUSTRE COLEGIO OFICIAL DE LICENCIADOS EN EDUCACIÓN FíSICA Y EN CIENCIAS DE LA ACTIVIDAD FíSICA Y DEL DEPORTE DE ANDALUCíA como colegiada EERCIENTE con el número 63.937, estando al día del pago de las correspondientes cuotas.

Y para que conste firmo la presente certificación en Sevilla, a 5 de mayo de 2020.

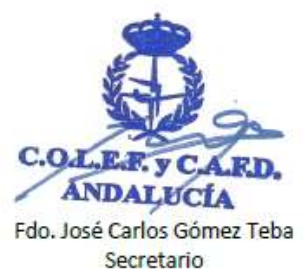

Seguro de responsabilidad civil.

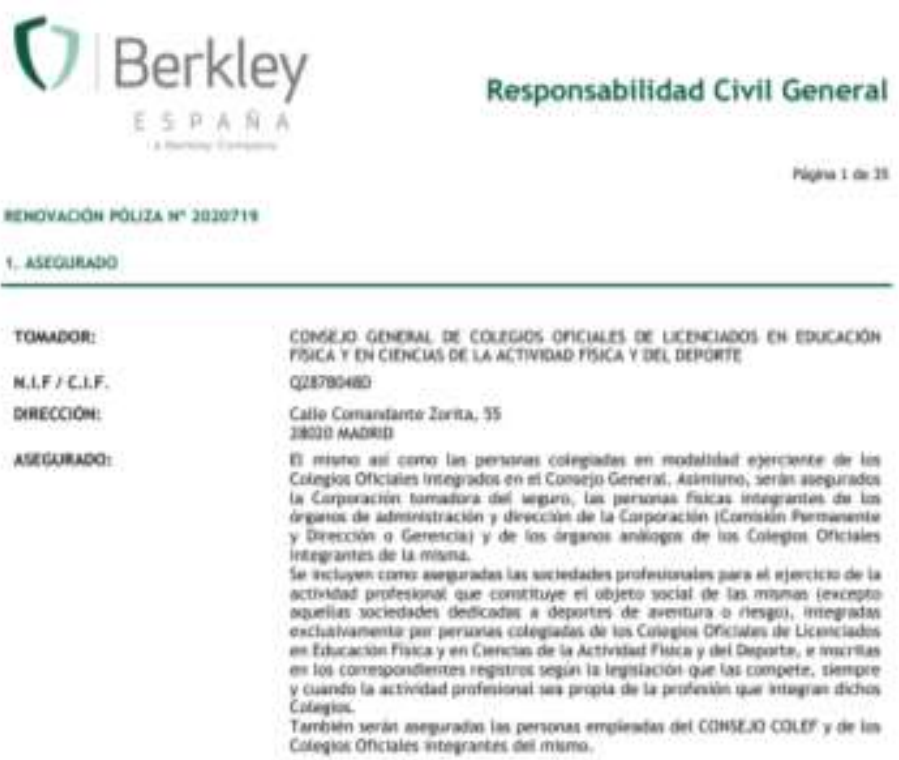




\section{Protección de Datos.}

A través de este documento, Irene Manzano Soler cumple con las directrices del Reglamento (UE) 2016/679 del Parlamento Europeo y del Consejo, de 27 de abril de 2016 relativo a la protección de las personas físicas en lo que respecta al tratamiento de datos personales y a la libre circulación de estos datos (RGPD), así como la Ley Orgánica de Protección de Datos y demás normativa vigente en cada momento, y vela por garantizar el correcto uso y tratamiento de los datos personales del usuario. Para ello, junto a cada formulario de recabo de datos de carácter personal, en los servicios que el usuario pueda solicitar a Irene Manzano Soler, hará saber al usuario, según lo dispuesto en el artículo 15.1 del RGPD, lo siguiente: (i) los fines del tratamiento; (ii) las categorías de datos personales de que se trate; (iii) los destinatarios o las categorías de destinatarios a los que se comunicaron o serán comunicados los datos personales, en particular destinatarios en terceros países u organizaciones internacionales; (iv) el plazo de conservación de los datos personales o, de no ser posible, los criterios utilizados para determinar este plazo; (v) la existencia del derecho a solicitar del responsable la rectificación o supresión de los datos personales o la limitación del tratamiento de datos personales relativos al interesado, o a oponerse a dicho tratamiento; (vi) el derecho a presentar una reclamación ante una autoridad de control; (vii) cuando los datos personales no se hayan obtenido del interesado, cualquier información disponible sobre su origen; (viii) la existencia de decisiones automatizadas, incluida la elaboración de perfiles a la que se refiere el artículo 22.1 y 4 del RGPD, y, al menos en tales casos, información significativa sobre la lógica aplicada, así como la importancia y las consecuencias previstas de dicho tratamiento para el interesado.

De conformidad en lo establecido en la normativa vigente de Protección de Datos de Carácter Personal, así como el Reglamento (UE) 2016/679 del Parlamento Europeo y del Consejo de 27 de abril de 2016 relativo a la protección de las personas físicas en lo que respecta al tratamiento de datos personales y a la libre circulación de estos datos (RGPD), y en el art. 2.2 de la Ley Orgánica 1/1982, de 5 de mayo, de protección civil del derecho al honor, a la intimidad personal y familiar y a la propia imagen, Emilia Soler Soler CONSIENTE EXPRESAMENTE A que se proceda a la publicación en el Trabajo Fin de Master de imágenes suyas tomadas por Irene Manzano Soler, y con la exclusiva finalidad académica. De igual manera, reconoce haber sido informado de la posibilidad de ejercitar los correspondientes derechos de acceso, rectificación, cancelación, oposición, olvido, limitación de tratamiento y portabilidad; de conformidad con lo establecido en el RGPD.

\section{Consentimiento informado y asunción de riesgos.}

\section{Propósito y explicación de los procedimientos}

Mediante este documento acepto voluntariamente participar en un plan de entrenamiento personal supervisado de acondicionamiento físico. También acepto tomar parte en las actividades del programa de entrenamiento personal que se me recomienden para la mejora de mi salud y bienestar general. Estas pueden incluir asesoramiento dietético, gestión del estrés y actividades formativas sobre salud y acondicionamiento físico. Los niveles de intensidad del ejercicio que se realizará se basarán en mi capacidad cardiorrespiratoria (corazón y pulmones) y muscular. Soy consciente de que se me puede requerir la realización de una prueba graduada de esfuerzo, así como otras pruebas físicas antes del comienzo del programa de entrenamiento personal para poder valorar y evaluar mi estado físico actual. Se me darán las instrucciones concretas en cuanto al tipo y volumen de ejercicio que debería realizar. Entrenadores capacitados para ello dirigirán mis actividades, controlarán mi rendimiento y evaluarán mi esfuerzo. Según mi estado de salud, se me podrá requerir durante las sesiones un control de la presión arterial y la frecuencia cardíaca para mantener la intensidad dentro de unos límites deseables. Soy consciente de que se espera mi asistencia a todas las sesiones y que siga las instrucciones del personal relativas al ejercicio, la dieta, la gestión del estrés y otros programas relacionados (salud/acondicionamiento físico). En caso de estar tomando medicamentos, ya he informado de ello al personal del programa y me comprometo a comunicarles de inmediato cualquier cambio al respecto tanto por mi parte como por parte del médico. En caso de que sea conveniente, se me valorará y evaluará periódicamente a intervalos regulares tras el inicio del programa. Se me ha informado de que durante mi participación en este programa de entrenamiento personal se me pedirá que complete las actividades físicas salvo en caso de síntomas como fatiga, falta de aire, molestias en la zona pectoral o similares.

Llegados a ese punto, se me ha informado de que tengo el derecho de disminuir la intensidad o poner fin al ejercicio y de que estoy obligado a informar al personal del programa de entrenamiento personal de mis 
síntomas. Así, declaro que se me ha informado de ello y me comprometo a informar al personal encargado de mi entrenamiento de mis síntomas, si se llegaran a producir. Soy consciente de que, durante el ejercicio, un entrenador personal supervisará periódicamente mi rendimiento con la posibilidad de que controle mi pulso y mi presión arterial o de que valore mi percepción del esfuerzo o cualquier otro parámetro que estime conveniente para así controlar mi progreso. Asimismo, para mi seguridad y beneficio según los parámetros anteriormente mencionados. También se me ha comunicado que durante el transcurso de mi programa de entrenamiento personal puede ser necesario el contacto físico y una colocación corporal adecuada de mi cuerpo para evaluar las reacciones musculares y corporales a ejercicios concretos, además de para asegurar que utilizo la técnica y postura adecuadas. Por ello doy mi autorización expresa para que se produzca el contacto físico por estos motivos.

\section{Asunción de riesgos}

Manifiesto que se me ha informado de que existe la posibilidad, aunque remota, de efectos negativos durante el ejercicio, como por ejemplo (y sin excluir otros) alteración de la presión arterial, mareos, trastornos del ritmo cardíaco y casos excepcionales de infarto, derrames o incluso riesgo de muerte. Asimismo, se me ha explicado que existe el riesgo de lesiones corporales, como por ejemplo (sin excluir otras) lesiones musculares, de ligamentos, tendones y articulaciones. Se me ha comunicado que se pondrán todos los medios disponibles para minimizar que estas incidencias se produzcan mediante controles adecuados de mi estado antes de cada sesión de entrenamiento y supervisión del personal durante el ejercicio, así como de mi prudencia frente al esfuerzo. Conozco perfectamente los riesgos asociados con el ejercicio, como lesiones corporales, infartos, derrames e incluso la muerte, y aun conociendo estos riesgos, deseo tomar parte como ya he manifestado.

Por ello, con la finalidad de participar en actividades asociadas al programa de Entrenamiento Personal, Yo asumo, acepto y eximo de cualquier responsabilidad a Irene Manzano Soler de toda responsabilidad por lesiones o accidentes que pudieran resultar de mi participación en cualquiera de las actividades del citado programa.

Yo entiendo los procedimientos aplicados por Irene Manzano Soler y manifiesto que he tenido la oportunidad de discutir mis necesidades específicas en relación a mi participación en el citado programa; como resultado de ello, yo voluntariamente acepto participar en este programa de ejercicio.

Además, y en consideración a otros posibles factores, yo manifiesto conocer la existencia de riesgos asociados a estas actividades, y estoy de acuerdo en aceptar las responsabilidades derivadas de mi participación y del uso de instalaciones y/o equipamiento específico o genérico.

Más específicamente, yo conozco y acepto la responsabilidad de accidentes o lesiones producidas por: - El uso del equipamiento de la instalación.

- La participación en actividades relacionadas con el programa.

- La realización de pruebas de valoración de mi aptitud física.

- Los incidentes que pudieran ocurrir durante el programa de entrenamiento.

\section{Beneficios que cabe esperar y alternativas disponibles a la prueba de esfuerzo}

Soy consciente de que este programa puede o no reportar beneficios a mi condición física o salud general Comprendo que la participación en sesiones de ejercicio y entrenamiento personal me permitirá aprender cómo realizar adecuadamente ejercicios de acondicionamiento físico, usar los diversos aparatos y regular el esfuerzo físico. Por tanto, debería sacar provecho de estas experiencias, ya que indicarían la manera en que mis limitaciones físicas pueden afectar mi capacidad de realizar las diversas actividades físicas. Soy asimismo consciente de que si sigo cuidadosamente las instrucciones del programa mejoraré con toda probabilidad mi capacidad para el ejercicio físico y mi forma física tras un período de 3 a 6 meses.

\section{Confidencialidad y uso de la información.}

Se me ha informado de que la información obtenida durante este programa de entrenamiento personal se tratará con máxima confidencialidad y poniendo sobre la misma todas las medidas de seguridad necesarias para garantizar su protección y secreto.

La información únicamente la van a usar para prestarme los servicios que les requiero, y en su caso, se cederán a Organismos y Entidades que se los requieran legalmente. También, me han informado de que los pueden destinar a terceros relacionados con la salud, fitness o a mi médico si fuera necesario. Fuera de esas excepciones, se me ha informado de que mis datos únicamente se usarán por razones de prescripción de ejercicio y evaluación de mi progreso en el programa. 


\section{Consultas y libertad del consentimiento}

Se me ha dado la oportunidad de preguntar por ciertas cuestiones en referencia a los procedimientos del programa. Soy asimismo consciente de que existen otros riesgos más improbables que pueden asociarse con este entrenamiento personal de acondicionamiento físico. A pesar del hecho de que no se me ha comunicado una relación exhaustiva de estos riesgos más improbables, aún deseo tomar parte en él. Confirmo que he leído este documento en su totalidad o que se me ha leído en caso de no ser capaz de leerlo personalmente.

Doy mi autorización expresa a que se lleven a cabo todos los servicios y procedimientos tal y como me ha comunicado el personal del programa.

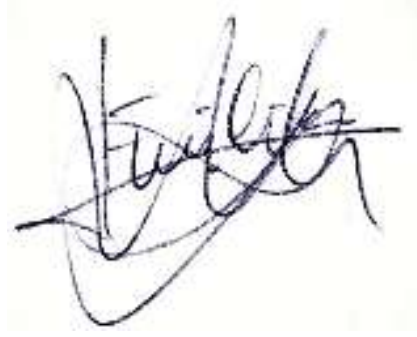

Emilia S.

10.4. Anexo 4. Protocolo de evaluación de perímetros
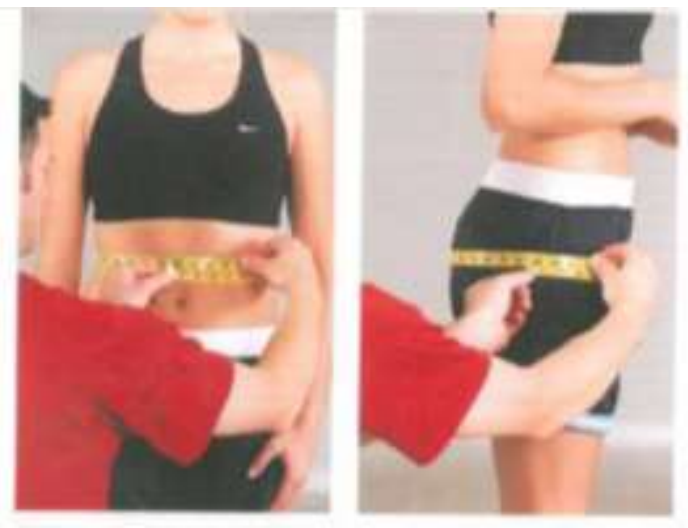

Extraido de: Manual NSCA. Coburn, J., \& Malek, M. (2014).

Cintura:

- Con los brazos cruzados sobre el tórax.

- Medición en el punto más estrecho entre la $10^{\circ}$ costilla y la cresta ilíaca.

- Se le pide al sujeto que baje los brazos y se mide al final de una espiración normal.

- En sujetos con alto porcentaje graso abdominal, resulta difícil su medición.

- Para ello, se puede elegir la opción de medir a la altura del ombligo.

- Importante si se realiza en el ombligo, siempre realizarlo tal punto

\section{Cadera:}

- Brazos cruzados sobre el pecho, pies juntos.

- Medición de la parte más prominente, más posterior de las nalgas.

- Usualmente sobre la sínfisis del pubis. 


\subsection{Anexo 5. Protocolo de evaluación de tensión arterial en reposo (NSCA) y valores de referencia}

\section{Consejos para la medición de la presión arterial}

1. El cliente debe estar sentado cómodamente, con la espalda apoyada y sin cruzar las piernas.

2. La parte superior del brazo debe estar al descubierto y no tener ninguna prenda de vestir restrictiva.

3. El brazo del cliente debe estar completamente relajado y apoyado aproximadamente a la altura del corazón.

4. La cámara de aire del manguito debe cubrir al menos el $80 \%$ de la parte superior del brazo.

5. El manguito debe desinflarse a una velocidad de 2 o $3 \mathrm{~mm} / \mathrm{s}$ y se deben registrar el primero y el último sonido perceptibles como PAS y PAD, respectivamente.

6. El cliente y el evaluador deben permanecer tranquilos y en silencio durante la prueba.

\section{Factores que afectan a la medición de la presión arterial}

- Tabaco ( + en reposo y durante el ejercicio).

- Cafeina (las respuestas al consumo de cafeina varian bastante y dependen del consumo y de la exposición previos, por lo que deberia evitarse su consumo antes de la medición de la PA).

= Estrés ( 1 en reposo y durante el ejercicio).

- Composición corporal ( en posición de decúbito supino y $t$ al pasar de la posición de decúbito supino a estar sentado o de pie).

- Hora del dia (. a primera hora de la mañana, t o - a primera hora de la tarde y por la tarde/noche).

- Medicación ( 1,10 - en reposo y durante el ejercicio: las respuestas a los medicamentos son muy variables y dependen del medicamento en cuestión).

Extraido de: Manual NSCA. Coburn, J., \& Malek, M. (2014). 


\subsection{Anexo 6. Ficha de evaluación inicial completa.}

- Visión frontal

- Pie cavo.

- Hallux valgus, juanete izquierdo completamente deformado. Izquierdo sobreprona un poco más por esto.

- Hombro derecho elevado por desviación de columna últimos niveles dorsales.

- Episodio doloroso hace un par de años. Sentía pesadez y ligero dolor por esa desviación en hombro izquierdo.

- Molestia en pectoral a la palpación.

- Visión lateral

- Cifosis dorsal moderada.

- Ligera retroversión de pelvis.

- Dedos garra.

- Visión posterior

- Escápula derecha deprimida, escápula izquierda elevada.

- Cadera izquierda ligeramente más elevada.

- Escoliosis últimos niveles dorsales (lado cóncavo derecha)

- Ligera rotación de tronco hacia izquierda, probablemente por su sobrepronación del pie (no tiene casi apoyo por juanete), pierna derecha posteriorizada.

- $\quad$ Corte oblicuo izquierdo.

- Side bending: le cuesta más hacia lado izquierdo. Rotación hacia la derecha cuando baja a izquierda. Lateral Shift.

- Tredelemburg: glúteo medio. Apoyo derecha rota tronco hacia la izquierda.

- Forward Bend: Limitación cadena posterior. Colapsa pie a sobrepronación. Desplazamiento hacia atrás del CG.

- Squat: no hay movilidad lumbopélvica, compensación torácica (caña de pescar). Falta de dorsiflexión aparentemente. En visión posterior carga en pie derecho. En vista frontal colapsa pie que arrastra rodilla. Desplazamiento hacia atrás del CG.

- Squat 1 pierna: inestabilidad general, mucho más con la izquierda. Compensa con pelvis hacia lado contralateral.

- Dorsflexión: Limitación cadena posterior. $23^{\circ}$ en ambas.

- Thomas: TFL derecho algo tenso

- Knee extended: rigidez isquiosurales, pierde anteversión pélvica en $130^{\circ}$ aproximadamente.

- Koala: ambos psoas débiles. Inclinación lateral para buscar ventaja mecánica de TFL.

- $\quad$ RI cadera: $22^{\circ}$

- $\quad$ RE cadera: $35^{\circ}$

- Movilidad torácica pica: OK

- Movilidad costal: OK no hay diferencias en bóvedas

- Adherencia diafragmática: OK

- Suelo pélvico: OK, sinergia trasverso.

- Movilidad escapular (elevación, abducción, tracción, tracción carga)

- Flexión de hombro escasa $160^{\circ}$, compensa con extensión torácica y con protracción de cabeza.

- Limitación pectoral y dorsal ancho

- Fibras de trapecio superior sobreactivadas en todos los patrones

- Movilidad escapular mejorable 
10.7. Anexo 7. Sesiones educativas y retos semanales.

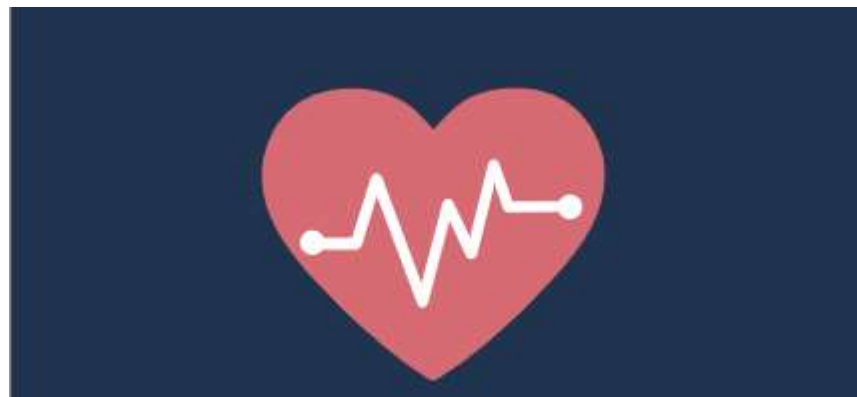

\section{HÁBITOS NO SALUDABLES}

Con respecto a nuestros objetivos:

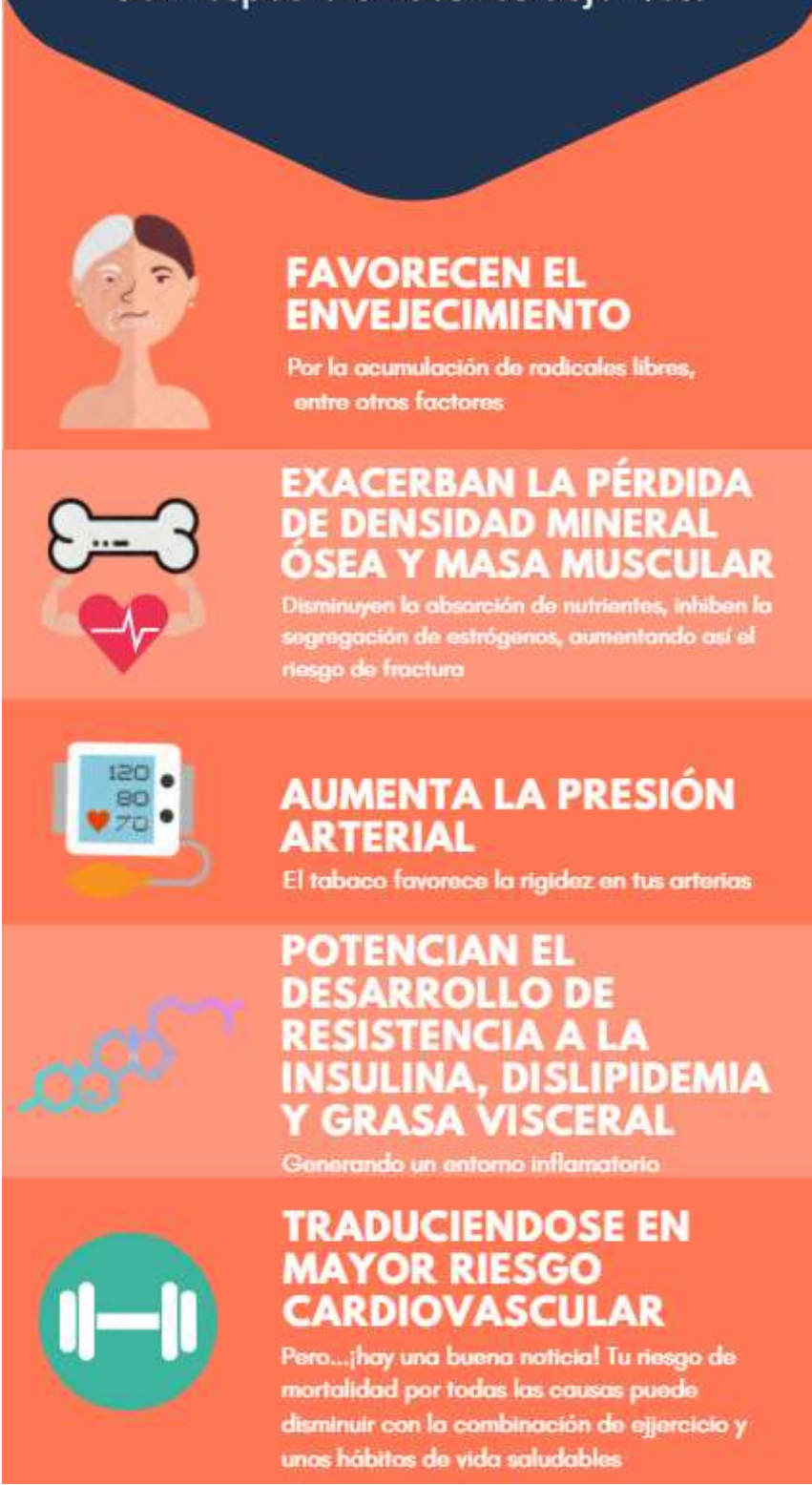




\section{RETO SEMANA 1}

2 días a la semana sin beber cerveza

\section{RETO SEMANA 2}

3 días a la semana sin beber cerveza

RETO SEMANA 3

4 días a la semana sin beber cerveza

RETO SEMANA 4

Cerveza sin alcohol todos los días, una cerveza puntual el fin de semana

\section{RETO SEMANA 5}

Mantenimiento alcohol. Reducción a 8 cigarros al día

RETO SEMANA 6

Mantenimiento alcohol. Reducción a 7 cigarros al día

RETO SEMANA 7

Mantenimiento alcohol. Reducción a 6 cigarros al día

\section{RETO SEMANA 8}

Mantenimiento alcohol. Reducción a 6 cigarros al día

\section{RETO SEMANA 9}

Mantenimiento alcohol. Reducción a 5 cigarros al día

\section{RETO SEMANA 10}

Mantenimiento alcohol. Reducción a 5 cigarros al día

\section{RETO SEMANA 11}

Mantenimiento alcohol. Reducción a 5 cigarros al día

\section{RETO SEMANA 12}

Mantenimiento alcohol. Reducción a 5 cigarros al día

\section{RETO SEMANA 13}

Mantenimiento alcohol. Reducción a 5 cigarros al día 
10.8. Anexo 8. Plantilla de registro y control del entrenamiento

\begin{tabular}{|c|c|c|c|c|c|c|c|c|c|c|}
\hline FECHA & ESTIMULO DE ENTRENAMIENTO GENERAL & $\begin{array}{c}\text { PRS } \\
\text { INICIAL }\end{array}$ & $\begin{array}{c}\text { SUEÑO } \\
1-10\end{array}$ & $\begin{array}{l}\text { SUEÑO } \\
\text { XIAOMI }\end{array}$ & $\begin{array}{c}\text { RPE } \\
\text { FINAL }\end{array}$ & $\begin{array}{c}\text { C. } \\
\text { INTERNA } \\
\text { (UA) }\end{array}$ & \begin{tabular}{c|} 
SUENNO \\
POSTERIOR O- \\
10
\end{tabular} & \begin{tabular}{|c|} 
SIUEÑO \\
POSTERIOR \\
XIAOMI \\
\end{tabular} & $\begin{array}{c}\text { DoMs } 1- \\
10\end{array}$ & NOTAS \\
\hline 03-jun & Patrones básicos bilaterales & 5 & 6 & 82 & 7 & 420 & 6 & 88 & 0 & \\
\hline 06-jun & Patrones básicos bilaterales & 3 & 6 & 82 & 6 & 360 & 6 & 81 & 0 & \\
\hline 10-jun & Patrones básicos unilaterales & 8 & 6 & 82 & 7 & 420 & 6 & 77 & 0 & PRS inicial por cansancio tras el trabajo \\
\hline 12-jun & Intro carga unilaterales-CORE, intro trabajo metabólico e impacto (met-imp) & 6 & 6 & 81 & 7 & 420 & 6 & 74 & 1 & Poco sueño profundo, se acostó muy tarde \\
\hline 15 -jun & Sobrecarga patrones, CORE, met-imp & 5 & 6 & 85 & 7 & 420 & 6 & 82 & 0 & \\
\hline 19-jun & Sobrecarga unilaterales, CORE, met-imp & 5 & 6 & 86 & 8 & 480 & 6 & 80 & 0 & Le costó conciliar el sueño, demasiado calor \\
\hline 22-jun & Sobrecarga bilaterales, CORE, met-imp & 5 & 4 & 55 & 7 & 420 & 6 & 67 & 0 & \\
\hline 26-jun & Sobrecarga unilaterales, imp-met & 5 & 6 & 87 & 7 & 420 & 8 & 94 & 0 & PRS inicial por la temperatura ambiental, tensión más baja \\
\hline 29-jun & Sobrecarga dominantes rodilla y dominantes cadera, jalones, met-imp & 5 & 7 & 93 & 6 & 360 & 6 & 92 & 0 & \\
\hline $02-\mathrm{jul}$ & Modificación: Isometrías, movilidad integrada, trabajo analítico & 8 & 7 & 95 & 8 & 480 & 7 & 96 & 0 & Modificación de la sesión por sensación de fatiga, temperatura ambiental \\
\hline 06-jul & Introducción MIVC desde básicos bilaterales & 4 & 7 & 92 & 7 & 420 & 6 & 88 & 0 & \\
\hline 09-jul & Introducción MIVC desde básicos unilaterales & 4 & 7 & 97 & 7,5 & 450 & 7 & 90 & 0 & \\
\hline $13-\mathrm{jul}$ & MIVC bilateral y multiplanar, isometrías, met-imp & 5 & 6 & 85 & 7 & 420 & 6 & 87 & 0 & \\
\hline $16-\mathrm{jul}$ & Propiocepción para evitar caída, fuerza y movilidad hombro, Iso, MIVC, met-imp & 5 & 5 & 88 & 7 & 420 & 7 & 89 & 0 & \\
\hline 20 -jul & MIVC bilateral y unilateral multiplano, iso, met-imp & 6 & 6 & 65 & 7 & 420 & 7 & 71 & 0 & \\
\hline 23-jul & Modificación lúdico y favs. Movilidad y fuerza hombro, iso, met-imp. & 5 & 5 & 88 & 6 & 360 & 8 & 97 & 1 & Carga emocional \\
\hline $27-\mathrm{jul}$ & MIVC y control glúteo medio, fuerza y movilidad rot externa y flex hombro, met-imp & 5 & 4 & 69 & 7 & 420 & 6 & 75 & 0 & \\
\hline 30-jul & Integración patrones laborales. Interválico met-imp. & 5 & 7 & 93 & 7 & 420 & 8 & 94 & 1 & \\
\hline 06-ago & Online, patrones controlados MIVC, autoeficacia, met-imp & 5 & 7 & 68 & 6 & 360 & 7 & 78 & 0 & PRS inicial por temperatura ambiental \\
\hline 09-ago & Saturación del sistema: apoyo monopodal, perturbaciones, doble tarea, Impacto-HIIT. & 5 & 5 & 74 & 7 & 420 & 7 & 81 & 1 & \\
\hline 13-ago & Variabilidad en empuje-tracción necesidades de movimiento, HIIT-imp & 4 & 6 & 80 & 6 & 360 & 6 & 88 & 0 & \\
\hline 16-ago & Sobrecarga y control monopodales de cadera, perturbaciones en el sistema, imp-MIIT & 5 & 5 & 66 & 6 & 360 & 7 & 80 & 0 & \\
\hline 20-ago & Sobrecarga y MIVC en patrones controlados, autoeficacia, HIIT con impacto. & 5 & 5 & 71 & 6 & 360 & 6 & 92 & 1 & \\
\hline 23-ago & Modificación dolor inespecífico zona lumbar: carga emocional semanal & 6 & 5 & 73 & 6 & 360 & 6 & 78 & 1 & \\
\hline 27-sep & Variabilidad empuje-tracción necesidades de movimiento, HIIT con impacto. & 4 & 7 & 84 & 7 & 420 & 6 & 85 & 0 & \\
\hline 30-ago & Fuerza en ROM empujes según patrones laborales, HIIT con impacto. & 4 & 5 & 77 & 7 & 420 & 7 & 89 & 0 & \\
\hline
\end{tabular}


